CRISTIANE MITIKO SATO FURUYAMA

\title{
AVALIAÇÃO DOS INDICADORES DE ILUMINAÇÃO ARTIFICIAL ESTUDO DE CASO: EDIFÍCIOS COMERCIAIS E ESCOLA
}

\author{
Dissertação apresentada à Faculdade de \\ Arquitetura e Urbanismo da Universidade de \\ São Paulo para a obtenção do título de \\ MESTRE em arquitetura e urbanismo
}

Área de concentração: Tecnologia da Arquitetura

Orientador: Prof. Dr. Marcelo de Andrade Roméro

São Paulo

2013 
AUTORIZO A REPRODUÇÃO E DIVULGAÇÃO TOTAL OU PARCIAL DESTE TRABALHO, POR QUALQUER MEIO CONVENCIONAL OU ELETRÔNICO, PARA FINS DE ESTUDO E PESQUISA, DESDE QUE CITADA A FONTE.

E-MAIL: crismitiko@yahoo.com.br

F992a Furuyama, Cristiane Mitiko Sato

Avaliação dos indicadores de iluminação artificial estudo de caso : edifícios comerciais e escola / Cristiane Mitiko Sato Furuyama. - São Paulo, 2013. 193 p. : il.

Dissertação (Mestrado - Área de Concentração: Tecnologia da Arquitetura) - FAUUSP.

Orientador: Marcelo de Andrade Romero

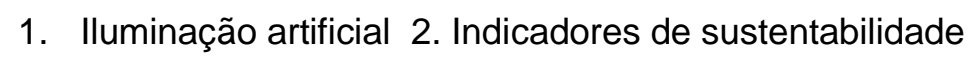
3. Energia (Eficiência) I.Título

CDU 628:93 


\section{DEDICATÓRIA}

Aos meus pais Kozo e Miyoko que sempre incentivaram meus estudos Ao meu marido Gustavo Furuyama que sempre acreditou na conclusão desse mestrado Ao meu filho Guilherme que é minha fonte de inspiração sempre 


\section{AGRADECIMENTOS}

Primeiramente e principalmente ao meu orientador Prof. Dr. Marcelo de Andrade Roméro por suas preciosas orientações, idéias e incentivos.

Aos meus grandes colegas e amigos que fiz ao longo do mestrado e que ajudaram, deram idéias e me incentivaram ao longo desses três anos: Silvia Bigoni, Corina Bianco, Altimar Cypriano e Luiz Felipe Xavier.

Aos meus amigos de profissão Juliana Kawasaki, Fábio Falanghe, Rodrigo Jardim, Rodrigo Salerno, Rúbia Mello, Katya Castellini e Paulo Torniziello que me apoiaram na decisão de fazer um mestrado e principalmente pela conclusão do mesmo.

Agradeço aos fabricantes de luminárias Itaim lluminação, Lumini, Philips e Erco por me fornecerem informações necessárias para as simulações.

Agradeço também às queridas secretárias Fernanda e lone.

E finalmente agradeço ao meu marido Gustavo, pois sem ele, não seria possível ter iniciado e finalizado este trabalho. 


\section{RESUMO}

O objetivo desse trabalho é verificar se os critérios e indicadores das certificações LEED New Construction, LEED Existing Building - Operations and Maintenance, LEED Comercial Interiors, AQUA Escritórios e Edifícios escolares e o regulamento brasileiro PROCEL, podem ser atendidos pelas tecnologias disponíveis no Brasil em termos de lâmpadas, luminárias, reatores (sistemas de iluminação), bem como avaliar se tais critérios e indicadores estão de acordo com as normas da ABNT e/ou normas internacionais.

Para verificar os indicadores, foram realizadas simulações através do programa de cálculo Dialux 4.10/2012, utilizando os arquivos fotométricos fornecidos pelos fabricantes mais especificados no Brasil.

Foram escolhidos dois estudos de caso para essa verificação, um escritório e uma escola que são ambientes comuns nas certificações e selos de sustentabilidade que serão analisados.

Os resultados das simulações mostrarão se é possível obter as certificações e/ou selo de sustentabilidade utilizando a tecnologia disponível referente aos sistemas de iluminação comercializados nos dias de hoje.

Palavras chave: iluminação artificial, indicadores de sustentabilidade, sistemas de iluminação, eficiência energética 


\section{ABSTRACT}

The main goal of this dissertation is to verify if Brazilian available technology can meet some certification's criteria and indicators. The chosen certifications are: LEED New Construction, LEED Existing Building - Operations and Maintenance, LEED Comercial Interiors, AQUA offices and educational buildings and the Brazilian standard PROCEL. Lamps, fixtures, ballasts (lighting systems), were analyzed to check whether these criteria and indicators are in line with the ABNT and / or international standards.

To check the indicators, simulations were performed using DIALUX 4.10/2012, a professional light planning software. In these simulations the most specified photometric files provided by the manufacturers were used.

To this research two cases were chosen for analysis, an regular office and a school, that are common environments in sustainability standards and certifications.

Simulation results will show if it is possible to obtain a certification using the available technology in lighting systems.

Keywords: artificial light, sustainability indicators, lighting systems, energy efficiency 


\section{SUMÁRIO}

Agradecimentos

Resumo

\section{Abstract}

Lista de abreviaturas e siglas

Lista de Figuras

Lista de Tabelas

Glossário

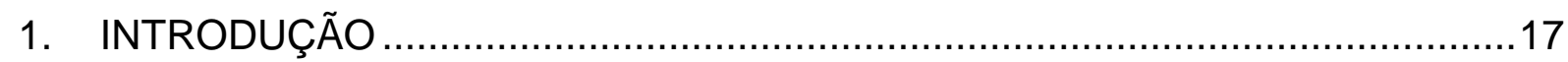

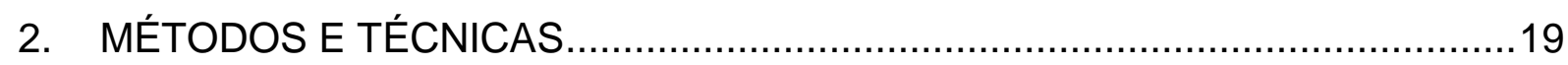

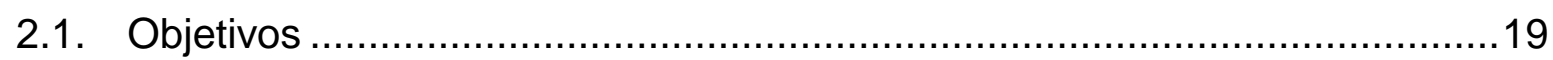

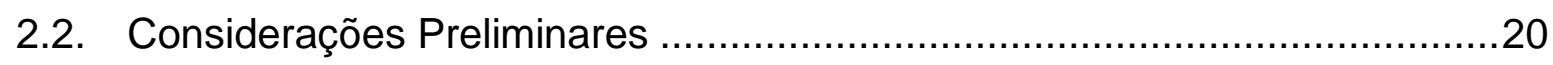

2.2.1. Levantamento de dados secundários .......................................20

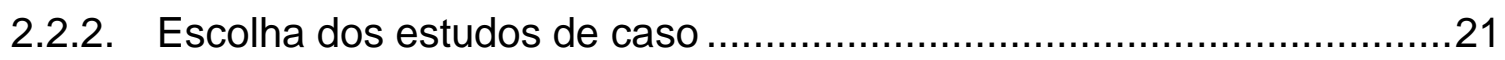

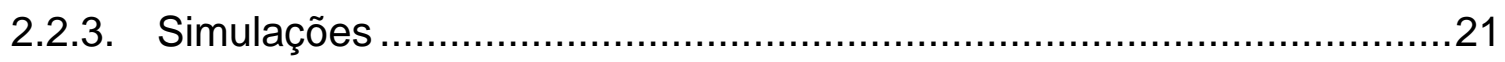

3. INDICADORES DE EFICIÊNCIA EM ILUMINAÇÃO ARTIFICIAL NOS SELOS E

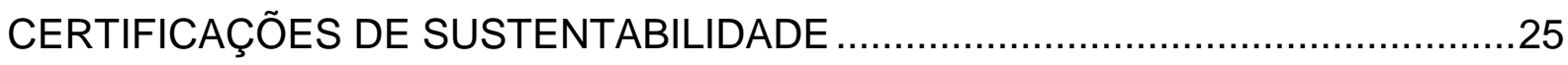

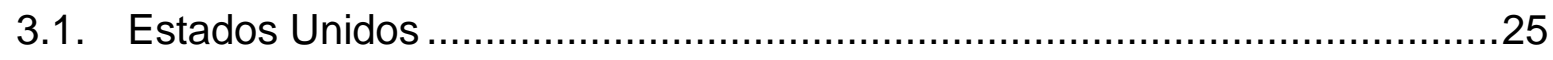

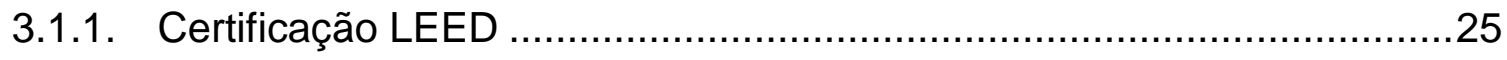

3.1.2. Norma ANSI/ASHRAE/IESNA Standard 90.1-2007..........................29

3.1.3. Lighting Handbook Reference \& Application - IESNA ....................... 31

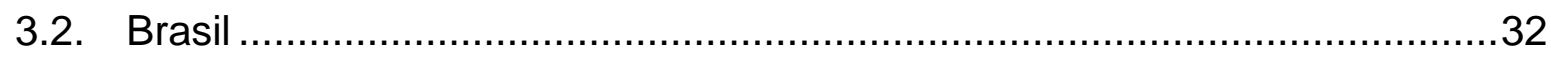

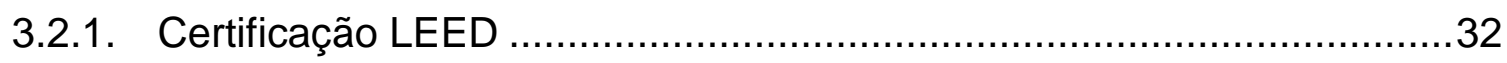

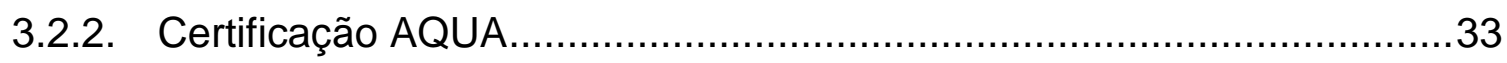

3.2.3. Regulamento Selo PROCEL Edifica .......................................... 35

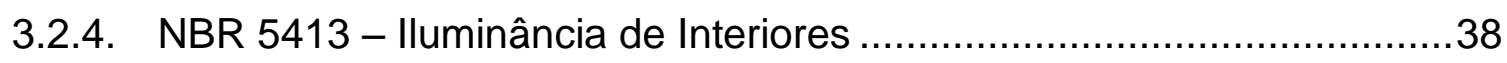

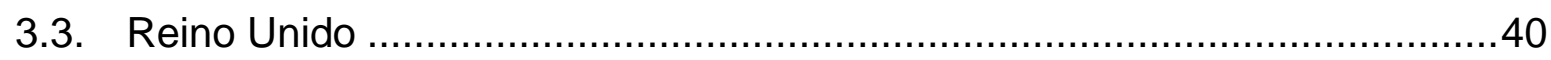




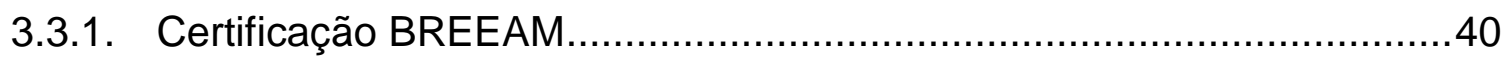

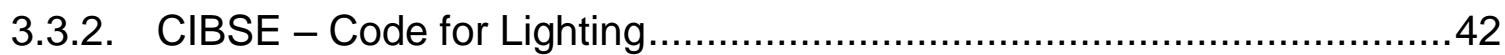

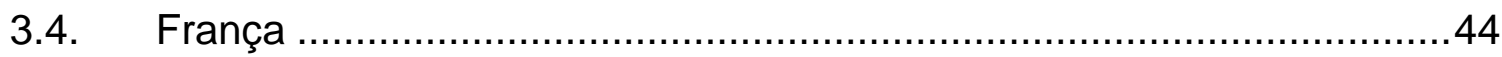

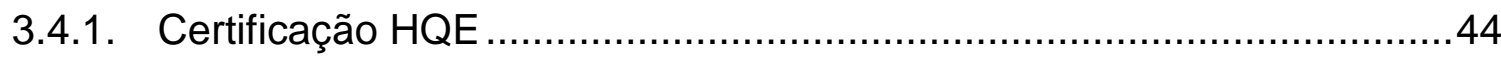

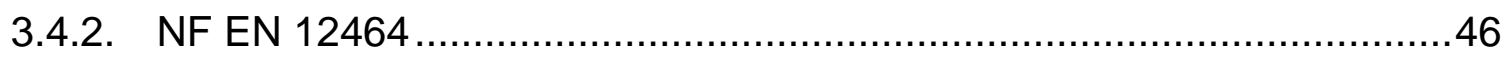

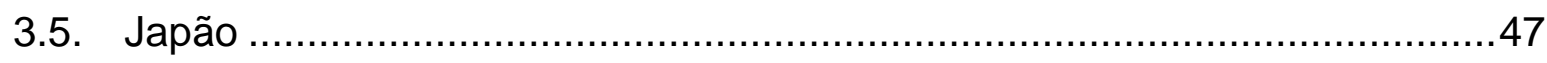

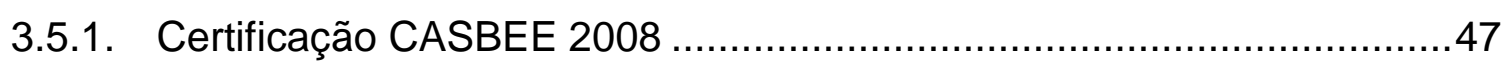

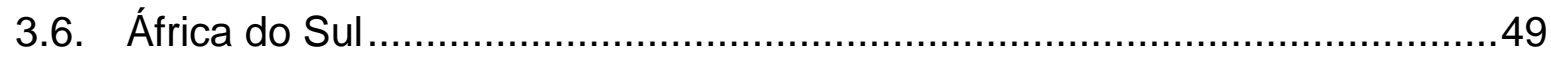

3.6.1. Certificação Green Star SA 2011.................................................... 49

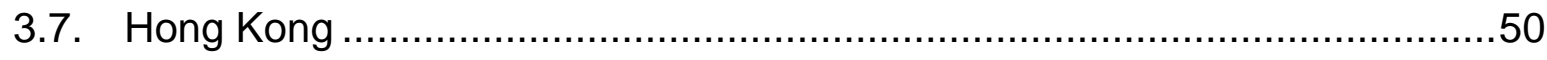

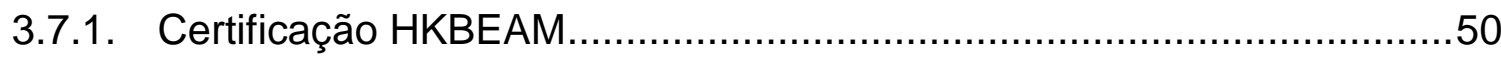

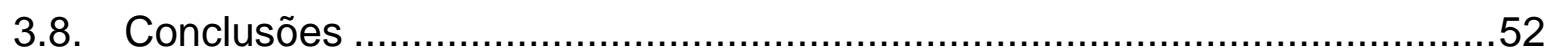

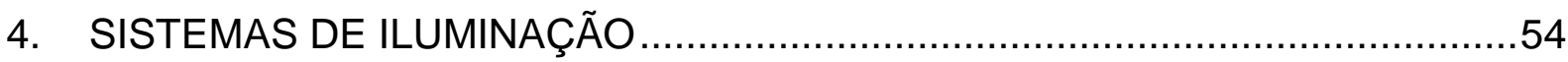

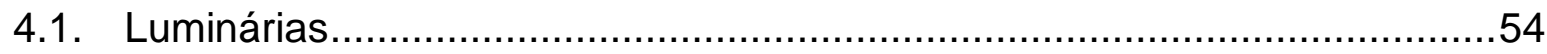

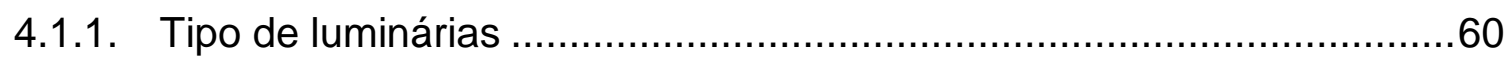

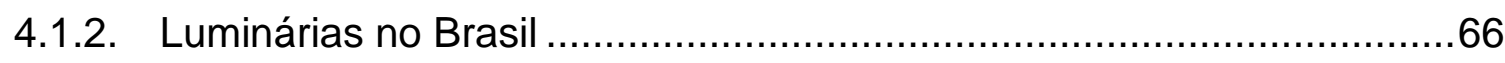

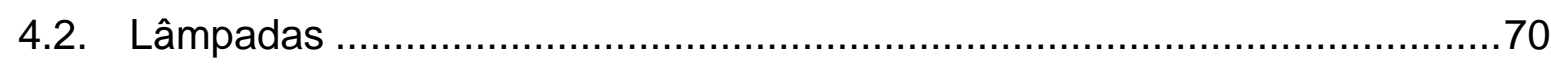

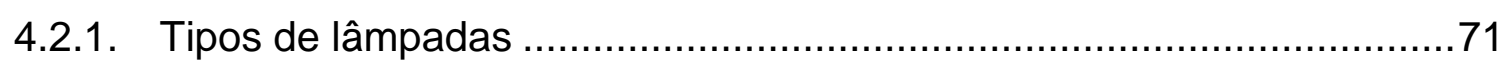

4.2.2. Lâmpadas no Brasil e no mundo .................................................... 75

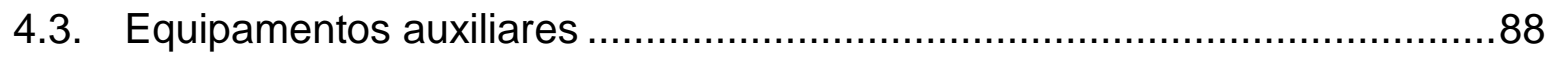

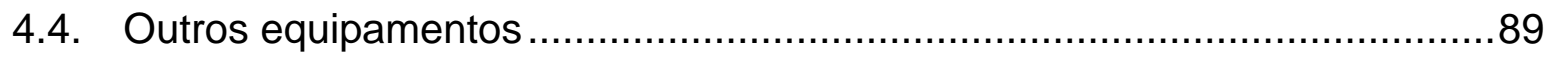

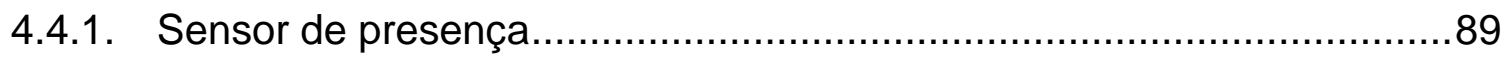

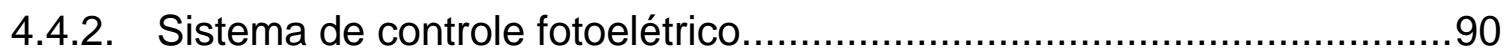

4.4.3. Automação no sistema de iluminação ...............................................90

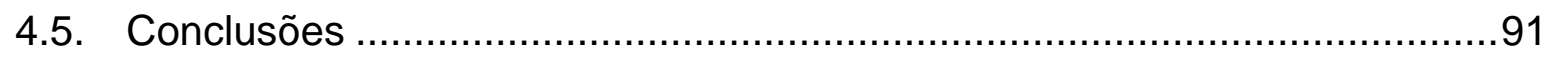

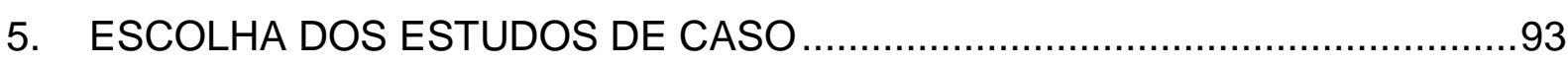

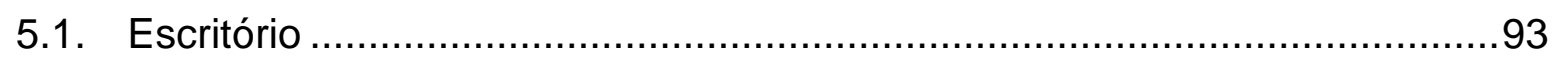




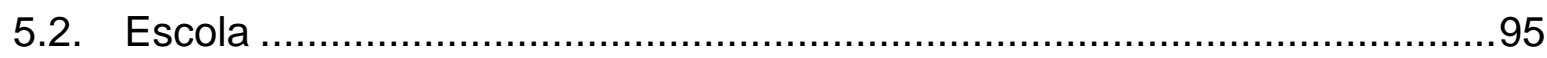

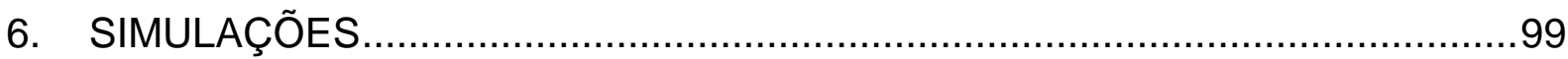

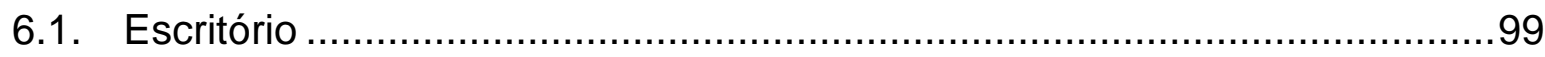

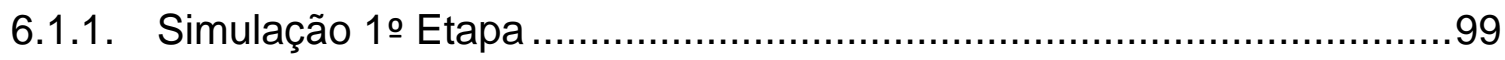

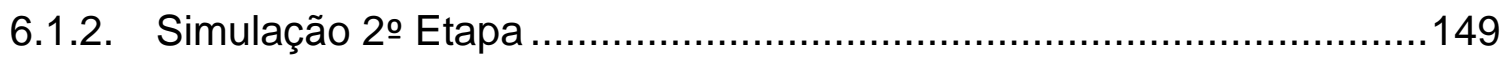

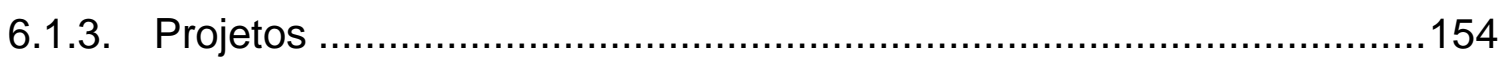

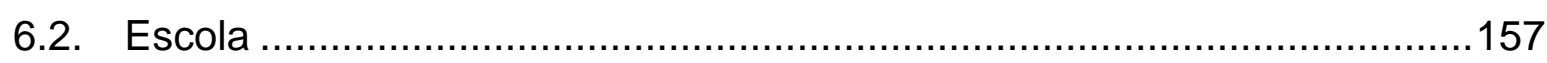

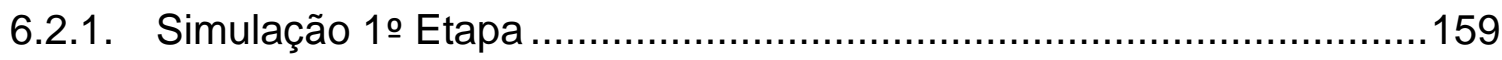

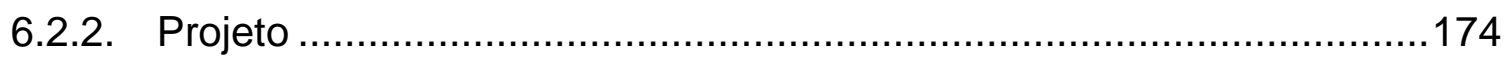

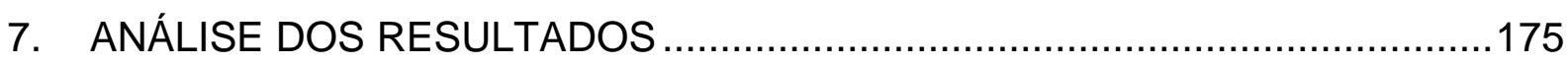

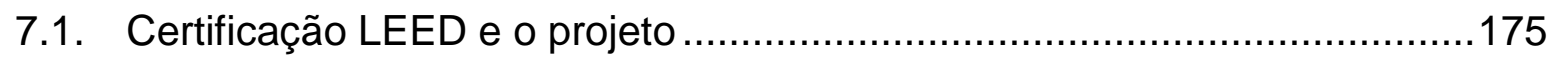

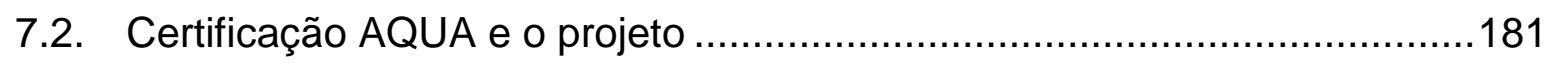

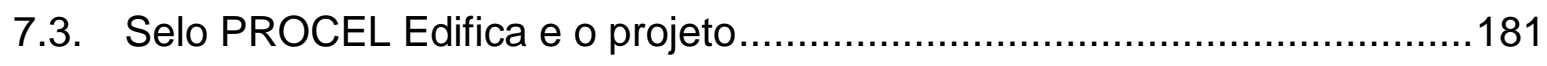

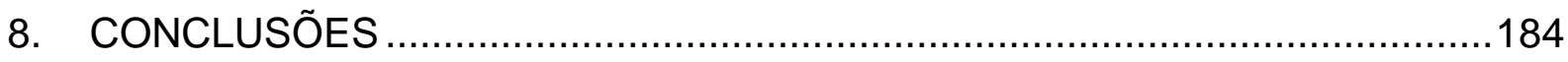

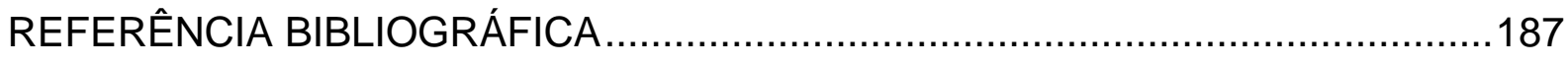

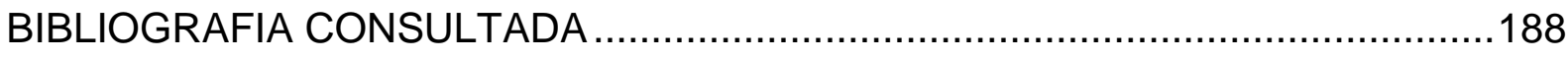

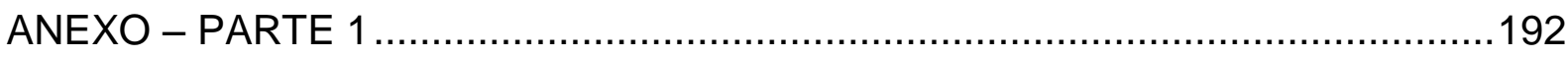

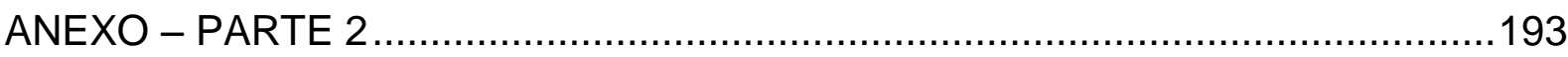

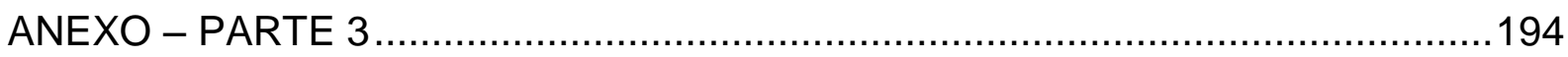




\section{LISTA DE FIGURAS}

Figura 1: Fluxograma - Metodologia.

Figura 2: Curva de distribuição luminosa com refletor pintado na cor branca luminária nacional

Figura 3: Curva de distribuição luminosa com refletor de alumínio - luminária nacional tipo 1

Figura 4: Curva de distribuição luminosa com refletor de alumínio - facho assimétrico - luminária nacional

Figura 5: Curva de distribuição luminosa com refletor de alumínio - luminária nacional tipo 2

Figura 6: Curva de distribuição luminosa com refletor de alumínio - luminária importada tipo 1

Figura 7: Curva de distribuição luminosa com refletor de alumínio - luminária importada tipo 2 .

Figura 8: Curva de distribuição luminosa com refletor de alumínio e aletas planas luminária nacional

Figura 9: Curva de distribuição luminosa com refletor de alumínio e aletas planas luminária importada

Figura 10: Curva de distribuição luminosa com refletor de alumínio e aletas parabólicas - luminária nacional

Figura 11: Curva de distribuição luminosa com refletor de alumínio e aletas parabólicas - luminária importada. .64

Figura 12: Curva de distribuição luminosa com difusor - luminária nacional .65

Figura 13: Curva de distribuição luminosa com difusor - luminária importada. .65

Figura 14: Curva de distribuição luminosa com LED 15W - luminária nacional. .66

Figura 15: Curva de distribuição luminosa com LED 14W - luminária importada .....66

Figura 16: Voltagem no mundo. .75

Figura 17: Pavimento tipo 1 .93

Figura 18: Pavimento tipo 2 .94

Figura 19: Pavimento tipo 3. .94

Figura 20: Pavimento tipo 4. .95

Figura 21: Escola tipo 1 - pavimento térreo e superior .96 
Figura 22: Escola tipo 2 - Pavimento térreo e superior. .97

Figura 23: Escola tipo 3 - Pavimento térreo e superior...........................................97

Figura 24: Escola tipo 4 - Pavimento térreo, 1o pavimento e 2o pavimento...............98

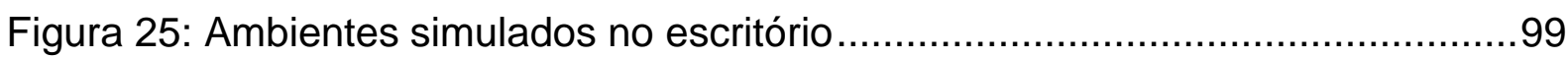

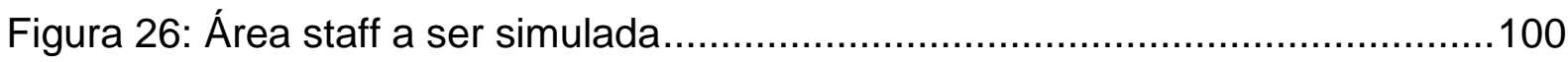

Figura 27: Simulação staff - luminária nacional tipo 6 com lâmpada fluorescente tubular para forro de gesso liso (Arquivo: ET-ST-FT-BR-1-MX.dlx) . 101

Figura 28: Simulação staff - luminária nacional tipo $11 \mathrm{com}$ lâmpada fluorescente tubular para forro de gesso liso (Arquivo: ET-ST-FT-BR-2-MX.dlx) 102 Figura 29: Simulação staff - luminária nacional tipo 6 com lâmpada fluorescente tubular para forro modulado (Arquivo: ET-ST-FT-BR-5-MX.dlx) 103

Figura 30: Simulação staff - luminária nacional tipo $11 \mathrm{com}$ lâmpada fluorescente tubular para forro modulado (Arquivo: ET-ST-FT-BR-6-MX.dlx) 103

Figura 31: Simulação staff - luminária importada tipo 12 com lâmpada fluorescente tubular para forro em gesso liso (Arquivo: ET-ST-FT-EX-3-MX.dlx) 105

Figura 32: Simulação staff - luminária importada tipo 13 com lâmpada fluorescente tubular para forro em gesso liso (Arquivo: ET-ST-FT-EX-4-MX.dlx) 105 Figura 33: Simulação staff - luminária importada tipo 12 com lâmpada fluorescente tubular para forro modulado (Arquivo: ET-ST-FT-EX-7-MX.dlx). 106 Figura 34: Simulação staff - luminária importada tipo 13 com lâmpada fluorescente tubular para forro modulado (Arquivo: ET-ST-FT-EX-8-MX.dlx). 106

Figura 35: Simulação staff - luminária nacional tipo 21 para fluorescente compacta (Arquivo: ET-ST-FC-BR-1-MX.dlx) 108

Figura 36: Simulação staff - luminária nacional tipo 24 para fluorescente compacta (Arquivo: ET-ST-FC-BR-2-MX.dlx) 108

Figura 37: Simulação staff - luminária importada tipo 33 para fluorescente compacta (Arquivo: ET-ST-FC-EX-3-MX.dlx) 110

Figura 38: Simulação staff - luminária importada tipo 40 para fluorescente compacta (Arquivo: ET-ST-FC-EX-4-MX.dlx) 110

Figura 39: Simulação staff - luminária nacional tipo 44 para LED (Arquivo: ET-STLE-BR-1-MX.dlx)

Figura 40: Simulação staff - luminária nacional tipo 48 para LED (Arquivo: ET-STLE-BR-2-MX.dlx) 
Figura 41: Simulação staff - luminária importada tipo 49 para LED (Arquivo: ET-STLE-EX-3-MX.dlX)

Figura 42: Simulação staff - luminária importada tipo 54 para LED (Arquivo: ET-STLE-EX-4-MX.dlx) .114

Figura 43: Sala individual a ser simulada 115

Figura 44: Simulação sala individual - luminária nacional tipo 26 para fluorescente compacta (Arquivo: ET-SI-FC-BR-1-MX.dlx) 116

Figura 45: Simulação sala individual - luminária eficiente nacional tipo 24 para fluorescente compacta

Figura 46: Simulação sala individual - luminária importada tipo 33 para fluorescente compacta (Arquivo: ET-SI-FC-EX-3-MX.dlx) ....

Figura 47: Simulação sala individual - luminária importada tipo 40 para fluorescente compacta (Arquivo: ET-SI-FC-EX-4-MX.dlx) .... 120

Figura 48: Simulação sala individual - luminária nacional tipo 60 para halógena (Arquivo: ET-SI-HA-BR-1-MX.dlX)

Figura 49: Simulação sala individual - luminária nacional tipo 61 para halógena (Arquivo: ET-SI-HA-BR-2-MX.dlx)

Figura 50: Simulação sala individual - luminária importada tipo 62 para halógena (Arquivo: ET-SI-HA-EX-3-MX.dlx) 124

Figura 51: Simulação sala individual - luminária importada tipo 65 para halógena (Arquivo: ET-SI-HA-EX-4-MX.dlx)

Figura 52: Simulação sala individual - luminária nacional tipo 69 para LED (Arquivo: ET-SI-LE-BR-1-MX.dlx)

Figura 53: Simulação sala individual - luminária eficiente nacional tipo 48 para LED (Arquivo: ET-SI-LE-BR-2-MX.dlx). 126

Figura 54: Simulação sala individual - luminária importada tipo 54 para LED (Arquivo: ET-SI-LE-EX-3-MX.dlx) 127

Figura 55: Simulação sala individual - luminária importada tipo 72 para LED (Arquivo: ET-SI-LE-EX-4-MX.dlx) 128

Figura 56: Sala de reunião a ser simulada 129

Figura 57: Simulação sala de reuniões - luminária nacional tipo 74 para fluorescente tubular (Arquivo: ET-SR-FT-BR-1-MX.dlx) 130 
Figura 58: Simulação sala de reuniões - luminária nacional tipo 75 para fluorescente tubular (Arquivo: ET-SR-FT-BR-2-MX.dlx)

Figura 59: Simulação sala de reuniões - luminária importada tipo 79 para fluorescente tubular (Arquivo: ET-SR-FT-EX-3-MX.dlx)

Figura 60: Simulação sala de reuniões - luminária importada tipo 80 para fluorescente tubular (Arquivo: ET-SR-FT-EX-4-MX.dlx)

Figura 61: Simulação sala de reuniões - luminária nacional tipo 86 - halógena e fluorescente compacta (Arquivo: ET-SR-FH-BR-1-MX.dlx) 134

Figura 62: Simulação sala de reuniões - luminária nacional tipo 84 - halógena e fluorescente compacta (Arquivo: ET-SR-FH-BR-2-MX.dlx)

Figura 63: Simulação sala de reuniões - luminária importada tipo 89 - halógena e fluorescente compacta (Arquivo: ET-SR-FH-EX-3-MX.dlx) 136

Figura 64: Simulação sala de reuniões - luminária importada tipo 92 - halógena e fluorescente compacta (Arquivo: ET-SR-FH-EX-4-MX.dlx)

Figura 65: Simulação sala de reuniões - luminária nacional tipo 1 - LED e fluorescente compacta (Arquivo: ET-SR-FL-BR-1-MX.dlx)

Figura 66: Simulação sala de reuniões - luminária nacional tipo 2 - LED e fluorescente compacta (Arquivo: ET-SR-FL-BR-2-MX.dlx) 139

Figura 67: Simulação sala de reuniões - luminária importada tipo 94 - LED e fluorescente compacta (Arquivo: ET-SR-FL-EX-3-MX.dlx) 140

Figura 68: Simulação sala de reuniões - luminária importada tipo 112 - LED e fluorescente compacta (Arquivo: ET-SR-FL-EX-4-MX.dlx)

Figura 69: Simulação sala de reuniões - luminária nacional tipo 69 - halógena e LED (Arquivo: ET-SR-LH-BR-1-MX.dlx)

Figura 70: Simulação sala de reuniões - luminária nacional tipo 48 - halógena e LED (Arquivo: ET-SR-LH-BR-2-MX.dlx) 142

Figura 71: Simulação sala de reuniões - luminária importada tipo 52 - halógena e LED (Arquivo: ET-SR-LH-EX-3-MX.dlx) 144

Figura 72: Simulação sala de reuniões - luminária importada tipo 71 - halógena e LED (Arquivo: ET-SR-LH-EX-4-MX.dlx)

Figura 73: Simulação sala de reuniões - luminária nacional tipo 69 - LED e LED (Arquivo: ET-SR-LL-BR-1-MX.dlx) 146 
Figura 74: Simulação sala de reuniões - luminária nacional tipo 48 - LED e LED (Arquivo: ET-SR-LL-BR-2-MX.dlx)

Figura 75: Simulação sala de reuniões - luminária importada tipo 52 - LED e LED (Arquivo: ET-SR-LL-EX-3-MX.dlx).

Figura 76: Simulação sala de reuniões - luminária importada tipo 71 - LED e LED (Arquivo: ET-SR-LL-EX-4-MX.dlx). 148

Figura 77: Simulação Staff - luminária nacional menos eficiente com fluorescente tubular (Arquivo: ET-ST-FT-BR-1-MI.dlx) 150

Figura 78: Simulação sala individual - luminária nacional menos eficiente com fluorescente compacta (Arquivo: ET-SI-FC-BR-1-MI.dlx)

Figura 79: Simulação sala de reuniões - luminária nacional menos eficiente com fluorescente compacta (Arquivo: ET-SR-FC-BR-1-MI.dlx) 151

Figura 80: Simulação staff - luminária nacional eficiente seguindo NBR ISO8995 (Arquivo: ET-ST-FT-BR-2-MX-ISO.dlx) 153

Figura 81: Simulação sala individual - luminária eficiente seguindo NBR ISO8995 (Arquivo: ET-SR-FT-BR-2-MX-ISO.dlx) 154

Figura 82: Ambientes simulados da escola..... 158

Figura 83: Simulação plano horizontal da sala de aula - luminária nacional tipo 101 com fluorescente tubular (Arquivo: EC-SA-FT-BR-1-MX.dlx) 160

Figura 84: Simulação plano vertical da sala de aula - luminária nacional tipo 101 com fluorescente tubular (Arquivo: EC-SA-FT-BR-1-MX.dlx).... 160

Figura 85: Simulação plano horizontal da sala de aula - luminária importada tipo 106 com fluorescente tubular (Arquivo: EC-AS-FT-EX-1-MX.dlx) 162 Figura 86: Simulação plano horizontal da sala de aula - sistema de iluminação importado tipo 108 com fluorescente tubular. 162

Figura 87: Simulação plano vertical da sala de aula - luminária importada tipo 106 com fluorescente tubular (Arquivo: EC-AS-FT-EX-1-MX.dlx).... 163

Figura 88: Simulação plano horizontal da sala de aula - luminária nacional com LED tipo 111 (Arquivo: EC-SA-LE-BR-1-MX.dlx)

Figura 89: Simulação plano vertical da sala de aula - luminária nacional com LED tipo 111 (Arquivo: EC-SA-LE-BR-1-MX.dlx) 164

Figura 90: Simulação plano horizontal da sala de aula - luminária importada tipo 113 (Arquivo: EC-SA-LE-EX-1-MX.dlx) 165 
Figura 91: Simulação plano vertical da sala de aula - luminária importada tipo 113

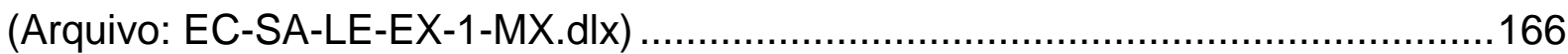

Figura 92: Simulação sala dos professores - luminária nacional tipo $101 \mathrm{com}$ fluorescente tubular (Arquivo: EC-SP-FT-BR-1-MX.dlx) 167

Figura 93: Simulação sala dos professores - luminária nacional tipo 111 com LED

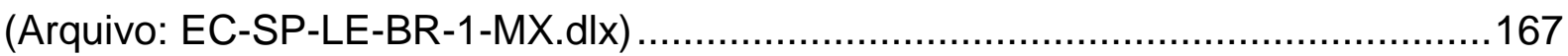

Figura 94: Simulação sala dos professores - luminária nacional tipo 101 com fluorescente tubular - distribuição 3 luminárias...............................................168

Figura 95: Simulação sala dos professores - luminária importada tipo $106 \mathrm{com}$ fluorescente tubular (Arquivo: EC-SP-FT-EX-1-MX.dlx) ….................................169

Figura 96: Simulação sala dos professores - luminária importada tipo 113 com LED

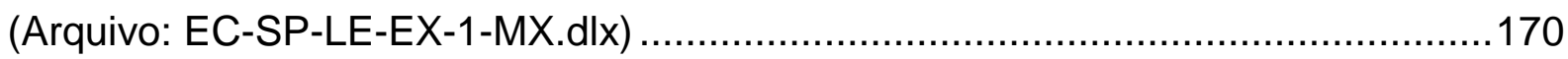

Figura 97: Simulação refeitório - luminária nacional tipo 114 com fluorescente tubular (Arquivo: EC-RE-FT-BR-1-MX.dlx) .................................................171

Figura 98: Simulação refeitório - luminária importada tipo 117 com fluorescente tubular (Arquivo: EC-RE-FT-EX-1-MX.dlx). 172

Figura 99: Simulação refeitório - luminária nacional tipo 111 com LED (Arquivo: ECRE-LE-BR-1-MX.dlx) 173

Figura 100: Simulação refeitório - luminária importada tipo 113 com LED (Arquivo: EC-RE-LE-EX-1-MX.dlx) 173 


\section{LISTA DE TABELAS}

Tabela 1: Comparativo de luminárias da simulação - 10 etapa ……….....................22

Tabela 2: Potência dos equipamentos auxiliares utilizados ...................................23

Tabela 3: Classificação de luminárias em relação ao fluxo luminoso ...........................56

Tabela 4: Classificação de luminárias de acordo com o grau de proteção contra sólidos

Tabela 5: Classificação de luminárias de acordo com o grau de proteção contra umidade .57

Tabela 6: Exemplo de avaliação de ofuscamento (UGR) 59

Tabela 7: Tabela de lâmpadas halógenas sem refletor no mercado internacional....76

Tabela 8: Tabela de lâmpadas halógenas sem refletor no mercado nacional .77

Tabela 9: Tabela de lâmpadas halógenas com refletor no mercado internacional....77

Tabela 10: Tabela de lâmpadas halógenas com refletor no mercado nacional .........78 Tabela 11: Tabela de lâmpadas fluorescentes compactas não integradas no mercado internacional .79

Tabela 12: Tabela de lâmpadas fluorescentes compactas não integradas no mercado nacional

Tabela 13: Tabela de lâmpadas fluorescentes tubulares T5 no mercado internacional

Tabela 14: Tabela de lâmpadas fluorescentes tubulares T5 no mercado nacional ...83

Tabela 15: Tabela de lâmpadas LED com refletor no mercado internacional .84

Tabela 16: Tabela de lâmpadas LED com refletor no mercado nacional .85

Tabela 17: Tabela de lâmpadas fluorescentes tubulares T5 no mercado internacional .85

Tabela 18: Tabela de lâmpadas fluorescentes tubulares T5 no mercado nacional...87 Tabela 19: Tabela simulação sistema de iluminação nacional com lâmpada fluorescente tubular - forro gesso liso. 101

Tabela 20: Tabela simulação sistema de iluminação nacional com lâmpada fluorescente tubular - forro modulado. 102

Tabela 21: Tabela simulação sistema de iluminação importado com lâmpada fluorescente tubular - forro de gesso liso. 104 
Tabela 22: Tabela simulação sistema de iluminação importado com lâmpada fluorescente tubular - forro de gesso modulado

Tabela 23: Tabela simulação sistema de iluminação nacional com lâmpada fluorescente compacta

Tabela 24: Tabela simulação sistema de iluminação importados com lâmpada fluorescente compacta 109

Tabela 25: Tabela sistema de iluminação nacional com LED 111

Tabela 26: Tabela sistema de iluminação importado com LED.

Tabela 27: Tabela sistema de iluminação nacional - fluorescente compacta e pendente

Tabela 28: Tabela sistema de iluminação importado - fluorescente compacta e pendente

Tabela 29: Tabela sistema de iluminação nacional - halógena e pendente 121

Tabela 30: Tabela sistema de iluminação importado - halógena e pendente 122

Tabela 31: Tabela sistema de iluminação nacional - LED e pendente 124

Tabela 32: Tabela sistema de iluminação importado - LED e pendente 126

Tabela 33: Tabela sistema de iluminação nacional - fluorescente tubular ou fluorescente compacta longa. 129

Tabela 34: Tabela sistema de iluminação importado - fluorescente tubular 131 Tabela 35: Tabela sistema de iluminação nacional - halógena e fluorescente compacta. 133

Tabela 36: Tabela sistema de iluminação importado - halógena e fluorescente compacta.

Tabela 37: Tabela sistema de iluminação nacional - LED e fluorescente compacta

Tabela 38: Tabela sistema de iluminação importado - LED e fluorescente compacta 140

Tabela 39: Tabela sistema de iluminação nacional - Halógena e LED

Tabela 40: Tabela sistema de iluminação importado - Halógena e LED . 143

Tabela 41: Tabela sistema de iluminação nacional - LED e LED 145

Tabela 42: Tabela sistema de iluminação importado - LED e LED 147

Tabela 43: Tabela sistema de iluminação Staff menos eficiente com fluorescente tubular 
Tabela 44: Tabela sistema de iluminação sala individual menos eficiente. 150

Tabela 45: Tabela sistema de iluminação sala de reuniões menos eficiente 150

Tabela 46: Tabela simulação staff seguindo norma NBR ISO8995 …...................152

Tabela 47: Tabela simulação sala individual seguindo norma NBR ISO8995 .........153

Tabela 48: Tabela resultados simulação do escritório 155

Tabela 49: Tabela simulação sala de aula sistema de iluminação nacional fluorescente tubular 159

Tabela 50: Tabela simulação sala de aula sistema de iluminação importado 161

Tabela 51: Tabela simulação sala de aula sistema de iluminação nacional - LED.163 Tabela 52: Tabela simulação sala de aula sistema de iluminação importado - LED 165

Tabela 53: Tabela de resultado da simulação de luminárias nacionais - sala dos professores. 166

Tabela 54: Tabela de resultado da simulação de luminárias importadas - sala dos professores. 169

Tabela 55: Tabela simulação refeitório sistema de iluminação nacional com fluorescente tubular 171

Tabela 56: Tabela de resultado da simulação de luminária fluorescente tubular importado - refeitório 171

Tabela 57: Tabela de resultado da simulação de luminária LED - refeitório 172

Tabela 58: Tabela resultados simulação - escola 174

Tabela 59: Resultado simulação sistema de iluminação mais eficiente do Brasil utilizando luminária LED (Projeto 1) 175

Tabela 60: Resultado simulação sistema de iluminação mais eficiente do Brasil utilizando luminária LED (Projeto 2). 176

Tabela 61: Resultado simulação sistema de iluminação mais eficiente do Brasil utilizando luminária fluorescente tubular (Projeto 3) 176

Tabela 62: Resultado simulação sistema de iluminação mais eficiente importado utilizando luminária fluorescente tubular (Projeto 4)

Tabela 63: Resultado simulação sistema de iluminação eficiente nacional utilizando luminária fluorescente tubular no staff e fluorescente compacta nas salas individuais (Projeto 5). 
Tabela 64: Resultado simulação sistema de iluminação eficiente nacional sem a utilização de luminárias com LED (Projeto 6)

Tabela 65: Resultado simulação sistema de iluminação menos eficiente nacional (Projeto 7).

Tabela 66: Resultado simulação sistema de iluminação nacional com valores da norma ISO8995. (Projeto 8) 179

Tabela 67: Resultado simulação sistema de iluminação eficiente nacional com fluorescentes tubulares (Projeto 9) 180

Tabela 68: Resultado simulação sistema de iluminação eficiente nacional com LED (Projeto 10) 180

Tabela 69: Limite máximo aceitável de densidade de potência de iluminação (DPI $\mathrm{L}_{\mathrm{L}}$ para o nível de eficiência pretendido 182

Tabela 71: Resumo do nível de eficiência alcançado nos projetos 182 


\section{LISTA DE ABREVIATURAS E SIGLAS}

ABILUX Associação Brasileira da Indústria de lluminação

ANSI American National Standard Institute

AQUA Alta Qualidade Ambiental

ASHRAE American Society of Heating, Refrigerating and Air-conditioning Engineers

BREEAM Building Research Establishment Environmental Assessment Method

CASBEE Comprehensive Assessment System for Built Environmental Efficiency

CIBSE Chartered Institution of Building Services Engineers

CIE Comission Internacionale de L'Eclairage

COBEE Congresso Brasileiro de Eficiência Energética

IES Iluminating Engineerging Society

IESNA Illuminating Engineering Society of North America

HKBEAM Hong Kong Building Environmental Assessment Method

HQE Haute Qualité Environnementale

LED Light Emitting Diode

LEED Leadership in Energy and Environmental Design

NBR Norma Brasileira

PROCEL Programa Nacional de Conservação de Energia Elétrica

UGR Unified Glare Rating 


\section{GLOSSÁRIO}

Consumo de energia

Depreciação do fluxo luminoso

Dimmer

Eficiência luminosa ( $\eta$

Fluxo luminoso $(\phi)$

Fator de manutenção

lluminância (E)
Intensidade luminosa (I)

Quantidade de energia utilizada na conversão de energia primária em energia secundária, na produção de energia útil ou na utilização final.

Redução do fluxo luminoso de uma lâmpada devido ao próprio desgaste da lâmpada e pelo acúmulo de poeira sobre sua superfície externa.

Dispositivo que possibilita variar o fluxo luminoso das lâmpadas em uma instalação para ajustar o nível de iluminância

Medida que indica a eficiência de uma lâmpada, "é o indicador da eficiência do processo de emissão de luz sob o ponto de vista do aproveitamento energético. É a razão entre o fluxo luminoso e a potência da lâmpada, em lúmen/Watt $(\mathrm{Im} / \mathrm{W})$.

Quantidade de luz emitida por uma fonte luminosa em todas as direções, e é medida em lúmen (Im)

Razão da iluminância média no plano de trabalho, após um período especificado de uso de uma instalação de iluminação, pela iluminância média obtida nas mesmas condições para uma instalação nova.

Fluxo luminoso que incide em uma superfície, é a luz refletida que não é visível. Sua unidade de medida é o fluxo luminoso em lúmen dividido pela área, conhecido com lux (Ix). Também conhecido como nível de iluminância .

Índice de reprodução de cor $\left(R_{a}\right)$ Medida que indica a cor real e aparente de um objeto ou superfície, onde quanto mais alto o valor mais fiel é a cor do objeto ou superfície. Ele varia de uma escala de 0 a 100 e não possui unidade de medida. Também conhecido com IRC da lâmpada.

Quantidade de luz emitida por uma fonte de luz em uma determinada direção dentro de um determinado ângulo, e sua medida é dada dividindo o fluxo luminoso $(\phi)$ pelo ângulo sólido unitário 
(esferorradiano), mais conhecido pela medida chamada candela (cd).

Luminância (L)

Potência elétrica

Temperatura de cor $\left(T_{c p}\right)$

Vida média

Vida útil
Intensidade luminosa produzida ou refletida por uma superfície, é a luz refletida visível. Sua unidade de medida é candela $/ \mathrm{m}^{2}\left(\mathrm{~cd} / \mathrm{m}^{2}\right)$

Trabalho realizado pela corrente elétrica em um determinado intervalo de tempo

Aparência de cor da luz, onde quanto mais alto o valor, mais branca é a cor da luz emitida. Sua emitida é dada em Kelvin (K)

Média aritmética do tempo de duração de cada lâmpada ensaiada, dada em horas.

Número de horas decorrido quando se atinge $70 \%$ da quantidade de luz inicial devido à depreciação do fluxo luminoso de cada lâmpada, somado ao efeito das respectivas queimas ocorridas no período. 


\section{INTRODUÇÃO}

As discussões sobre sustentabilidade tiveram início na Conferência de Estocolmo em 1972 e ao longo do tempo, tornaram-se cada vez mais presentes e constantes, incluindo a busca de soluções sustentáveis em relação a aspectos ambientais, sociais e econômicas.

O interesse no setor energético, no que diz respeito à sustentabilidade, é amplo e engloba questões como saneamento, uso e racionamento da água, transportes, o ambiente construído e seus impactos na cidade, entre outros.

De acordo com os professores Dr. Marcelo Romero e Dr. Lineu dos Reis, o conceito de eficiência energética surgiu como decorrência da crise do petróleo e permanece ativo nos dias de hoje devido ao sucesso das ferramentas criadas para conter essa crise e pela constante elevação de tarifas energéticas. Da mesma forma, na construção civil, ela desencadeou o desenvolvimento de normas reguladoras visando a economia de energia. (ROMERO; REIS, 2012).

Atualmente, contribui para o aumento do interesse nas normas reguladoras e na obtenção do selo de sustentabilidade, o constante aumento das tarifas de energia.

A primeira certificação sustentável é atribuída ao BREEAM do Reino Unido, seguido pela certificação HQE da França e LEED dos Estados Unidos. Com a globalização, muitos países passaram a adotar em seus países essas certificações e regulamentos sustentáveis relacionados à eficiência energética. O Brasil acompanha esse processo e certifica seus edifícios com os selos LEED e AQUA e a etiquetagem do PROCEL Edifica.

Em todas as certificações e selos de sustentabilidade que serão analisados, o quesito energia está sempre presente, e a iluminação natural e artificial são seus itens.

Segundo a Eletrobrás juntamente com a PROCEL ${ }^{1}$, "a iluminação é responsável por, aproximadamente, $24 \%$ do consumo de energia elétrica no setor

\footnotetext{
${ }^{1}$ Eletrobrás/PROCEL Educação. Conservação de Energia. Eficiência Energética de Equipamentos e Instalações. Itajubá. Universidade Federal de Itajubá, 2006. P. 216
} 
residencial, $44 \%$ no setor comercial e serviços públicos e $1 \%$ no setor industrial", ou seja, uma grande porcentagem dos gastos com iluminação provém da iluminação artificial.

Apesar do projeto que otimiza a iluminação natural ser considerado um dos fatores que reduzem o uso de energia elétrica e mesmo sabendo que, em proporções variáveis, a iluminação natural deve ser completada pela iluminação artificial, ele não foi objeto de estudo deste trabalho, optando por somente estudar a iluminação artificial. 


\section{MÉTODOS E TÉCNICAS}

\subsection{Objetivos}

O objetivo desse trabalho é verificar se os critérios e indicadores das certificações LEED New Construction, LEED Existing Building - Operations and Maintenance, LEED Comercial Interiors, AQUA Escritórios e Edifícios escolares e o regulamento brasileiro PROCEL, podem ser atendidos pelas tecnologias disponíveis no Brasil em relação às lâmpadas, luminárias e reatores (sistemas de iluminação), bem como avaliar se tais critérios e indicadores estão de acordo com as normas da ABNT e/ou das normas internacionais.

A normatização tem aumentado muito nos últimos anos, e atualmente, as certificações e selos de sustentabilidade que são voluntários, tendem a se tornar compulsórios. O selo PROCEL, por exemplo, será obrigatório a partir de 2020 para edifícios públicos.

Portanto, é importante saber, se os sistemas de iluminação comercializados no Brasil atualmente, atendem os indicadores de iluminação artificial das certificações e selos de sustentabilidade. 


\subsection{Considerações Preliminares}

Os métodos e técnicas utilizados para a pesquisa seguem as seguintes etapas e o fluxograma mostrado na figura 1.

\section{FLUXOGRAMA DA PESQUISA}

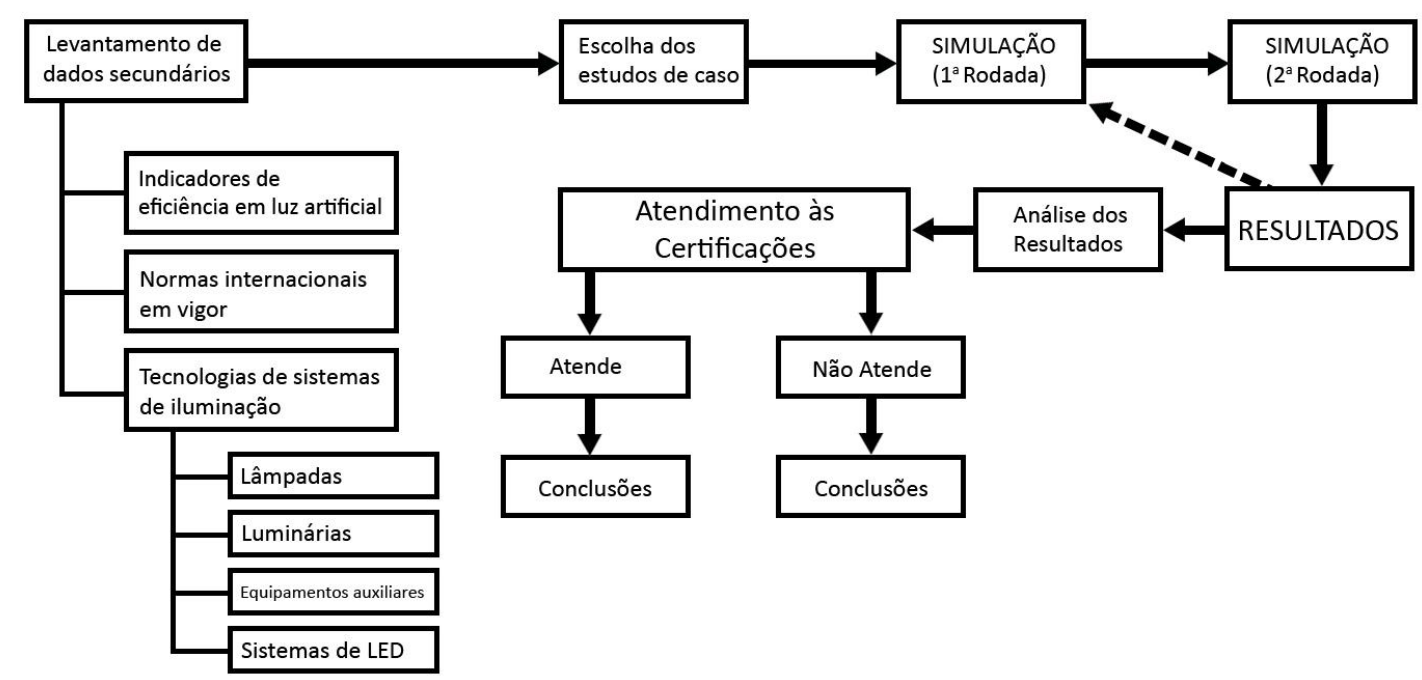

Figura 1: Fluxograma - Metodologia.

Fonte: autora

\subsubsection{Levantamento de dados secundários}

Foi realizado um levantamento dos seguintes dados:

1) Indicadores de eficiência em luz artificial nos selos e certificações de sustentabilidade mais atuantes do mundo, inclusive no Brasil.

Foram levantados os dados das certificações LEED, AQUA, BREEAM, HQE, CASBEE, GREEN STAR AS e HKBEAM, além do selo PROCEL Edifica.

2) Normas internacionais e nacionais em vigor.

As normas internacionais e nacionais são referentes à iluminação artificial dos países onde as certificações e selos de sustentabilidade foram levantados:

- Estados Unidos: Norma ANSI/ASHRAE/IESNA Standard 90.1-2007 
Lighting Handbook Reference \& Application - IESNA

- Brasil: NBR 5413 - Iluminância de Interiores

- Reino Unido: CIBSE - Code for Lighting

- França: NF EN 12464

3) Tecnologias dos sistemas de iluminação

Foi pesquisada a tecnologia existente no Brasil e no exterior, comparando a eficiência em:

- Luminárias

- Lâmpadas

- Equipamentos auxiliares (transformadores, reatores, fontes e drivers)

- Sistemas de LED

\subsubsection{Escolha dos estudos de caso}

Como estudos de caso, foram escolhidos dois: um escritório e uma escola. A justificativa da escolha desses ambientes é que ambos possuem indicadores e/ou mencionam parâmetros de indicadores de iluminação artificial nas certificações e selos de sustentabilidade presentes no Brasil.

Para o estudo de caso do escritório, foram escolhidas plantas que simulassem um ambiente de escritório e escola padrões.

\subsubsection{Simulações}

Optou-se por fazer simulações ao invés de analisar ambientes existentes, pois assim pode-se analisar os resultados baseados nos mesmos parâmetros, sem a interferência da iluminação natural, manutenção em relação à limpeza e depreciação dos sistemas de iluminação. 
O programa escolhido para realizar os cálculos foi o Dialux 4.10/2012, que segundo o professor Luis Lancelle ${ }^{2}$, engenheiro especialista em softwares de iluminação, é um dos que possuem mais recursos. Além disso, muitos lighting designers e professores, como Antônio Carlos Mingrone e Nelson Solano, recomendam seu uso por seus resultados serem o mais próximo do real.

Nos parâmetros de dados de cálculo, optou-se por não utilizar o fator de depreciação pois os fornecedores do sistema em LED, como mostra pesquisa realizada pela equipe do prof. Antônio Carlos Saidel ${ }^{3}$, ainda não fornecem valores compatíveis de depreciação com o aplicado. Para a pesquisa, utilizou-se apenas o fator de manutenção do ambiente como sendo de 0,80 , considerando um ambiente limpo conforme indicação do programa de cálculo.

Para encontrar o valor do fator de manutenção total de um sistema de iluminação, se leva em consideração os seguintes fatores: declínio da potência em lúmen de uma lâmpada, envelhecimento da lâmpada, efeitos de redução de potência de luz devido ao acúmulo de sujeita nas luminárias e a redução da refletância devido ao acúmulo de sujeira do ambiente.

As simulações foram realizadas em 2 (duas) etapas, onde na primeira etapa foram selecionadas diversas luminárias de determinados fabricantes, para analisar qual sistema de iluminação consome menos energia. Nessa seleção, foram incluídas apenas as luminárias que proporcionassem conforto visual ao usuário. Considerouse um pé direito padrão de 2,70m em ambos os casos.

Para verificação do menor consumo do sistema de iluminação, além das simulações, foi criada a seguinte tabela 1 a seguir:

Tabela 1: Comparativo de luminárias da simulação - 10 etapa

\begin{tabular}{|c|c|c|c|c|c|c|c|}
\hline $\begin{array}{c}\text { Código } \\
\text { luminária }\end{array}$ & $\begin{array}{c}\text { Qtde } \\
\text { peças }\end{array}$ & Emédio & Emín & Emáx & $\begin{array}{c}\text { Potência } \\
\text { Conj (W) }\end{array}$ & $\begin{array}{c}\text { Potência } \\
\text { total (W) }\end{array}$ & $\begin{array}{c}\text { Tipo/ Anexo } \\
\text { luminária }\end{array}$ \\
\hline & & & & & & & \\
\hline & & & & & & & \\
\hline
\end{tabular}

Fonte: Autora

2 LANCELLE, Luis. Softwares para projetos de iluminação. São Paulo. Disponível em: http://www.lumearquitetura.com.br/softwares.html

3 9o COBEE, 2012, Centro de convenções Frei Caneca. Avaliação da Tecnologia LED - Estudos. 
Onde os dados de quantidade de peças, Emédio, Emín e Emáx foram retirados dos resultados fornecidos pelo Dialux 4.10/2012. Os sistemas de iluminação que apresentarem menor consumo serão utilizados para análise dos resultados. Os mesmos ficarão assinalados em negrito e itálico.

A coluna Tipo/Anexo luminária é para indicar no Anexo Parte 2, a ficha técnica de cada luminária utilizada nas simulações. As fichas foram fornecidas pelos fabricantes. Caso não haja ficha técnica disponível, será gerada uma ficha técnica simples através do programa Dialux 4.10/2012.

Para cálculo da potência consumida pelo conjunto foram utilizados os seguintes equipamentos auxiliares listados conforme tabela 2 abaixo:

Tabela 2: Potência dos equipamentos auxiliares utilizados

\begin{tabular}{|c|c|c|c|}
\hline Lâmpada & Equipamento auxiliar & Marca/modelo & $\begin{array}{c}\text { Potência } \\
\text { consumida (W) }\end{array}$ \\
\hline \multirow{2}{*}{$\begin{array}{l}\text { Fluorescente tubular } \\
\qquad 14 \mathrm{~W}\end{array}$} & $\begin{array}{l}\text { Reator eletrônico } \\
\text { dimerizável } 2 \times 14 \mathrm{~W}\end{array}$ & $\begin{array}{c}\text { Osram / QTi } \\
\text { 2x14/24/220-240 DIM }\end{array}$ & 30,6 \\
\hline & $\begin{array}{c}\text { Reator eletrônico } \\
\text { dimerizável } 1 \times 14 \mathrm{~W}\end{array}$ & $\begin{array}{c}\text { Osram / QTi } \\
1 \times 14 / 24 / 220-240 \text { DIM }\end{array}$ & 15,4 \\
\hline \multirow{2}{*}{$\begin{array}{l}\text { Fluorescente tubular } \\
\qquad 28 \mathrm{~W}\end{array}$} & $\begin{array}{c}\text { Reator eletrônico } \\
\text { dimerizável } 1 \times 28 \mathrm{~W}\end{array}$ & $\begin{array}{c}\text { Osram / QTi } \\
1 \times 28 / 54 / 220-240 \text { DIM }\end{array}$ & 30,5 \\
\hline & $\begin{array}{c}\text { Reator eletrônico } \\
\text { dimerizável } 2 \times 28 \mathrm{~W}\end{array}$ & $\begin{array}{c}\text { Osram / QTi } \\
\text { 2x28/54/220-240 DIM }\end{array}$ & 60,3 \\
\hline $\begin{array}{l}\text { Fluorescente tubular } \\
24 \mathrm{~W}\end{array}$ & $\begin{array}{c}\text { Reator eletrônico } \\
\text { dimerizável 2x24W }\end{array}$ & $\begin{array}{c}\text { Osram / QTi } \\
2 \times 14 / 24 / 220-240 \text { DIM }\end{array}$ & 50 \\
\hline $\begin{array}{c}\text { Fluorescente compacta } \\
\text { longa } 36 \mathrm{~W}\end{array}$ & $\begin{array}{c}\text { Reator eletrônico } \\
\text { dimerizável 2x36W }\end{array}$ & $\begin{array}{c}\text { Osram / QTi 2x36/220- } \\
\text { 240 DIM }\end{array}$ & 69 \\
\hline \multirow{2}{*}{$\begin{array}{l}\text { Fluorescente compacta } \\
\text { dupla 4P } 26 \mathrm{~W}\end{array}$} & $\begin{array}{c}\text { Reator eletrônico } \\
\text { dimerizável 2x26W }\end{array}$ & $\begin{array}{c}\text { Osram / QTi-T/E 2x18- } \\
42 / 220-240 \text { DIM }\end{array}$ & 56 \\
\hline & $\begin{array}{c}\text { Reator eletrônico } \\
\text { dimerizável } 1 \times 26 \mathrm{~W}\end{array}$ & $\begin{array}{c}\text { Osram / QTi-T/E 1x18- } \\
42 / 220-240 \text { DIM }\end{array}$ & 29 \\
\hline \multirow{2}{*}{$\begin{array}{c}\text { Fluorescente compacta } \\
\text { dupla 4P } 32 \mathrm{~W}\end{array}$} & $\begin{array}{c}\text { Reator eletrônico } \\
\text { dimerizável } 1 \times 32 \mathrm{~W}\end{array}$ & $\begin{array}{c}\text { Osram / QTi-T/E 1x18- } \\
42 / 220-240 \text { DIM }\end{array}$ & 36 \\
\hline & $\begin{array}{c}\text { Reator eletrônico } \\
\text { dimerizável } 2 \times 32 \mathrm{~W}\end{array}$ & $\begin{array}{c}\text { Osram / QTi-T/E 1x18- } \\
\text { 42/220-240 DIM }\end{array}$ & 69 \\
\hline \multirow{2}{*}{$\begin{array}{l}\text { Fluorescente compacta } \\
\text { dupla } 4 \mathrm{P} 42 \mathrm{~W}\end{array}$} & $\begin{array}{c}\text { Reator eletrônico } \\
\text { dimerizável } 1 \times 42 \mathrm{~W}\end{array}$ & $\begin{array}{c}\text { Osram / QTi-T/E 2x18- } \\
42 / 220-240 \text { DIM }\end{array}$ & 47 \\
\hline & $\begin{array}{c}\text { Reator eletrônico } \\
\text { dimerizável } 2 \times 42 \mathrm{~W}\end{array}$ & $\begin{array}{c}\text { Osram / QTi-T/E 2x18- } \\
42 / 220-240 \text { DIM }\end{array}$ & 90 \\
\hline
\end{tabular}

Fonte: Autora

No caso das luminárias com LED, considerou-se uma perda de $10 \%$ para equipamentos auxiliares, pois nenhum dos fabricantes fornece esse valor. 
Considerou-se também que os equipamentos auxiliares serão dimerizáveis, pois em algumas certificações e selos, a possibilidade de controle dos sistemas de iluminação é considerada.

Foram escolhidos para simulações iniciais, aplicadas no estudo de caso do escritório, 2 (dois) tipos de sistema de iluminação com mesma lâmpada utilizada em maior escala em projetos luminotécnicos de escritórios. Após os cálculos realizados, obtemos os sistemas mais eficientes no Brasil e no exterior.

À medida que são feitas as simulações na primeira etapa, descarta-se uma série de sistemas de iluminação, pois o consumo final mostrado nas simulações não atenderia um projeto eficiente.

Na segunda etapa das simulações com os sistemas mais eficientes no Brasil e no exterior, foi feito um projeto luminotécnico na planta base escolhida. Dessa forma, podemos compara-los e verificar se atendem os indicadores de iluminação artificial dos certificados e selos de sustentabilidade.

Todos os ambientes foram simulados para que se alcançasse o nível médio solicitado na norma. 


\section{INDICADORES DE EFICIÊNCIA EM ILUMINAÇÃO ARTIFICIAL NOS SELOS E CERTIFICAÇÕES DE SUSTENTABILIDADE}

Nesse capítulo, foi feito o levantamento dos indicadores de iluminação artificial existentes nas principais certificações de sustentabilidade atuantes no mundo, nomeadamente nos países: Estados Unidos, Brasil, Reino Unido, França, Japão, África do Sul e Hong Kong.

Foram também levantadas as principais normas e leis referentes à iluminação artificial de alguns desses países. Citaremos apenas aquelas referentes à escritórios e escolas.

\subsection{Estados Unidos}

\subsubsection{Certificação LEED}

A certificação LEED nos Estados Unidos teve início em 1998 e foi concebida por uma ONG americana, a U.S. Green Building Concil (USGBC).

Para análise, nesse trabalho, foram levantados 4 tipos de certificações conforme diferentes tipos de uso: Commercial Interiors 2009, Existing Buildings 2009 e New Constrution 2009.

O guia faz referências em relação à iluminação artificial nas seguintes categorias:

- Espaço sustentável (Sustainable Sites - SS) que pede a redução da poluição luminosa.

- Energia e atmosfera (Energy \& Atmosphere - EA) que leva em consideração o desempenho energético eficiente e o consumo mínimo de energia conforme norma ANSI/ASHRAE/IESNA Standard 90.1-2007.

- Qualidade ambiental interna (Indoor Environmental Quality - EQ) que leva em consideração o controle da iluminação. 
De acordo com a pontuação atribuída a cada requisito, o edifício obtém a certificação dividida em: Certified, Silver, Gold ou Platinum.

\subsubsection{LEED for New Construction and Major Renovation 2009}

De acordo com o guia no Anexo I, em relação ao espaço sustentável (SS), o edifício recebe pontos por reduzir a poluição luminosa noturna do edifício.

- Iluminação interna: entre 23:00h e 5:00h deve-se reduzir a potência luminosa em $50 \%$ das linhas de luminárias não emergenciais próximas às aberturas para o exterior. Depois do horário do expediente podemse providenciar sensores de presença ou interruptores manuais que não ultrapassem 30 minutos ou em todas as aberturas do edifício para vista externa haja controle/ fechamento para redução de $10 \%$ transmissão de luz do interior para o exterior.

- Iluminação exterior: lluminar somente áreas para segurança e conforto. A densidade de potência da iluminação exterior deve seguir a norma ANSI / ASHRAE / IESNA Standard 90.1-2007. E dependendo da zona que o edifício se encontra (áreas em desenvolvimento, áreas residenciais, áreas de alta densidade residencial ou baixa comercial e áreas comerciais intensas), também deve cumprir os requisitos da IESNA RP-33 em relação ao nível de iluminação geral externa.

No quesito Energia e Atmosfera (EA), deve-se seguir a norma ANSI / ASHRAE / IESNA Standard 90.1-2007 4 que traz a densidade de potência para consumo mínimo de energia ou a ASHRAE Advanced Energy Guide (conforme região/estado dos Estados Unidos).

Por fim, para iluminação artificial a certificação leva em consideração, para Qualidade ambiental interna (IEQ), o controle de iluminação artificial para 90\% dos ocupantes, promovendo assim a produtividade, o bem-estar e o conforto. Desta

\footnotetext{
${ }^{4}$ Ver tabela no capítulo 3.1 .2
} 
forma permite-se que cada indivíduo possa se adequar às suas necessidades individuais e às necessidades da tarefa a ser executada.

\subsubsection{LEED for Existing Buildings - Operations and Maintenance 2009}

Conforme o guia no Anexo II, para prédios existentes no crédito do espaço sustentável (SS) o edifício deve reduzir a poluição luminosa interna e externa.

No interior do edifício, as linhas de luminárias não emergenciais próximas às aberturas devem ser desligadas automaticamente durante o período noturno após horário de expediente. Esse período não pode ultrapassar 2.190 horas por ano (50\% das horas noturnas anuais). Para utilizar o edifício após horário de expediente deverá ser previsto controle/ interruptores manuais.

Para iluminação externa, existem três opções para a obtenção de pontos. Ganham-se pontos se houver redução na poluição luminosa, desde que anteriormente o edifício tenha sido certificado em LEED New Construction ou Schools ou se ele foi certificado pelo LEED Core \& Shell Development, além de ter $75 \%$ da área certificada pelo LEED Commercial Interiors. Ou ainda, se as luminárias externas de 50W ou mais não emitirem luz diretamente para o céu. Na opção três, resumidamente deve-se medir os níveis de iluminação em espaços regulares no perímetro da construção e o nível medido não deve ser maior que $20 \%$ do nível medido com as luzes apagadas. É proibido utilizar a média das medições.

No crédito Qualidade ambiental interna (IEQ), assim como para obter a certificação LEED New Construction and Major Renovation, pontua os edifícios onde $50 \%$ dos usuários possam controlar o sistema de iluminação artificial para ajuste de necessidades e de acordo com a exigência de cada tarefa. 


\subsubsection{LEED for Commercial Interiors 2009}

Para obtenção de pontos no quesito Espaço Sustentável (SS), pode-se obter pontos se houver redução na potência luminosa em $50 \%$ das linhas de luminárias não emergenciais próximas às aberturas para o exterior entre 23:00h e 5:00h. Ou ainda, após horário do expediente pode-se providenciar sensores de presença ou interruptores manuais que não ultrapassem 30 minutos.

No LEED Commercial Interiors, no quesito Energia e Atmosfera (EA), pode-se obter até 5 pontos se 0 edifício reduzir a densidade de potência relacionado à iluminação abaixo do permitido pela norma ANSI / ASHRAE / IESNA Standard 90.12007 através do método espaço por espaço (Space-by-Space Method) ou pela área construída (Space Method). Abaixo conforme guia do LEED no Anexo III segue a pontuação de acordo com porcentagem reduzida:

\begin{tabular}{|c|c|}
\hline $\begin{array}{c}\text { Lighting Power Density Reduction } \\
\text { Below the Standard }\end{array}$ & Points \\
\hline $15 \%$ & 1 \\
\hline $20 \%$ & 2 \\
\hline $25 \%$ & 3 \\
\hline $30 \%$ & 4 \\
\hline $35 \%$ & 5 \\
\hline
\end{tabular}

Fonte: LEED 2009 for Commercial Interiors - USGBC (updated February 2011)

Ainda em Energia e Atmosfera (EA) podem-se obter pontos caso haja medição e monitoramento dos sistemas de iluminação e automação em $75 \%$ ou mais da área total do edifício.

Assim como nas certificações mencionadas anteriormente, em Qualidade Ambiental Interna (IEQ), há pontuação se houver o controle individual de iluminação artificial para no mínimo $90 \%$ dos ocupantes. 


\subsubsection{LEED for Schools - New Construction and Major Renovations 2009}

Como podemos ver no Anexo IV, o guia em questão segue praticamente o guia LEED for New Construction and Major Renovations no que diz respeito à redução da poluição visual da iluminação artificial, porém faz ressalva à iluminação de quadras esportivas, que não precisam seguir a densidade de potência da norma ANSI/ ASHRAE/ IESNA Standard 90.1-2007, mas devem ser programados para apagar após às 23:00h e em casos de eventos esportivos após esse horário, deve ser previsto acendimento/ apagamento manual.

Assim como para outras certificações LEED deve seguir em relação a densidade de potência a norma ANSI/ ASHRAE/ IESNA Standard 90.1-2007 para áreas internas.

Para o item Qualidade ambiental interna (IEQ) o controle de iluminação artificial é levado em conta da seguinte maneira:

- Caso 1: Em escritórios administrativos e outros espaços com ocupação regular devem prever controle de iluminação individual para $90 \%$ dos ocupantes permitindo ajustes necessários individuais e de tarefas e providenciar controle do sistema de iluminação para espaços destinados à aprendizagem como salas de aulas, laboratórios, sala de artes, sala de música, ginásios, etc.

Caso 2: Em salas de aula prever 2 sistemas de iluminação: geral e para vídeo conferência.

\subsubsection{Norma ANSI/ASHRAE/IESNA Standard 90.1-2007}

Essa norma americana traz requisitos mínimos de eficiência energética na construção de edifício e é utilizada para obtenção do certificado LEED. 
O capítulo que nos interessa é o capítulo 9 que traz recomendações referentes à iluminação artificial, onde se encontram tabelas para o cálculo da potência instalada permitida em W/m $/ \mathrm{m}^{2}$ ou W/fs${ }^{2}$ e pode ser feita por dois métodos: o de área construída (Area Method) ou pelo método espaço por espaço (Space-bySpace Method). Há tabelas com recomendações de densidade de potência tanto para espaços internos como para espaços externos. Ver Anexo IV onde temos as tabelas completas recomendadas pela norma.

Abaixo seguem alguns dos valores recomendados da norma que serão utilizados na dissertação:

\begin{tabular}{|l|l|}
\hline \multicolumn{2}{|l|}{ Área interna - Método área construída (Area Method) } \\
\hline Ambiente & $\begin{array}{l}\text { Densidade de potência } \\
\text { luminosa máxima }\end{array}$ \\
\hline Centro de convenções & $13 \mathrm{~W} / \mathrm{m}^{2}$ \\
\hline Ginásio & $12 \mathrm{~W} / \mathrm{m}^{2}$ \\
\hline Biblioteca & $14 \mathrm{~W} / \mathrm{m}^{2}$ \\
\hline Escritórios & $11 \mathrm{~W} / \mathrm{m}^{2}$ \\
\hline Escola / Universidade & $13 \mathrm{~W} / \mathrm{m}^{2}$ \\
\hline
\end{tabular}

\begin{tabular}{|c|c|}
\hline $\begin{array}{l}\text { Área interna - Método espa( } \\
\text { Space Method) }\end{array}$ & por espaço (Space-by- \\
\hline Ambiente & $\begin{array}{l}\text { Densidade de potência } \\
\text { luminosa máxima }\end{array}$ \\
\hline Escritório (espaço fechado) & $12 \mathrm{~W} / \mathrm{m}^{2}$ \\
\hline $\begin{array}{l}\text { Escritório (espaço aberto) ou } \\
\text { Staff }\end{array}$ & $12 \mathrm{~W} / \mathrm{m}^{2}$ \\
\hline $\begin{array}{l}\text { Sala de conferência/ reunião/ } \\
\text { multiuso }\end{array}$ & $14 \mathrm{~W} / \mathrm{m}^{2}$ \\
\hline $\begin{array}{l}\text { Sala de aula/ leitura / } \\
\text { treinamento }\end{array}$ & $15 \mathrm{~W} / \mathrm{m}^{2}$ \\
\hline $\begin{array}{l}\text { Auditório/ platéia - para } \\
\text { ginásio }\end{array}$ & $4 \mathrm{~W} / \mathrm{m}^{2}$ \\
\hline
\end{tabular}




\begin{tabular}{|l|l|}
\hline $\begin{array}{l}\text { Auditório/ platéia - para } \\
\text { centro de convenções }\end{array}$ & $8 \mathrm{~W} / \mathrm{m}^{2}$ \\
\hline Laboratório & $15 \mathrm{~W} / \mathrm{m}^{2}$ \\
\hline Corredor / circulação & $5 \mathrm{~W} / \mathrm{m}^{2}$ \\
\hline Escada - uso ativo & $6 \mathrm{~W} / \mathrm{m}^{2}$ \\
\hline Espaços específicos das edificações \\
\hline Ambiente & $\begin{array}{l}\text { Densidade de potência } \\
\text { luminosa máxima }\end{array}$ \\
\hline Ginásio / Academia & $15 \mathrm{~W} / \mathrm{m}^{2}$ \\
\hline Área de jogos dichas e & $12 \mathrm{~W} / \mathrm{m}^{2}$ \\
\hline Área de exercícios & $10 \mathrm{~W} / \mathrm{m}^{2}$ \\
\hline Biblioteca & $18 \mathrm{~W} / \mathrm{m}^{2}$ \\
\hline $\begin{array}{l}\text { Arquivos de } \\
\text { catalogação }\end{array}$ & $13 \mathrm{~W} / \mathrm{m}^{2}$ \\
\hline Estantes & \\
\hline Área de leitura & \\
\hline
\end{tabular}

Fonte: ANSI/ASHRAE/IESNA Standard 90.1-2007

Essa norma tem a finalidade de trazer economia de energia ao edifício com gastos referentes à iluminação artificial.

\subsubsection{Lighting Handbook Reference \& Application - IESNA}

O guia Lighting Handbook trata de iluminação em geral e foi estabelecido pelo IESNA desde 1979. O capítulo que nos interessa é o capítulo 11 que trata de considerações importantes para o projeto de iluminação e traz o nível em lux e footcandles adequados de iluminação para tarefas específicas.

Ao utilizar o guia, o projetista deve levar em consideração o tipo de atividade a serem realizadas, características da tarefa visual, idade dos ocupantes, importância do desempenho visual no que diz respeito à velocidade e precisão e 
reflexão da luz. Como podemos ver no Anexo VI, o guia traz o passo a passo dos procedimentos para utilização adequada dos valores do mesmo.

Abaixo, temos alguns valores que serão importantes para a dissertação:

\begin{tabular}{|c|c|c|}
\hline \multirow{2}{*}{ Ambiente } & \multirow{2}{*}{$\begin{array}{l}\text { Categoria de } \\
\text { iluminância }\end{array}$} & Intervalos de iluminância \\
\hline & & Lux \\
\hline Salas de aula - geral & $\mathrm{D}$ & $200-300-500$ \\
\hline Laboratório de ciências & $E$ & $500-750-1000$ \\
\hline Salas de leitura & $\mathrm{F}$ & $1000-1500-2000$ \\
\hline Bibliotecas - áreas de leitura & $\mathrm{D}$ & $200-300-500$ \\
\hline Estante de livros & D & $200-300-500$ \\
\hline Escritório & $D / E^{*}$ & $200-300-500-750-1000$ \\
\hline
\end{tabular}

Fonte: Lighting Handbook Reference \& Application - IESNA - Cap.11

* Para algumas tarefas especificas, o nível dependerá da atividade a ser realizada. O guia faz referência para busca do nível adequado de iluminação dessas outras tarefas mais especificas.

\subsection{Brasil}

\subsubsection{Certificação LEED}

A certificação LEED no Brasil teve início em 2008 e é concebida pelo GBC Brasil (Green Building Concil Brasil).

Até o momento a certificação LEED no país deve seguir as mesmas diretrizes do LEED americano, mas está em andamento um projeto de regionalização do LEED para o país.

Inclusive a norma ANSI/ASHRAE/IESNA STANDARD 90.1-2007 deve ser seguida em relação à densidade de potência luminosa. Atualmente, a obtenção da certificação é voluntária. 


\subsubsection{Certificação AQUA}

A certificação AQUA teve início em 2007 e é dada pela Fundação Vanzolini. O seu referencial técnico foi baseado no HQE da França.

Os manuais estão disponíveis na internet e para este trabalho serão considerados os referenciais técnicos: Edifícios do setor de serviços - Escritórios e edifícios escolares 2007 e Qualidade Ambiental de Edifícios em Renovação Edifícios do Setor de Serviços 2010. A certificação é dividida em desempenhos Bom, Superior e Excelente.

Diferente do LEED, o AQUA faz referência apenas a norma que diz respeito ao nível de iluminação dos ambientes, seguindo a NBR 5413 - 1992.

Para questões referentes à iluminação artificial analisaremos as seguintes categorias:

- Eco-construção: que leva em conta a relação do edifício com o seu entorno e escolha de produtos para a construção

- Eco-gestão: que leva em consideração a gestão da energia com a redução do consumo de energia primária e dos poluentes associados e a manutenção do desempenho ambiental adquirido no que diz respeito à iluminação artificial.

- Conforto visual em relação à iluminação artificial

\subsubsection{Referencial Técnico de Certificação. Edifícios do setor de serviços. Escritórios - Edifícios escolares 2007}

Da relação do edifício com seu entorno, o referencial técnico diz respeito à iluminação exterior não somente para criar um conforto visual satisfatório, mas é importante também a questão da sensação de segurança, principalmente das áreas de circulação externa entre saída dos usuários do edifício até estacionamentos ou 
saídas do terreno, nas áreas onde há iluminação natural é fraca e nas áreas de estocagem de resíduos de uso e operação.

No capítulo que diz respeito à escolha de produtos para a construção, é levado em consideração se no projeto luminotécnico são especificados lâmpadas fluorescentes que apresentam o selo PROCEL. Como o próprio referencial técnico cita essas lâmpadas através de testes, apresentam menor consumo de energia e menor substituição ao longo do tempo, contribuindo assim para menor geração de poluentes, uma vez que são compostas por mercúrio.

$\mathrm{Na}$ gestão de energia o referencial técnico solicita a redução do consumo de energia primária e dos poluentes associados, e é levada em consideração a área e a potência instalada. Porém o AQUA faz recomendações referentes ao consumo KWh/ano.m ${ }^{2}$ área útil (Cep: Coeficiente de consumo de energia primária), e nesse valor está incluso também o consumo de energia em relação ao resfriamento, ao aquecimento da água, ventilação e outros equipamentos auxiliares além do consumo com iluminação artificial.

Ainda na questão da gestão de energia, é importante permanência do desempenho dos sistemas de iluminação onde deve haver um acompanhamento e controle do desempenho dos sistemas de iluminação durante o uso e operação do edifício. A escolha dos sistemas de iluminação deve ser concebida de modo a facilitar a manutenção, inclusive no que diz respeito ao acesso desses sistemas.

Por fim, o referencial técnico para obtenção da certificação, pede alguns requisitos para o conforto visual do usuário. Em relação à iluminação artificial as recomendações se referem ao nível de iluminância média conforme norma brasileira NBR 5413, uniformidade na iluminação de um ambiente, cuidados com ofuscamentos e qualidade da luz emitida (temperatura de cor e IRC adequados), além do controle do meio visual individual pelos usuários.

Como podemos ver no Anexo VII e na tabela de quadro de avaliação, o nível de iluminância média mantida é de 500 lux para escritórios e 300 lux para edifícios escolares em salas de aula de ensino fundamental e médio. Para salas de aula no período noturno, o nível aumenta para 500 lux. 


\subsubsection{Referencial Técnico de Certificação da Qualidade Ambiental de Edifícios em Renovação. Edifícios do setor de serviços 2010}

Da relação do edifício com seu entorno, esse referencial técnico de renovação solicita as mesmas condições do referencial técnico de certificação onde se deve pensar na iluminação exterior em função do conforto e da segurança. Para renovação de edifícios, deve-se ainda tomar o cuidado para que a iluminação exterior não cause incômodos visuais noturnos para a vizinhança.

Na gestão de energia, há a preocupação de melhorar a aptidão do edifico de maneira a reduzir as necessidades energéticas inclusive da iluminação artificial. Assim como no referencial técnico para certificação, é solicitada a redução do consumo de energia primária e dos poluentes associados, onde parte desse consumo é relacionada ao consumo com os sistemas de iluminação artificial.

Há também a preocupação na concepção dos sistemas para garantir uma manutenção simplificada, além do acompanhamento do consumo de energia inclusive para detecção de falhas.

Como pode ser visto no Anexo VIII, os requisitos de conforto visual para iluminação artificial são os mesmos do referencial técnico para certificação em edifícios do setor de edifícios onde a norma NBR 5413 deve ser seguida e os requisitos em relação à qualidade da luz também.

\subsubsection{Regulamento Selo PROCEL Edifica}

O selo PROCEL Edifica é emitido pelo INMETRO e é também conhecido como RTQ-C (Regulamento Técnico da Qualidade do Nível de Eficiência Energética de Edifícios Comerciais, de Serviços e Públicos). A etiquetagem ainda é voluntária, e assim como ocorreu em países europeus tem previsão de ser compulsiva para edifícios públicos a partir de 2020.

A etiquetagem é aplicada para construções com área útil superior a $500 \mathrm{~m}^{2}$. documento analisado é de 2010. 
A regulamentação leva em consideração em relação à iluminação artificial a eficiência e potência instalada, a divisão do acionamento dos circuitos, desligamento automático do sistema de iluminação e deve seguir a tabela do método de cálculo da densidade de potência de iluminação conforme estabelecido pelo regulamento técnico da qualidade.

Para o cálculo da densidade de potência, como pode ser visto no Anexo IX, deve se aplicar o método da área do edifício ou o método das atividades do edifício. O primeiro deve ser utilizado para edifícios com até três atividades principais ou que estas atividades ocupem mais de $30 \%$ do edifício e o segundo é utilizado para avaliar separadamente os ambientes do edifício.

Para utilizar a avaliação do método da área do edifício conforme o manual RQT-C deve-se:

a. Identificar a atividade principal do edifício, de acordo com a Tabela 4.1 , e a densidade de potência de iluminação limite $\left(D P I_{L}-W / m^{2}\right)$ para cada nível de eficiência;

b. Determinar a área iluminada do edifício;

c. Multiplicar a área iluminada pela $\mathrm{DPI}_{\mathrm{L}}$, para encontrar a potência limite do edifício;

d. Quando o edifício for caracterizado por até três atividades principais determina-se a densidade de potência de iluminação limite $\left(\mathrm{DPI}_{\mathrm{L}}\right)$ para cada atividade e a área iluminada para cada uma. A potência limite para o edifício será a soma das potências limites para cada atividade do edifício;

(...)

e. Comparar a potência total instalada no edifício e a potência limite para determinar o nível de eficiência do sistema de iluminação;

f. Após determinar o nível de eficiência alcançado pelo edifício devese verificar 0 atendimento dos pré-requisitos em todos os ambientes;

g. Se existirem ambientes que não atendam aos pré-requisitos, o EqNum deverá ser corrigido através da ponderação entre os níveis 
de eficiência e potência instalada dos ambientes que não atenderam aos pré-requisitos e a potência instalada e o nível de eficiência encontrado para o sistema de iluminação. ${ }^{5}$

E para utilizar o método das atividades do edifício deve-se:

a. Identificar adequadamente as atividades encontradas no edifício, de acordo com a tabela 4.2;

b. Consultar a densidade de potência de iluminação limite $\left(D P I_{L}-\right.$ $\mathrm{W} / \mathrm{m}^{2}$ ) para cada nível de eficiência para cada uma das atividades, na tabela 4.2;

(...)

c. Multiplicar a área iluminada de cada atividade pela $D P I_{L}$, para encontrar a potência limite para cada atividade. A potência limite para o edifício será a soma das potências limites das atividades;

d. Calcular a potência instalada no edifício e compará-la com a potência limite do edifício, identificando o EqNum (equivalente numérico) do sistema de iluminação;

e. Se existirem ambientes que não atendam aos pré-requisitos, o EqNum deverá ser corrigido através da ponderação entre os níveis de eficiência e potência instalada e o nível de eficiência encontrado para o sistema de iluminação.

(...)

$$
K=\frac{A_{t}+A_{p t}}{A_{p t}}
$$

Onde:

$K=$ índice de ambiente (adimensional)

$A_{t}=$ área de teto $\left(m^{2}\right)$

$A_{p t}=$ área do plano de trabalho $\left(m^{2}\right)$

$A_{p}=$ áreas de parede entre o plano iluminante e plano de trabalho $\left(\mathrm{m}^{2}\right)$

\footnotetext{
${ }^{5}$ PROCEL Edifica. RTQ-C (Regulamento Técnico da Qualidade do Nível de Eficiência Energética de Edifícios Comerciais, de Serviços e Públicos) - p.40 a 41
} 


$$
R C R=\frac{2,5 x H_{p} x P}{A}
$$

Onde:

RCR: Room Cavity Ratio (adimensional);

$H_{p}:$ Altura de parede, considerar altrua entre o plano iluminante e 0 plano de trabalho $\left(\mathrm{m}^{2}\right)$;

$P$ : Perímetro do ambiente $\left(m^{2}\right)$;

A: Área do ambiente $\left(m^{2}\right)$;

Quando existirem ambientes que utilizem este recurso $(K / R C R), 0$ EqNum será encontrado através da ponderação dos equivalentes numéricos destes ambientes e do edifício por suas potências. ${ }^{6}$

O regulamento abre exceções para o cálculo de potência de algumas situações como, por exemplo: iluminação de destaque de galerias, museus, iluminação de vitrines, entre outros.

\subsubsection{NBR 5413 - lluminância de Interiores}

A norma brasileira de lluminância de Interiores foi revisada pela última vez em 1992. Segundo o engenheiro eletricista Elvo Calixto que participou do comitê de estudos de revisão da norma em 1982, a atual norma foi baseada no documento americano "Iluminating Engineering of Society North America" (IESNA) ${ }^{7}$.

\footnotetext{
${ }^{6}$ PROCEL Edifica. RTQ-C (Regulamento Técnico da Qualidade do Nível de Eficiência Energética de Edifícios Comerciais, de Serviços e Públicos) - p.43 a 44

${ }^{7}$ Portal Lumière. Notícias: NBR 5413: O que e por que deve mudar? 29/09/08 -15:25 por Nara Faria.
} 
A norma atual tem como objetivo estabelecer "os valores de iluminâncias médias mínimas em serviço para iluminação artificial em interiores, onde se realizem atividades de comércio, indústria, ensino, esporte e outras."

A norma traz tabelas com três valores de iluminância por tipo de atividade. Em geral, para cálculo é utilizado o valor mediano, com exceção de refletâncias ou contrastes altos, onde a velocidade e/ou precisão não são tão importantes e quando a tarefa é executada ocasionalmente é utilizado o valor mais baixo. E em casos onde a tarefa se apresente com refletâncias e contrastes baixos, onde há necessidade de precisão na tarefa ou a capacidade visual do observador está abaixo da média, utilizaremos o valor mais alto.

No Anexo $X$ podemos notar que a tabela de níveis de iluminância é bem semelhante ao documento da IESNA. Abaixo, alguns valores em lux que serão utilizados na dissertação:

“5.3.5. Bibliotecas

- sala de leitura $300-500-750$

- recinto das estantes $200-300-500 \quad "$

“ 5.3.13. Escolas

- salas de aula $200-300-500$

- quadros negros $300-500-750(\ldots)$

- laboratórios

- geral $150-200-300$

- local $300-500-750$

“5.3.14. Escritórios

- escritórios de:

- registros, cartografia, etc. $750-1000-1500$

- desenho, engenharia mecânica 
arquitetura

$750-1000-1500$

- desenho decorativo e esboço $300-500-750$

\subsection{Reino Unido}

\subsubsection{Certificação BREEAM}

A certificação BREEAM no Reino Unido teve início em 1990 e foi estabelecida pelo Building Research Establishment (BRE) Global.

Para análise de indicadores será levado em conta apenas o manual técnico do BREEAM New Construction 2011 disponível para download na internet. Estará presente nesse trabalho apenas os indicadores de iluminação artificial referentes à escritórios e edifícios escolares.

Para a obtenção dessa certificação, o edifício deve atender requisitos e dependendo da pontuação alcançada o edifício recebe uma classificação com número de estrelas, de 0 (zero - desclassificado) até 6 (seis - acima do nível).

A seguir levantaremos os principais requisitos que o BREEAM traz em relação à iluminação artificial:

- Saúde e bem estar (Health and Wellbeing - Hea): que leva em consideração o conforto visual e proteção e segurança.

- Energia (Energy - Ene): que considera o monitoramento do consumo de energia e iluminação externa.

- Poluição (Pollution - Pol): que leva em consideração a redução da poluição luminosa noturna.

No quesito de conforto visual, para iluminação artificial, em questões de nível de iluminância deve seguir a CIBSE Code for Lighting 2009 para áreas internas e para áreas externas o BS5489-1:2003+A2:2008 Lighting of roads and public amenity areas. 
O BREEAM traz uma série de tópicos que devem ser levados em conta para o projeto de iluminação artificial tais como: cuidado especial ao projetar em áreas com telas de computadores; em ambientes de escritórios separar os circuitos em áreas próximas às janelas que recebem contribuição da luz natural e longe da janela; e em bibliotecas separar as áreas de leitura, balcão de trabalho e estantes. No Anexo XI, podemos ver os outros tópicos que o guia técnico traz.

Ao final de cada quesito, o guia técnico traz algumas definições que devem ser levados em consideração ao projetar, como por exemplo, a separação de circuitos, o controle individual parcial de alguns sistemas de iluminação, o uso de reatores de alta frequência, plano de trabalho que deve normalmente ser considerado $0,70 \mathrm{~m}$ acima do piso, etc.

No tópico Proteção e Segurança, para áreas externas o nível de iluminação deve seguir a norma BS5489-1:2003+A2:2008 para segurança no acesso dos usuários ao edifício.

Na gestão de energia do edifício, a certificação BREEAM assim como o AQUA considera se há monitoramento do consumo de energia em relação à iluminação artificial.

Ainda relacionado à energia, a certificação pontua o edifício que especifica e se preocupa com a eficiência energética das luminárias para áreas externas, onde o sistema de iluminação deve atender os seguintes requisitos:

- Equipamentos de iluminação para circulações, acesso e vias devem ter uma eficácia de no mínimo "50 lamp lumens/circuit Watt” quando o IRC é maior ou igual a 60 e se for menor que 60 uma eficácia de "60 lamp lumens/ circuit Watt".

- Equipamentos de iluminação para áreas de estacionamento, acesso à ruas/ estradas e holofotes, devem ter uma eficácia de no mínimo "70 lamp lumens/circuit Watt" quando o IRC é maior ou igual a 60 e se for menor que 60 uma eficácia de "80 lamp lumens/ circuit Watt".

- Equipamentos de iluminação externa para sinalização e luz de balizamento no piso devem ter uma eficácia de pelo menos 60 lumens/ 
Watt quando a potência é maior ou igual á $25 \mathrm{~W}$ ou 50 lumens/Watt quando a potência é menor que 25W.

- As luminárias externas devem ter sensor de luz ou programação para que apague durante o dia, porém também é aceitável que haja um sistema manual de acendimento.

O guia ainda traz para recomendações para uma iluminação eficiente dentro dos elevadores onde se a eficácia for maior que 55 lumens/ Watt a iluminação deve ser desligada caso fique ociosa por um determinado período.

Na certificação BREEAM assim como no LEED, é importante a redução da poluição luminosa noturna assim como o consumo de energia do mesmo. Com exceção da iluminação destinada à segurança a iluminação externa pode ser desligado automaticamente das 23:00h às 07:00h. Para iluminação de segurança que será utilizada nesse horário, poderá ter dispositivos que reduzam o nível de iluminação dos mesmos permanecendo no limite do nível mínimo permitido.

\subsubsection{CIBSE - Code for Lighting}

O Código para lluminação do CIBSE é publicado desde 1936 e segue normas internacionais como o CIE (ver Anexo XX) e abrange vários aspectos da iluminação desde o nível de iluminância adequado até o limite de ofuscamento. No Anexo XII temos as principais recomendações em relação à iluminação artificial. Abaixo seguem exemplos que serão utilizados na dissertação, e estão separadas por tipo e locais de uso. 
Edifícios escolares

\begin{tabular}{|l|l|l|l|}
\hline \multicolumn{1}{|c|}{ Ambientes } & \multicolumn{1}{|c|}{$\begin{array}{c}\text { Iluminância } \\
\text { mantida (lux) }\end{array}$} & $\begin{array}{c}\text { Índice limite } \\
\text { de } \\
\text { ofuscamento } \\
\text { unificado }\end{array}$ & $\begin{array}{c}\text { Índice de } \\
\text { reprodução } \\
\text { de cor mínimo } \\
\left(\mathrm{R}_{\mathrm{a}}\right)\end{array}$ \\
\hline Salas de aula & 300 & 19 & 80 \\
\hline $\begin{array}{l}\text { Salas de aula para período noturno e } \\
\text { educação para adultos }\end{array}$ & 500 & 19 & 80 \\
\hline Laboratórios & 500 & 19 & 80 \\
\hline Sala de computação & 300 & 19 & 80 \\
\hline Circulação, corredores & 100 & 25 & 80 \\
\hline Sala de professores & 300 & 19 & 80 \\
\hline
\end{tabular}

Fonte: CIBSE - Code for lighting

\section{Escritórios}

\begin{tabular}{|l|c|c|c|}
\hline \multicolumn{1}{|c|}{ Ambientes } & $\begin{array}{c}\text { Iluminância } \\
\text { mantida (lux) }\end{array}$ & $\begin{array}{c}\text { Índice limite } \\
\text { de } \\
\text { ofuscamento } \\
\text { unificado }\end{array}$ & $\begin{array}{c}\text { Índice de } \\
\text { reprodução } \\
\text { de cor mínimo } \\
\left(\mathrm{R}_{\mathrm{a}}\right)\end{array}$ \\
\hline Arquivamento, cópia, etc. & 300 & 19 & 80 \\
\hline Escrever, digitar, ler, processar dados & 500 & 19 & 80 \\
\hline Desenho técnico & 750 & 16 & 80 \\
\hline Estações de CAD & 500 & 19 & 80 \\
\hline Conferência e sala de reunião & 500 & 19 & 80 \\
\hline Recepção & 300 & 22 & 80 \\
\hline Arquivos & 200 & 25 & 80 \\
\hline
\end{tabular}

Fonte: CIBSE - Code for lighting

Além disso, o código explica o passo a passo para fazer um bom projeto de iluminação. 


\subsection{França}

\subsubsection{Certificação HQE}

A Associação HQE foi criada em 1996 e é quem emite o selo verde de edificações na França. Os guias para obtenção da certificação estão disponíveis na internet e serão levados em consideração para esse trabalho: Escritório/ Educação 2008 e Reforma de escritório / educação 2010.

Para o edifício ter o certificado HQE deve cumprir os seguintes requisitos que variam de acordo com o desempenho (Niveau BASE, Niveau PERFORMANT e Niveau TRES PERFORMANT):

- Localização e construção: que leva em consideração a relação da construção com seu entorno no que diz respeito à iluminação artificial externa.

- Gestão: que leva em consideração a gestão de energia, e a manutenção e sustentabilidade do desempenho ambiental em relação à iluminação artificial.

- Conforto: que leva em consideração o conforto visual em relação à iluminação artificial.

- Saúde: que considera a qualidade sanitária dos espaços, a qualidade sanitária do ar e da água.

\subsubsection{HQE - Guide Pratique du referentiela pour la qualite environnementale des bâtiments - Bureau / Enseignment 2008}

Da relação da construção com o entorno, o guia traz preocupações em relação à iluminação exterior de um projeto que visa segurança e conforto para os usuários. Recomenda-se que sejam iluminadas as áreas de circulação externa 
ligadas ao estacionamento, às saídas dos edifícios, as áreas estocagem de resíduos de uso e operação e áreas onde a iluminação natural é insuficiente.

Há preocupação ainda com o incômodo visual causada pela própria iluminação interna do edifício ou pelos displays ou sinalização do mesmo.

No item que se refere à gestão de energia, o HQE faz referência para redução de energia (incluso pela iluminação artificial) e pede que se minimize o uso da iluminação artificial nas áreas externas, estacionamentos, etc. conforme norma RT 2005 e sugere que se usem LEDs para reduzir assim o consumo de energia.

Ainda com relação à gestão de energia, o edifício que reduzir o consumo de energia primária, incluso iluminação, ganhará pontos adicionais onde o consumo é

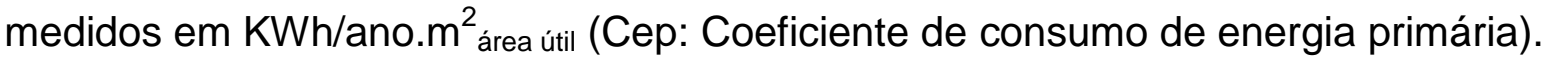

Está presente no regulamento, a importância do monitoramento do consumo e desempenho de energia ligados à iluminação artificial e a facilidade de manutenção dos equipamentos utilizados e instalados.

No que diz respeito ao conforto visual, o guia faz referência ao nível de iluminação artificial no plano de trabalho que deve obedecer à norma NF EN 12464. O nível de iluminação deve também ser uniforme e a luz deve ter uma boa reprodução de cor de acordo com a tarefa realizada, e uma boa qualidade de luz emitida (temperatura de cor adequada). Deve-se ainda, evitar o ofuscamento e os usuários devem ter o controle visual da iluminação individual.

O guia traz como nível ideal de iluminação o valor abaixo:

- Escritórios e salas de aula (educação primária e secundária): 300 lux

- Salas de aula (para educação de adultos e aula noturna): 500 lux

Apesar da norma NF EN 12464 pedir para escritórios o valor de 500 lux, os profissionais que elaboraram este guia sugerem que o valor de 300 lux é suficiente para realizar a tarefa (Ver Anexo XIII - item 10.2.1). 


\subsubsection{Guide Pratique du Referentiel pour la Qualite Environnementale des Bâtiments em Renovation - Bureau / Enseignement 2010}

Com relação do edifício e seu entorno, assim como no guia para se obter a certificação, há uma preocupação na questão da iluminação exterior com o conforto e segurança do usuário em áreas de circulação principal do edifício para os estacionamentos e saída até a via. O guia também pede para redução da poluição visual noturna do edifício e de displays.

Em gestão de energia, assim como nos outros referencias, o edifício deve reduzir o consumo de energia primária em relação à iluminação interna e externa. Deve também prever divisão de circuitos, zonas de sensor de presença, etc., enfim deve haver um monitoramente e controle da iluminação artificial.

No item conforto visual, assim como nos guias referenciais anteriores do HQE, o guia faz referência ao nível de iluminação artificial no plano de trabalho que deve obedecer à norma NF EN 12464, deve ser uniforme e a luz deve ter uma boa reprodução de cor de acordo com a tarefa realizada e uma boa qualidade de luz emitida (temperatura de cor adequada). Deve-se ainda, evitar o ofuscamento e os usuários devem ter o controle visual da iluminação individual. Ver Anexo XIV para maiores detalhes.

\subsubsection{NF EN 12464}

A norma NF EN 12464 de 2002 é uma norma europeia que segue basicamente a norma CIE 8995 e leva em consideração o nível de iluminação mínimo na área de trabalho, a uniformidade da luz, a preocupação com o ofuscamento, a aparência de cor e a reprodução de cor da luz emitida.

No Anexo XV temos as tabelas com o nível de iluminância, e abaixo segue uma tabela com os principais valores que serão utilizados: 
Escritórios

\begin{tabular}{|l|c|c|c|}
\hline \multicolumn{1}{|c|}{ Ambientes } & $\begin{array}{c}\text { Iluminância } \\
\text { mantida (lux) }\end{array}$ & $\begin{array}{c}\text { Índice limite } \\
\text { de } \\
\text { ofuscamento } \\
\text { unificado }\end{array}$ & $\begin{array}{c}\text { Índice de } \\
\text { reprodução } \\
\text { de cor mínimo } \\
\left(\mathrm{R}_{\mathrm{a}}\right)\end{array}$ \\
\hline Arquivamento, cópia, etc. & 300 & 19 & 80 \\
\hline Escrever, digitar, ler, processar dados & 500 & 19 & 80 \\
\hline Desenho técnico & 750 & 16 & 80 \\
\hline Estações de CAD & 500 & 19 & 80 \\
\hline Conferência e sala de reunião & 500 & 19 & 80 \\
\hline Recepção & 300 & 22 & 80 \\
\hline Arquivos & 200 & 25 & 80 \\
\hline
\end{tabular}

Fonte: NF EN 12464/2002

Edifícios escolares

\begin{tabular}{|l|c|c|c|}
\hline \multicolumn{1}{|c|}{ Ambientes } & $\begin{array}{c}\text { Iluminância } \\
\text { mantida (lux) }\end{array}$ & $\begin{array}{c}\text { Índice limite } \\
\text { de } \\
\text { ofuscamento } \\
\text { unificado }\end{array}$ & $\begin{array}{c}\text { Índice de } \\
\text { reprodução } \\
\text { de cor mínimo } \\
\left(\mathrm{R}_{\mathrm{a}}\right)\end{array}$ \\
\hline Salas de aula & 300 & 19 & 80 \\
\hline $\begin{array}{l}\text { Salas de aula para período noturno e } \\
\text { educação para adultos }\end{array}$ & 500 & 19 & 80 \\
\hline Laboratórios & 500 & 19 & 80 \\
\hline Sala de computação & 300 & 19 & 80 \\
\hline Circulação, corredores & 100 & 25 & 80 \\
\hline Sala de professores & 300 & 19 & 80 \\
\hline
\end{tabular}

Fonte: NF EN 12464/2002

\subsection{Japão}

\subsubsection{Certificação CASBEE 2008}

A certificação CASBEE teve início em 2002 e é promovido pelo Japan Sustainable Building Consortium. 
Os manuais estão disponíveis na internet mediante cadastro e são gratuitos. Será estudado nesse trabalho somente o New Construction 2008.

Para obtenção do certificado o edifício deve cumprir requisitos em relação à qualidade ambiental da construção e da redução de carga ambiental do edifício. Dividindo a pontuação do primeiro pelo segundo obtemos a classificação do edifício em Excellent, Very Good, Good, Fairy Poor e Poor.

Entre as novas construções alguns requisitos não são aplicados à todos os edifícios. Os requisitos estão assinalados por tipo de edifícios que serão obrigatórios ou que são aplicáveis. Os edifícios estão divididos nas seguintes categorias: escritórios, escolas, varejo, restaurantes, halls, hospitais, hotéis, apartamentos e fábricas. O trabalho entrará apenas no que diz respeito à escritórios e escolas.

No Anexo XVI, temos os quesitos que estão relacionados à iluminação artificial e serão comentados abaixo.

No quesito Qualidade ambiental da construção $(Q)$, em Ambiente Interno (Q1): que leva em consideração o conforto luminoso, onde se deve tomar o cuidado com o ofuscamento das luminárias obedecendo ao Technical Guideline for Office Illumination JIEC-001. Esse cuidado deve ser tomado em escritórios.

O manual traz também algumas referências que devem ser seguidas em relação ao nível de iluminação na área de trabalho. Para salas de exame e escritórios o guia considera com sendo um nível ideal até 500 lux, para salas de espera até 150 lux e para escolas até 400 lux. Os níveis considerados anteriormente foram baseados no Lighting of Indoor Work Places JIES-008, 1999. O nível de iluminação também deverá ser uniforme e deve haver um controle individual da luz artificial para alguns casos.

No quesito Redução da carga ambiental do edifício (L), em Energia (LR1), considera a eficiência dos sistemas de serviço do edifício obtido através da escolha dos sistemas de iluminação mais eficientes, divisão de circuitos e métodos que evitem o desperdício de energia como sensores de presença, sensor de luz natural, ajuste de iluminação individual, etc.. E o monitoramento do consumo de energia em relação à iluminação artificial também é levado em consideração. 
No item Ambiente externo (LR3), assim como o BREEAM, o LEED e o HQE a certificação japonesa faz referência à redução da poluição luminosa conforme diretrizes locais, eficiência dos equipamentos utilizados, ofuscamento do edifício iluminado e seu impacto no meio ambiente e os impactos dos outdoors luminosos.

\section{6. África do Sul}

\subsubsection{Certificação Green Star SA 2011}

A certificação GREEN STAR SA foi baseada no GREEN STAR da Austrália e foi desenvolvido por um grupo técnico voluntário. O primeiro guia publicado oficialmente foi em 2008 para escritórios. A certificação é dada pelo Green Building Concil of South Africa.

$\mathrm{Na}$ África do Sul estão disponíveis os guias para certificação de escritórios, centros comerciais e uma versão piloto para unidades residenciais. Para estudo neste trabalho, serão levados em conta apenas o guia para escritórios.

A certificação é dada dependendo da somatória do número de pontos obtidos em cada categoria e há 3 classificações: Best Practice, South African Excellence e World Leadership. As categorias relacionadas com iluminação artificial são as seguintes:

- Qualidade ambiental interna (Indoor environment quality): que levam em consideração os níveis de iluminação artificial.

- Energia (Energy): que considera a densidade de potência de iluminação.

- Emissão (Emission): que considera a redução da poluição luminosa.

Para iluminação artificial, o manual recomenda, por exemplo, o nível de iluminação média mantida de 400 lux para área de trabalho em escritórios de acordo com as boas práticas internacionais segundo o Green Building Concil da África do Sul (GBCSA) em resposta ao guia piloto de 2008 (Ver Anexo XVII). Porém, segundo 
a norma SANS 0114-1 - Interior lighting - part 1: Artificial lighting of interiors, a norma exige que se tenha o nível de 500 lux para a mesma área de trabalho.

Por outro lado, para certificação do edifício, a densidade de potência em iluminação artificial sugere que o valor seja de $12 \mathrm{~W} / \mathrm{m}^{2}$ conforme tabela contida no guia referente à energia. (Ver Anexo XVII).

Ainda no quesito para economia de energia, a ferramenta de avaliação concede pontos para os seguintes valores para consumo de energia, considerando o fator de manutenção de 0,80:

- 1 ponto para o uso de energia de $3,0 \mathrm{~W} / \mathrm{m}^{2}$ por $100 \mathrm{lux}$;

- 2 pontos para o uso de energia de $2,5 \mathrm{~W} / \mathrm{m}^{2}$ por 100 lux;

- 3 pontos para o uso de energia de $2,0 \mathrm{~W} / \mathrm{m}^{2}$ por $100 l u x$;

- 4 pontos para o uso de energia de $1,5 \mathrm{~W} / \mathrm{m}^{2}$ por $100 l u x$.

Ainda é levado em consideração o controle de iluminação por circuitos e controle individual.

Em relação à poluição luminosa do edifício, a certificação leva em consideração o edifício cuja fachada não produza luminosidade acima de 10 candelas $/ \mathrm{m}^{2}$, e que $95 \%$ dos espaços externos obedeçam aos requisitos da CIBSE LG06 (Lighting Guide - the Outdoor Environment) em relação aos níveis de iluminância.

\subsection{Hong Kong}

\subsubsection{Certificação HKBEAM}

A certificação HKBEAM teve início em 1996 e é de iniciativa privado do The Real Estate Developers Association of Hong Kong. 
Estão disponíveis na versão em inglês os guias referentes à New Buildings (novas construções) e Existing Buildings (construções existentes). Ambos serão levados em consideração para esse trabalho e foram atualizados em 2010.

Para obtenção do certificado o edifício deve somar pontos cumprindo os seguintes requisitos em iluminação artificial:

- Aspectos do terreno: redução da poluição luminosa noturna

- Uso da energia: onde é levado em consideração o sistema de iluminação dos estacionamentos

- Qualidade ambiental interna: que considera a qualidade da iluminação artificial

\subsubsection{HKBEAM New Buildings 2010}

A certificação pontua em casos de redução da poluição luminosa noturna e caso não haja quantidade de luz desnecessária. Para isso deve seguir o guia CIBSE Factfile conforme a tabela presente no guia no Anexo XVIII.

Para economia de energia, a certificação leva em consideração o uso de equipamentos eficientes nos estacionamentos. Nas áreas internas do edifício, são consideradas a qualidade e a quantidade da iluminação artificial, se é atendido o nível de iluminação do ambiente de acordo com a tarefa a ser realizada, se a UGR está dentro dos valores limite, se a temperatura de cor da lâmpada utilizada está adequada para a tarefa, e ainda um ponto extra é dado se há o controle do sistema de iluminação artificial com sensores de presença e sensores de iluminação natural.

Os valores a serem seguidos são de acordo com o código CIBSE Lighting Guide como na certificação BREEAM, como pode ser visto no Anexo XI. Para áreas que não são de ocupação contínua, pode-se seguir o guia da IESNA.

No Apêndice do guia, ainda há referência para a eficiência energética do edifício, no entanto deve ser considerado somente em casos em que não haja 
prejuízo nas condições de qualidade e quantidade de iluminação artificial. Podemos ver no Anexo XVIII a tabela 8.4. que mostram esses valores.

\subsubsection{HKBEAM Existing Buidings 2010}

Como podemos ver no Anexo XIX, em relação à iluminação artificial, o guia traz as mesmas recomendações/ exigências para novas construções, exceto no Apêndice onde não faz referência à densidade de potência em relação à iluminação artificial.

\subsection{Conclusões}

Com o levantamento das certificações, normas e regulamentos dos Estados Unidos, Brasil, Reino Unido, França, Japão, África do Sul e Hong Kong, percebemos que em alguns países, com relação à iluminação artificial, a importância da economia de energia é mais importante que a qualidade do projeto de iluminação.

Na certificação LEED tanto nos Estados Unidos quanto no Brasil e no Green Stars da África do Sul o mais importante é a eficiência energética dos sistemas de iluminação versus a área, medida pela densidade de potência em $\mathrm{W} / \mathrm{m}^{2}$. Enquanto que nas outras certificações, está claro que a qualidade da luz no projeto tem mais importância.

Nas certificações AQUA, BREEAM, HQE, CASBEE e HKBEAM em termos de iluminação artificial fazem sempre referência às normas de iluminação interior dos seus países referentes ao nível de iluminação, além de fazerem referência às características voltadas à qualidade da luz como temperatura de cor da lâmpada, índice de reprodução de cor da lâmpada, uniformidade no nível de iluminação.

Por se tratarem de certificações sustentáveis fazem referência à eficiência energética do sistema luminárias, lâmpadas e equipamentos auxiliares, mas é claro que em primeiro plano vem a qualidade de projeto em termos de iluminação artificial. 
Pelo levantamento das normas vigentes nos países em geral em relação à iluminação artificial, a grande maioria é baseada na norma internacional CIE 8995 como podemos ver nos valores de nível de iluminação comparando, por exemplo, a CIE 8995, com a CISBE e a NF EN 12464. Praticamente os valores e as recomendações são as mesmas.

Outro ponto importante do levantamento é em relação à regulamentação do PROCEL Edifica no Brasil, onde procura avaliar a eficiência energética do sistema com os níveis de iluminação vigentes na norma NBR 5413. No entanto, o que se a regulamentação tem mostrado é que ainda no país é difícil obter a classificação máxima.

Em relação aos níveis de iluminação das normas, guias dos diferentes países, pelo estudo realizado pela arquiteta Claudia N. D. Amorim em comparação aos níveis, 34\% dos valores da CIE são maiores que os da NBR 5413, 34\% são menores e 32\% são equivalentes. Essa diferença de níveis é um ponto interessante a ser estudado, pois quanto menor o valor, mais fácil seria obter a certificação em casos onde a densidade de potência é mais importante. No caso do Brasil para a certificação LEED e da regulamentação de etiquetagem do selo PROCEL Edifica.

Com os dados do levantamento desse trabalho, é possível analisar as certificações e regulamentações referentes à iluminação artificial verificando se no Brasil são aplicadas adequadamente. 


\section{SISTEMAS DE ILUMINAÇÃO}

Após o levantamento dos indicadores das certificações e selos de sustentabilidade mais atuantes do mundo, foi realizado um levantamentos dos principais sistemas de iluminação do mundo, com ênfase no Brasil e nos sistemas que são utilizados em projetos para obtenção das certificações/selos de sustentabilidade.

Considerou-se como sistema de iluminação o conjunto luminária, lâmpada e quando necessário um equipamento auxiliar.

O levantamento tem como objetivo comparar os sistemas de iluminação disponíveis no exterior e no Brasil, para posteriormente analisar se a tecnologia disponível no país consegue atender os principais indicadores referentes à iluminação artificial das certificações de sustentabilidades mais atuantes no país.

\subsection{Luminárias}

As luminárias são equipamentos que servem para controlar e distribuir a luz proveniente da lâmpada. Uma luminária eficiente é aquela que otimiza o desempenho do conjunto lâmpada e equipamento auxiliar e é medida através da relação entre a luz emitida pela luminária e a luz emitida pela lâmpada.

Uma luminária é formada basicamente por corpo, porta-lâmpada e dispositivos para modificar a distribuição espacial da luz como refletores, aletas, difusor, refrator e louver.

- Corpo da luminária: é a estrutura básica da luminária que pode ser composta de diversos materiais adequados de acordo com sua utilização e que proporcionem segurança aos usuários e onde ela será instalada. 
- Porta-lâmpada ou receptáculo para fonte luminosa: é um elemento de fixação que funciona como contato elétrico entre o circuito de alimentação e a lâmpada.

- Refletores: servem para modificar a distribuição do fluxo luminoso de uma fonte através da reflexão da luz. Os refletores podem ser parabólicos, elipsoidais, esféricos ou hiperbólicos. Podem ser também calandrados ou multifacetados, e geralmente são feitos de alumínio ou chapa de aço pintada.

- Refratores: servem para modificar a distribuição do fluxo luminoso de uma fonte através da refração da luz. Em muitas luminárias os refratores são utilizados com a finalidade de vedar a luminária protegendo a parte interna contra poeira, chuva, impactos, etc.

- Aletas: possibilitam o controle de ofuscamento causado pela fonte luminosa. Podem ser parabólicas ou planas e são feitas em alumínio ou em chapa de aço pintada.

- Difusores: são elementos translúcidos, foscos ou leitosos que são colocadas nas luminárias a fim de reduzir a luminosidade e o ofuscamento da fonte de luz, e podem também ser utilizada para aumentar a abertura de facho de uma luminária. São feitas geralmente de vidro fosco, acrílico ou policarbonato.

- Louvers: são elementos semelhantes a uma grelha e possibilitam assim com as aletas, controlar o ofuscamento causado pela fonte luminosa. Esses elementos impedem a visão direta das lâmpadas sob determinados ângulos.

As luminárias podem ser classificadas de acordo com a Comission Internacionale de $L$ 'Eclairage $(\mathrm{CIE})$ conforma a porcentagem de luz emitida para cima e para baixo tomando com base um plano horizontal de referência. A seguir segue uma tabela para melhor compreensão dessa classificação: 
Tabela 3: Classificação de luminárias em relação ao fluxo luminoso

\begin{tabular}{|c|c|c|c|}
\hline \multirow{2}{*}{$\begin{array}{c}\text { Classificação da } \\
\text { luminária }\end{array}$} & \multicolumn{3}{|c|}{ Fluxo luminoso em relação ao plano horizontal (\%) } \\
\hline & Para o teto & $\begin{array}{l}\text { Para o plano de } \\
\text { trabalho }\end{array}$ & Figura $^{8}$ \\
\hline Direta & $0-10 \%$ & $90-100 \%$ & \\
\hline Semi-indireta & $10-40 \%$ & $60-90 \%$ & \\
\hline Indireta & $90-100 \%$ & $0-10 \%$ & \\
\hline Semi-indireta & $60-90 \%$ & $10-40 \%$ & \\
\hline Difusa & $40-60 \%$ & $40-60 \%$ & \\
\hline Direta-Indireta & $40-60 \%$ & $40-60 \%$ & \\
\hline
\end{tabular}

Fonte: Autora

A CIE também classifica as luminárias de acordo com seu grau de proteção representado pelas letras IP (Ingress Protection) seguidos de dois números. O primeiro representa a proteção contra penetração de poeira e objetos sólidos e o segundo número indica o grau de proteção contra penetração de água. A seguir temos a Tabela 4 e Tabela 5 com os valores do IP:

\footnotetext{
${ }^{8}$ Figura tirada do catálogo geral de produtos Itaim lluminação 2008 - página 23
} 
Tabela 4: Classificação de luminárias de acordo com o grau de proteção contra sólidos

\begin{tabular}{|c|l|}
\hline $1^{0}$ algarismo & \multicolumn{1}{|c|}{ Descrição } \\
\hline 0 & Sem proteção \\
\hline 1 & Proteção contra objetos sólidos maiores de $50 \mathrm{~mm}$ \\
\hline 2 & Proteção contra objetos sólidos maiores de 12mm \\
\hline 3 & Proteção contra objetos sólidos maiores de 2,5mm \\
\hline 4 & Proteção contra objetos sólidos maiores de 1,0mm \\
\hline 5 & Proteção contra poeira \\
\hline 6 & Hermética contra poeira \\
\hline
\end{tabular}

Fonte: Catálogo Itaim Iluminação 2008

Tabela 5: Classificação de luminárias de acordo com o grau de proteção contra umidade

\begin{tabular}{|c|l|}
\hline $2^{0}$ algarismo & \multicolumn{1}{|c|}{ Descrição } \\
\hline 0 & Sem proteção \\
\hline 1 & Proteção contra gotas de água \\
\hline 2 & Proteção contra gotas de água, inclinação 15 \\
\hline 3 & $\begin{array}{l}\text { Proteção contra água pulverizada até 60 } \\
\text { direção contra água pulverizada em qualquer }\end{array}$ \\
\hline 4 & $\begin{array}{l}\text { Proteção contra jatos de água (Bico: 6,3mm / } \\
\text { Pressão: 30Kpa) }\end{array}$ \\
\hline 6 & $\begin{array}{l}\text { Proteção contra jatos de água (Bico: 12,5mm / } \\
\text { Pressão: 100Kpa) }\end{array}$ \\
\hline 7 & Proteção contra efeitos de imersão até 1m \\
\hline 8 & Proteção contra submersão \\
\hline
\end{tabular}

Fonte: Catálogo Itaim Iluminação 2008

Segundo Nelson Solano ${ }^{9}$, podemos considerar a classificação das luminárias quanto à distribuição e o efeito da luz no ambiente. Esta classificação é conhecida como Sistema principal divididas em iluminação geral, localizada e de tarefa; e Sistema secundário que é dividido em luz de destaque, de efeito, decorativa, modulação de intensidade e luz arquitetônica.

- Iluminação geral: onde as luminárias estão distribuídas regularmente pelo teto e a iluminação produzida no plano horizontal é homogênea.

\footnotetext{
${ }^{9}$ Manual Osram, Iluminação: Conceitos e projetos. Impresso em 22/12/2006. Página 10
} 
- lluminação localizada: onde as luminárias estão concentradas somente em locais onde se tenha interesse em iluminar onde a iluminação produzida no plano de trabalho é maior que das outras áreas.

- lluminação de tarefa: onde as luminárias estão perto da tarefa visual e do plano de trabalho em uma área mais concentrada e pequena.

- Iluminação de destaque: onde as luminárias dão ênfase em objetos arquitetônicos. A quantidade de luz é de 3,5 a 10 vezes maior para que realmente se tenha essa diferença da quantidade de luz.

- lluminação de efeito: é quando se quer utilizar a luz como sendo o destaque, como por exemplo: contraste de luz e sombra, jogos de fachos de luz, etc.

- Iluminação decorativa: é quando o objeto a ser destacado é a própria luminária, como por exemplo, lustres antigos.

- Modulação de intensidade (dimerização): é um dispositivo onde podemos reduzir ou aumentar a intensidade da luz de uma ou um conjunto de luminárias.

- Luz arquitetônica: é quando um elemento arquitetônico serve de suporte à luz, como por exemplo: sancas, corrimãos, cornijas, etc.

Outro parâmetro que é levado em conta em normas européias é o índice de ofuscamento unificado - Unified Glare Rating (UGR) que a CIE define como o nível de desconforto por ofuscamento. $O$ valor que será utilizado para projeto será o Limiting Unified Glare Rating (UGR $\mathrm{L}_{\mathrm{L}}$ ) que é o valor máximo permitido para o nível de ofuscamento em projeto.

Para encontrar o UGR de uma luminária aplicamos a seguinte fórmula:

$$
\mathrm{UGR}=8 \log \left(\frac{0,25}{L_{b}} \sum \frac{L 2 \omega}{\rho 2}\right), \text { onde }
$$

$\mathrm{Lb}=$ luminância de fundo $\left(\mathrm{cd} / \mathrm{m}^{2}\right)$

$\mathrm{L}$ = luminância da parte luminosa de cada luminária na direçaõ do olho do observador $\left(\mathrm{cd} / \mathrm{m}^{2}\right)$ 
$\omega$ = ângulo sólido da parte luminosa de cada luminária junto ao olho do observador (esterradiano)

$\rho=$ índice de posição Guth de cada luminária individualmente relacionado ao seu deslocamento a partir da linha de visão

Em geral a UGR deverá ser fornecida pelo fabricante de luminárias ou é obtida através de softwares de cálculos luminotécnicos. Segue abaixo um exemplo de como ela é fornecida em forma de tabela:

Tabela 6: Exemplo de avaliação de ofuscamento (UGR)

\begin{tabular}{|c|c|c|c|c|c|c|c|c|c|c|c|}
\hline \multicolumn{12}{|c|}{ Glare Evaluation According to UGR } \\
\hline \multicolumn{2}{|l|}{$\rho$ Ceiling } & 70 & 70 & 50 & 50 & 30 & 70 & 70 & 50 & 50 & 30 \\
\hline \multicolumn{2}{|l|}{$\rho$ Walls } & 50 & 30 & 50 & 30 & 30 & 50 & 30 & 50 & 30 & 30 \\
\hline \multicolumn{2}{|l|}{$\rho$ Floor } & 20 & 20 & 20 & 20 & 20 & 20 & 20 & 20 & 20 & 20 \\
\hline \multicolumn{2}{|c|}{$\begin{array}{l}\text { Room Size } \\
X \quad Y\end{array}$} & \multicolumn{5}{|c|}{$\begin{array}{l}\text { Viewing direction at right angles } \\
\text { to lamp axis }\end{array}$} & \multicolumn{5}{|c|}{$\begin{array}{l}\text { Viewing direction parallel } \\
\text { to lamp axis }\end{array}$} \\
\hline $2 \mathrm{H}$ & $\begin{array}{r}2 \mathrm{H} \\
3 \mathrm{H} \\
4 \mathrm{H} \\
6 \mathrm{H} \\
8 \mathrm{H} \\
12 \mathrm{H}\end{array}$ & $\begin{array}{l}13.4 \\
13.9 \\
14.0 \\
14.0 \\
14.0 \\
14.0\end{array}$ & $\begin{array}{l}14.5 \\
14.8 \\
14.9 \\
14.9 \\
14.8 \\
14.7\end{array}$ & $\begin{array}{l}13.7 \\
14.2 \\
14.3 \\
14.4 \\
14.3 \\
14.3\end{array}$ & $\begin{array}{l}14.7 \\
15.1 \\
15.2 \\
15.2 \\
15.1 \\
15.0\end{array}$ & $\begin{array}{l}14.9 \\
15.3 \\
15.5 \\
15.5 \\
15.4 \\
15.4\end{array}$ & $\begin{array}{l}18.3 \\
19.2 \\
19.6 \\
19.9 \\
20.0 \\
20.0\end{array}$ & $\begin{array}{l}19.4 \\
20.2 \\
20.5 \\
20.7 \\
20.8 \\
20.8\end{array}$ & $\begin{array}{l}18.6 \\
19.5 \\
19.9 \\
20.2 \\
20.3 \\
20.4\end{array}$ & $\begin{array}{l}19.6 \\
20.4 \\
20.8 \\
21.0 \\
21.1 \\
21.1\end{array}$ & $\begin{array}{l}19.9 \\
20.7 \\
21.0 \\
21.3 \\
21.4 \\
21.5\end{array}$ \\
\hline $4 \mathrm{H}$ & $\begin{array}{r}2 \mathrm{H} \\
3 \mathrm{H} \\
4 \mathrm{H} \\
6 \mathrm{H} \\
8 \mathrm{H} \\
12 \mathrm{H}\end{array}$ & $\begin{array}{l}14.5 \\
15.5 \\
15.9 \\
16.0 \\
16.0 \\
16.0\end{array}$ & $\begin{array}{l}15.4 \\
16.3 \\
16.6 \\
16.6 \\
16.6 \\
16.5\end{array}$ & $\begin{array}{l}14.9 \\
15.9 \\
16.3 \\
16.4 \\
16.5 \\
16.4\end{array}$ & $\begin{array}{l}15.7 \\
16.6 \\
16.9 \\
17.0 \\
16.9 \\
16.9\end{array}$ & $\begin{array}{l}16.0 \\
17.0 \\
17.3 \\
17.4 \\
17.4 \\
17.3\end{array}$ & $\begin{array}{l}18.5 \\
19.6 \\
20.1 \\
20.6 \\
20.7 \\
20.8\end{array}$ & $\begin{array}{l}19.4 \\
20.4 \\
20.8 \\
21.1 \\
21.2 \\
21.3\end{array}$ & $\begin{array}{l}18.8 \\
20.0 \\
20.5 \\
21.0 \\
21.1 \\
21.3\end{array}$ & $\begin{array}{l}19.7 \\
20.7 \\
21.1 \\
21.5 \\
21.6 \\
21.7\end{array}$ & $\begin{array}{l}19.9 \\
21.0 \\
21.5 \\
21.9 \\
22.0 \\
22.1\end{array}$ \\
\hline $8 \mathrm{H}$ & $\begin{array}{r}4 \mathrm{H} \\
6 \mathrm{H} \\
8 \mathrm{H} \\
12 \mathrm{H}\end{array}$ & $\begin{array}{l}16.6 \\
16.9 \\
17.0 \\
17.0\end{array}$ & $\begin{array}{l}17.1 \\
17.4 \\
17.4 \\
17.3\end{array}$ & $\begin{array}{l}17.0 \\
17.4 \\
17.5 \\
17.5\end{array}$ & $\begin{array}{l}17.5 \\
17.8 \\
17.8 \\
17.8\end{array}$ & $\begin{array}{l}17.9 \\
18.2 \\
18.3 \\
18.3\end{array}$ & $\begin{array}{l}20.2 \\
20.8 \\
21.0 \\
21.2\end{array}$ & $\begin{array}{l}20.8 \\
21.2 \\
21.4 \\
21.5\end{array}$ & $\begin{array}{l}20.7 \\
21.3 \\
21.5 \\
21.7\end{array}$ & $\begin{array}{l}21.2 \\
21.7 \\
21.8 \\
22.0\end{array}$ & $\begin{array}{l}21.6 \\
22.1 \\
22.3 \\
22.5\end{array}$ \\
\hline $12 \mathrm{H}$ & $\begin{array}{l}4 \mathrm{H} \\
6 \mathrm{H} \\
8 \mathrm{H}\end{array}$ & $\begin{array}{l}16.6 \\
17.1 \\
17.2\end{array}$ & $\begin{array}{l}17.1 \\
17.5 \\
17.6\end{array}$ & $\begin{array}{l}17.1 \\
17.6 \\
17.7\end{array}$ & $\begin{array}{l}17.5 \\
17.9 \\
18.0\end{array}$ & $\begin{array}{l}17.9 \\
18.4 \\
18.5\end{array}$ & $\begin{array}{l}20.2 \\
20.8 \\
21.1\end{array}$ & $\begin{array}{l}20.7 \\
21.2 \\
21.4\end{array}$ & $\begin{array}{l}20.7 \\
21.3 \\
21.6\end{array}$ & $\begin{array}{l}21.1 \\
21.6 \\
21.9\end{array}$ & $\begin{array}{l}21.5 \\
22.1 \\
22.4\end{array}$ \\
\hline \multicolumn{12}{|c|}{ Variation of the observer position for the luminaire distances $\mathrm{S}$} \\
\hline \multicolumn{2}{|c|}{$\begin{array}{l}\mathrm{S}=1.0 \mathrm{H} \\
\mathrm{S}=1.5 \mathrm{H} \\
\mathrm{S}=2.0 \mathrm{H}\end{array}$} & \multicolumn{5}{|c|}{$\begin{array}{lll}+1.2 & / & -2.1 \\
+2.4 & / & -3.7 \\
+3.9 & / & -4.3\end{array}$} & \multicolumn{5}{|c|}{$\begin{array}{lll}+0.4 & / & -0.5 \\
+1.1 & / & -1.3 \\
+1.4 & / & -1.8\end{array}$} \\
\hline \multicolumn{2}{|c|}{$\begin{array}{l}\text { Standard table } \\
\text { Correction } \\
\text { Summand }\end{array}$} & & & $\begin{array}{l}\text { BK02 } \\
-7.7\end{array}$ & & & & & $\begin{array}{l}\text { BK03 } \\
-6.2\end{array}$ & & \\
\hline
\end{tabular}

Fonte: Tabela gerada pelo programa Dialux 4.10/2012 - autora

Para encontrar o valor da UGR, devemos a partir do comprimento, largura e a distância do ponto do observador até a luminária fazer os seguintes cálculos:

- Dividir comprimento pela distância do ponto a ser calculado $=X \mathrm{XH}$

- Dividir largura pela distância do ponto a ser calculado = YH 
A partir desses 2 valores, cruzados com as refletâncias do ambiente, encontramos o valor da UGR, que deve ser calculado para cada sistema de iluminação presente no ambiente. $O$ valor base será o maior valor encontrado.

Outra informação que serão utilizadas para a simulação são os dados fotométricos das luminárias. Elas são importantes para os cálculos luminotécnicos para encontrar a quantidade de peças para determinado nível de iluminação requerido no ambiente. Esses dados fotométricos estão contidos nos arquivos IES que são arquivos que contém informações sobre a distribuição da intensidade de uma fonte de luz e são utilizados diretamente em programas de cálculo luminotécnico e fornecidos pelo fabricante.

Os dados fotométricos são: curva de distribuição luminosa, rendimento da luminária, tabela de fator de utilização, diagrama de luminância e curvas de limitação de ofuscamento.

\subsubsection{Tipo de luminárias}

\subsubsection{Luminárias com refletor pintadas na cor branca}

São luminárias de alto rendimento e sem controle de ofuscamento. Devido ao fato de ser pintada na cor branca, segundo Juliana Iwashita ${ }^{10}$ em sua dissertação, apresentam curvas de distribuição mais abertas no sentido transversal, pois a luz difunde nesse sentido quando o refletor é branco. A seguir um exemplo de curva de distribuição luminosa com esse tipo de refletor:

\footnotetext{
${ }^{10}$ IWASHITA, Juliana. Eficiência energética em sistemas de iluminação de interiores: análise de luminárias comerciais. São Paulo: Universidade de São Paulo, 2004. P.34
} 


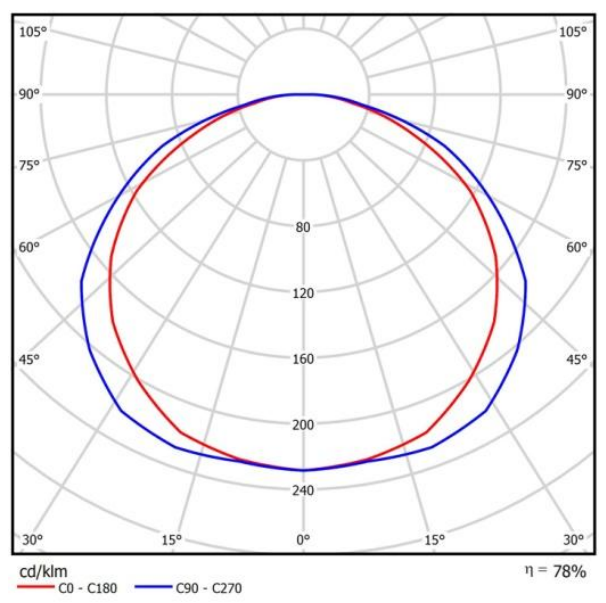

Figura 2: Curva de distribuição luminosa com refletor pintado na cor branca - luminária nacional

Por tratar-se de luminárias mais simples, utilizadas na maioria das vezes em ambientes mais simples como garagens, depósitos, circulações, etc., não foram encontradas curvas de distribuição luminosa de luminárias do mercado internacional.

Nas simulações, esse tipo de luminária não será utilizado, pois apesar de ter um alto rendimento, não oferece ao usuário conforto visual para as áreas de trabalho analisadas.

\subsubsection{Luminárias com refletor de alumínio}

São luminárias que apresentam curvas de distribuição luminosa e rendimento muito distintas devido ao próprio desenho do refletor. Apesar de direcionarem melhor o fluxo luminoso, na maioria dos casos não possui um bom controle de ofuscamento. Segue abaixo alguns exemplos de curva de distribuição luminosa com esse tipo de refletor: 


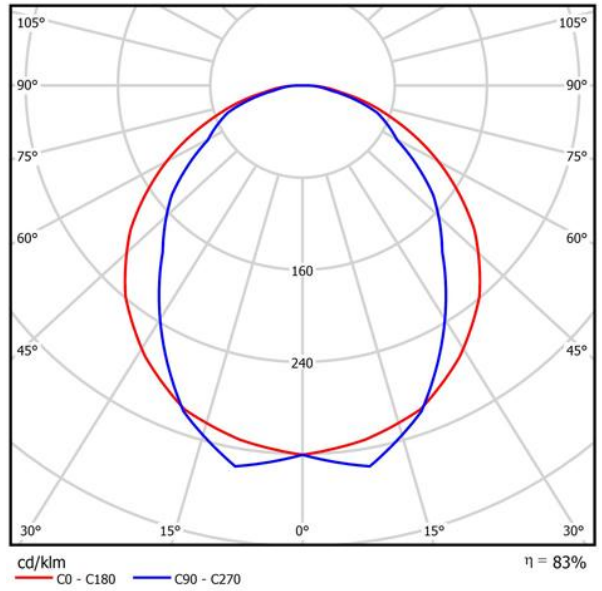

Figura 3: Curva de distribuição luminosa com refletor de alumínio - luminária nacional tipo 1

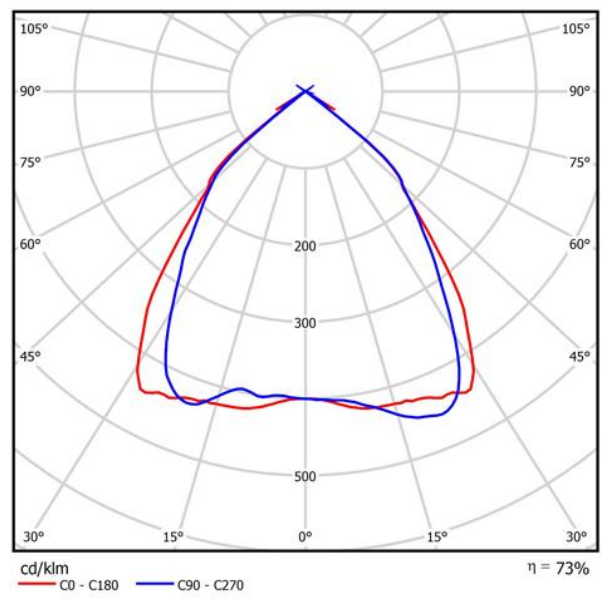

Figura 5: Curva de distribuição luminosa com refletor de alumínio - luminária nacional tipo 2

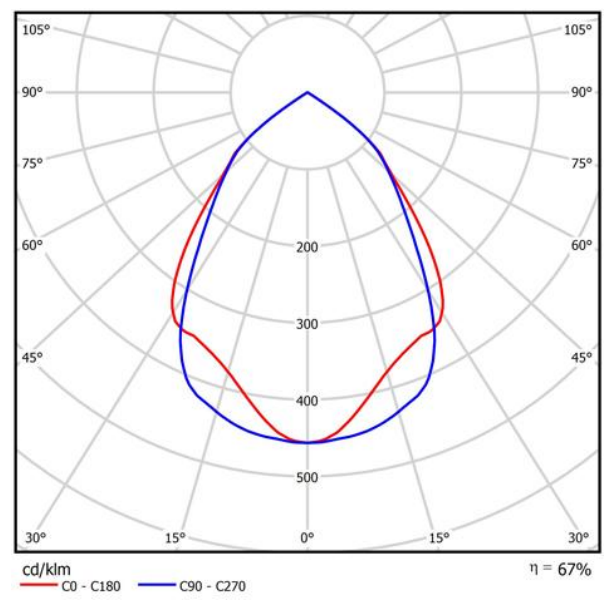

Figura 6: Curva de distribuição luminosa com refletor de alumínio - luminária importada tipo 1

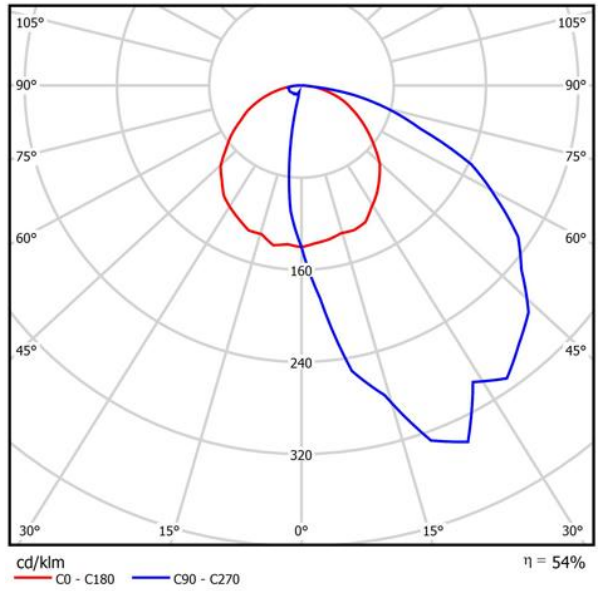

Figura 4: Curva de distribuição luminosa com refletor de alumínio - facho assimétrico luminária nacional

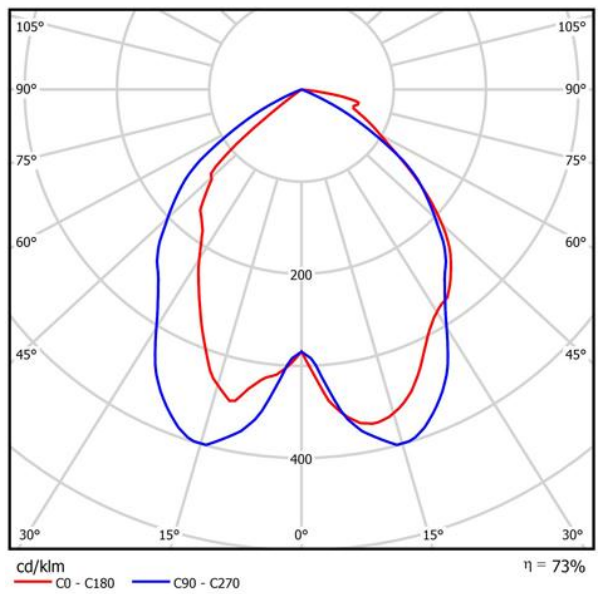

Figura 7: Curva de distribuição luminosa com refletor de alumínio - luminária importada tipo 2 
Como podemos observar nas curvas de distribuição luminosa acima, o desenho do refletor direciona o fluxo luminoso da lâmpada. A figura 4 mostra que o fluxo luminoso é assimétrico, ou seja, a maior parte da luz é direcionada para um dos lados da luminária.

Para os exemplos selecionados, as figuras 5, 6 e 7 são curvas de distribuição luminosa de luminárias com características semelhantes utilizando o mesmo tipo de lâmpada. Observamos pelas curvas de distribuição luminosa, que o desenho do refletor da luminária da figura 5 tem um controle de ofuscamento pior que o da luminária da figura 6.

As luminárias com curva de distribuição luminosa da figura 6 e 7 são do mesmo fabricante, e dependendo do efeito de luz definido pelo projetista ou da necessidade de troca de efeito de luz, o fabricante permite que apenas com a troca do refletor se obtenha o efeito desejado, sem a necessidade de troca da luminária por completo. Isso não ocorre com as luminárias nacionais.

\subsubsection{Luminárias com refletor de alumínio e aletas planas ou parabólicas}

As luminárias com refletor de alumínio e aletas são luminárias com controle de ofuscamento. As aletas planas possuem o controle de ofuscamento apenas no sentido longitudinal, enquanto as aletas parabólicas permitem o controle de ofuscamento tanto no sentido longitudinal quanto no transversal. A seguir, temos exemplos de curva luminosa desse tipo de luminárias. 


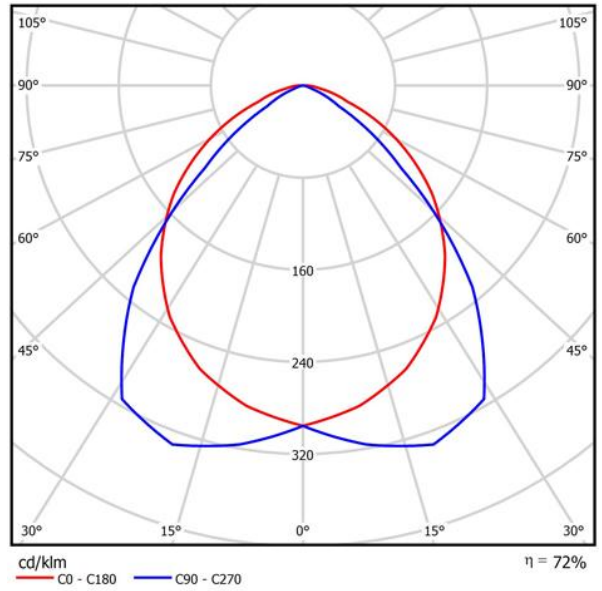

Figura 8: Curva de distribuição luminosa com refletor de alumínio e aletas planas - luminária nacional

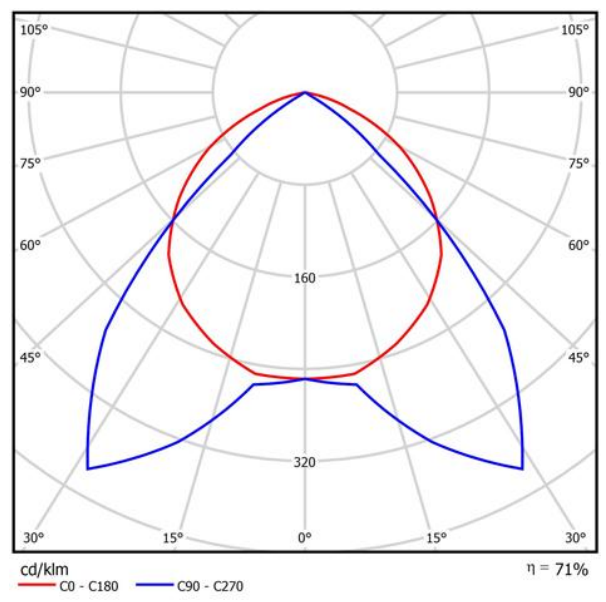

Figura 10: Curva de distribuição luminosa com refletor de alumínio e aletas parabólicas luminária nacional

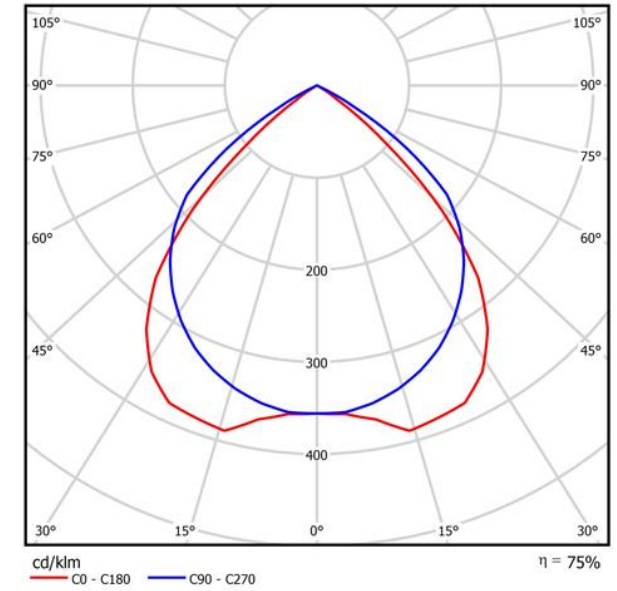

Figura 9: Curva de distribuição luminosa com refletor de alumínio e aletas planas - luminária importada

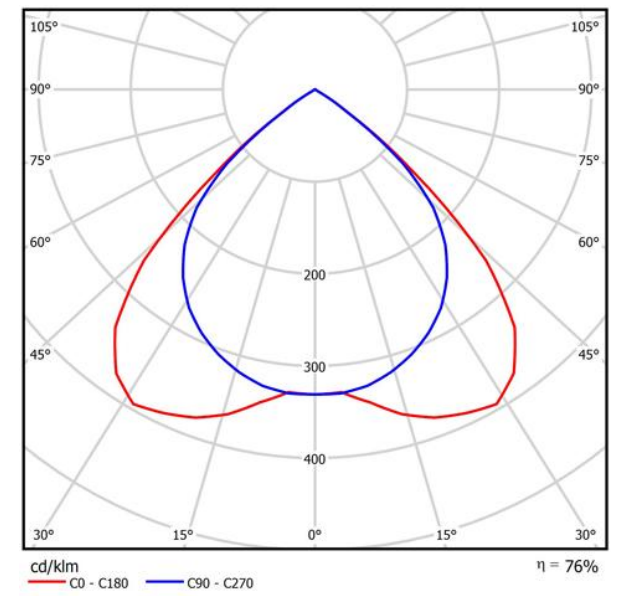

Figura 11: Curva de distribuição luminosa com refletor de alumínio e aletas parabólicas luminária importada

Comparando as curvas de distribuição luminosa das luminárias importadas e nacionais, não há diferença nas curvas das luminárias de aletas planas (figura 8 e 9), no entanto a eficiência da luminária importada é maior que a luminária nacional. Isso significa que a qualidade do alumínio utilizado na luminária importada é melhor que a nacional.

Nas curvas de distribuição das luminárias de aletas parabólicas (figura 10 e 11), observamos que a eficiência da luminária importada também é maior que a nacional, e observamos que no sentido longitudinal da luminária nacional o ofuscamento é maior que da luminária importada, ultrapassando $45^{\circ}$. 
Observamos pelas figuras 8 e 10, que a intensidade luminosa de uma luminária com aletas parabólicas é maior que uma com aletas planas.

\subsubsection{Luminárias com difusor translúcido ou leitoso}

As luminárias com difusor apresentam curvas de distribuição luminosa homogênea no sentido transversal e longitudinal, pois o mesmo tem a função de espalhar a luz de maneira homogênea. Seguem curvas de distribuição luminosa com difusores.

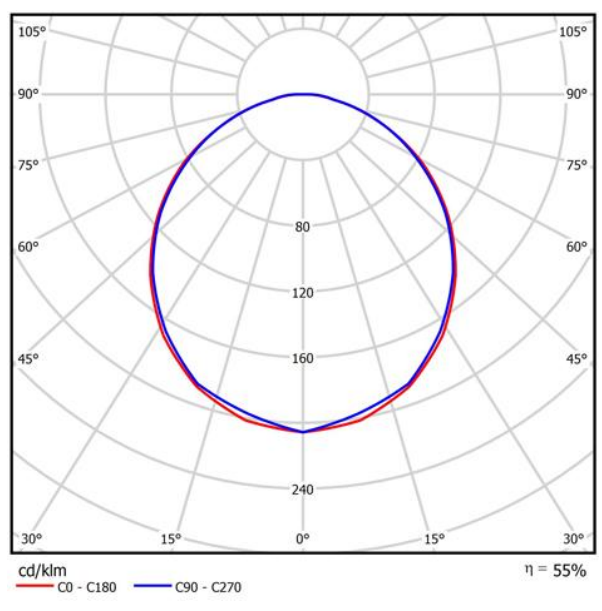

Figura 12: Curva de distribuição luminosa com difusor - luminária nacional

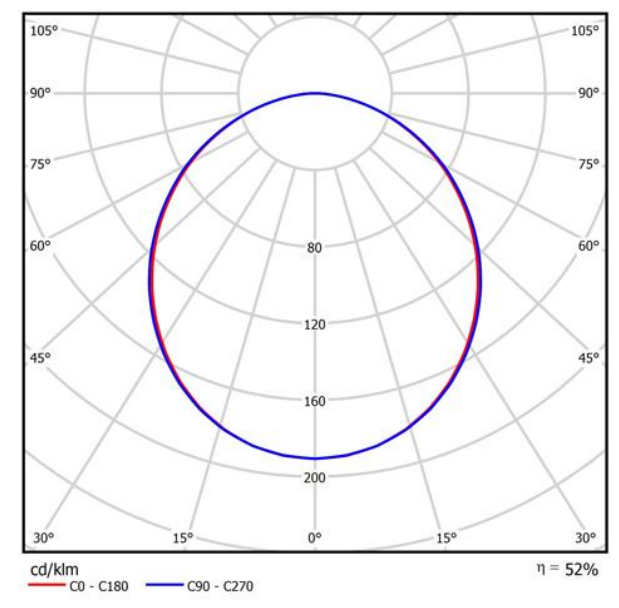

Figura 13: Curva de distribuição luminosa com difusor - luminária importada

Novamente percebemos que a intensidade luminosa da luminária importada é maior que a luminária nacional. Isto pode ocorrer devido à qualidade do refletor e/ou do material do difusor. 


\subsubsection{Luminárias com LED}

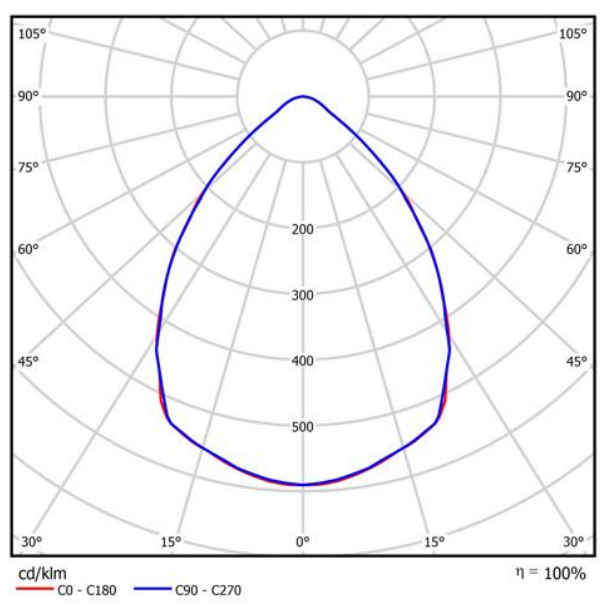

Figura 14: Curva de distribuição luminosa com LED 15W - luminária nacional

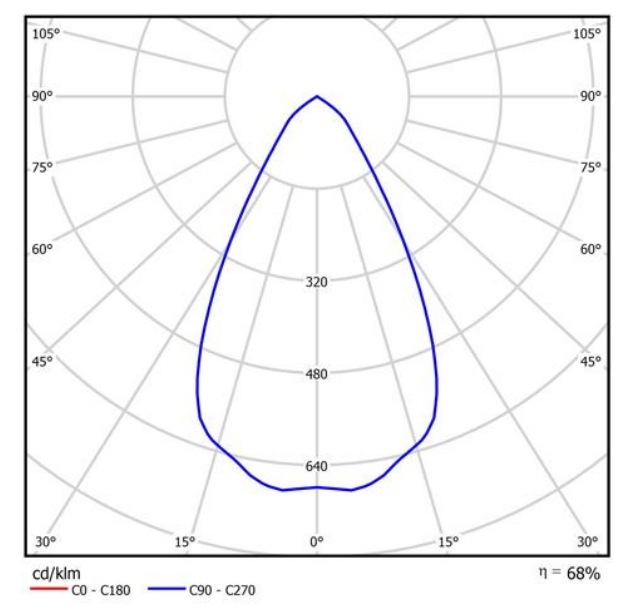

Figura 15: Curva de distribuição luminosa com LED 14W - luminária importada

Para análise foram escolhidas duas luminárias com características semelhantes e mesma potência. Observando as figuras 14 e 15 percebemos que a luminária importada tem um maior controle de ofuscamento e uma maior intensidade luminosa. Neste caso, o desenho do refletor influencia no comportamento de luz do LED.

No caso de luminárias que utilizam o LED deve-se atentar para a questão da qualidade do LED, como a temperatura de cor e o IRC e se o fabricante utiliza o binning para manter essa qualidade.

\subsubsection{Luminárias no Brasil}

Para projetos de certificação no Brasil, os principais lighting designers do país especificam em $80 \%$ dos projetos, luminárias de 2 de fabricantes que possuem as melhores luminárias no quesito eficiência, e que fornecem dados para cálculo em seus projetos. Até onde se tem conhecimento, as luminárias mais utilizadas são as da Itaim Iluminação e Lumini, ambas com fábrica em São Paulo. 
Serão citados mais outros três fabricantes que possuem luminárias que poderiam ser utilizadas nos projetos de certificações, mas na maioria dos casos acabam não sendo viáveis devido ao seu alto custo por serem importadas. No entanto, os lighting designers especificam em menor quantidade e apenas alguns tipos de luminárias são utilizadas. São as luminárias da Philips, da Erco e da Zumtobel.

\section{ITAIM ILUMINAÇÃO}

A fábrica Itaim lluminação teve início em 1965 e desde então vem desenvolvendo luminárias principalmente para obras corporativas. É a única nesse ramo que é certificada pela ISO 9001 - Sistema de Gestão de Qualidade, ISO 14001 - Sistema de Gestão Ambiental, OHSAS 18001 - Sistema de Segurança e Saúde Ocupacional e recentemente duas de suas luminárias foram certificadas pela ABNT, mostrando sua preocupação com qualidade e desempenho dos seus produtos e no seu processo de produção.

Seus produtos são divididos por categorias e tipo de instalação: interno de embutir, sobrepor, pendentes, industriais, específicas, arandelas, balizadores, projetores e trilhos; externo de embutir de piso, projetores, balizadores, arandelas e postes.

No seu catálogo e site, encontramos a descrição da luminária, do que é feito, quais os componentes, tipo e quantidade de lâmpadas, forma de instalação (se é de embutir, sobrepor, pendente, no teto, na parede, etc.), grau de proteção, dimensões da peça e caso seja de embutir fornece dimensões do nicho, rendimento da luminária, fator de utilização para cálculos, curva de distribuição luminosa, diagrama de iluminância, foto e croqui da peça, além de sugestões para aplicação da peça.

Há também um programa próprio da empresa para cálculos luminotécnicos, onde fornecendo os dados da sala (comprimento, largura e altura), nível de iluminação necessário e escolhendo a luminária a ser utilizado, o programa traz quantas peças são necessárias para atender o nível para aquele ambiente. Além 
disso, traz em separada os arquivos IES utilizados em programas de cálculo luminotécnico.

\section{LUMINI}

A Lumini iniciou suas atividades na década de 80. Nessa primeira etapa 0 objetivo era atender as necessidades de peças que fossem adequadas ao projeto de um lighting designer, pois na época o mercado nacional de iluminação não tinha essa preocupação. Hoje em dia é um dos fabricantes que tem uma grande variedade de produtos tanto para obras corporativas como para obras residenciais com luminárias decorativas.

Seus produtos estão divididos em uso interno, estes divididos em embutidos, aplicados, de mesa, sistemas, embutidos no piso, arandelas, pendentes, projetores, luminárias de piso e balizadores; e uso externo divididos em arandelas, balizadores, projetores, postes e projetores de piso.

Nos seus catálogos e site encontramos a descrição da luminária, componentes, materiais utilizados, tipo e quantidade de lâmpadas, medidas da peça e caso seja de embutir medidas do nicho, grau de proteção, forma de instalação, fotos e croquis da peça.

Fornece também a curva de luminância, a curva fotométrica, distribuição de intensidades em cd/1000lm e tabela de fator de utilização, além de alguns arquivos IES para utilização em programas de cálculos.

\section{ERCO}

A ERCO foi fundada em 1943, mas somente em 1946 depois da reconstrução do pós-guerra que a marca se tornou uma das maiores e mais conhecidas na Europa. Em 1968, analisando o mercado, Klaus Jürgen Maack verificou mudanças no comportamento dos alemães, onde o público começou a se tornar mais exigente, lançando então o slogan da empresa que vem até os dias de hoje: "Light not luminaires" (Luz e não luminárias). 
A empresa valoriza os efeitos da luz e não a luminária em si, para isso Maack seguiu cinco princípios em sua estratégia: a luz seria o ponto central da empresa, ao invés de produtos individuais a empresa pensará em sistemas de produtos, os resultados da tecnologia de iluminação devem estar concentrados na fase de desenvolvimento dos produtos, os produtos devem ter uma longevidade de pelo menos dez anos e o trabalho deve ser feito por designers de renome.

Hoje em dia é uma das mais importantes marcas não só da Alemanha Europa, mas possui pontos de revenda em todo o mundo, inclusive no Brasil. A ERCO propõe que nos projetos feitos com seus produtos, deve-se ter um conforto visual eficiente através da iluminação vertical, qualidade de projeto, tecnologia de iluminação eficaz, inteligência no controle da luz e lâmpadas eficientes.

As luminárias são divididas por famílias de produtos (pelo design da peça) ou pelo efeito de luz que criam e podem ser para áreas internas de trilho, de embutir no teto, de sobrepor, pendentes, de parede (tanto de embutir como sobrepor) e de piso; e para áreas externas projetores, luminárias de fachada, áreas abertas, de embutir no teto, de sobrepor no teto e de embutir no piso. Além dessas linhas, a ERCO também fornece programas para controle da luz.

No site e nos catálogos da ERCO, além de guias com efeitos de luz, há informações como descrição da luminária, materiais do que são feitas as peças, componentes, número e tipo de lâmpadas utilizadas, grau de proteção, medidas das peças, se a peça é de embutir traz também a medida do nicho, forma de instalação além do próprio manual de instalação, fotos e croquis da peça, curva fotométrica, tabela de fator de utilização, tabela de distâncias que devem estar uma das outras e do objeto a ser iluminado para um maior aproveitamento da luz.

Além disso, traz os arquivos IES e eulumdat para uso em programas de cálculos, este último muito utilizado na Europa e modelado em 3D. Traz também desenhos em 3D para programas como Autocad e 3D Max para uso em desenhos de projeto. 


\section{PHILIPS}

Dos lighting designers consultados, poucos citaram utilizar as luminárias da Philips, e os que especificam utilizam as luminárias em LED, pois estas apresentam grande eficiência, IRC maior que 80 , e temperatura de cor de $3000 \mathrm{~K}$ e $4000 \mathrm{~K}$.

\section{ZUMTOBEL}

A Zumtobel existe há mais de 50 anos e é uma empresa austríaca, fornecedor internacional de soluções em iluminação em ambientes internos e externos. Seus produtos atendem aos requisitos em termos de ergonomia, eficiência energética e valor estético. Seus produtos atendem o mercado de escritórios, escolas, hotéis, saúde, indústria, entre outros.

Na Europa é um dos maiores concorrentes da empresa ERCO devido à qualidade dos produtos.

A empresa, assim como a ERCO, fornece os arquivos IES e eulumdat para programas de cálculos luminotécnicos.

\subsection{Lâmpadas}

"As lâmpadas são fontes luminosas de origem elétrica"11 e são divididas em dois grandes grupos segundo Rüdiger Ganslandt e Harald Hofmann ${ }^{12}$ : lâmpadas radiadores térmicos e lâmpadas de descarga.

Dentro do grupo das lâmpadas radiadores térmicos estão: as lâmpadas incandescentes, halógenas incandescentes e de baixa voltagem. E no grupo das lâmpadas de descarga, as lâmpadas de baixa pressão que são as fluorescentes tubulares e as compactas, e de alta pressão estão as de vapor de mercúrio, metálicos e as de sódio.

\footnotetext{
${ }^{11}$ RODRIGUES, Pierre. Manual de lluminação Eficiente. Procel, 1a․ edição, julho 2002. P. 11

${ }^{12}$ GANSLANDT, R.; HOFMANN, H.. Handbook of Lighting Design, Erco Edition. P. 44
} 
As lâmpadas radiadores térmicos possuem essa terminação porque em seu interior há um filamento metálico que se torna incandescente devido ao aquecimento pela passagem de corrente elétrica, produzindo assim a luz.

Já nas lâmpadas de descarga, a luz é gerada pela passagem de corrente elétrica através da excitação das moléculas de um único gás ou mistura de gases ou ainda de vapores.

\subsubsection{Tipos de lâmpadas}

\subsubsection{Lâmpadas incandescentes}

As lâmpadas incandescentes foram as primeiras lâmpadas a serem comercializadas. Elas possuem um filamento de tungstênio com alta resistência elétrica por onde passa a corrente elétrica e assim produz luz e calor. São do tipo clássico (formato pêra), bolinha, vela e refletora. A refletora possui uma tecnologia mais atual onde a lâmpada é revestida por uma superfície refletora que direciona a luz.

As principais características delas são que não precisa de equipamento auxiliar para seu funcionamento, possuem temperatura de cor de 2700K e IRC 100. Porém, não possuem uma eficácia muito alta, são de curta duração e produzem muito calor.

\subsubsection{Lâmpadas halógenas}

As lâmpadas halógenas também têm o mesmo princípio de funcionamento das lâmpadas incandescentes, porém além do filamento de tungstênio trabalham em conjunto com o halogênio. Podem ser ligadas diretamente na rede sem necessidade de equipamento auxiliar que são do tipo halopin ou cápsula, palito e lâmpada com refletor parabólico (conhecido como lâmpada PAR). 
Nesse mesmo conjunto de lâmpadas, temos as que trabalham em $12 \mathrm{~V}$ e necessitam de um transformador, que são de base bipino, com refletor dicróico e as lâmpadas do tipo cápsula ou base bipino que são "envelopadas" em uma superfície refletora de alumínio (conhecidas como lâmpadas $A R$ ).

Pela presença do halogênio em sua composição, a durabilidade da lâmpada aumenta em relação à incandescente e a eficácia também é maior, sua temperatura de cor também é de $2700 \mathrm{~K}$, possui IRC 100 e seu tamanho é reduzido se comparadas. As lâmpadas que funcionam em baixa tensão duram mais que as de tensão de rede, pois o transformador regula a tensão de rede.

As lâmpadas com refletor dicróico (conhecidas como lâmpadas dicróicas), refletor parabólico (PAR) e com refletor de alumínio (AR) possuem e produzem diferentes fachos de luz. Em geral são utilizadas para luz de destaque de objetos.

\subsubsection{Lâmpadas fluorescentes}

As lâmpadas fluorescentes são lâmpadas de descarga da baixa pressão, onde a luz é produzida através da ativação do pó fluorescente em seu interior pela energia ultravioleta da descarga. Em geral são divididas em três tipos: fluorescentes compactas integradas, fluorescentes compactas não integradas e fluorescentes tubulares.

As lâmpadas fluorescentes compactas integradas são aquelas em que o equipamento auxiliar (reator) estão integradas na própria lâmpada e podem assim, ser ligadas diretamente na rede. Segundo Paula Freitas ${ }^{13}$, na década de 80 foi criada para substituir a lâmpada incandescente visando a economia de energia. Hoje em dia temos vários formatos inclusive alguns são bem similares ao formato da lâmpada incandescente clássica.

Comparadas às incandescentes, elas são mais eficientes economizando até $80 \%$ de energia, possuem longa vida útil (cerca de 5 a 6 vezes maior), baixa

\footnotetext{
${ }^{13}$ FREITAS, Paula Campos Fadul. Luminotécnica e lâmpadas elétricas. Faculdade de Engenharia elétrica da Universidade Federal de Uberlândia. P. 21
} 
emissão de calor, temperatura de cor entre $2700 \mathrm{~K}$ a $6500 \mathrm{~K}$, IRC por volta de $80-85$ (já considerado ótimo) e uma boa eficiência luminosa.

Já as lâmpadas fluorescentes compactas não integradas necessitam de um equipamento auxiliar (no caso um reator). São lâmpadas de tamanho reduzido de longa vida útil (cerca de 8 a 10 vezes maior que uma incandescente), baixa emissão de calor, boa eficiência luminosa, temperatura de cor entre $2700 \mathrm{~K}$ a $4000 \mathrm{~K}$, IRC também entre 80-85. A vantagem dela sobre a fluorescente compacta integrada é que podemos substituir apenas a lâmpada ou o reator, uma vez que a durabilidade do reator é maior que o da lâmpada.

Por fim, temos as fluorescentes tubulares, que necessitam do reator como equipamento auxiliar. Possuem comprimentos variados entre $400 \mathrm{~mm}$ e $2400 \mathrm{~mm}$ e cada vez mais o diâmetro dessas lâmpadas são menores, assim como a eficiência luminosa aumenta. As versões mais conhecidas são as T12 (38mm) ou T10 (33mm) com potências de 20W, 40W ou de $110 \mathrm{~W}$; T8 $(26 \mathrm{~mm})$ com potências de $16 \mathrm{~W}$ e $32 \mathrm{~W}$ e a mais recente conhecida é a T5 $(16 \mathrm{~mm})$ com potências de $14 \mathrm{~W}, 28 \mathrm{~W}, 54 \mathrm{~W}$ e $80 \mathrm{~W}$.

Esses tipos de lâmpadas são muito utilizadas em projetos corporativos, pois tem uma elevada eficiência energética, grande durabilidade, grande variedade de IRC desde 60 até 90, temperatura de cor entre $2700 \mathrm{~K}$ a $6500 \mathrm{~K}$, e hoje em dia alguns fabricantes fornecem até $8000 \mathrm{~K}$.

\subsubsection{Lâmpadas de vapor de mercúrio}

As lâmpadas de vapor de mercúrio possuem em seu interior vapor de mercúrio à alta pressão e necessitam de um reator para seu acendimento, e demoram cerca de 4 a 5 minutos para atingir seu fluxo máximo. Se for apagada, o mercúrio precisa ser esfriado para que acenda novamente, o que leva cerca de 3 a 10 minutos dependendo da potência da lâmpada. 
Sua eficiência luminosa é relativamente alta e possui uma vida útil elevada, porém seu IRC é baixo entre 20 e 45 . Sua aparência de cor é mais para um brancoazulado, muito utilizada em vias públicas.

\subsubsection{Lâmpadas de vapor de sódio}

As lâmpadas de vapor de sódio de alta pressão segundo Pierre Rodrigues ${ }^{14}$ é a mais eficiente das lâmpadas de descarga de alta pressão. Possuem em seu interior vapor de sódio de alta pressão e necessitam de equipamento auxiliar para seu acendimento (reator e ignitor). Assim como as lâmpadas de vapor de mercúrio demoram a atingir seu fluxo máximo (cerca de 5 a 8 minutos) e quando apagada, também precisam ser resfriadas para que acenda novamente.

Elas são muito utilizadas para substituir as lâmpadas de vapor de mercúrio por causa da sua eficiência luminosa e sua elevada vida útil, porém seu IRC é muito baixo (cerca de 20 a 30) e sua temperatura de cor é mais amarelada por volta de $2000 \mathrm{~K}$.

\subsubsection{Lâmpadas de vapor metálico}

As lâmpadas de multivapor metálico possuem em seu interior mercúrio de alta pressão e uma mistura de iodeto metálico. Elas necessitam de equipamento auxiliar para seu acendimento (reator e ignitor) e assim como as outras lâmpadas de descarga de alta pressão, levam um tempo para atingir o fluxo luminoso máximo.

Comparadas às lâmpadas de vapor de sódio e de mercúrio tem um elevado IRC de 65 a 85 , e temperatura de cor entre $3000 \mathrm{~K}$ a $4900 \mathrm{~K}$.

\footnotetext{
${ }^{14}$ RODRIGUES, Pierre. Manual de lluminação Eficiente. Procel, 1a. edição, julho 2002. P. 16
} 


\subsubsection{Lâmpadas no Brasil e no mundo}

Nessa parte do trabalho serão descritos os principais tipos de lâmpadas e seus dados mais relevantes para um projeto eficiente. Não será considerada a família das lâmpadas incandescentes, pois países como Austrália, Califórnia e União Européia já foi banido o uso da mesma desde 2009. No Brasil, já esta em andamento um projeto de lei que proibirá a fabricação, venda e uso desse tipo de lâmpada.

Serão tomados como base três principais fabricantes que são marcas conhecidas internacionalmente e produzem lâmpadas aqui no país. Segundo a pesquisa anual realizada pela revista Projeto e Construção são as marcas mais lembradas e utilizadas que somam aproximadamente $62 \%$ do mercado de lâmpadas. Para efeito comparativo da eficiência energética de lâmpadas, será considerado apenas o fluxo luminoso das lâmpadas em $220 \mathrm{~V}$, pois como podemos observar na figura abaixo, a maior parte do mundo utiliza a voltagem de $220 \mathrm{~V}$.

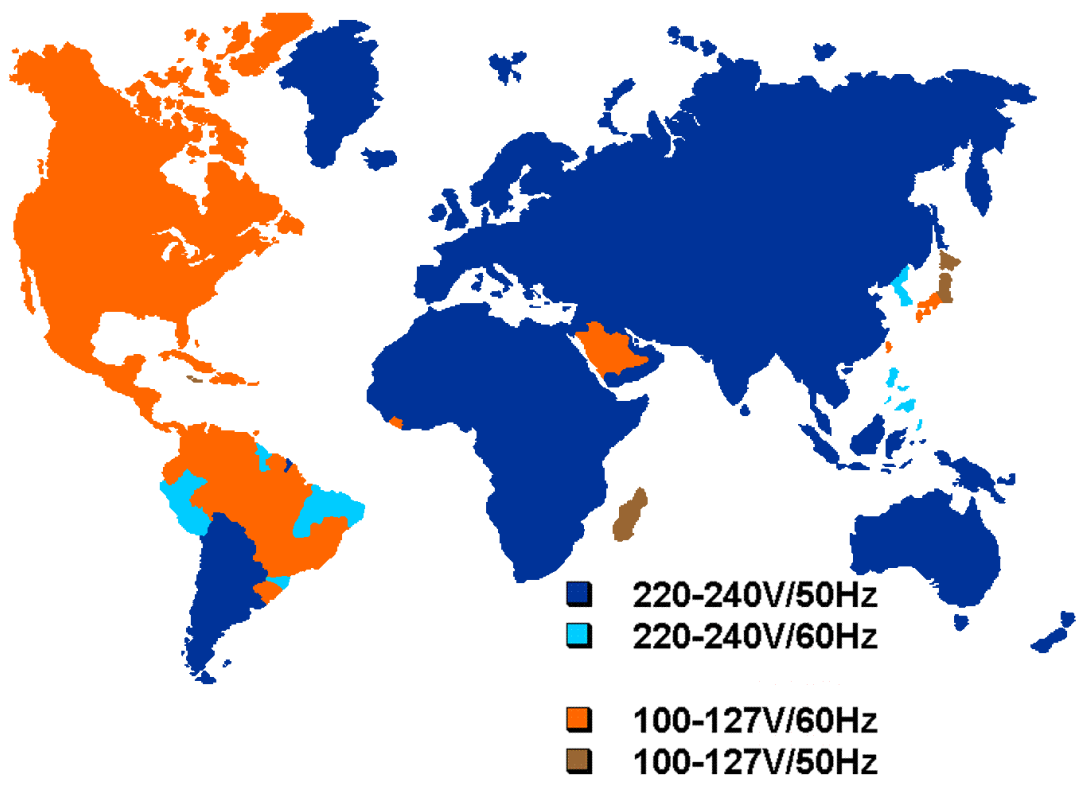

Figura 16: Voltagem no mundo.

Fonte: http://users.telenet.be/worldstandards/eletriciy.htm 


\section{OSRAM}

A Osram é um fabricante alemão e sua história teve início em 1906, chegando ao Brasil apenas em 1922, onde começou a produzir lâmpadas em 1955. Comparando o catálogo internacional com o nacional, observa-se que não são fabricados ou importados para o Brasil alguns tipo de lâmpadas.

Para compararmos a eficiência luminosa das lâmpadas internacionais das nacionais, seguem tabelas divididas por família de lâmpadas que serão utilizadas para as simulações, com dados de eficiência luminosa, fluxo luminoso, potência, temperatura de cor, IRC e vida útil, e uma análise das lâmpadas existentes no Brasil e no mundo.

Tabela 7: Tabela de lâmpadas halógenas sem refletor no mercado internacional

\begin{tabular}{|c|c|c|c|c|c|c|c|}
\hline Desenho & $\begin{array}{c}\text { Potência } \\
\text { (W) }\end{array}$ & $\begin{array}{c}\text { Fluxo } \\
\text { luminoso } \\
\text { (Im) }\end{array}$ & $\begin{array}{c}\text { Eficiência } \\
\text { luminosa } \\
(\operatorname{lm} / \mathrm{W})\end{array}$ & Base & $\mathrm{T}_{\mathrm{C}}(\mathrm{K})$ & IRC & $\begin{array}{l}\text { Vida útil } \\
\text { (h) }\end{array}$ \\
\hline \multicolumn{8}{|c|}{ HALOSTAR ECO } \\
\hline \multirow{6}{*}{$\begin{array}{l}\pi \\
11\end{array}$} & 7 & 105 & 15,00 & G4 & 2800 & 100 & 4000 \\
\hline & 14 & 240 & 17,14 & G4 & 2800 & 100 & 4000 \\
\hline & 25 & 500 & 20 & GY6,35 & 2800 & 100 & 4000 \\
\hline & 35 & 860 & 24,57 & GY6,35 & 2900 & 100 & 4000 \\
\hline & 50 & 1180 & 23,60 & GY6,35 & 3000 & 100 & 4000 \\
\hline & 60 & 1650 & 27,50 & GY6,35 & 3000 & 100 & 4000 \\
\hline \multicolumn{8}{|c|}{ HALOSTAR STANDARD } \\
\hline \multirow{4}{*}{ 响 } & 10 & 140 & 14,00 & G4 & 2800 & 100 & 2000 \\
\hline & 20 & 320 & 16,00 & G4 & 2800 & 100 & 2000 \\
\hline & 35 & 600 & 17,14 & GY6,35 & 2900 & 100 & 2000 \\
\hline & 50 & 720 & 14,40 & GY6,35 & 3000 & 100 & 2000 \\
\hline \multicolumn{8}{|c|}{ HALOSTAR STARLITE } \\
\hline \multirow{8}{*}{ ता } & 5 & 55 & 11,00 & G4 & 2700 & 100 & 4000 \\
\hline & 10 & 130 & 13,99 & G4 & 2800 & 100 & 4000 \\
\hline & 20 & 300 & 15,00 & G4 & 2800 & 100 & 4000 \\
\hline & 20 & 290 & 14,50 & GY6,35 & 2800 & 100 & 4000 \\
\hline & 35 & 580 & 16,57 & GY6,35 & 2900 & 100 & 4000 \\
\hline & 50 & 900 & 18,00 & GY6,35 & 3000 & 100 & 4000 \\
\hline & 75 & 1450 & 19,33 & GY6,35 & 3000 & 100 & 4000 \\
\hline & 90 & 1800 & 20,00 & GY6,35 & 3000 & 100 & 4000 \\
\hline
\end{tabular}


Tabela 8: Tabela de lâmpadas halógenas sem refletor no mercado nacional

\begin{tabular}{|c|c|c|c|c|c|c|c|}
\hline Desenho & $\begin{array}{l}\text { Potência } \\
\text { (W) }\end{array}$ & $\begin{array}{c}\text { Fluxo } \\
\text { luminoso } \\
\text { (Im) }\end{array}$ & $\begin{array}{c}\text { Eficiência } \\
\text { luminosa } \\
(\operatorname{Im} / \mathrm{W})\end{array}$ & Base & $\mathrm{T}_{\mathrm{C}}(\mathrm{K})$ & IRC & $\begin{array}{l}\text { Vida útil } \\
\text { (h) }\end{array}$ \\
\hline \multicolumn{8}{|c|}{ HALOSTAR ECO } \\
\hline \multirow{2}{*}{$\begin{array}{l}\text { (4) } \\
\text { and }\end{array}$} & 35 & 860 & 24,57 & GY6,35 & 2900 & 100 & 4000 \\
\hline & 60 & 1650 & 27,50 & GY6,35 & 3000 & 100 & 4000 \\
\hline \multicolumn{8}{|l|}{ HALOSTAR } \\
\hline \multirow{2}{*}{$\begin{array}{l}\text { (4) } \\
\text { (II) }\end{array}$} & 20 & 320 & 16,00 & G4 & 2800 & 100 & 2000 \\
\hline & 50 & 910 & 18,20 & GY6,35 & 3000 & 100 & 2000 \\
\hline
\end{tabular}

Comparando a Tabela 7 e 8 , observa-se que no Brasil a diversidade e potência das famílias de lâmpadas é menor que o mercado nacional.

Aqui no Brasil a linha ECO da Osram ainda é novidade para essa família de lâmpadas e traz benefícios como menor consumo de energia e mesma quantidade de luz, e em alguns casos maior vida útil. Essa nova tecnologia que está sendo aplicada nas diversas famílias de lâmpadas da Osram é de grande importância para projetos que procuram certificações de sustentabilidade.

Tabela 9: Tabela de lâmpadas halógenas com refletor no mercado internacional

\begin{tabular}{|c|c|c|c|c|c|c|c|}
\hline Desenho & $\begin{array}{l}\text { Potência } \\
\text { (W) }\end{array}$ & $\begin{array}{c}\text { Fluxo } \\
\text { luminoso } \\
(\mathrm{Im})\end{array}$ & $\begin{array}{l}\text { Abertura } \\
\text { de facho }\end{array}$ & Base & $\mathrm{T}_{\mathrm{C}}(\mathrm{K})$ & IRC & $\begin{array}{l}\text { Vida útil } \\
\text { (h) }\end{array}$ \\
\hline \multicolumn{8}{|c|}{ DECOSTAR 51 ECO } \\
\hline \multirow{14}{*}{$\square_{\square}$} & 14 & 2800 & $10 \circ$ & GU5.3 & 3000 & 100 & 5000 \\
\hline & 14 & 480 & $36 \div$ & GU5.3 & 3000 & 100 & 5000 \\
\hline & 20 & 5500 & 10 응 & GU5.3 & 3000 & 100 & 5000 \\
\hline & 20 & 2000 & 240 & GU5.3 & 3000 & 100 & 5000 \\
\hline & 20 & 1000 & 36응 & GU5.3 & 3000 & 100 & 5000 \\
\hline & 20 & 1000 & $60 \circ$ & GU5.3 & 3000 & 100 & 5000 \\
\hline & 35 & 11000 & $10 \circ$ & GU5.3 & 3000 & 100 & 5000 \\
\hline & 35 & 4100 & $24 \%$ & GU5.3 & 3000 & 100 & 5000 \\
\hline & 35 & 2200 & $36 \circ$ & GU5.3 & 3000 & 100 & 5000 \\
\hline & 35 & 1050 & $60 \circ$ & GU5.3 & 3000 & 100 & 5000 \\
\hline & 50 & 15000 & $10 \circ$ & GU5.3 & 3100 & 100 & 5000 \\
\hline & 50 & 5300 & 240 & GU5.3 & 3100 & 100 & 5000 \\
\hline & 50 & 2850 & $36 \circ$ & GU5.3 & 3100 & 100 & 5000 \\
\hline & 50 & 1450 & $60 \circ$ & GU5.3 & 3100 & 100 & 5000 \\
\hline \multicolumn{8}{|c|}{ DECOSTAR 51 STANDARD } \\
\hline & 20 & 3000 & 10 은 & GU5.3 & 3000 & 100 & 2000 \\
\hline & 20 & 480 & 38 - & GU5.3 & 3000 & 100 & 2000 \\
\hline
\end{tabular}




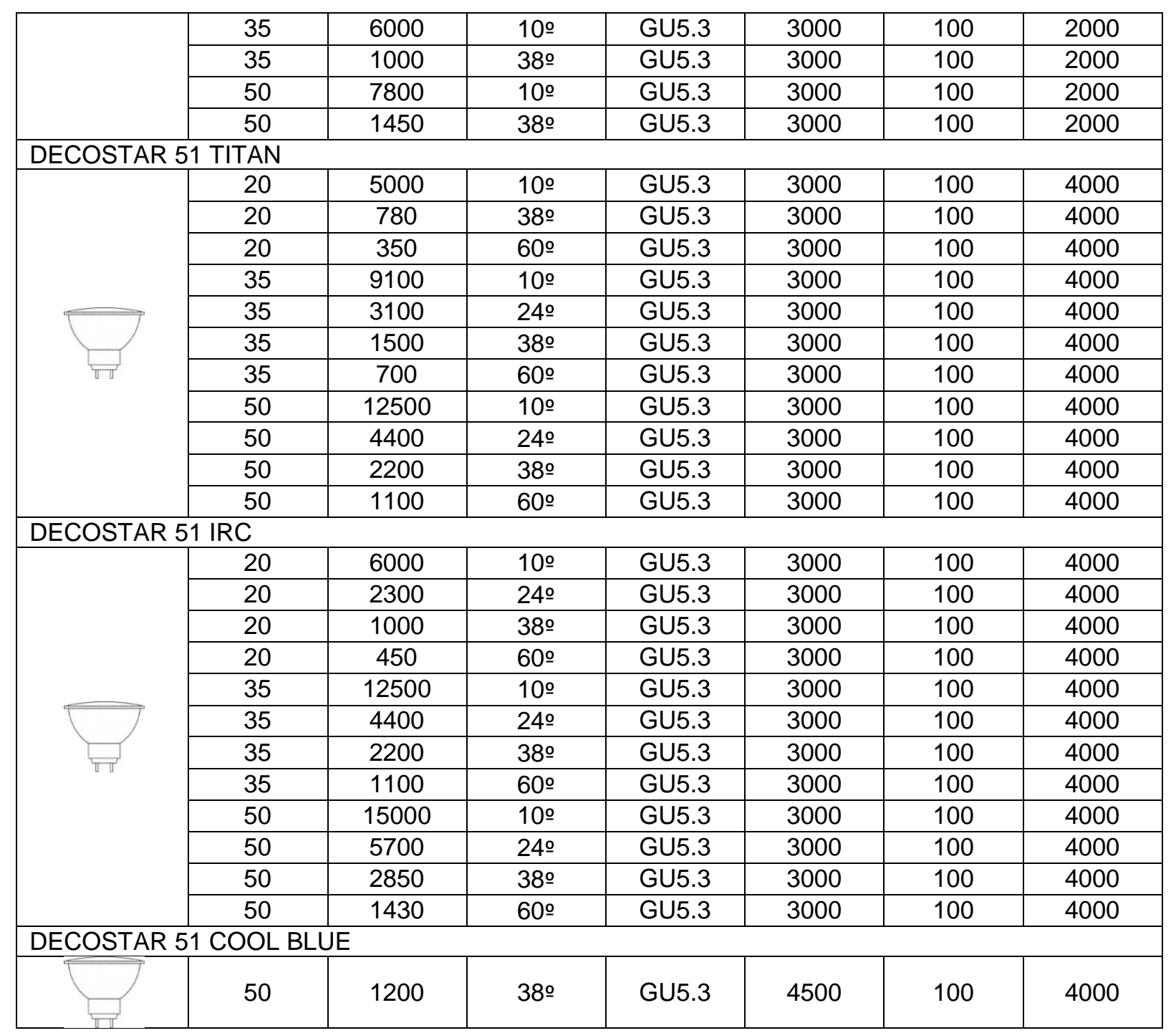

Tabela 10: Tabela de lâmpadas halógenas com refletor no mercado nacional

\begin{tabular}{|c|c|c|c|c|c|c|c|}
\hline Desenho & $\begin{array}{l}\text { Potência } \\
\text { (W) }\end{array}$ & $\begin{array}{c}\text { Fluxo } \\
\text { luminoso } \\
(\mathrm{Im})\end{array}$ & $\begin{array}{l}\text { Abertura } \\
\text { de facho }\end{array}$ & Base & $\mathrm{T}_{\mathrm{C}}(\mathrm{K})$ & IRC & $\begin{array}{l}\text { Vida útil } \\
\text { (h) }\end{array}$ \\
\hline \multicolumn{8}{|c|}{ DECOSTAR 51 ECO } \\
\hline \multirow{4}{*}{$\square_{\bar{v}}$} & 35 & 11000 & 100 & GU5.3 & 3100 & 100 & 5.000 \\
\hline & 35 & 4100 & 240 & GU5.3 & 3100 & 100 & 5.000 \\
\hline & 35 & 2200 & $36 \circ$ & GU5.3 & 3100 & 100 & 5.000 \\
\hline & 35 & 1050 & $60 \circ$ & GU5.3 & 3100 & 100 & 5.000 \\
\hline \multicolumn{8}{|c|}{ DECOSTAR 51 TITAN } \\
\hline \multirow{4}{*}{$\square_{\pi}$} & 20 & 350 & $60 \circ$ & GU5.3 & 3100 & 100 & 4.000 \\
\hline & 50 & 12500 & 10 은 & GU5.3 & 3000 & 100 & 4.000 \\
\hline & 50 & 2200 & $36 \div$ & GU5.3 & 3000 & 100 & 4.000 \\
\hline & 50 & 1100 & 60 은 & GU5.3 & 3000 & 100 & 4.000 \\
\hline \multicolumn{8}{|c|}{ DECOSTAR 51 COOL BLUE } \\
\hline & 50 & 1200 & 38은 & GU5.3 & 5000 & 100 & 4.000 \\
\hline \multicolumn{8}{|c|}{ DECOSTAR $51 \mathrm{~S}$} \\
\hline & 20 & 3000 & $10 \circ$ & GU5.3 & 3000 & 100 & 2.000 \\
\hline
\end{tabular}




\begin{tabular}{|c|c|c|c|c|c|c|c|}
\hline & 20 & 450 & $36 \circ$ & GU5.3 & 3000 & 100 & 2.000 \\
\cline { 2 - 7 } & 50 & 9000 & 10 o & GU5.3 & 3000 & 100 & 2.000 \\
\cline { 2 - 7 } & 50 & 1300 & $36 \circ$ & GU5.3 & 3000 & 100 & 2.000 \\
\hline
\end{tabular}

Observando a tabela 9 e 10, verificamos que somente uma parte das lâmpadas do mercado internacional é comercializada aqui no Brasil. Sendo que nessa família, somente uma parte das lâmpadas do tipo ECO está presente no mercado nacional.

Esse tipo de lâmpada é utilizado em projetos de eficiência principalmente para efeitos decorativos e em casos onde o IRC precisa ser de 100, como por exemplo, em lojas de vestuários e jóias.

Como essa lâmpada é utilizada, na maioria das vezes, para efeitos decorativos e de destaque, neste trabalho só utilizaremos a lâmpada do tipo dicróica.

Tabela 11: Tabela de lâmpadas fluorescentes compactas não integradas no mercado internacional

\begin{tabular}{|c|c|c|c|c|c|c|c|}
\hline Desenho & $\begin{array}{l}\text { Potência } \\
\text { (W) }\end{array}$ & $\begin{array}{c}\text { Fluxo } \\
\text { luminoso } \\
(\mathrm{Im})\end{array}$ & $\begin{array}{c}\text { Eficiência } \\
\text { luminosa } \\
(\mathrm{Im} / \mathrm{W})\end{array}$ & Base & $\mathrm{T}_{\mathrm{C}}(\mathrm{K})$ & IRC & $\begin{array}{l}\text { Vida útil } \\
\text { (h) }\end{array}$ \\
\hline \multicolumn{8}{|l|}{ DULUX S } \\
\hline \multirow{4}{*}{ 酋 } & 5 & 257 & 51,40 & G23 & $\begin{array}{l}2700,3000 \\
4000,6500\end{array}$ & 80 & 10.000 \\
\hline & 7 & 405 & 57,85 & G23 & $\begin{array}{l}2700,3000, \\
4000,6500\end{array}$ & 80 & 10.000 \\
\hline & 9 & 600 & 66,66 & G23 & $\begin{array}{l}2700,3000 \\
4000,6500\end{array}$ & 80 & 10.000 \\
\hline & 11 & 900 & 81,81 & G23 & $\begin{array}{l}2700,3000, \\
4000,6500\end{array}$ & 80 & 10.000 \\
\hline \multicolumn{8}{|l|}{ DULUX S/E } \\
\hline \multirow{3}{*}{ 理训 } & 7 & 405 & 57,85 & $2 \mathrm{G} 7$ & $\begin{array}{c}2700,3000 \\
4000\end{array}$ & 80 & 20.000 \\
\hline & 9 & 600 & 66,66 & $2 \mathrm{G} 7$ & $\begin{array}{c}2700,3000 \\
4000\end{array}$ & 80 & 20.000 \\
\hline & 11 & 900 & 81,81 & $2 \mathrm{G} 7$ & $\begin{array}{c}2700,3000 \\
4000\end{array}$ & 80 & 20.000 \\
\hline \multicolumn{8}{|l|}{ DULUX D } \\
\hline \multirow{4}{*}{ 廌= } & 10 & 600 & 60,00 & G24d & $\begin{array}{c}2700,3000 \\
4000\end{array}$ & 80 & 10.000 \\
\hline & 13 & 900 & 69,23 & G24d & $\begin{array}{c}2700,3000 \\
4000\end{array}$ & 80 & 10.000 \\
\hline & 18 & 1200 & 66,66 & G24d & $\begin{array}{c}2700,3000 \\
4000\end{array}$ & 80 & 10.000 \\
\hline & 26 & 1800 & 69,23 & G24d & $\begin{array}{c}2700,3000 \\
4000\end{array}$ & 80 & 10.000 \\
\hline \multicolumn{8}{|l|}{ DULUX D ES } \\
\hline \multirow[t]{2}{*}{ 廌= } & 16 & 1150 & 71,87 & G24d & $\begin{array}{c}2700,3000 \\
4000\end{array}$ & 80 & 10000 \\
\hline & 23 & 1750 & 76,08 & G24d & 2700,3000 & 80 & 10000 \\
\hline
\end{tabular}




\begin{tabular}{|c|c|c|c|c|c|c|c|}
\hline & & & & & 4000 & & \\
\hline \multicolumn{8}{|l|}{ DULUX D/E } \\
\hline \multirow{4}{*}{ 氞ळ } & 10 & 600 & 60,00 & G24q & $\begin{array}{c}2700,3000 \\
4000\end{array}$ & 80 & 20000 \\
\hline & 13 & 900 & 69,23 & G24q & $\begin{array}{c}2700,3000 \\
4000\end{array}$ & 80 & 20000 \\
\hline & 18 & 1200 & 66,66 & G24q & $\begin{array}{c}2700,3000 \\
4000\end{array}$ & 80 & 20000 \\
\hline & 26 & 1800 & 69,23 & G24q & $\begin{array}{c}2700,3000 \\
4000\end{array}$ & 80 & 20000 \\
\hline \multicolumn{8}{|c|}{ DULUX D/E XT } \\
\hline \multirow{2}{*}{ 島= } & 18 & 1200 & 66,66 & G24q & 3000,4000 & 80 & 36000 \\
\hline & 26 & 1800 & 69,23 & G24q & 3000,4000 & 80 & 36000 \\
\hline \multicolumn{8}{|c|}{ DULUX T PLUS } \\
\hline \multirow{3}{*}{ 廌莑 } & 13 & 900 & 69,23 & GX24d & $\begin{array}{c}2700,3000 \\
4000\end{array}$ & 80 & 3200 \\
\hline & 18 & 1200 & 66,66 & GX24d & $\begin{array}{c}2700,3000, \\
4000\end{array}$ & 80 & 3900 \\
\hline & 26 & 1800 & 69,23 & GX24d & $\begin{array}{c}2700,3000 \\
4000\end{array}$ & 80 & 10000 \\
\hline \multicolumn{8}{|c|}{ DULUX T/E PLUS } \\
\hline \multirow{5}{*}{ 國= } & 13 & 900 & 69,23 & GX24q & $\begin{array}{c}2700,3000 \\
4000\end{array}$ & 80 & 20000 \\
\hline & 18 & 1200 & 66,66 & GX24q & $\begin{array}{c}2700,3000 \\
4000\end{array}$ & 80 & 20000 \\
\hline & 26 & 1800 & 69,23 & GX24q & $\begin{array}{c}2700,3000 \\
4000\end{array}$ & 80 & 20000 \\
\hline & 32 & 2400 & 75,00 & GX24q & $\begin{array}{c}2700,3000 \\
4000\end{array}$ & 80 & 20000 \\
\hline & 42 & 3200 & 76,19 & GX24q & $\begin{array}{c}2700,3000 \\
4000\end{array}$ & 80 & 13000 \\
\hline \multicolumn{8}{|c|}{ DULUX T/E XT } \\
\hline \multirow{2}{*}{ 國弄 } & 32 & 2400 & 75,00 & GX24q & $\begin{array}{c}2700,3000 \\
4000\end{array}$ & 80 & 36000 \\
\hline & 42 & 3200 & 76,19 & GX24q & $\begin{array}{c}2700,3000 \\
4000\end{array}$ & 80 & 36000 \\
\hline \multicolumn{8}{|c|}{ DULUX T/E HE } \\
\hline \multirow{3}{*}{ 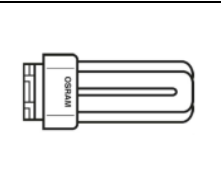 } & 11 & 890 & 80,90 & GR14q & 3000,4000 & 80 & 20000 \\
\hline & 14 & 1175 & 83,92 & GR14q & 3000,4000 & 80 & 20000 \\
\hline & 17 & 1460 & 85,88 & GR14q & 3000,4000 & 80 & 20000 \\
\hline \multicolumn{8}{|l|}{ CLF SQUARE } \\
\hline \multirow{5}{*}{ 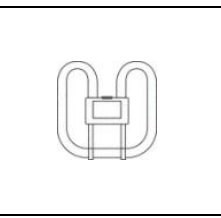 } & 16 & 1150 & 71,87 & GR8 & 2700,3500 & 80 & 10000 \\
\hline & 28 & 2200 & 78,57 & GR8 & 2700,3500 & 80 & 10000 \\
\hline & 16 & 1050 & 65,62 & GR10q & 2700,3500 & 80 & 10000 \\
\hline & 28 & 2050 & 73,21 & GR10q & 2700,3500 & 80 & 10000 \\
\hline & 38 & 2735 & 71,97 & GR10q & 2700,3500 & 80 & 10000 \\
\hline \multicolumn{8}{|l|}{ DULUX L HE } \\
\hline \multirow{4}{*}{ 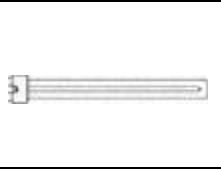 } & 16 & 1600 & 10,00 & $2 G \times 11$ & 3000,4000 & 80 & 20000 \\
\hline & 22 & 2200 & 10,00 & $2 \mathrm{GX11}$ & 3000,4000 & 80 & 20000 \\
\hline & 26 & 2600 & 10,00 & $2 \mathrm{GX11}$ & 3000,4000 & 80 & 20000 \\
\hline & 28 & 2800 & 10,00 & $2 \mathrm{GX11}$ & 3000,4000 & 80 & 20000 \\
\hline \multicolumn{8}{|l|}{ DULUX L } \\
\hline \multirow[t]{2}{*}{ 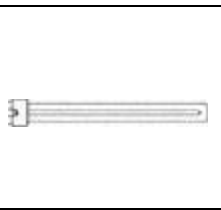 } & 18 & 1200 & 66,66 & $2 \mathrm{G} 11$ & $\begin{array}{c}2700,3000, \\
4000,6000, \\
8000\end{array}$ & 80 & 20000 \\
\hline & 24 & 1800 & 75,00 & $2 \mathrm{G} 11$ & $\begin{array}{l}2700,3000, \\
4000,6000,\end{array}$ & 80 & 20000 \\
\hline
\end{tabular}




\begin{tabular}{|c|c|c|c|c|c|c|c|}
\hline & & & & & 8000 & & \\
\hline & 36 & 2900 & 80,55 & $2 \mathrm{G} 11$ & $\begin{array}{c}2700,3000, \\
4000,6000 \\
8000\end{array}$ & 80 & 20000 \\
\hline & 40 & 3500 & 87,50 & $2 \mathrm{G} 11$ & $\begin{array}{c}2700,3000, \\
4000,6000, \\
8000\end{array}$ & 80 & 20000 \\
\hline & 55 & 4800 & 87,27 & $2 \mathrm{G} 11$ & $\begin{array}{c}2700,3000, \\
4000,6000, \\
8000\end{array}$ & 80 & 20000 \\
\hline & 80 & 6000 & 75,00 & $2 \mathrm{G} 11$ & $\begin{array}{c}2700,3000 \\
4000,6000 \\
8000\end{array}$ & 80 & 20000 \\
\hline \multicolumn{8}{|l|}{ DULUX L XT } \\
\hline \multirow{4}{*}{ 包 } & 18 & 1200 & 66,66 & $2 \mathrm{G} 11$ & 3000,4000 & 80 & 36000 \\
\hline & 24 & 1800 & 75,00 & $2 \mathrm{G} 11$ & 3000,4000 & 80 & 36000 \\
\hline & 36 & 2900 & 80,55 & $2 \mathrm{G} 11$ & 3000,4000 & 80 & 36000 \\
\hline & 55 & 4800 & 87,27 & $2 \mathrm{G} 11$ & 3000,4000 & 80 & 36000 \\
\hline \multicolumn{8}{|l|}{ DULUX F } \\
\hline \multirow{3}{*}{ 政: } & 18 & 1100 & 61,11 & $2 \mathrm{G} 10$ & $\begin{array}{c}2700,3000 \\
4000\end{array}$ & 80 & 20000 \\
\hline & 24 & 1705 & 71,04 & $2 \mathrm{G} 10$ & $\begin{array}{c}2700,3000 \\
4000\end{array}$ & 80 & 20000 \\
\hline & 36 & 2810 & 78,05 & $2 \mathrm{G} 10$ & $\begin{array}{c}2700,3000 \\
4000\end{array}$ & 80 & 20000 \\
\hline
\end{tabular}

Tabela 12: Tabela de lâmpadas fluorescentes compactas não integradas no mercado nacional

\begin{tabular}{|c|c|c|c|c|c|c|c|}
\hline Desenho & $\begin{array}{l}\text { Potência } \\
\text { (W) }\end{array}$ & $\begin{array}{c}\text { Fluxo } \\
\text { luminoso } \\
(\mathrm{Im})\end{array}$ & $\begin{array}{c}\text { Eficiência } \\
\text { luminosa } \\
(\operatorname{Im} / \mathrm{W})\end{array}$ & Base & $\mathrm{T}_{\mathrm{C}}(\mathrm{K})$ & IRC & $\begin{array}{l}\text { Vida útil } \\
\text { (h) }\end{array}$ \\
\hline \multicolumn{8}{|c|}{ DULUX S (SIMPLES) } \\
\hline \multirow{4}{*}{ 可曰” } & 5 & 250 & 50,0 & G23 & 2700,4000 & $80-89$ & 10.000 \\
\hline & 7 & 400 & 57,14 & G23 & 2700,4000 & $80-89$ & 10.000 \\
\hline & 9 & 600 & 66,66 & G23 & 2700,4000 & $80-89$ & 10.000 \\
\hline & 11 & 900 & 81,81 & G23 & 2700,4000 & $80-89$ & 10.000 \\
\hline \multicolumn{8}{|c|}{ DULUX S/E (SIMPLES) } \\
\hline \multirow{2}{*}{ 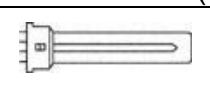 } & 9 & 600 & 66,66 & $2 \mathrm{G} 7$ & 4000 & $80-89$ & 20.000 \\
\hline & 11 & 900 & 81,81 & $2 \mathrm{G} 7$ & 4000 & $80-89$ & 20.000 \\
\hline \multicolumn{8}{|c|}{ DULUX D (DUPLO) } \\
\hline \multirow{2}{*}{ 廌= } & 18 & 1200 & 66,66 & G24d-2 & 2700,4000 & $80-89$ & 10.000 \\
\hline & 26 & 1800 & 69,23 & G24d-3 & 2700,4000 & $80-89$ & 10.000 \\
\hline \multicolumn{8}{|c|}{ DULUX D/E (DUPLO) } \\
\hline \multirow{2}{*}{ 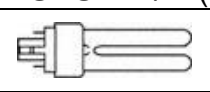 } & 18 & 1200 & 66,66 & G24q-2 & 2700,4000 & $80-89$ & 10.000 \\
\hline & 26 & 1800 & 69,23 & G24q-3 & 2700,4000 & $80-89$ & 10.000 \\
\hline \multicolumn{8}{|c|}{ DULUX T (TRIPLA) } \\
\hline \multirow{2}{*}{ 司 } & 18 & 1200 & 66,66 & GX24d-2 & 2700,4000 & $80-89$ & 10.000 \\
\hline & 26 & 1800 & 69,23 & GX24d-3 & 2700,4000 & $80-89$ & 10.000 \\
\hline \multicolumn{8}{|c|}{ DULUX T/E (TRIPLA) } \\
\hline \multirow[b]{2}{*}{ 國电” } & 32 & 2400 & 75,00 & GX24d-3 & 2700,4000 & $80-89$ & 20.000 \\
\hline & 42 & 3200 & 76,19 & $\mathrm{G} \times 24 d-4$ & 2700,4000 & $80-89$ & 20.000 \\
\hline \multicolumn{8}{|c|}{ DULUX L (LONGA) } \\
\hline \multirow{2}{*}{ 限 } & 36 & 2900 & 80,55 & $2 \mathrm{G} 11$ & 2700,4000 & $80-89$ & 20.000 \\
\hline & 55 & 4800 & 87,27 & $2 \mathrm{G} 11$ & 2700,4000 & $80-89$ & 20.000 \\
\hline \multicolumn{8}{|c|}{ DULUX F (FLAT) } \\
\hline
\end{tabular}




\begin{tabular}{|r|l|l|l|l|l|l|l|}
\hline & 36 & 2800 & 77,77 & $2 \mathrm{G} 10$ & 3000,4000 & $80-89$ & 10.000 \\
\hline
\end{tabular}

Tabela 13: Tabela de lâmpadas fluorescentes tubulares T5 no mercado internacional

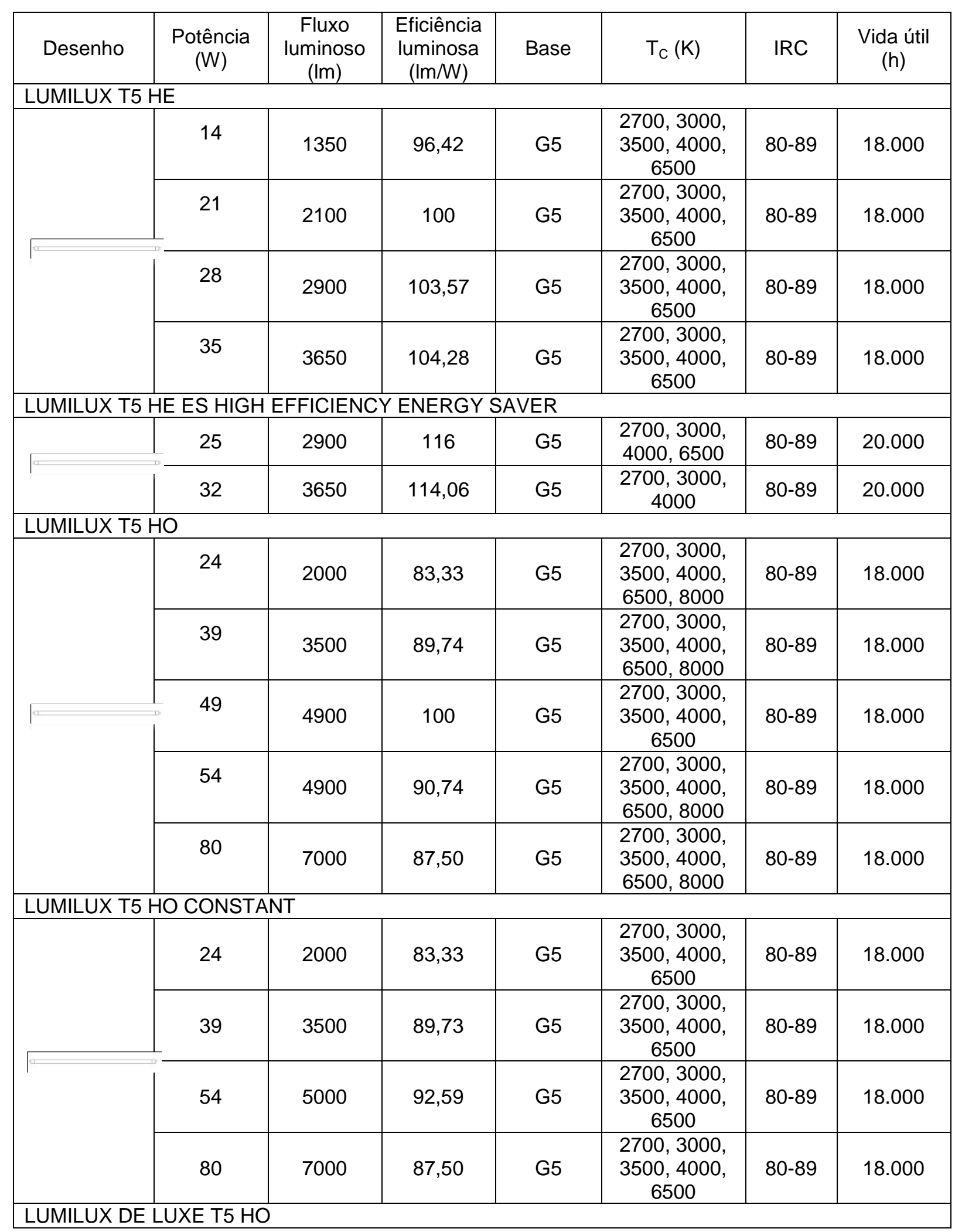




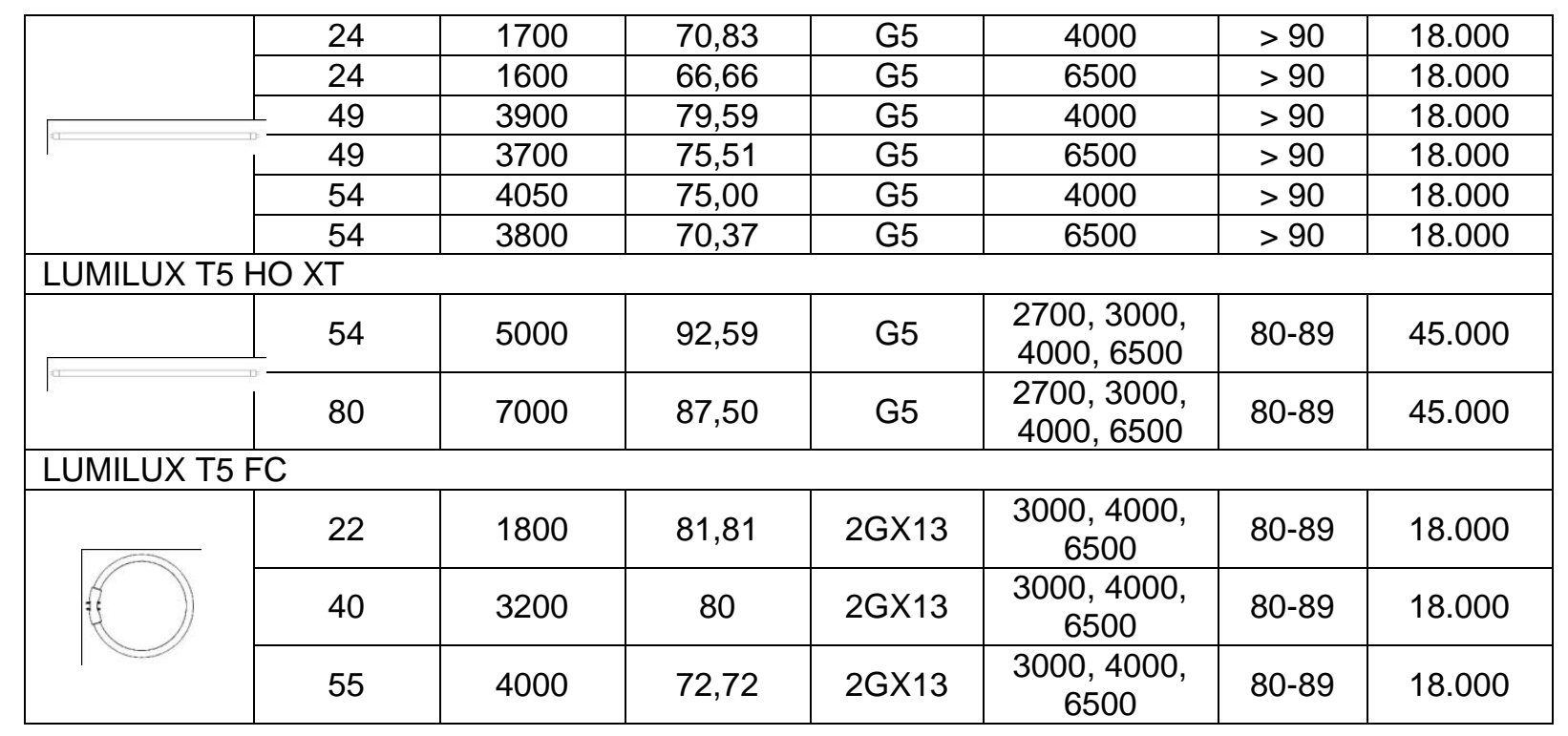

Tabela 14: Tabela de lâmpadas fluorescentes tubulares T5 no mercado nacional

\begin{tabular}{|c|c|c|c|c|c|c|c|}
\hline Desenho & $\begin{array}{l}\text { Potência } \\
\text { (W) }\end{array}$ & $\begin{array}{c}\text { Fluxo } \\
\text { luminoso } \\
(\mathrm{Im})\end{array}$ & $\begin{array}{c}\text { Eficiência } \\
\text { luminosa } \\
(\operatorname{lm} / \mathrm{W})\end{array}$ & Base & $\mathrm{T}_{\mathrm{C}}(\mathrm{K})$ & IRC & $\begin{array}{l}\text { Vida útil } \\
\text { (h) }\end{array}$ \\
\hline \multicolumn{8}{|c|}{ FAMÍLIA LUMILUX T5 HE } \\
\hline & 14 & 1350 & 96,42 & G5 & $\begin{array}{c}3000,4000 \\
5000\end{array}$ & $80-89$ & 18.000 \\
\hline & 21 & 2100 & 100 & G5 & 3000,4000 & $80-89$ & 18.000 \\
\hline & 28 & 2900 & 103,57 & G5 & 3000,4000 & $80-89$ & 18.000 \\
\hline & 28 & 2750 & 98,21 & G5 & 5000 & $80-89$ & 18.000 \\
\hline & 35 & 3650 & 104,28 & G5 & 3000,4000 & $80-89$ & 18.000 \\
\hline \multicolumn{8}{|c|}{ FAMÍLIA LUMILUX T5 HO } \\
\hline \multirow{4}{*}{ 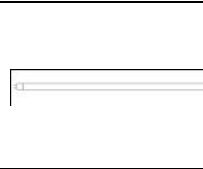 } & 24 & 2000 & 83,33 & G5 & 3000,4000 & $80-89$ & 18.000 \\
\hline & 54 & 5000 & 92,59 & G5 & 3000,4000 & $80-89$ & 18.000 \\
\hline & 54 & 4750 & 87,96 & G5 & 6500 & $80-89$ & 18.000 \\
\hline & 80 & 7000 & 87,5 & G5 & 3000,4000 & $80-89$ & 18.000 \\
\hline \multicolumn{8}{|c|}{ FAMÍLIA LUMILUX T5 ES (Energy Saver) } \\
\hline & 25 & 2900 & 116 & G5 & 3000,4000 & $80-89$ & 18.000 \\
\hline & 50 & 5000 & 100 & G5 & 3000,4000 & $80-89$ & 18.000 \\
\hline \multicolumn{8}{|c|}{ FAMÍLIA LUMILUX T5 SKYWHITE } \\
\hline & 54 & 4500 & 83,33 & G5 & 8000 & $80-90$ & 18.000 \\
\hline \multicolumn{8}{|c|}{ FAMÍLIA CIRCLINE T9 } \\
\hline & 22 & 1050 & 47,72 & G10q & 6500 & $70-79$ & - \\
\hline & 32 & 1700 & 53,12 & G10q & 6500 & $70-79$ & - \\
\hline
\end{tabular}

Assim como nas comparações anteriores, analisando as Tabelas 11 e 12, 13 e 14, observa-se que há uma grande variedade em relação ao tipo e potência de lâmpadas e temperatura de cor disponíveis no mercado internacional que o nacional.

Comparando as famílias de lâmpadas da tabela 11 e 12, por exemplo, para um lâmpada fluorescente compacta tripla, no mercado internacional há uma 
lâmpada de 32W com mesma eficiência luminosa, porém com uma vida útil maior de quase o dobro de horas. Isso acarreta em uma menor troca de lâmpadas e uma redução na poluição ao descarte dessas lâmpadas.

Comparando a tabela 13 e 14, notamos que no mercado internacional temos lâmpadas mais eficientes que podem ser utilizadas em projetos. Por exemplo, no caso de uma lâmpada de $28 \mathrm{~W}$, podemos substituí-la por uma lâmpada de $25 \mathrm{~W}$ de mesmo fluxo luminoso e de $2.000 \mathrm{~h}$ de vida útil a mais.

Por fim, para o levantamento de lâmpadas, consideraremos as lâmpadas LEDs que estão sendo muito utilizadas na substituição direta de lâmpadas incandescentes e halógenas. Neste trabalho, citaremos apenas as substitutas das lâmpadas halógenas dicróicas que serão utilizadas nas simulações.

Tabela 15: Tabela de lâmpadas LED com refletor no mercado internacional

\begin{tabular}{|c|c|c|c|c|c|c|c|c|}
\hline Desenho & $\begin{array}{l}\text { Potência } \\
\text { (W) }\end{array}$ & $\begin{array}{c}\text { Fluxo } \\
\text { luminoso } \\
(\mathrm{Im})\end{array}$ & $\begin{array}{c}\text { Intensidade } \\
\text { luminosa } \\
\text { (cd) }\end{array}$ & $\begin{array}{l}\text { Abertura } \\
\text { de facho }\end{array}$ & Base & $\mathrm{T}_{\mathrm{C}}(\mathrm{K})$ & IRC & $\begin{array}{l}\text { Vida útil } \\
\text { (h) }\end{array}$ \\
\hline \multicolumn{9}{|c|}{ PARATHOM PRO MR16 } \\
\hline \multirow{26}{*}{$\pi$} & 5,5 & 200 & 600 & $24 ㅇ$ & GU5,3 & 2700 & 90 & 25.000 \\
\hline & 5,5 & 220 & 650 & 240 & GU5,3 & 3000 & 90 & 25.000 \\
\hline & 5,5 & 270 & 750 & $24 \div$ & GU5,3 & 4000 & 90 & 25.000 \\
\hline & 7 & 315 & 900 & 24 은 & GU5,3 & 2700 & 80 & 25.000 \\
\hline & 7 & 350 & 1050 & $24 \div$ & GU5,3 & 3000 & 80 & 25.000 \\
\hline & 7 & 450 & 1200 & 240 & GU5,3 & 4000 & 80 & 25.000 \\
\hline & 11 & 450 & 1350 & 240 & GU5,3 & 2700 & 80 & 25.000 \\
\hline & 11 & 500 & 1500 & 240 & GU5,3 & 3000 & 80 & 25.000 \\
\hline & 11 & 620 & 1900 & 240 & GU5,3 & 6500 & 70 & 25.000 \\
\hline & 5,5 & 190 & 500 & $36 \circ$ & GU5,3 & 2800 & 80 & 25.000 \\
\hline & 5,5 & 200 & 500 & 36응 & GU5,3 & 3000 & 80 & 25.000 \\
\hline & 5,5 & 250 & 600 & $36 \circ$ & GU5,3 & 6500 & 70 & 25.000 \\
\hline & 5,5 & 200 & 500 & 360 & GU5,3 & 2700 & 90 & 25.000 \\
\hline & 5,5 & 220 & 600 & $36 \circ$ & GU5,3 & 3000 & 90 & 25.000 \\
\hline & 5,5 & 270 & 650 & $36 \circ$ & GU5,3 & 4000 & 80 & 25.000 \\
\hline & 7 & 315 & 800 & 360 & GU5,3 & 2700 & 80 & 25.000 \\
\hline & 7 & 350 & 950 & $36 \div$ & GU5,3 & 3000 & 80 & 25.000 \\
\hline & 7 & 450 & 1100 & 360 & GU5,3 & 4000 & 80 & 25.000 \\
\hline & 10 & 350 & 950 & 360 & GU5,3 & 3000 & 80 & 25.000 \\
\hline & 10 & 450 & 1200 & $36 \circ$ & GU5,3 & 6500 & 70 & 25.000 \\
\hline & 10 & 315 & 800 & $36 \circ$ & GU5,3 & 2700 & 80 & 25.000 \\
\hline & 10 & 350 & 950 & 360 & GU5,3 & 3000 & 80 & 25.000 \\
\hline & 10 & 450 & 1200 & 360 & GU5,3 & 6500 & 70 & 25.000 \\
\hline & 11 & 450 & 1100 & 360 & GU5,3 & 2700 & 80 & 25.000 \\
\hline & 11 & 500 & 1200 & 360 & GU5,3 & 3000 & 80 & 25.000 \\
\hline & 11 & 620 & 1500 & $36 \circ$ & GU5,3 & 6500 & 70 & 25.000 \\
\hline
\end{tabular}


Tabela 16: Tabela de lâmpadas LED com refletor no mercado nacional

\begin{tabular}{|c|c|c|c|c|c|c|c|c|}
\hline Desenho & $\begin{array}{l}\text { Potência } \\
\text { (W) }\end{array}$ & $\begin{array}{c}\text { Fluxo } \\
\text { luminoso } \\
(\mathrm{Im})\end{array}$ & $\begin{array}{c}\text { Intensidade } \\
\text { luminosa } \\
\text { (cd) }\end{array}$ & $\begin{array}{l}\text { Abertura } \\
\text { de facho }\end{array}$ & Base & $\mathrm{T}_{\mathrm{C}}(\mathrm{K})$ & IRC & $\begin{array}{l}\text { Vida útil } \\
\text { (h) }\end{array}$ \\
\hline \multicolumn{9}{|c|}{ PARATHOM PRO MR16 } \\
\hline \multirow{4}{*}{${ }_{v v}$} & 4,5 & 185 & 450 & 360 & GU5,3 & 3000 & s/inf & 25.000 \\
\hline & 5,5 & 200 & 500 & 360 & GU5,3 & $\begin{array}{l}2700 \\
3000\end{array}$ & s/inf & 25.000 \\
\hline & 10 & 450 & 1200 & $36 \circ$ & GU5,3 & 2700 & s/inf & 25.000 \\
\hline & 10 & 350 & 950 & $36 \circ$ & GU5,3 & 3000 & s/inf & 25.000 \\
\hline
\end{tabular}

Novamente, comparando as tabelas de lâmpadas LEDs do mercado nacional (Tabela 15) e internacional (Tabela 16), observamos que muitas lâmpadas não chegaram ao mercado nacional. Além disso, o catálogo de lâmpadas nacionais não informa o IRC das lâmpadas, prejudicando assim o projetista a especificar esse tipo de lâmpada em ambientes onde a reprodução de cor é fundamental.

\section{PHILIPS}

A Philips é uma empresa que surgiu em 1891 e foi fundada pelo engenheiro Gerard Philips na Holanda, com o objetivo de fabricar lâmpadas incandescentes e filamentos de carbono para as mesmas. Assim como na Osram, muitas lâmpadas não são fabricadas e comercializadas no Brasil.

Para comparações de eficiência energética, ficaremos restritos apenas a algumas lâmpadas fluorescentes tubulares T5, que são as mais utilizadas em projetos de eficiência em obras comerciais e possuem diferenciais e uma grande variedade em relação às lâmpadas do fabricante Osram.

Tabela 17: Tabela de lâmpadas fluorescentes tubulares T5 no mercado internacional

\begin{tabular}{|c|c|c|c|c|c|c|c|}
\hline Desenho & $\begin{array}{c}\text { Potência } \\
(\mathrm{W})\end{array}$ & $\begin{array}{c}\text { Fluxo } \\
\text { luminoso }\end{array}$ & $\begin{array}{c}\text { Eficiência } \\
\text { luminosa }\end{array}$ & Base & $\mathrm{T}_{\mathrm{C}}(\mathrm{K})$ & $\mathrm{IRC}$ & $\begin{array}{c}\text { Vida útil } \\
(\mathrm{h})\end{array}$ \\
\hline
\end{tabular}




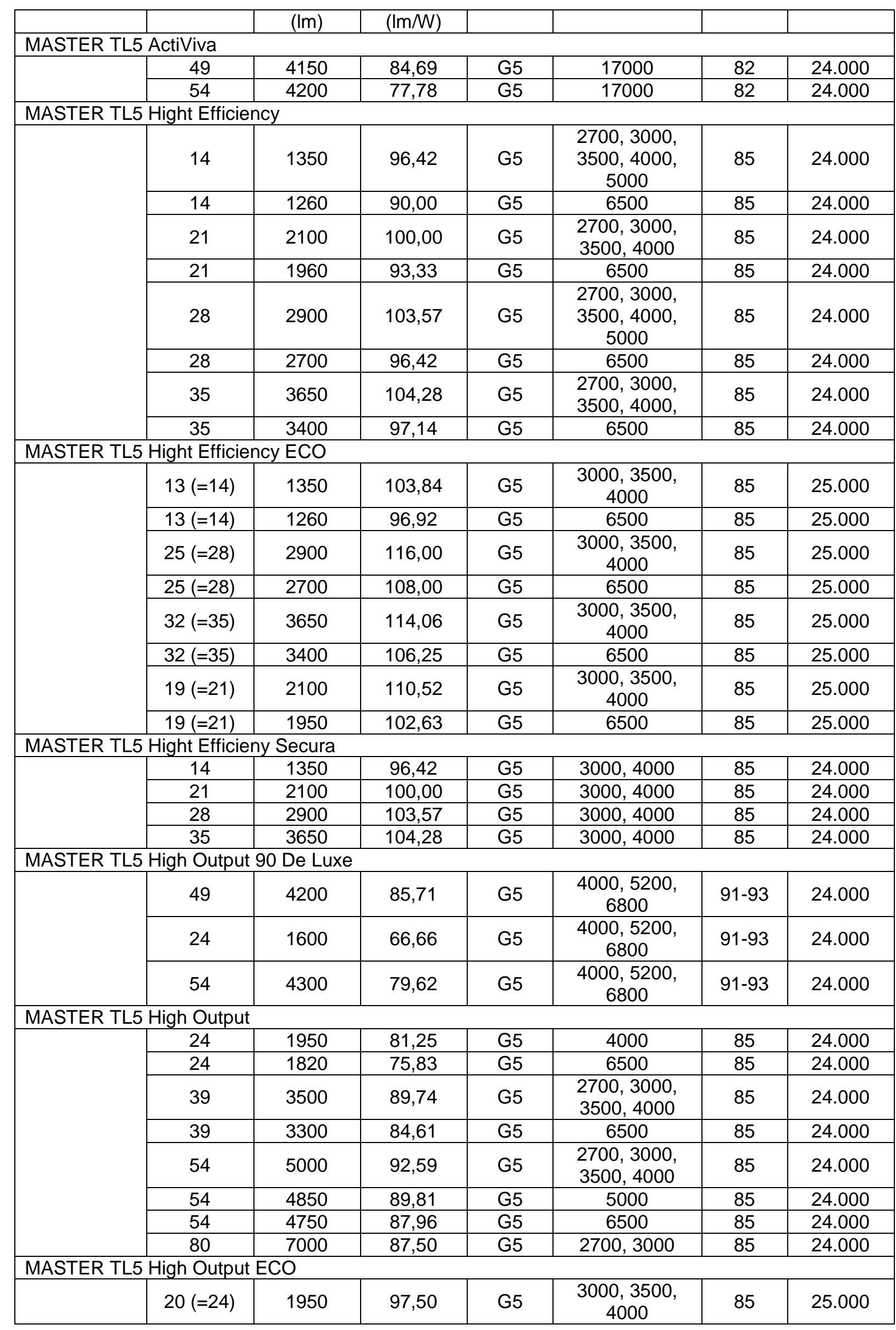




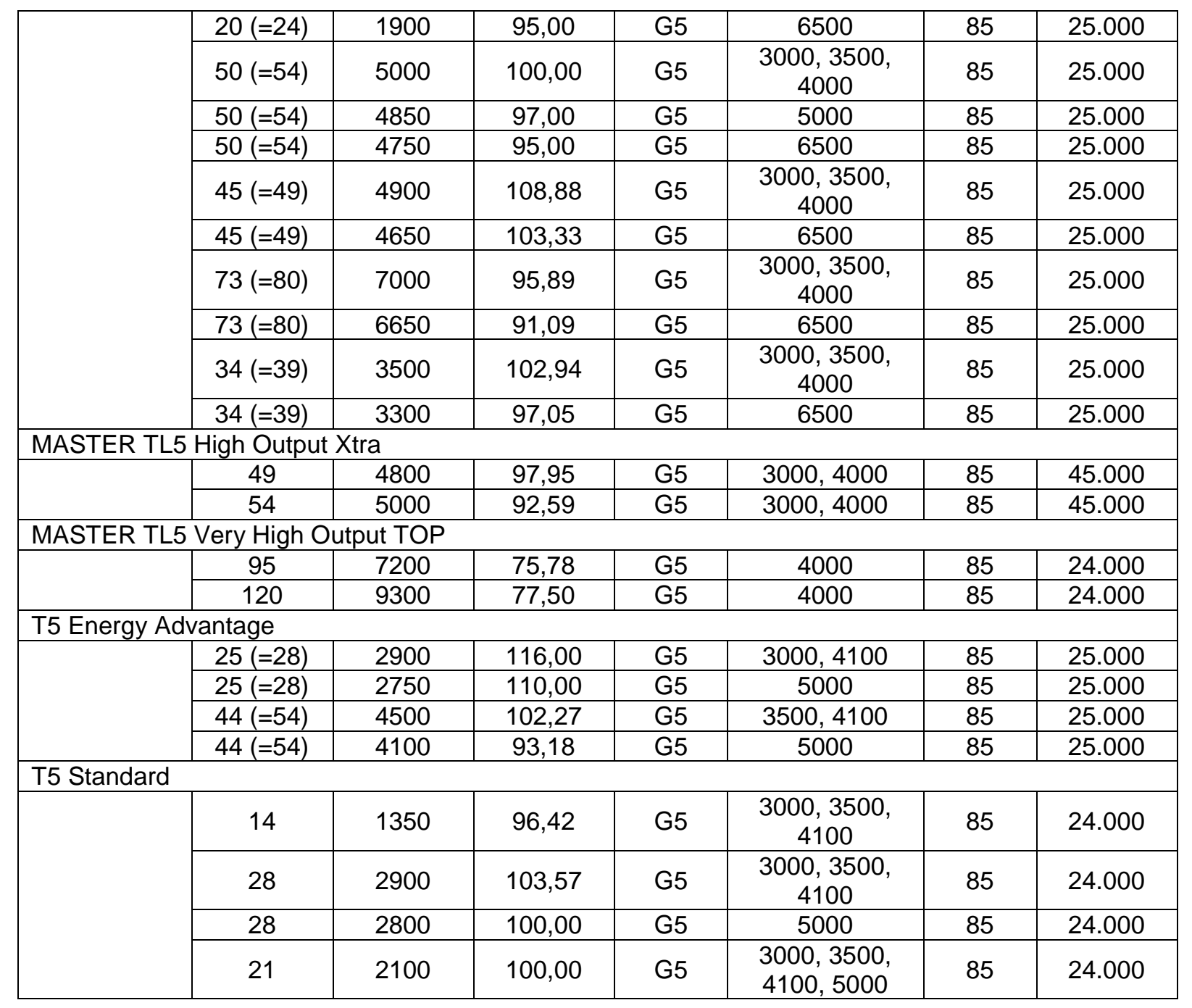

Tabela 18: Tabela de lâmpadas fluorescentes tubulares T5 no mercado nacional

\begin{tabular}{|c|c|c|c|c|c|c|c|}
\hline Desenho & $\begin{array}{l}\text { Potência } \\
\text { (W) }\end{array}$ & $\begin{array}{c}\text { Fluxo } \\
\text { luminoso } \\
(\mathrm{Im})\end{array}$ & $\begin{array}{c}\text { Eficiência } \\
\text { luminosa } \\
(\operatorname{Im} / \mathrm{W})\end{array}$ & Base & $\mathrm{T}_{\mathrm{C}}(\mathrm{K})$ & IRC & $\begin{array}{l}\text { Vida útil } \\
\text { (h) }\end{array}$ \\
\hline \multicolumn{8}{|c|}{ MASTER TL5 ActiViva } \\
\hline & 54 & 4250 & 78,70 & G5 & 17000 & 82 & 24.000 \\
\hline \multicolumn{8}{|c|}{ MASTER TL5 Super 80} \\
\hline & 14 & 1350 & 96,42 & G5 & $\begin{array}{c}3000,4000 \\
5000\end{array}$ & 85 & 24.000 \\
\hline & 28 & 2600 & 92,85 & G5 & $\begin{array}{c}3000,4000, \\
5000\end{array}$ & 85 & 24.000 \\
\hline & 54 & 4450 & 82,40 & G5 & 3000,4000 & 85 & 24.000 \\
\hline & 54 & 4250 & 78,70 & G5 & 5000,6500 & 85 & 24.000 \\
\hline & 80 & 6150 & 76,87 & G5 & 3000,4000 & 85 & 24.000 \\
\hline \multicolumn{8}{|c|}{ MASTER TL5 Eco } \\
\hline & 25 & 2450 & 98,00 & G5 & 3000,4000 & 85 & 24.000 \\
\hline & 50 & 4400 & 88,00 & G5 & 3000,4000 & 85 & 24.000 \\
\hline & 73 & 6150 & 84,24 & G5 & 3000,4000 & 85 & 24.000 \\
\hline
\end{tabular}


Comparando as Tabelas 17 e 18, observamos que assim como no fabricante Osram, apenas alguns tipos de lâmpadas são fabricadas aqui, e que no mercado internacional já temos lâmpadas mais eficientes que no mercado nacional, além de uma grande variedade de temperatura de cor.

\section{GE lluminação}

A General Electric (GE) Company foi fundada em $1892 \mathrm{com}$ a finalidade de produzir e comercializar os produtos necessários para a indústria da iluminação fundindo com a empresa de Thomas Edison.

A GE tem uma linha com lâmpadas incandescentes, halógenas, fluorescentes compactas e tubulares e de descarga de alta pressão. Em seu site não encontramos até então informações sobre as lâmpadas comercializadas aqui no Brasil. As informações estão sendo dirigidas para o site internacional com os produtos descritos em inglês.

\subsection{Equipamentos auxiliares}

Em relação aos equipamentos auxiliares tanto no exterior quanto no Brasil, são fabricadas no país, apenas transformadores, reatores e fontes de acordo com a lâmpada e potência existentes e utilizadas. Em geral recomenda-se que utilize o equipamento auxiliar do mesmo fabricante que a lâmpada, para melhores desempenhos.

Como no Brasil, o Inmetro já estabeleceu desde 2005 que somente os reatores de alto desempenho podem ser comercializados, os reatores não apresentam grandes problemas para um desempenho eficiente. Em geral, na escolha do reator, deve-se observar o fator de perdas, onde quanto maior é o valor, maior é o gasto com energia; e o fator de fluxo luminoso que deve estar entre $0,95 \mathrm{e}$ 1,00 . 
Existem também equipamentos auxiliares dimerizáveis, que geram economia de energia. Por exemplo, se uma lâmpada de potência $100 \mathrm{~W}$ é dimerizada $60 \%$, apenas $60 \%$ do fluxo luminoso será emitido pela lâmpada e $40 \%$ da potência será economizada. Todas as lâmpadas podem ser dimerizadas, com exceção das lâmpadas fluorescentes compactas integradas e as de descarga de alta pressão.

As lâmpadas fluorescentes compactas não integradas, fluorescentes tubulares e halógenas em $12 \mathrm{~V}$ necessitam de reatores e transformadores adequados que permitam a dimerização. Tanto a Philips como a Osram fornecem esses equipamentos auxiliares. Novamente, deve-se atentar para o valor do fator de perda de um reator, para obtenção de um conjunto mais eficiente.

\subsection{Outros equipamentos}

\subsubsection{Sensor de presença}

O sensor de presença é um aparelho que detecta a presença de uma pessoa no ambiente. Ela pode dectar a presença através do movimento ou através da variação de temperatura, sendo que este último é mais eficiente, pois o mesmo faz uma leitura da temperatura local. Qualquer variação de temperatura acionará as luzes do ambiente.

O sensor de presença é utilizado, geralmente, em ambientes de uso pouco frequente, tais como sanitários, circulação, áreas técnicas, entre outros. Sua utilização traz economia de energia, pois esses ambientes não precisam ficar com o sistema de iluminação ligado todo o tempo. Em muitos casos, o botão liga / desliga não é eficaz, pois frequentemente os usuários não tem o costume de desligar a iluminação ao sair do ambiente. 


\subsubsection{Sistema de controle fotoelétrico}

O sistema de controle fotoelétrico é um sensor que identifica a presença de luz natural no ambiente, controlando automaticamente a quantidade de luz artificial através de dimmers.

Quanto maior a quantidade de luz natural, menor será a quantidade de luz artificial no ambiente, ou seja, menor será a potência elétrica fornecida.

\subsubsection{Automação no sistema de iluminação}

A automação predial engloba as seguintes utilidades em um edifício: sistemas elétricos, hidráulicos, ar condicionado (quente/frio), elevadores, segurança (como controle de acesso, alarmes, circuito fechado de televisão (CFTV), alarmes), detecção de incêndio, irrigação, gerenciamento de vagas de estacionamento, e a convergência de redes e gerenciamento.

A automação nos sistemas de iluminação permite controlar a intensidade da luz com a utilização dos dimmers, comandos e cenas, reduzindo assim a quantidade de luz de um ambiente conforme preferência do usuário ou juntamente com o sensor de luz natural, conforme necessidade de luz artificial no ambiente. Dessa forma, os sistemas de iluminação não estarão ligados em 100\% todo o tempo de uso.

Permite também, programar o acendimento e desligamento automático e dimerização de ambientes pré-estabelecidos ao longo do dia. Por exemplo, a iluminação externa será acessa ao escurecer e apagada no amanhecer. Há diversas maneiras de fazer uma programação para tornar o sistema de iluminação mais eficiente, conforme uso diário do escritório.

Além disso, a automação pode gerenciar e monitorar os sistemas de iluminação quanto ao consumo e sua funcionabilidade. Por enquanto, esses equipamentos de automação são importados. 


\subsection{Conclusões}

Pelas curvas de iluminância apresentadas, observamos que no geral as luminárias importadas apresentam melhor desempenho que as nacionais. Podemos citar como principais diferenças, o cuidado com o desenho do refletor para melhorar a distribuição da luz, o material utilizado no refletor e no difusor.

No entanto, as luminárias brasileiras também estão buscando a qualidade. Percebemos isso principalmente nas luminárias da Itaim onde a fábrica tem um grande interesse em divulgar as certificações que possui.

O grande problema de se utilizar luminárias importadas seria a variação do câmbio, pois esse valor, em geral, é repassado ao cliente. O ideal é sempre calcular o pay back do conjunto.

Outro problema que pode ocorrer, é que muitas dessas luminárias importadas não utilizam lâmpadas e equipamentos fabricados no país. No caso de queima de equipamento ou lâmpada, o cliente terá que recorrer também a importação, ficando muitas vezes dependente do tempo que o produto demora a chegar ao país.

Em todas as comparações feitas entre lâmpadas do mercado nacional e internacional observou-se que no mercado internacional existe uma variedade maior de tipo de lâmpadas e potências. E que, a exemplo do caso da Osram, que está desenvolvendo a tecnologia ECO, somente agora esta tecnologia está vindo para o Brasil e, mesmo assim, somente em algumas potências.

Para projetos com selos de sustentabilidade, cada vez mais a procura por luminárias LED vêm aumentando. Porém somente agora os produtos nacionais com LED estão sendo desenvolvidos de maneira satisfatória em relação à qualidade dos produtos. Até o momento, a grande maioria das luminárias com LED eram importadas, e por esse motivo, depara-se novamente com o problema da taxa de câmbio e do tempo de importação.

Para um projeto sustentável em relação à iluminação artificial, devemos nos atentar sempre para o conjunto luminária, lâmpadas e equipamentos, pois esse 
sistema dita a economia de energia, além de fornecer a qualidade de projeto em questões de nível de iluminação, IRC e temperatura de cor.

Concluímos pelas comparações de produtos importados e nacionais que o Brasil, a principio, não tem as mesmas condições para um projeto de eficiência energética com relação aos sistemas de iluminação. 


\section{ESCOLHA DOS ESTUDOS DE CASO}

Para verificação se os indicadores de iluminação artificial das certificações e/ou selos de sustentabilidade são compatíveis com a tecnologia disponível no Brasil, optou-se por simular um pavimento tipo de escritório e um pavimento tipo de uma escola, ambientes presentes em todas as certificações e/ou selos de sustentabilidade atuantes no Brasil.

\subsection{Escritório}

Foram analisados 4 pavimentos tipo escolhidos aleatoriamente que possuíssem os seguintes ambientes: staff, sala de reunião e salas individuais.

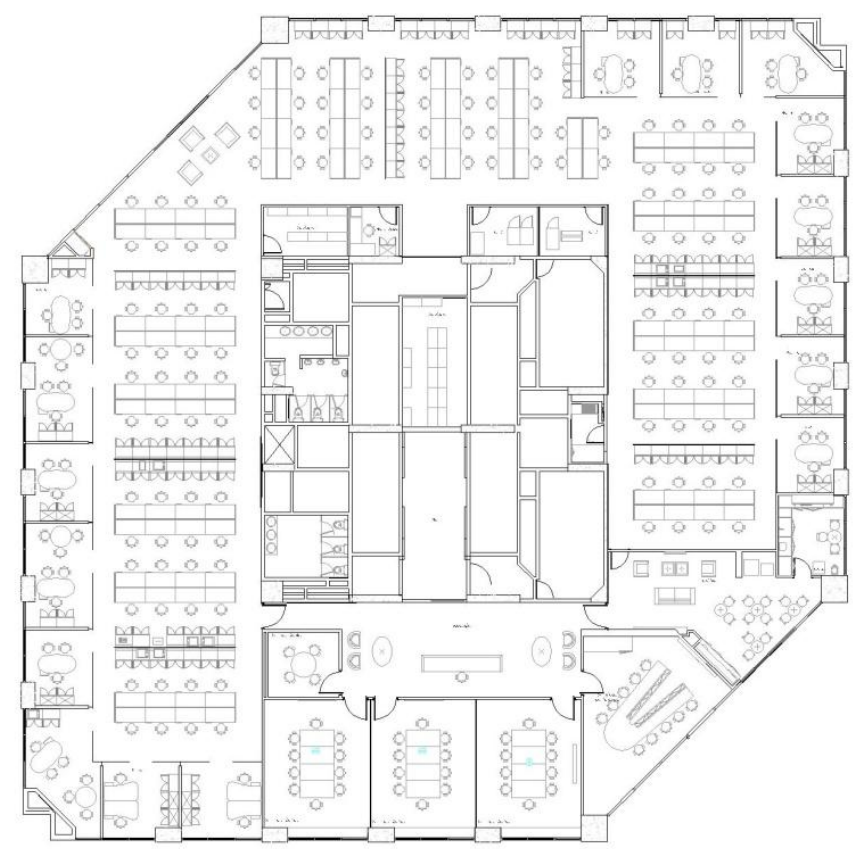

Figura 17: Pavimento tipo 1 


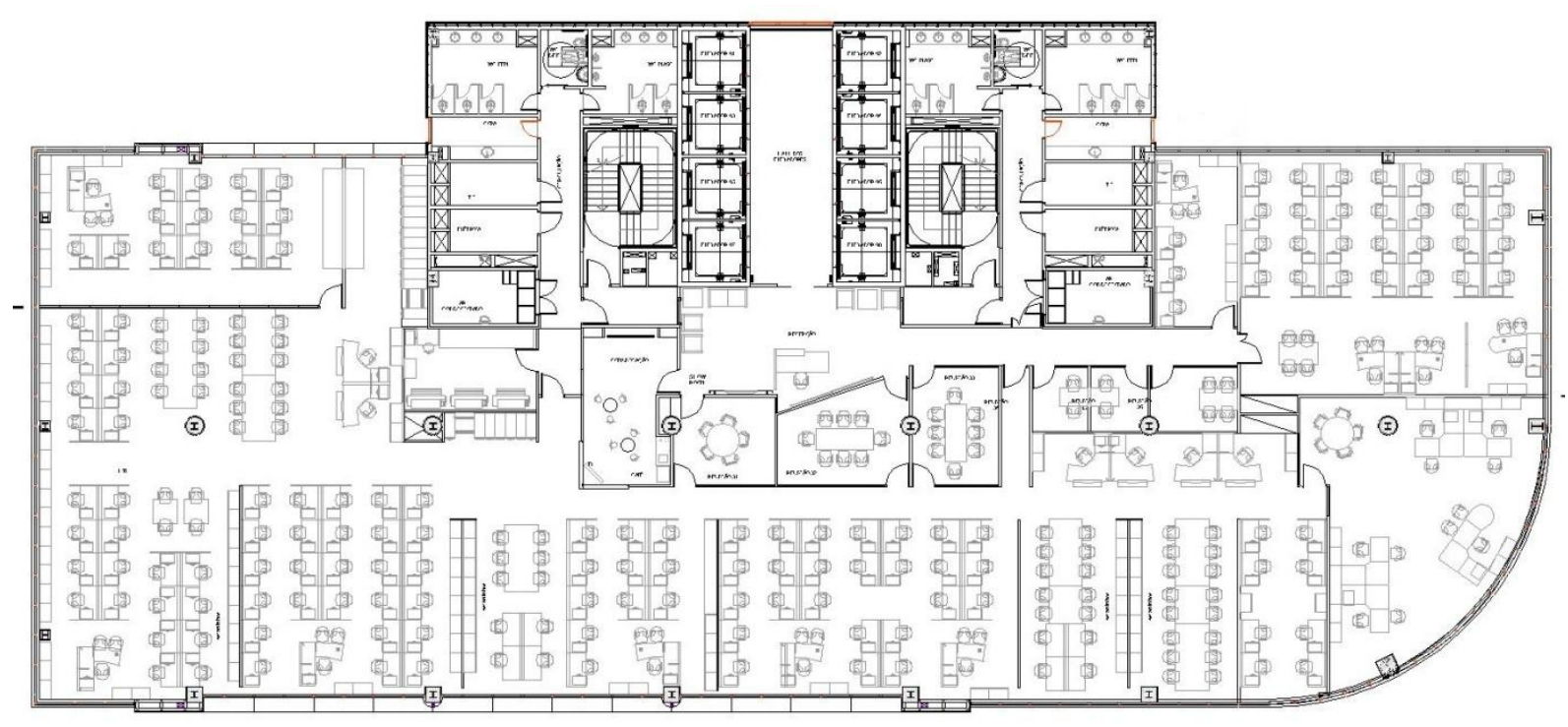

Figura 18: Pavimento tipo 2

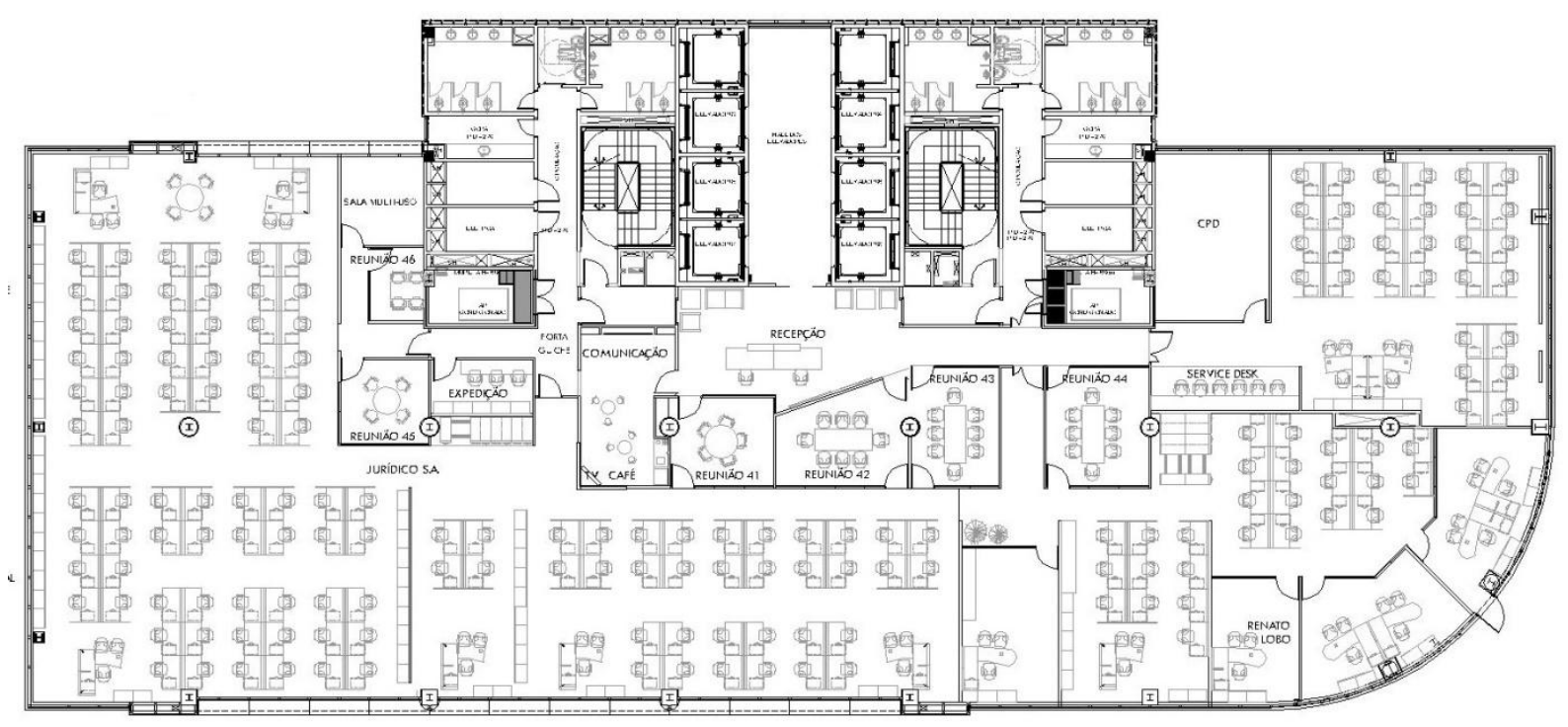

Figura 19: Pavimento tipo 3 


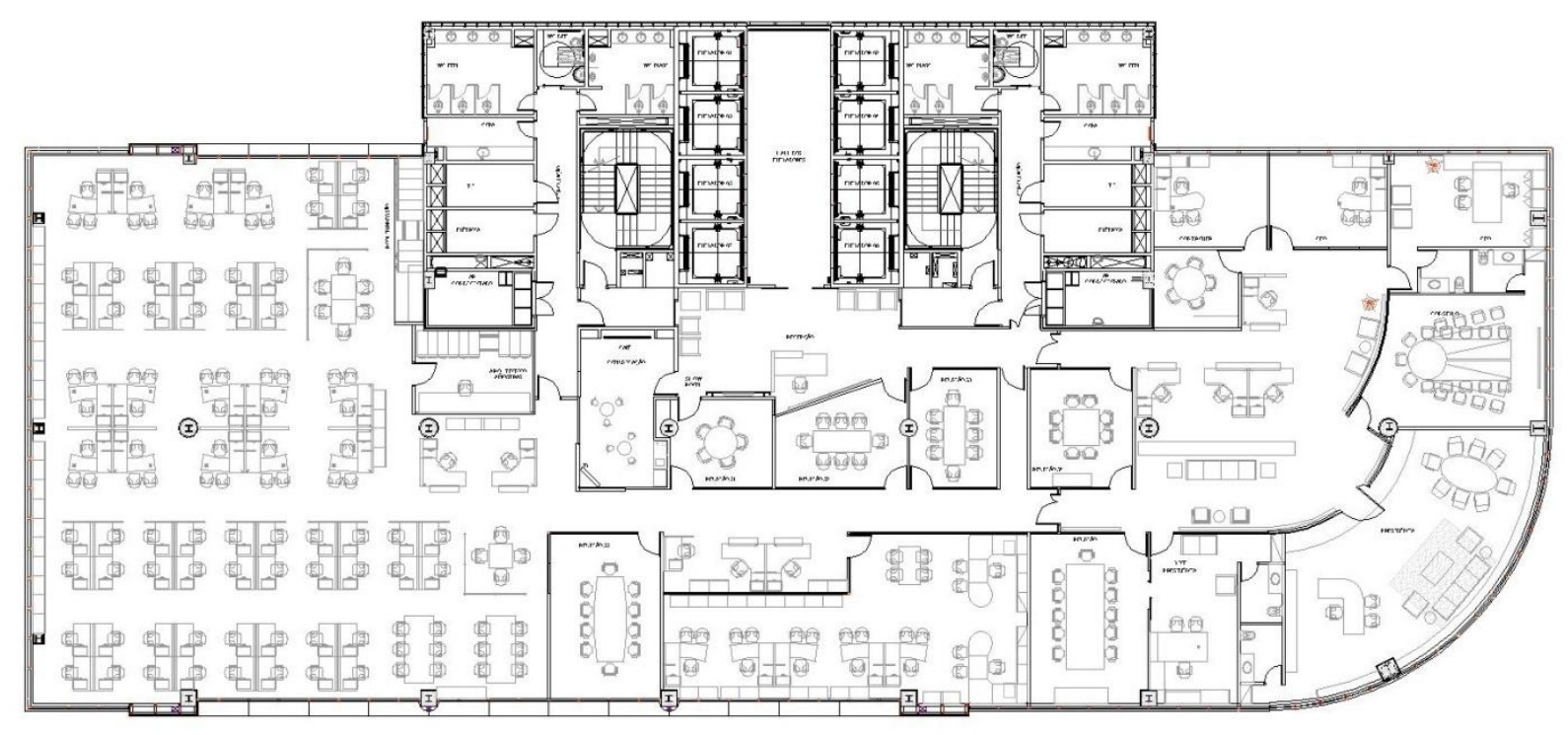

Figura 20: Pavimento tipo 4

Comparando os quatro pavimentos tipo das figuras 17, 18, 19 e 20, optou-se pelo pavimento tipo 3 (figura 19), pois possui uma grande área de staff, algumas salas de reunião e algumas salas individuais. Possui um layout típico que podemos considerar para a grande maioria dos escritórios.

Para estudo de caso, consideraremos um layout fixo, pois em alguns ambientes será especificado luz pontual e de destaque.

A planta da figura 17 também poderia ser considerada, porém o staff tem uma configuração diferenciada em forma de "U". As plantas das figuras 17 e 19 foram descartadas, pois a primeira apresenta somente uma sala de reunião e várias salas que podem ser consideradas como staff e a última possui uma área pequena de staff.

\subsection{Escola}

Foram analisados 4 escolas tipo escolhidas pelo site da Fundação para o desenvolvimento da Educação (FDE), onde será feito a simulação das salas de aula, secretaria, centro de leitura e refeitório. 

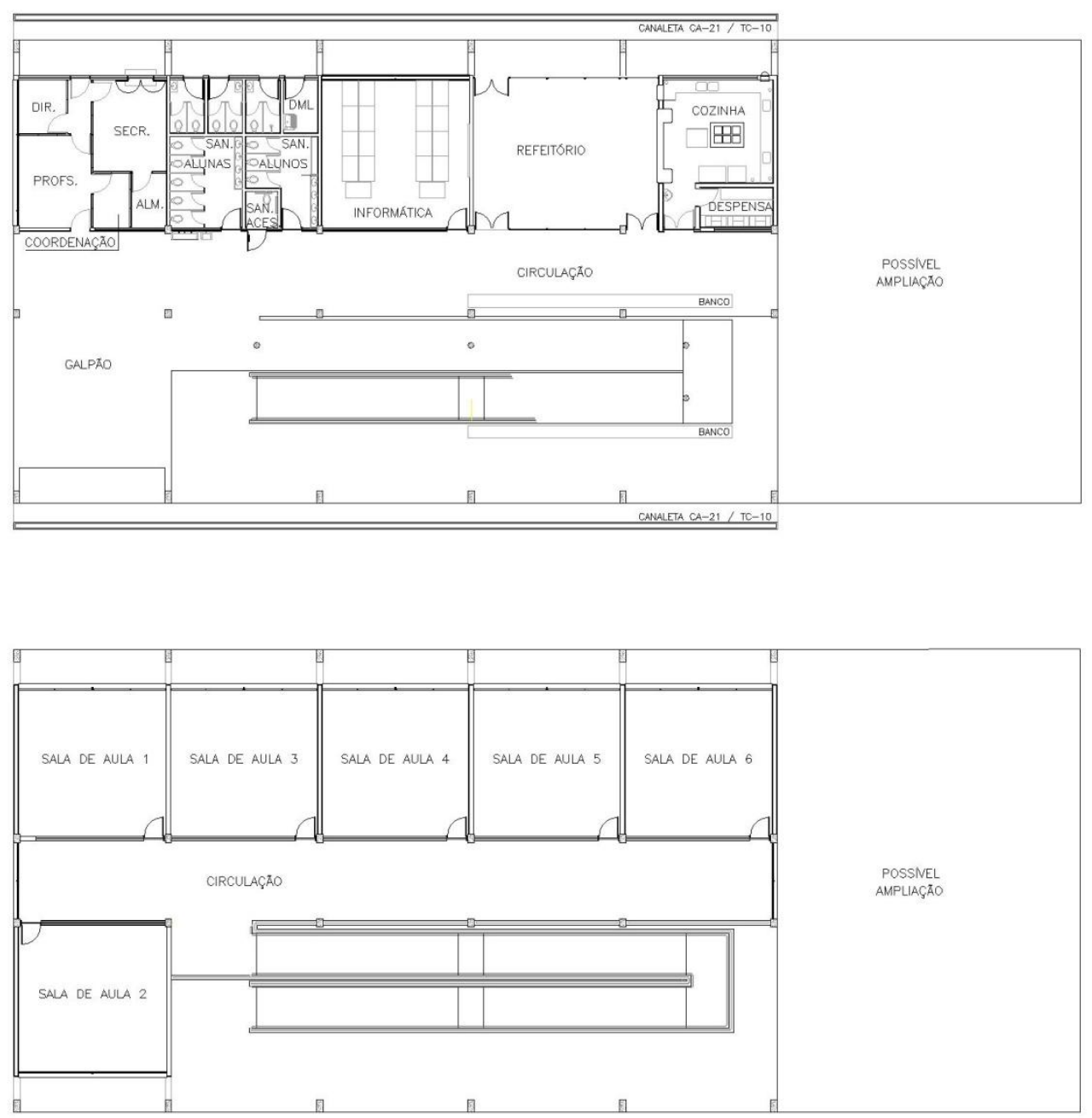

Figura 21: Escola tipo 1 - pavimento térreo e superior

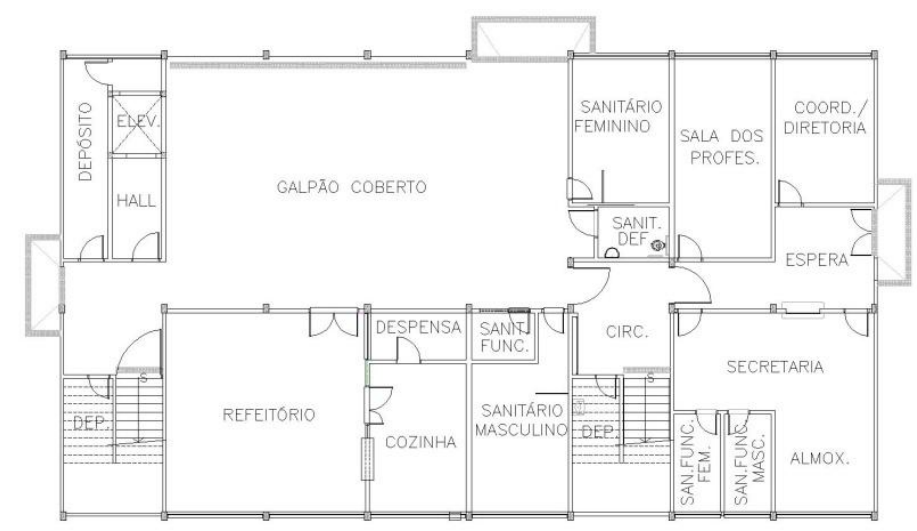




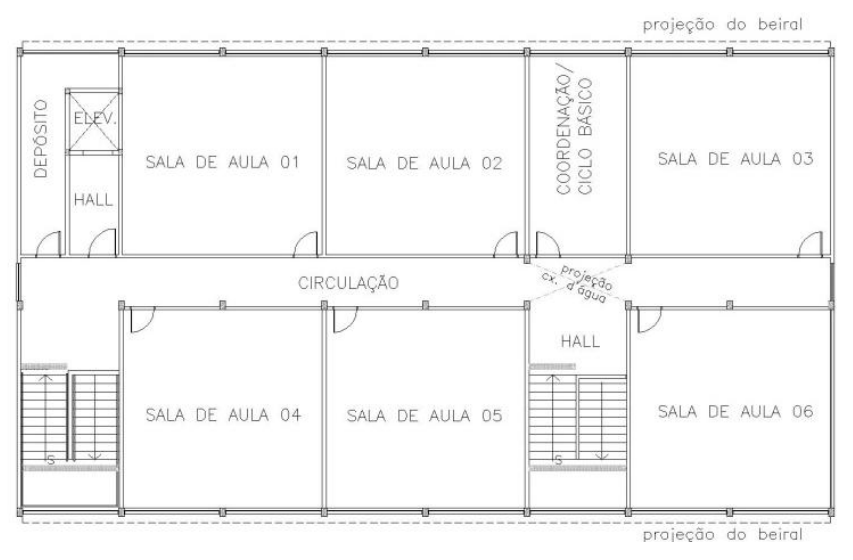

Figura 22: Escola tipo 2 - Pavimento térreo e superior
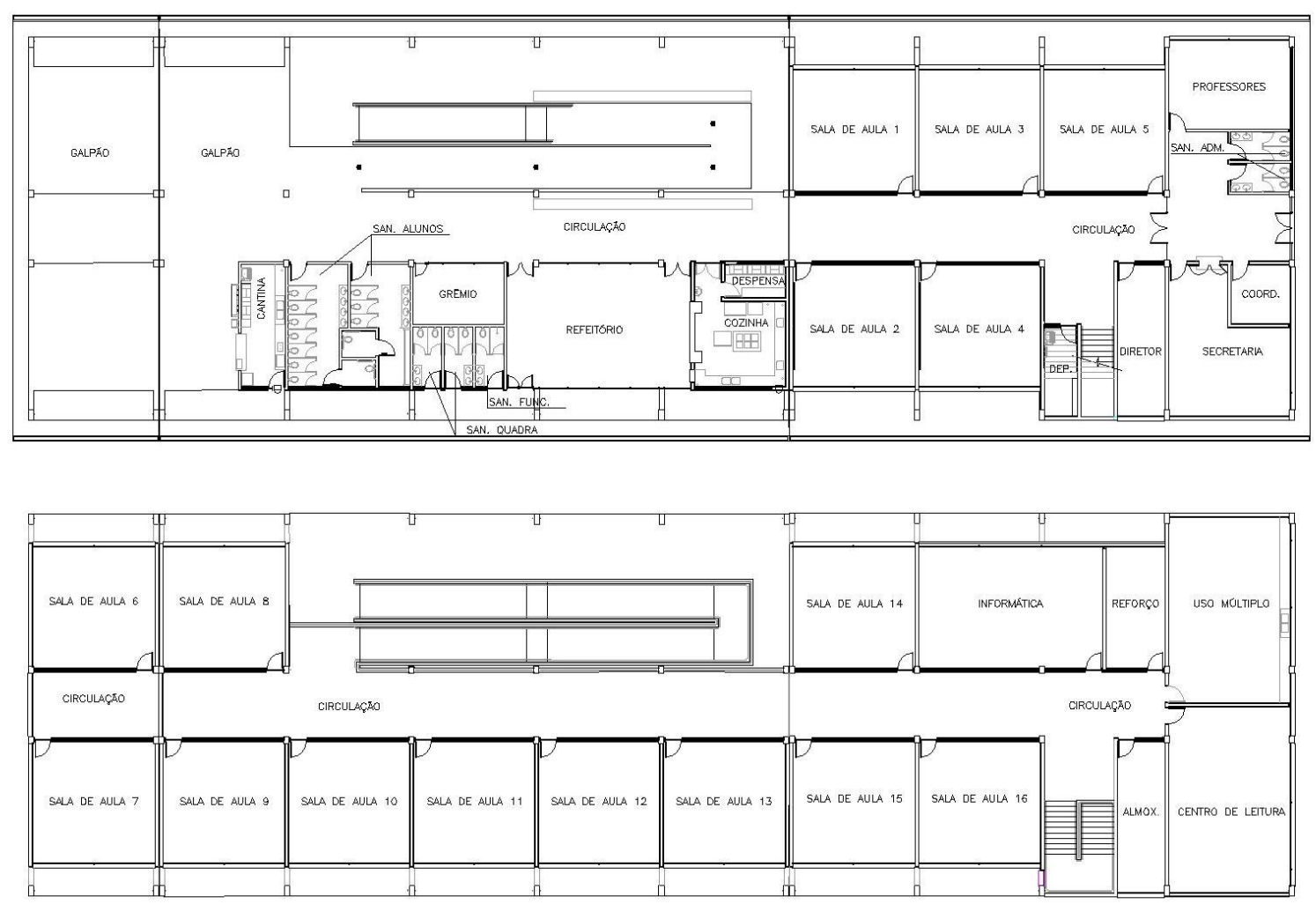

Figura 23: Escola tipo 3 - Pavimento térreo e superior 

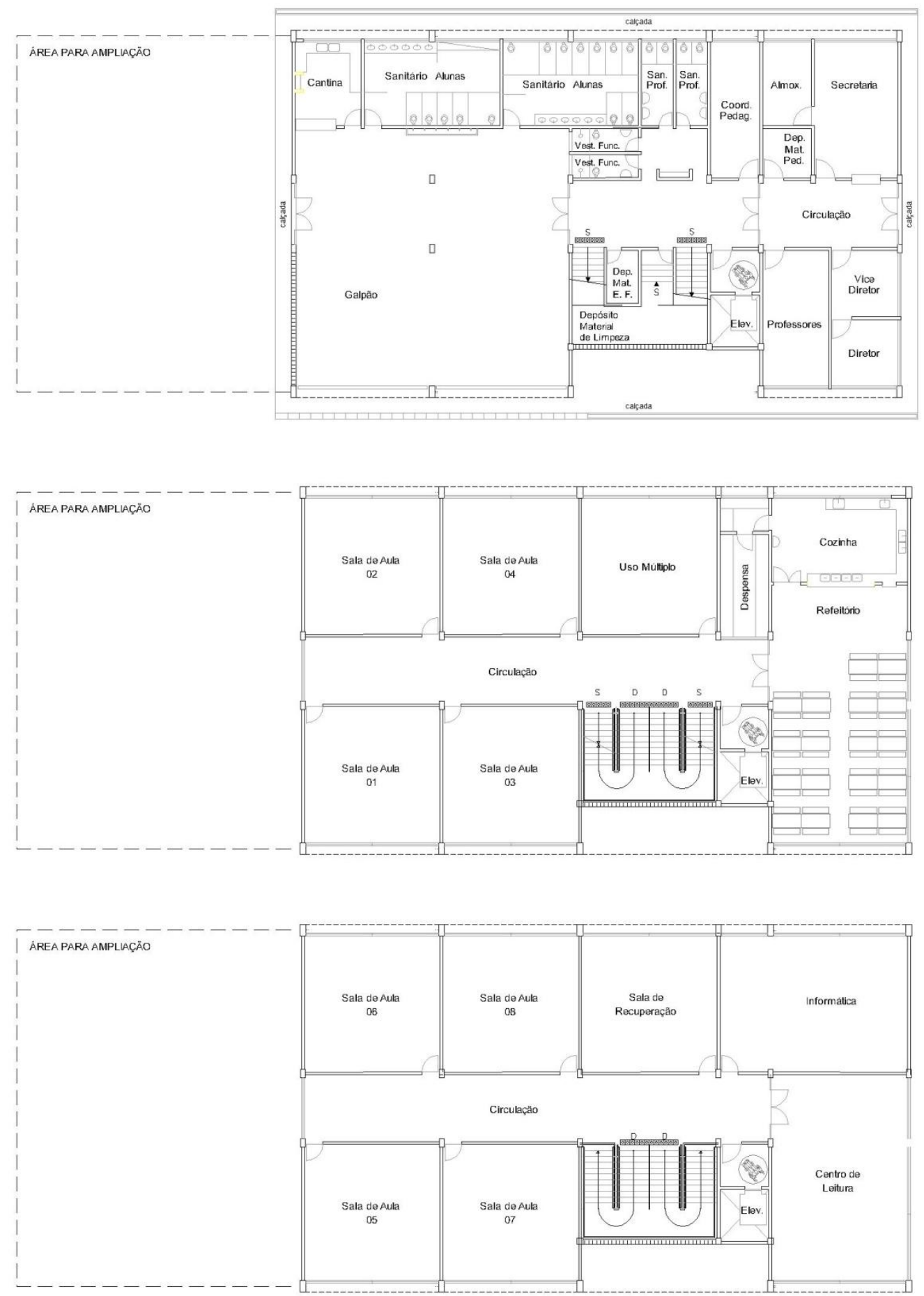

Figura 24: Escola tipo 4 - Pavimento térreo, 10 pavimento e 2o pavimento

Analisando as plantas das figuras $21,22,23$ e 24, observamos que todas as plantas possuem as salas a serem analisadas nas simulações.

Optou-se pela planta da figura 23 por ser a mais complexa em relação à tipologia de ambientes. 


\section{SIMULAÇÕES}

As simulações foram realizadas em duas etapas. A primeira etapa foi para a escolha do sistema de iluminação mais eficiente. E a segunda etapa, foi feita a simulação do edifício todo para verificação dos índices de iluminação artificial no projeto do escritório e escola.

\subsection{Escritório}

Para o escritório, dividiu-se a planta em 3 (três) salas base: staff, sala individual e sala de reuniões. Os ambientes escolhidos estão assinalados na figura 25 abaixo:

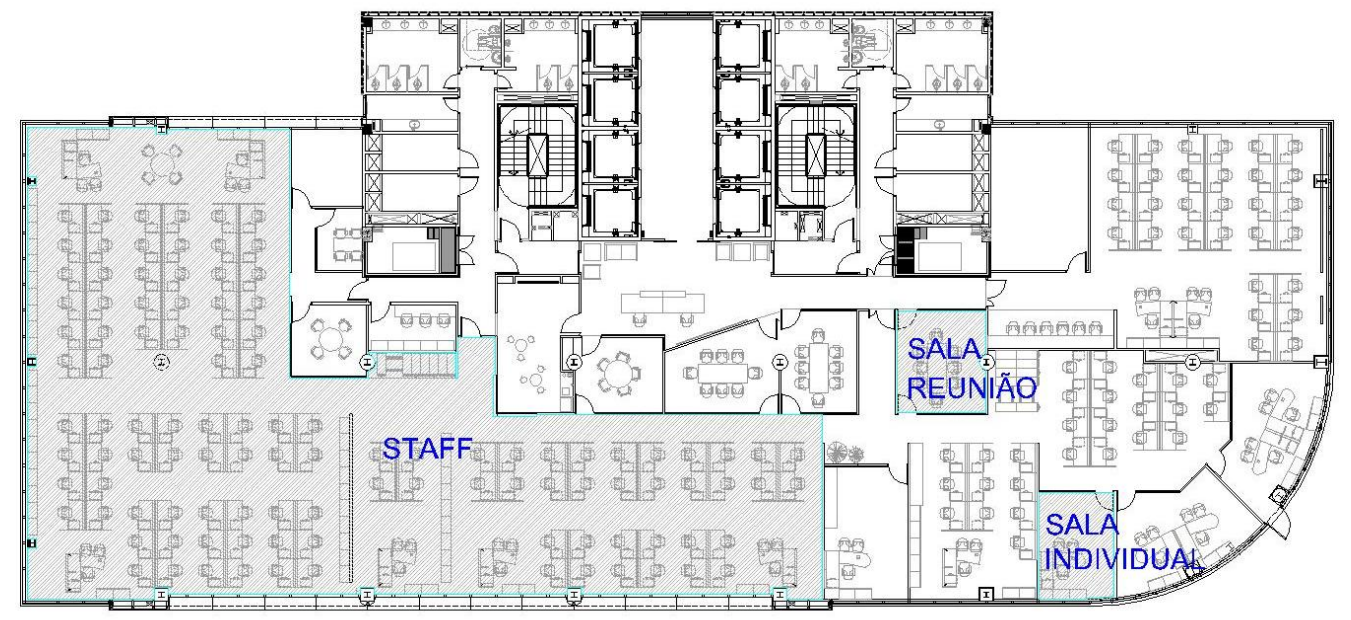

Figura 25: Ambientes simulados no escritório

\subsubsection{Simulação 10 Etapa}




\subsubsection{Staff}

Para o staff, foram realizadas simulações com dois tipos de forro, forro em gesso liso e forro modulado de $625 \times 625 \mathrm{~mm}$.

$\mathrm{Na}$ simulação do staff foram utilizadas 3 tipos de sistemas de iluminação utilizando lâmpada fluorescente tubular ou fluorescente compacta ou LED. O layout da área de staff é o mostrado na figura 26.

Foram escolhidas inicialmente as luminárias mais comercializadas de cada fabricante, e que tivessem além de um bom rendimento, proporcionassem um bom conforto visual.

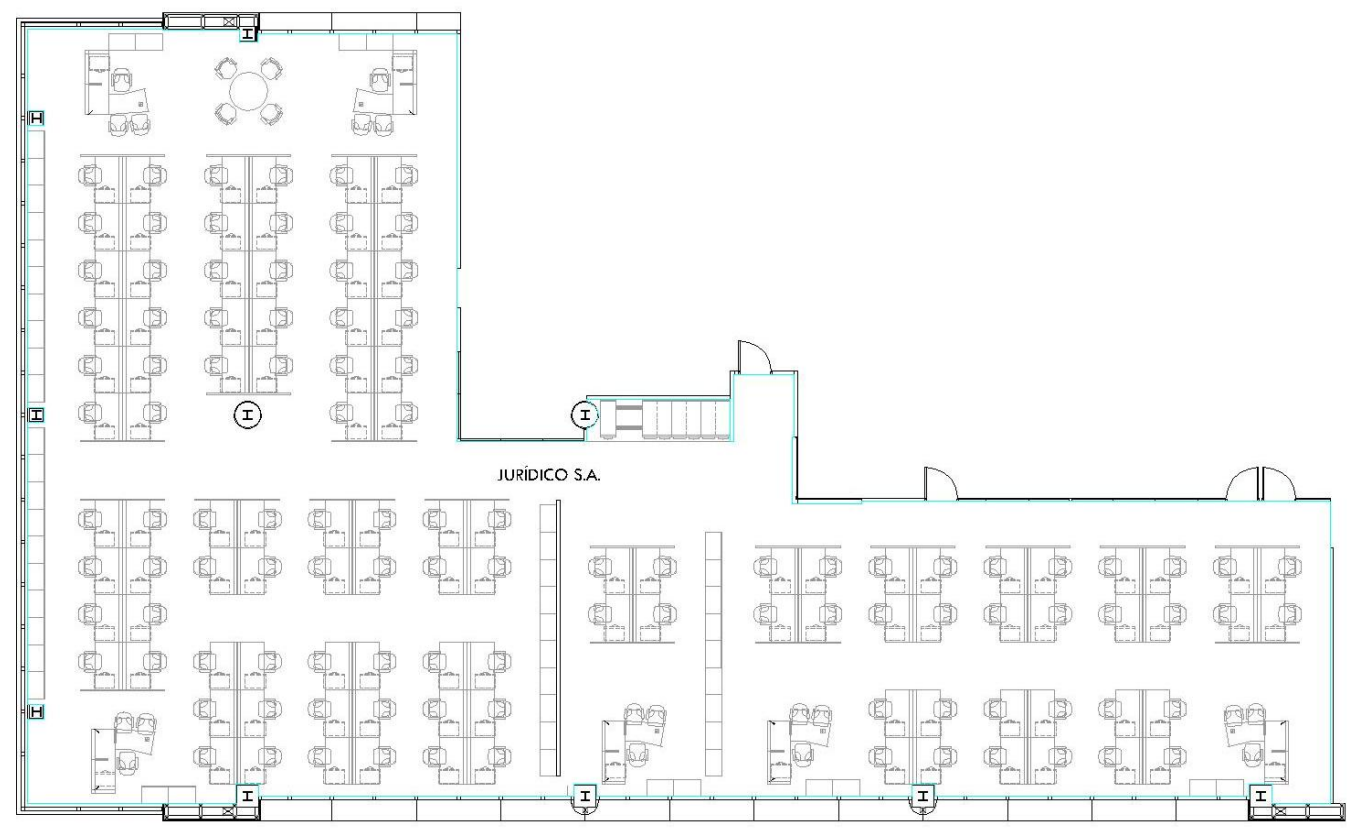

Figura 26: Área staff a ser simulada

A seguir, temos a tabela utilizada para escolha dos sistemas de iluminação mais eficiente. No primeiro caso, as luminárias escolhidas são quadradas, com opção para forro modulado e forro liso, com aletas parabólicas, refletor em alumínio anodizado, para 3 ou 4 lâmpadas fluorescente tubular de 14W.

Nos anexos, pode-se ver a ficha técnica de cada luminária escolhida para simulações. As fichas técnicas são as fornecidas por cada fabricante. 
Tabela 19: Tabela simulação sistema de iluminação nacional com lâmpada fluorescente tubular - forro gesso liso

\begin{tabular}{|c|c|c|c|c|c|c|c|c|}
\hline Fabricante & Código peça & $\begin{array}{l}\text { Qtde } \\
\text { pças }\end{array}$ & $\begin{array}{c}\text { Eméd } \\
(\text { Ix) }\end{array}$ & $\begin{array}{c}\text { Emín } \\
\text { (Ix) }\end{array}$ & $\begin{array}{c}\text { Emáx } \\
\text { (Ix) }\end{array}$ & $\begin{array}{l}\text { Potência } \\
\text { conj (W) }\end{array}$ & $\begin{array}{l}\text { Potência } \\
\text { total (W) }\end{array}$ & $\begin{array}{c}\text { Tipo/ } \\
\text { Anexo } \\
\text { Iuminária }\end{array}$ \\
\hline $\begin{array}{c}\text { Itaim } \\
\text { Iluminação }\end{array}$ & $20034 \times 14 W$ & 103 & 541 & 117 & 661 & 61,20 & 6303,6 & 1 \\
\hline $\begin{array}{c}\text { Itaim } \\
\text { Iluminação }\end{array}$ & $20564 \times 14 W$ & 121 & 515 & 139 & 599 & 61,20 & 7405,2 & 2 \\
\hline $\begin{array}{c}\text { Itaim } \\
\text { Iluminação }\end{array}$ & $23454 \times 14 W$ & 103 & 556 & 112 & 719 & 61,20 & 6303,6 & 3 \\
\hline $\begin{array}{c}\text { Itaim } \\
\text { Iluminação }\end{array}$ & $26454 \times 14 W$ & 108 & 591 & 36 & 757 & 61,20 & 6609,6 & 4 \\
\hline $\begin{array}{c}\text { Itaim } \\
\text { Iluminação }\end{array}$ & $26904 \times 14 W$ & 101 & 510 & 71 & 675 & 61,20 & 6181,2 & 5 \\
\hline $\begin{array}{c}\text { Itaim } \\
\text { Iluminação }\end{array}$ & $26914 \times 14 W$ & 90 & 522 & 70 & 704 & 61,20 & 5508,0 & 6 \\
\hline $\begin{array}{c}\text { Itaim } \\
\text { lluminação }\end{array}$ & $27454 \times 14 W$ & 97 & 594 & 133 & 733 & 61,20 & 5936,40 & 7 \\
\hline Lumini & FE-1438 4x14W & 107 & 545 & 23 & 685 & 61,20 & 6548,4 & 8 \\
\hline Lumini & FE-1594 4x14W & 131 & 519 & 18 & 722 & 61,20 & 8017,2 & 9 \\
\hline Lumini & FE-1569 4x14W & 96 & 542 & 64 & 738 & 61,20 & 5875,2 & 10 \\
\hline $\begin{array}{c}\text { Itaim } \\
\text { Iluminação }\end{array}$ & $26933 \times 14 W$ & 119 & 528 & 36 & 633 & 46 & 5474,0 & 11 \\
\hline
\end{tabular}

As simulações acima foram realizadas considerando um forro de gesso liso, alcançando o nível médio de 500 lux de acordo com a norma NBR 5413/1992. Seguem na figura 27 e 28 os resultados da simulação com os 2 sistemas de iluminação que apresentaram o menor consumo.

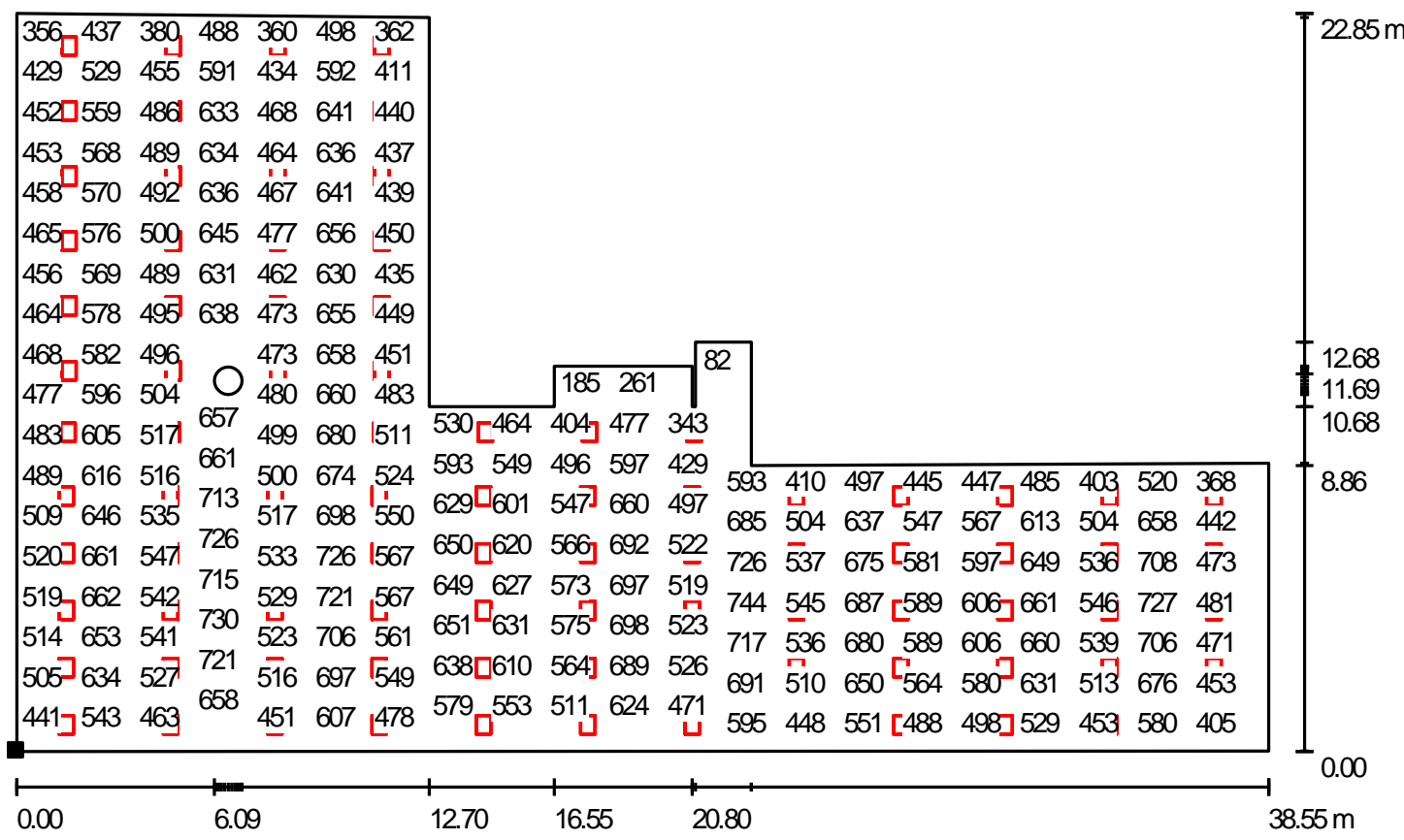

Figura 27: Simulação staff - luminária nacional tipo 6 com lâmpada fluorescente tubular para forro de gesso liso (Arquivo: ET-ST-FT-BR-1-MX.dlx) 


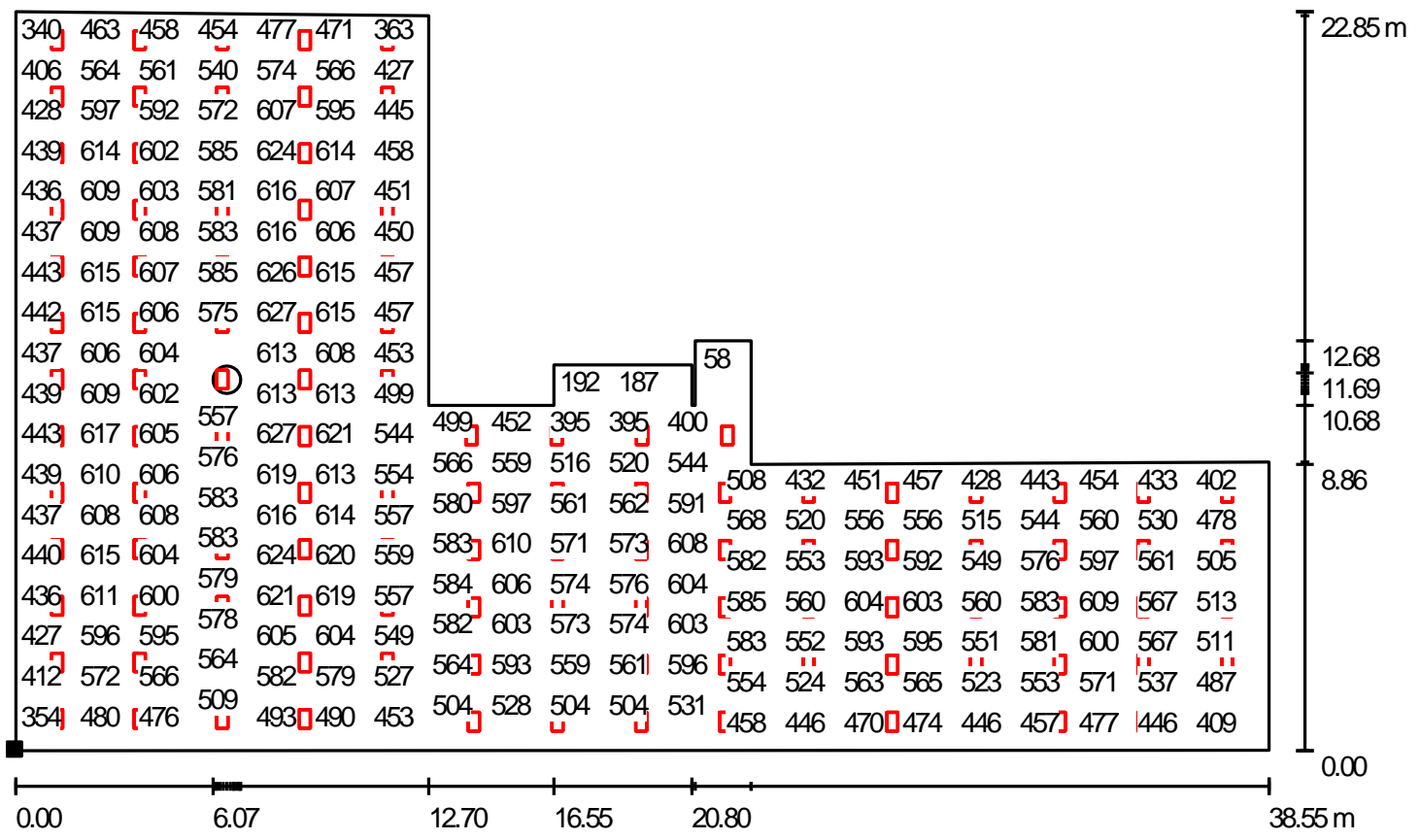

Figura 28: Simulação staff - luminária nacional tipo 11 com lâmpada fluorescente tubular para forro de gesso liso (Arquivo: ET-ST-FT-BR-2-MX.dlx)

Para simulação do forro modulado, foram utilizadas as mesmas luminárias eficientes encontradas na Tabela 19. Fazendo a simulação, obtiveram-se os seguintes valores:

Tabela 20: Tabela simulação sistema de iluminação nacional com lâmpada fluorescente tubular - forro modulado

\begin{tabular}{|c|c|c|c|c|c|c|c|c|}
\hline Fabricante & Código peça & $\begin{array}{c}\text { Qtde } \\
\text { pças }\end{array}$ & $\begin{array}{c}\text { Eméd } \\
(\mathrm{Ix})\end{array}$ & $\begin{array}{c}\text { Emín } \\
(\mathrm{Ix})\end{array}$ & $\begin{array}{c}\text { Emáx } \\
(\mathrm{Ix})\end{array}$ & $\begin{array}{c}\text { Potência } \\
\text { conj (W) }\end{array}$ & $\begin{array}{c}\text { Potência } \\
\text { total (W) }\end{array}$ & $\begin{array}{c}\text { Tipo/ } \\
\text { Anexo } \\
\text { luminária }\end{array}$ \\
\hline $\begin{array}{c}\text { Itaim } \\
\text { Iluminação }\end{array}$ & $26914 \times 14 W$ & 94 & 566 & 28 & 842 & 61,20 & 5752,8 & 6 \\
\hline $\begin{array}{c}\text { Itaim } \\
\text { Iluminação }\end{array}$ & $26933 \times 14 W$ & 140 & 633 & 25 & 779 & 46 & 6440,0 & 11 \\
\hline
\end{tabular}

Comparando os resultados da Tabela 19 e da Tabela 20, observa-se que a quantidade de peças aumentou nas duas situações. Logo, o consumo energético em iluminação artificial, será maior onde temos forro modulado.

Apesar da maioria dos escritórios, optar por utilizar o forro modulado para facilidades de manutenção, recomenda-se o uso de forro de gesso liso, pois assim, teremos um melhor desempenho no que diz respeito aos indicadores de iluminação. Deste modo, para as próximas simulações, não consideraremos mais o forro modulado. 


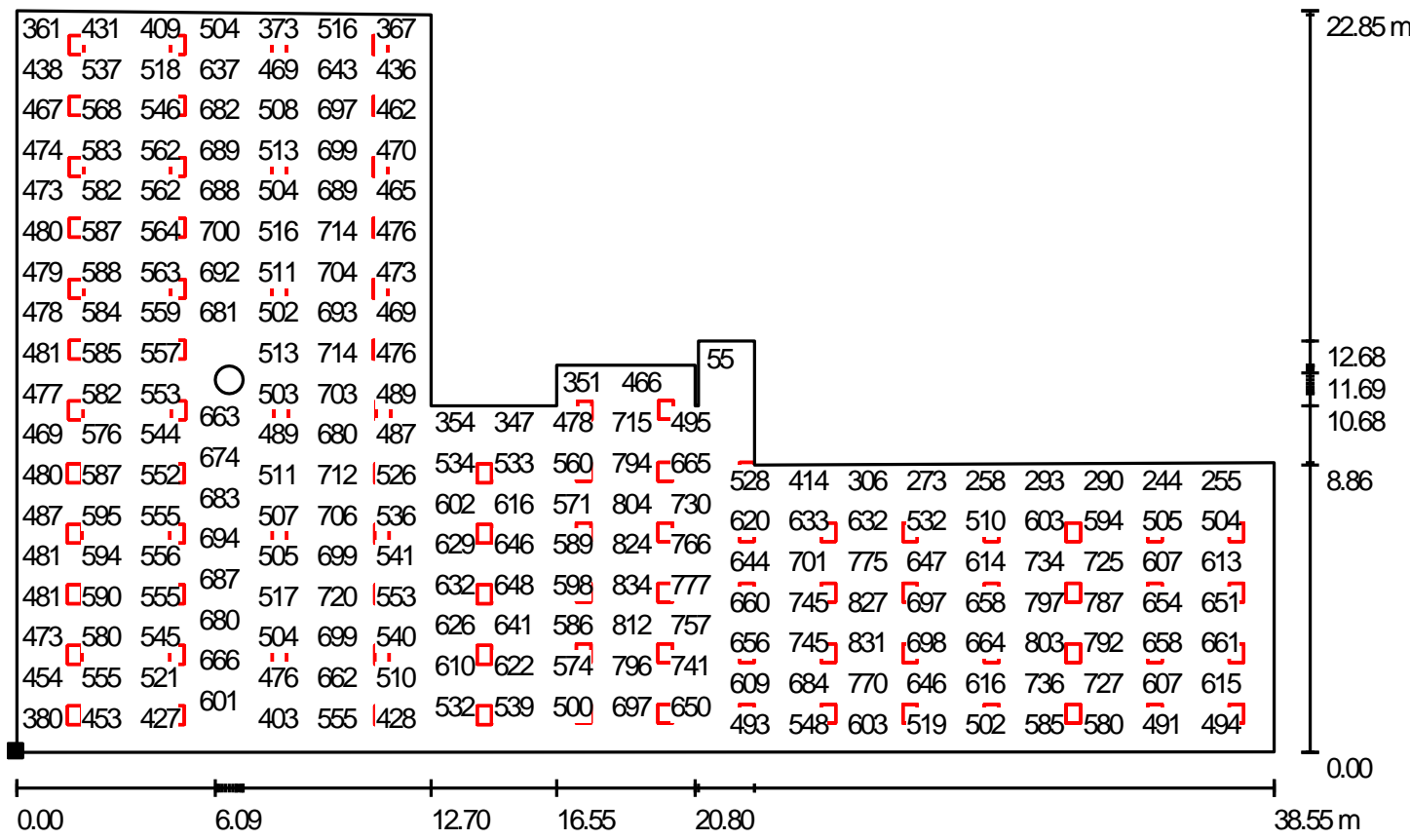

Figura 29: Simulação staff - luminária nacional tipo 6 com lâmpada fluorescente tubular para forro modulado (Arquivo: ET-ST-FT-BR-5-MX.dlx)

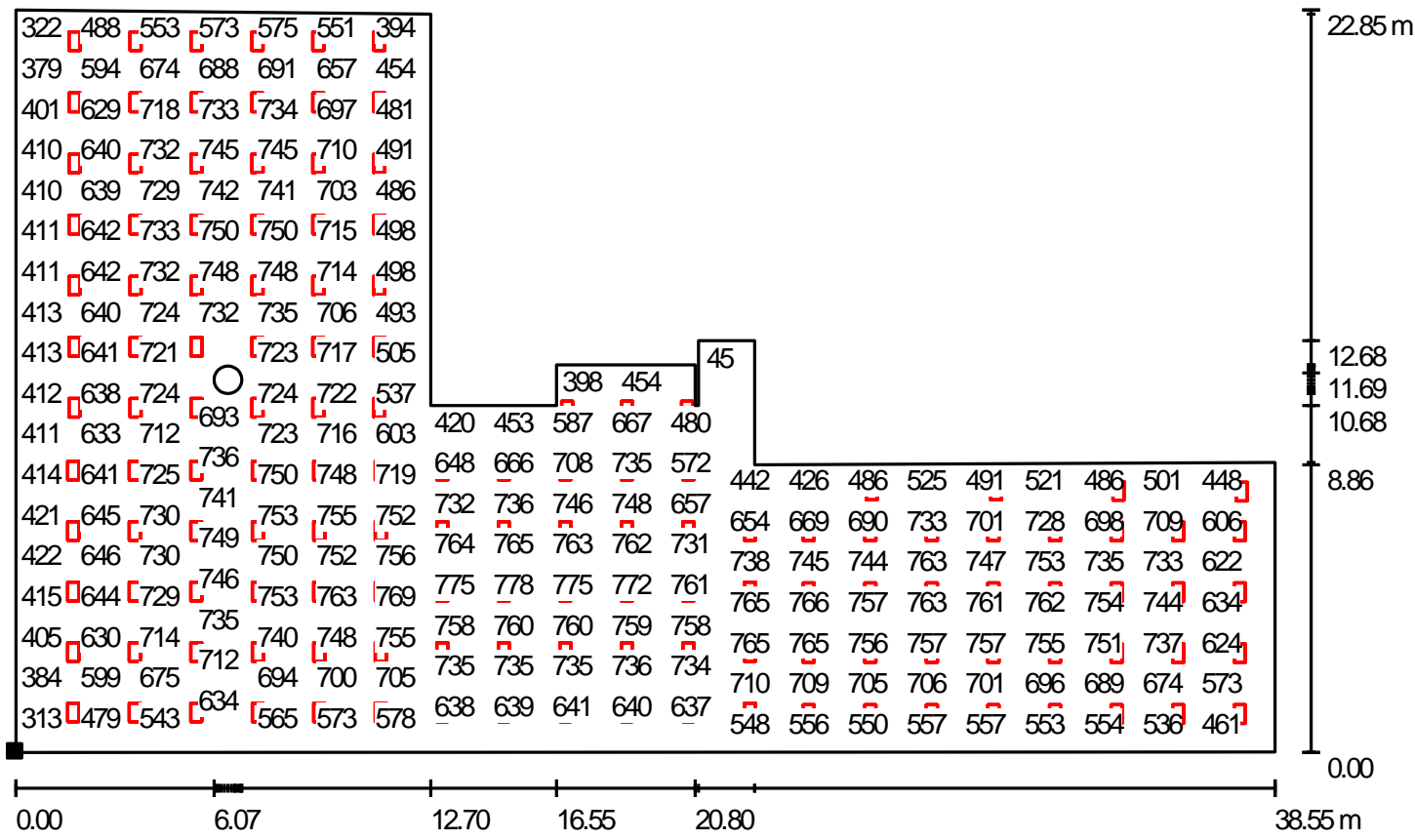

Figura 30: Simulação staff - luminária nacional tipo 11 com lâmpada fluorescente tubular para forro modulado (Arquivo: ET-ST-FT-BR-6-MX.dlx)

Comparando as figuras 29 e $30 \mathrm{com}$ as figuras 27 e 28 , respectivamente, observa-se que o nível de iluminação ponto a ponto aumenta devido ao aumento de luminárias. 
Do mesmo modo que foi realizada a simulação para luminárias nacionais, foi feita com luminárias comercializadas no exterior.

Tabela 21: Tabela simulação sistema de iluminação importado com lâmpada fluorescente tubular - forro de gesso liso

\begin{tabular}{|c|c|c|c|c|c|c|c|c|}
\hline Fabricante & Código peça & $\begin{array}{c}\text { Qtde } \\
\text { pças }\end{array}$ & $\begin{array}{c}\text { Eméd } \\
(\mathbf{I x})\end{array}$ & $\begin{array}{c}\text { Emín } \\
\mathbf{( I x )}\end{array}$ & $\begin{array}{c}\text { Emáx } \\
(\mathbf{I x})\end{array}$ & $\begin{array}{c}\text { Potência } \\
\text { conj (W) }\end{array}$ & $\begin{array}{c}\text { Potência } \\
\text { total (W) }\end{array}$ & $\begin{array}{c}\text { Tipo/ } \\
\text { Anexo } \\
\text { luminária }\end{array}$ \\
\hline Zumtobel & $\begin{array}{c}\text { MIREL2-42176166 } \\
\mathbf{3 x 1 4 W}\end{array}$ & $\mathbf{1 0 8}$ & $\mathbf{5 3 3}$ & $\mathbf{1 4}$ & $\mathbf{6 5 3}$ & $\mathbf{4 6}$ & $\mathbf{4 9 6 8 , 0}$ & $\mathbf{1 2}$ \\
\hline Zumtobel & $\begin{array}{c}\text { MIREL2 -42176184 } \\
\mathbf{4 x 1 4 W}\end{array}$ & $\mathbf{8 0}$ & $\mathbf{5 5 4}$ & $\mathbf{7 0}$ & $\mathbf{7 3 6}$ & $\mathbf{6 1 , 2 0}$ & $\mathbf{4 8 9 6 , 0}$ & $\mathbf{1 3}$ \\
\hline Zumtobel & $\begin{array}{c}\text { MIREL2 }-42176099 \\
\mathbf{3 x 1 4 W}\end{array}$ & 121 & 529 & 113 & 624 & 46 & 5566,0 & 14 \\
\hline Zumtobel & $\begin{array}{c}\text { MIREL2 }-42176115 \\
\mathbf{4 x 1 4 W}\end{array}$ & 96 & 568 & 19 & 732 & 61,20 & 5875,2 & 15 \\
\hline
\end{tabular}

Tabela 22: Tabela simulação sistema de iluminação importado com lâmpada fluorescente tubular - forro de gesso modulado

\begin{tabular}{|c|c|c|c|c|c|c|c|c|}
\hline Fabricante & Código peça & $\begin{array}{c}\text { Qtde } \\
\text { pças }\end{array}$ & $\begin{array}{c}\text { Eméd } \\
(\mathrm{Ix})\end{array}$ & $\begin{array}{c}\text { Emín } \\
(\mathrm{Ix})\end{array}$ & $\begin{array}{c}\text { Emáx } \\
(\mathrm{Ix})\end{array}$ & $\begin{array}{c}\text { Potência } \\
\text { conj (W) }\end{array}$ & $\begin{array}{c}\text { Potência } \\
\text { total (W) }\end{array}$ & $\begin{array}{c}\text { Tipo/ } \\
\text { Anexo } \\
\text { luminária }\end{array}$ \\
\hline Zumtobel & $\begin{array}{c}\text { MIREL2 }-42176166 \\
3 \times 14 W\end{array}$ & 119 & 594 & 24 & 769 & 46 & 5474,0 & 12 \\
\hline Zumtobel & $\begin{array}{c}M I R E L 2-42176184 \\
4 \times 14 W\end{array}$ & 96 & 660 & 61 & 959 & 61,20 & 5875,2 & 13 \\
\hline
\end{tabular}

Comparando as Tabelas 21 e 22, utilizando a mesma luminária eficiente para lâmpada fluorescente tubular, nota-se que há um aumento no número de luminárias para uso em forro modulado, assim como ocorreu na simulação da luminária nacional.

O aumento de peças varia de $5 \%$ até $20 \%$ a mais em forro modulado, dependendo do tipo de luminária. Esse valor pode prejudicar a obtenção da certificação e/ou selo de sustentabilidade.

As figuras 31, 32, 33 e 34 mostram o nível ponto a ponto das simulações realizadas com as luminárias importadas. 


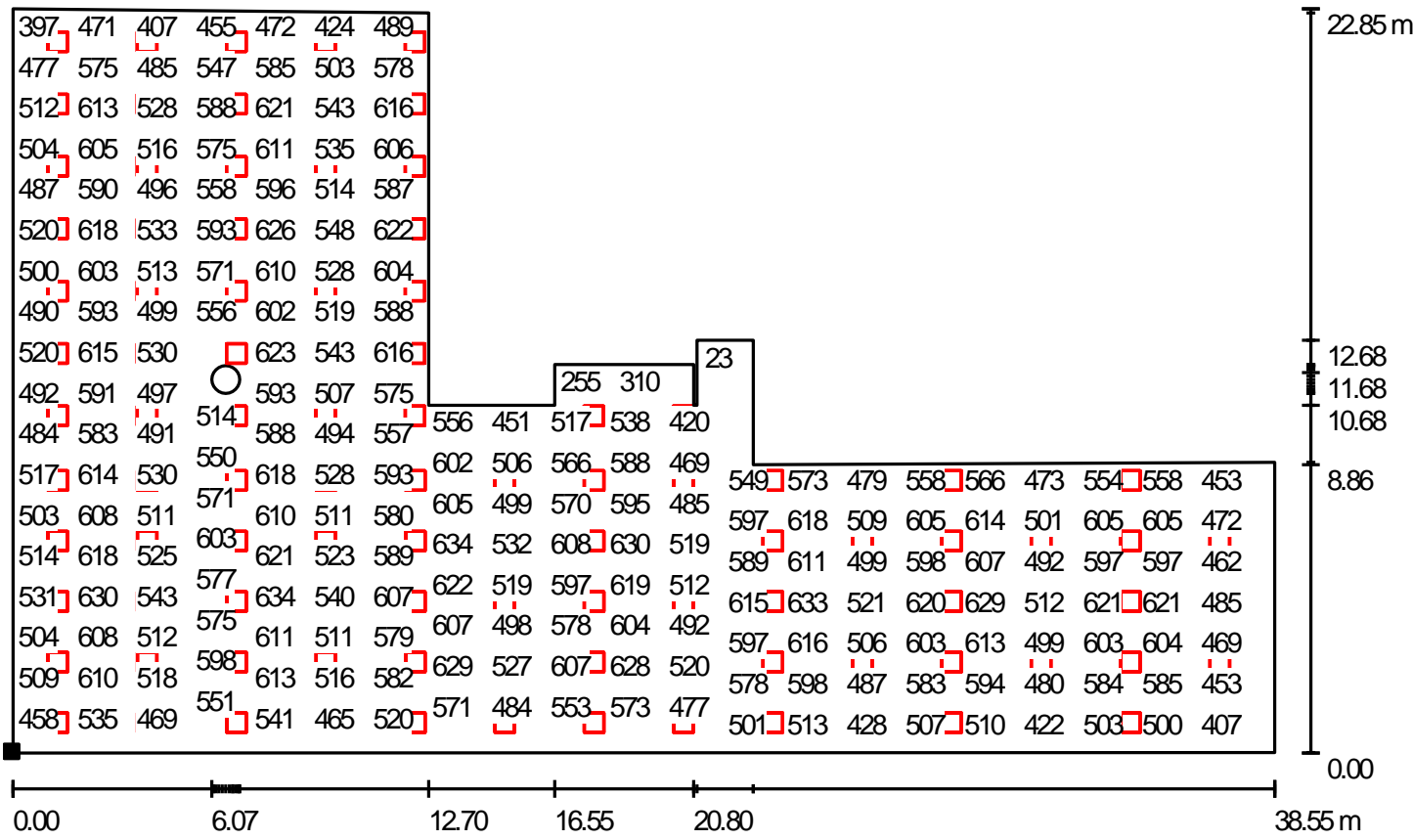

Figura 31: Simulação staff - luminária importada tipo 12 com lâmpada fluorescente tubular para forro em gesso liso (Arquivo: ET-ST-FT-EX-3-MX.dlx)

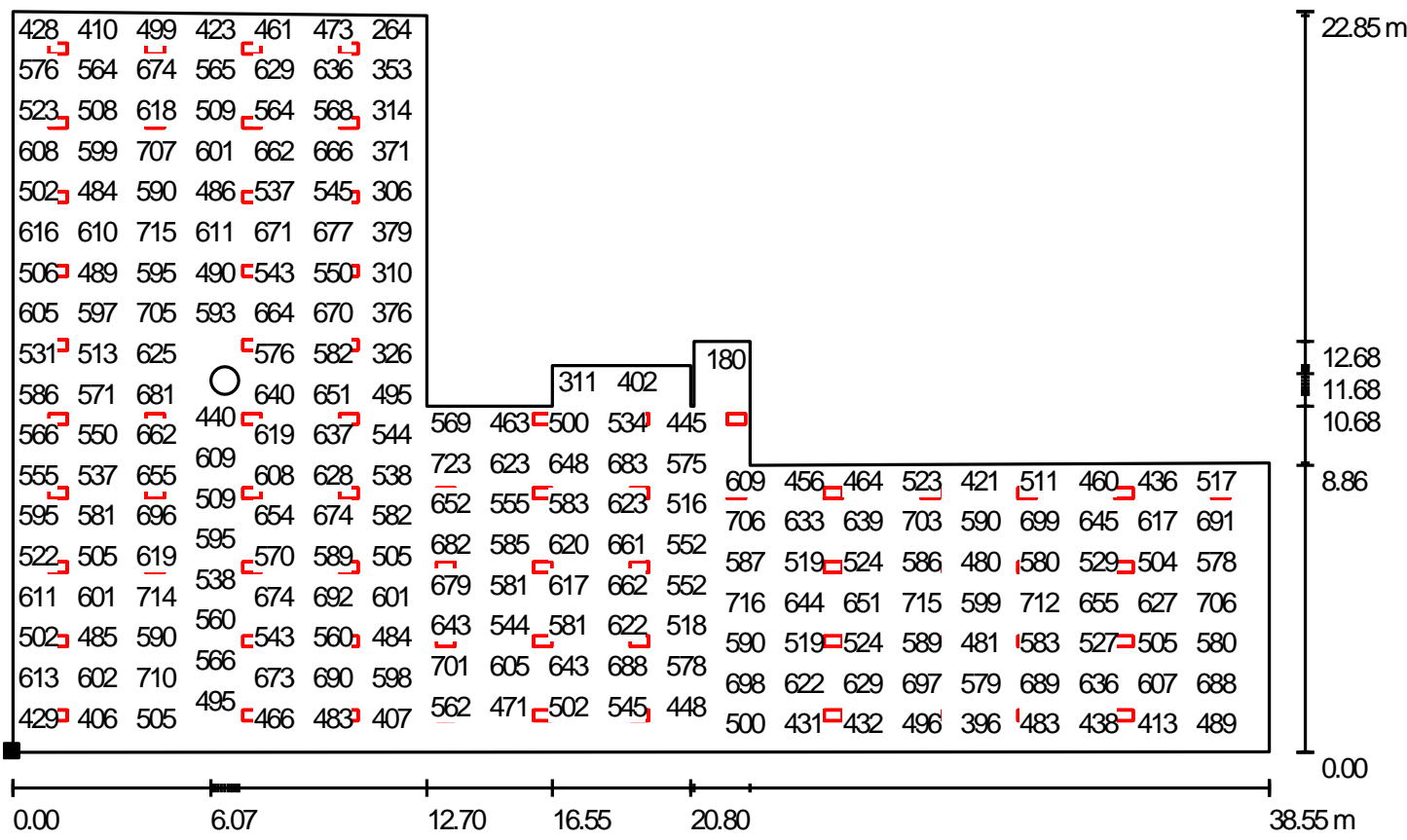

Figura 32: Simulação staff - luminária importada tipo 13 com lâmpada fluorescente tubular para forro em gesso liso (Arquivo: ET-ST-FT-EX-4-MX.dlx) 


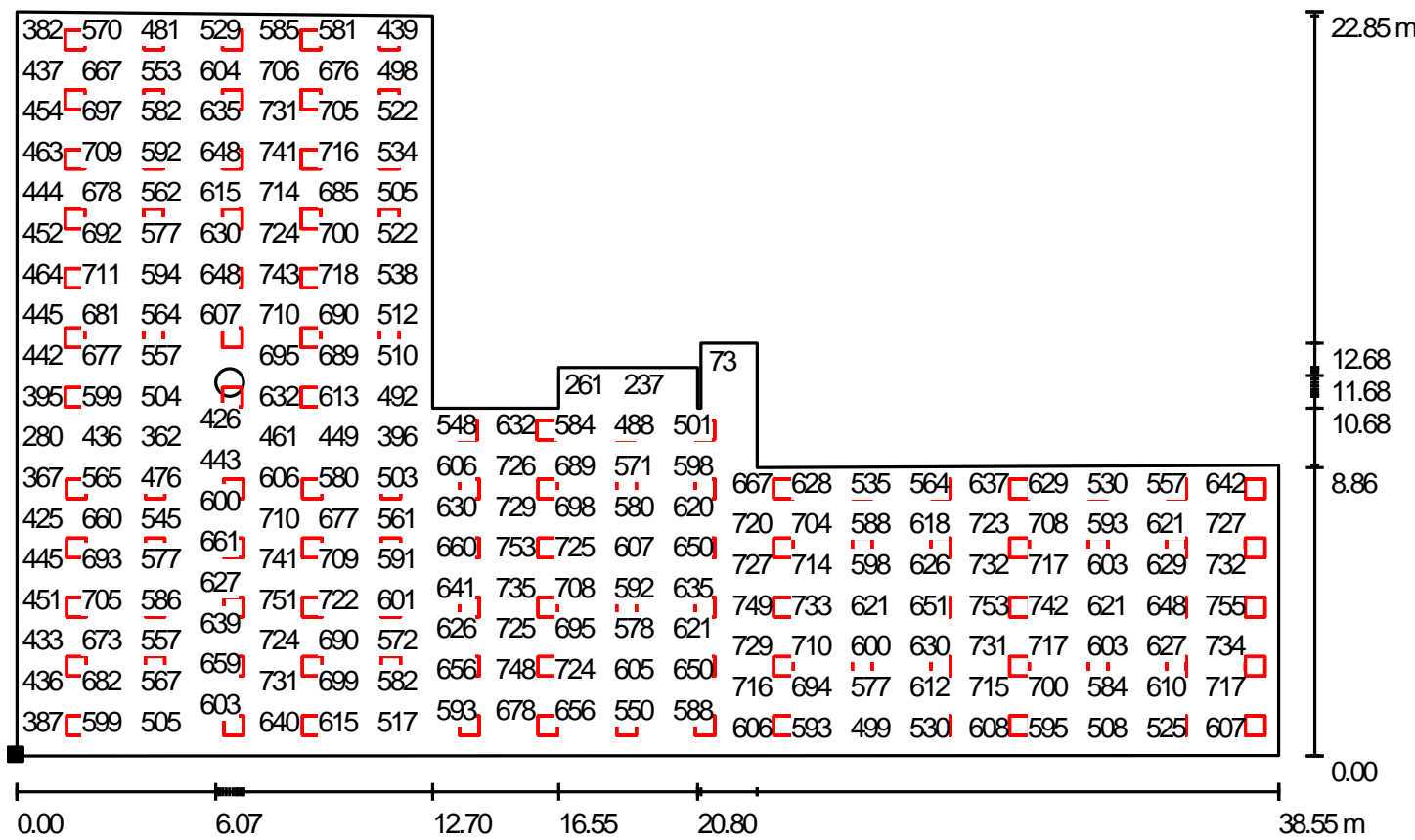

Figura 33: Simulação staff - luminária importada tipo 12 com lâmpada fluorescente tubular para forro modulado (Arquivo: ET-ST-FT-EX-7-MX.dlx)

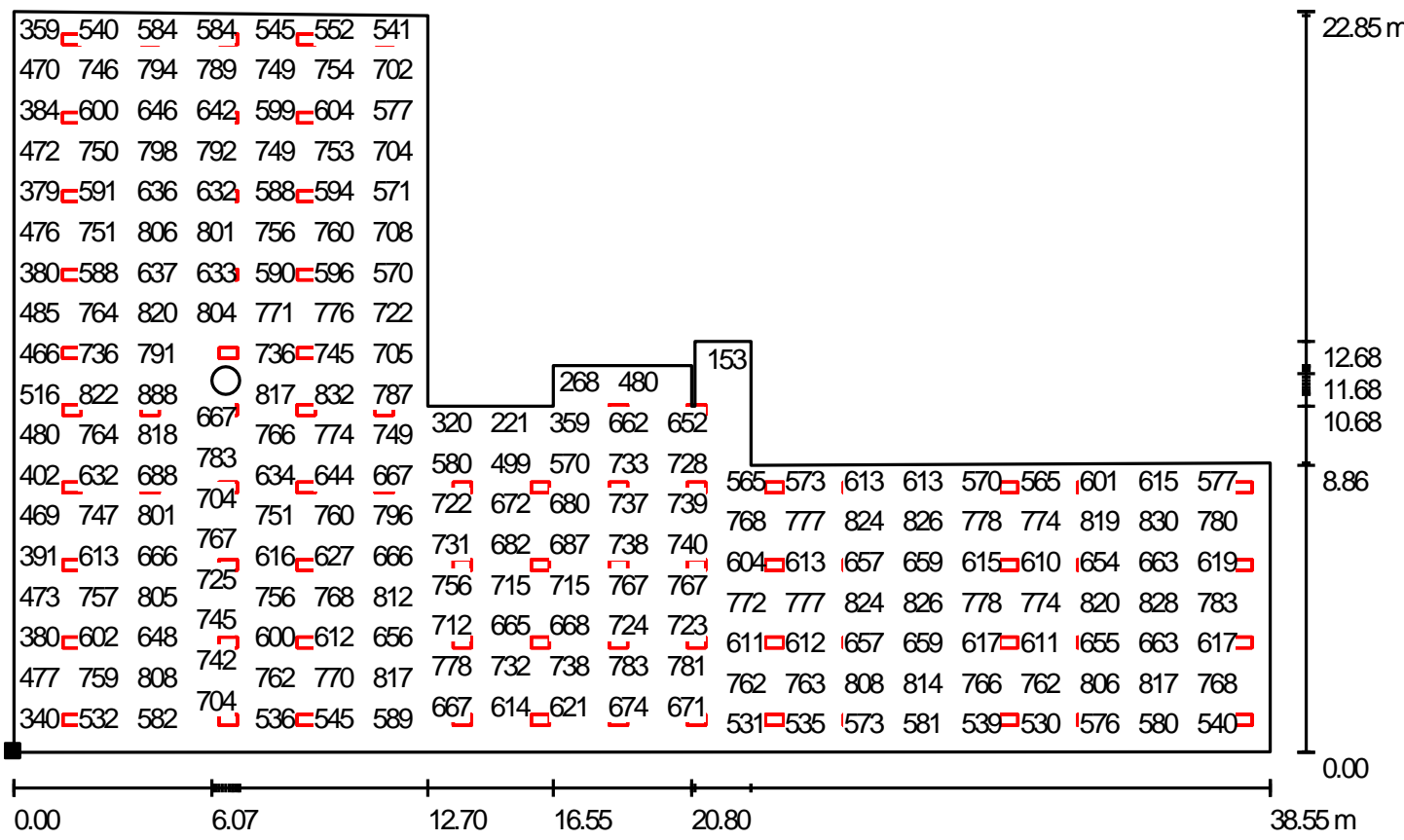

Figura 34: Simulação staff - luminária importada tipo 13 com lâmpada fluorescente tubular para forro modulado (Arquivo: ET-ST-FT-EX-8-MX.dlx) 
A segunda parte da simulação do staff foi utilizada sistemas de iluminação para lâmpadas fluorescentes compactas com reator não integrado. Utilizamos tanto luminárias redondas como quadradas para verificar o desempenho da peça.

Tabela 23: Tabela simulação sistema de iluminação nacional com lâmpada fluorescente compacta

\begin{tabular}{|c|c|c|c|c|c|c|c|c|}
\hline Fabricante & Código peça & $\begin{array}{l}\text { Qtde } \\
\text { pças }\end{array}$ & $\begin{array}{c}\text { Eméd } \\
(\mathrm{Ix})\end{array}$ & $\begin{array}{c}\text { Emín } \\
\text { (Ix) }\end{array}$ & $\begin{array}{c}\text { Emáx } \\
\text { (Ix) }\end{array}$ & $\begin{array}{l}\text { Potência } \\
\text { conj (W) }\end{array}$ & $\begin{array}{l}\text { Potência } \\
\text { total (W) }\end{array}$ & $\begin{array}{c}\text { Tipo/ } \\
\text { Anexo } \\
\text { Iuminária }\end{array}$ \\
\hline $\begin{array}{c}\text { Itaim } \\
\text { Iluminação }\end{array}$ & 2056 2x36W & 131 & 496 & 20 & 638 & 69,00 & 9039,0 & 16 \\
\hline $\begin{array}{c}\text { Itaim } \\
\text { Iluminação }\end{array}$ & Dravita 2x26W & 244 & 520 & 81 & 652 & 56,00 & 13664,0 & 17 \\
\hline $\begin{array}{c}\text { Itaim } \\
\text { Iluminação }\end{array}$ & Diamante 2x26W & 177 & 537 & 116 & 701 & 56,00 & 9912,0 & 18 \\
\hline $\begin{array}{c}\text { Itaim } \\
\text { Iluminação }\end{array}$ & Iolita 2x26W & 201 & 522 & 93 & 599 & 56,00 & 11256,0 & 19 \\
\hline $\begin{array}{c}\text { Itaim } \\
\text { Iluminação }\end{array}$ & Peróla & 237 & 511 & 93 & 631 & 56,00 & 13272,0 & 20 \\
\hline $\begin{array}{c}\text { Itaim } \\
\text { Iluminação }\end{array}$ & Delfos $1 \times 32 W$ & 208 & 510 & 82 & 586 & 36,00 & 7488 & 21 \\
\hline $\begin{array}{c}\text { Itaim } \\
\text { Iluminação }\end{array}$ & Delfos $2 \times 32 W$ & 122 & 525 & 171 & 610 & 69,00 & 8418,0 & 22 \\
\hline Lumini & E-4034 1x32W & 355 & 519 & 120 & 605 & 36,00 & 12780,0 & 23 \\
\hline Lumini & $E-40391 \times 32 W$ & 191 & 507 & 13 & 597 & 36,00 & 6876,0 & 24 \\
\hline Lumini & E-4430-LR 1x32W & 300 & 514 & 26 & 615 & 36,00 & 10800,0 & 25 \\
\hline $\begin{array}{c}\text { Itaim } \\
\text { Iluminação }\end{array}$ & Delfos $1 \times 42 W$ & 168 & 528 & 133 & 607 & 47,00 & 7488,0 & 26 \\
\hline $\begin{array}{c}\text { Itaim } \\
\text { Iluminação }\end{array}$ & Delfos 2x42W & 96 & 548 & 26 & 702 & 90,00 & 8640,0 & 27 \\
\hline Lumini & E-4039 1x42W & 147 & 542 & 101 & 670 & 47,00 & 6909,0 & 28 \\
\hline
\end{tabular}

$\mathrm{Na}$ Tabela 23, observa-se que as luminárias em negrito possuem o menor consumo. A luminária tipo 21 é uma luminária redonda, com aletas parabólicas e refletor em alumínio anodizado, enquanto a do tipo 24 é uma luminária redonda, sem aletas, com refletor em alumínio anodizado. Apesar da última não possuir um controle de ofuscamento através de aletas, segundo fabricante, o controle é obtido através do próprio desenho do refletor e recuo da fonte luminosa.

Nas figuras 35 e 36, temos a distribuição ponto a ponto com as luminárias acima descritas. Observa-se que os valores estão bem próximos. 


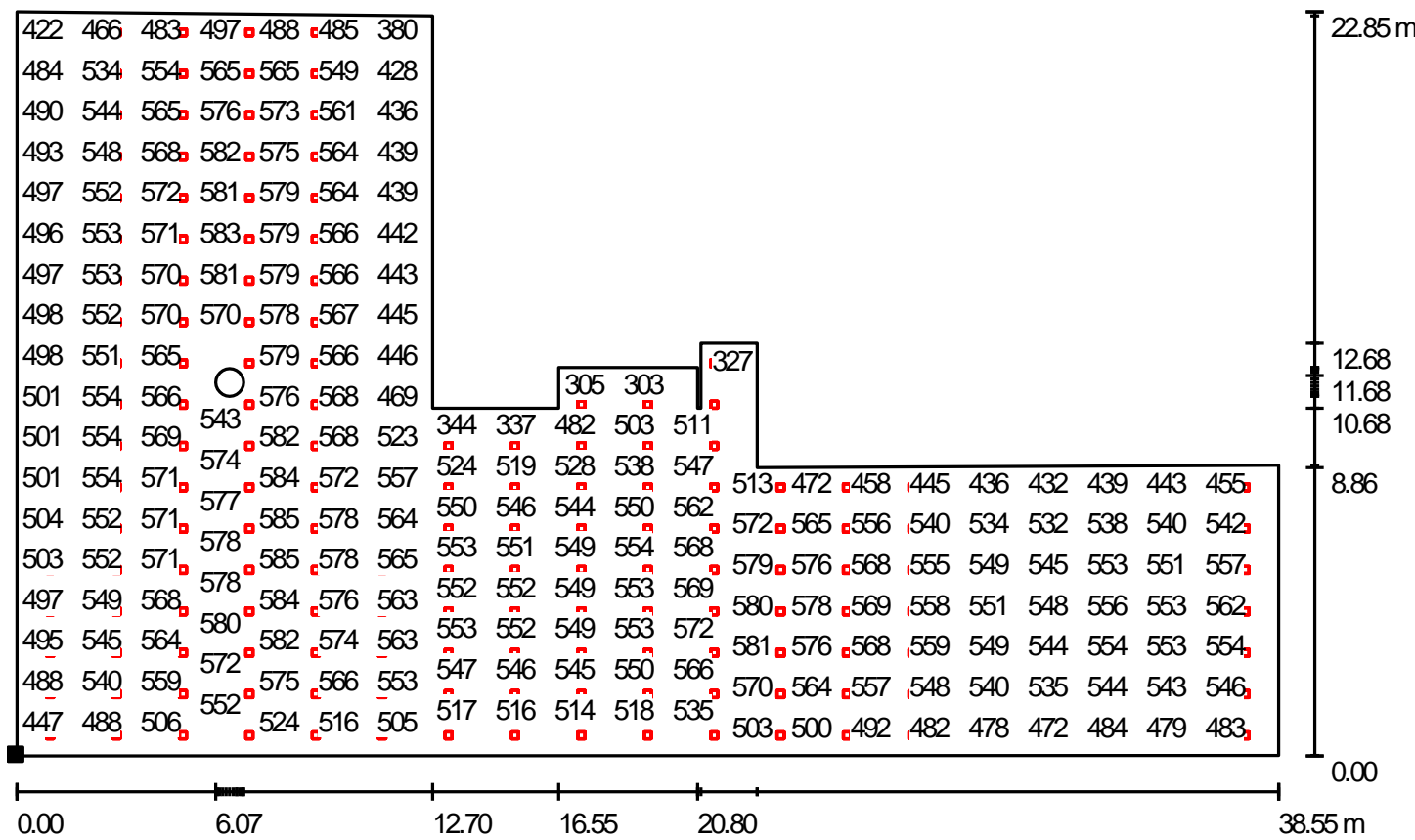

Figura 35: Simulação staff - luminária nacional tipo 21 para fluorescente compacta (Arquivo: ET-ST-FCBR-1-MX.dlx)

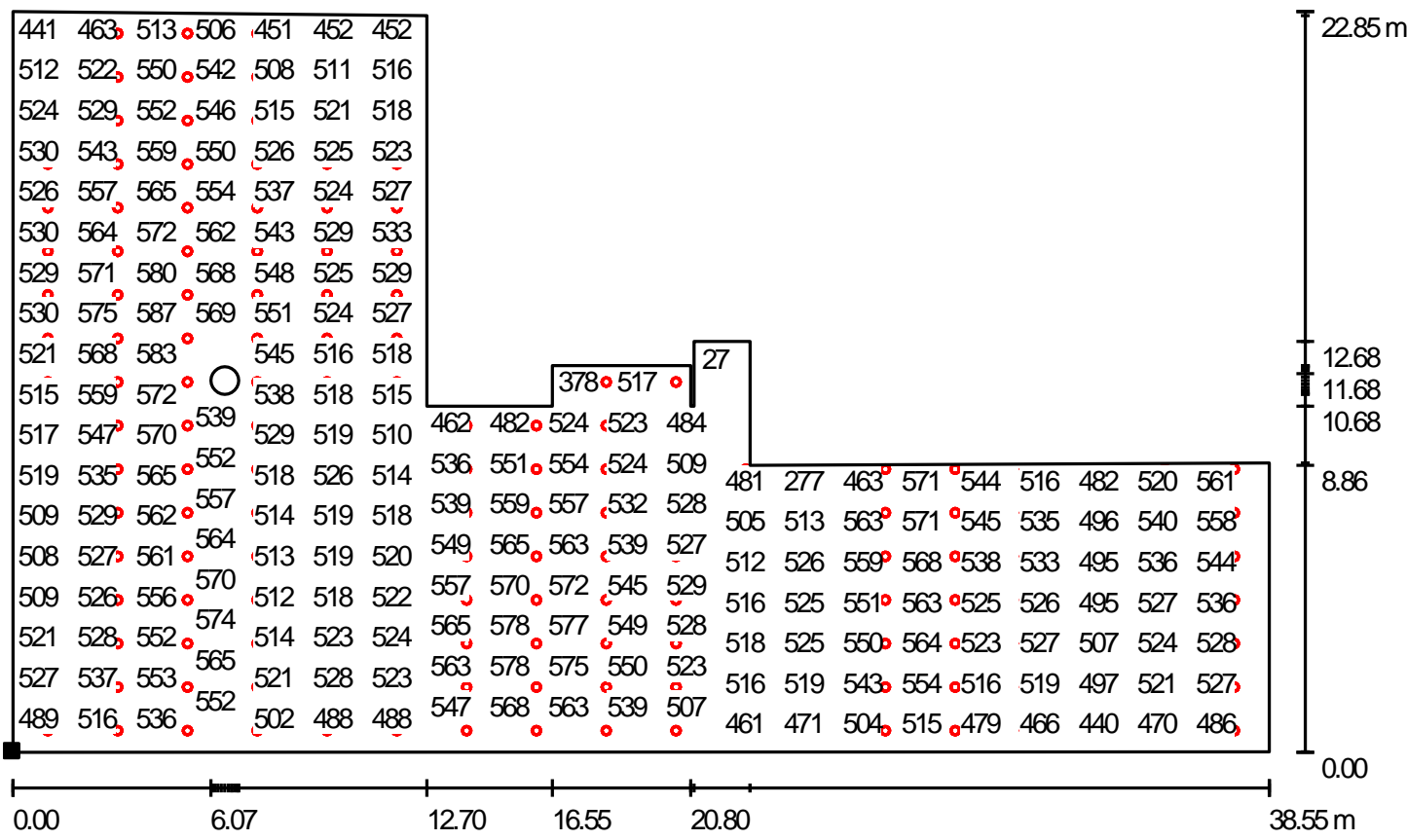

Figura 36: Simulação staff - luminária nacional tipo 24 para fluorescente compacta (Arquivo: ET-ST-FCBR-2-MX.dlx) 
Conforme foram feitas as simulações, para a escolha das próximas luminárias, já foram descartadas certas tipologias de sistemas de iluminação, então, o número que peças que serão utilizadas para próximas simulações tendem a diminuir.

As luminárias da Tabela 24 são quadradas, com refletor em alumínio anodizado e controle de ofuscamento no próprio desenho do refletor. Ambas as luminárias escolhidas são para fluorescente compacta tripla de $32 \mathrm{~W}$. As luminárias do tipo 33 e 40 são as que apresentaram menor consumo, com nível médio de 500 lux no staff.

Tabela 24: Tabela simulação sistema de iluminação importados com lâmpada fluorescente compacta

\begin{tabular}{|c|c|c|c|c|c|c|c|c|}
\hline Fabricante & Código peça & $\begin{array}{c}\text { Qtde } \\
\text { pças }\end{array}$ & $\begin{array}{c}\text { Eméd } \\
\mathbf{( I x )}\end{array}$ & $\begin{array}{c}\text { Emín } \\
\mathbf{( I x )}\end{array}$ & $\begin{array}{c}\text { Emáx } \\
\mathbf{( I x )}\end{array}$ & $\begin{array}{c}\text { Potência } \\
\text { conj (W) }\end{array}$ & $\begin{array}{c}\text { Potência } \\
\text { total (W) }\end{array}$ & $\begin{array}{c}\text { Tipo/ } \\
\text { Anexo } \\
\text { luminária }\end{array}$ \\
\hline Erco & $47618.0001 \times 32 W$ & 208 & 518 & 75 & 641 & 36,00 & 7488,0 & 29 \\
\hline Erco & $47616.0002 \times 32 W$ & 129 & 536 & 113 & 654 & 69,00 & 8901,0 & 30 \\
\hline Erco & $47619.0001 \times 32 W$ & 201 & 524 & 81 & 663 & 36,00 & 7236,0 & 31 \\
\hline Erco & $47617.0002 \times 32 W$ & 122 & 544 & 172 & 663 & 69,00 & 8418,0 & 32 \\
\hline Erco & $\mathbf{3 7 6 1 8 . 0 0 0 1 \times 3 2 W}$ & $\mathbf{1 7 3}$ & $\mathbf{5 1 5}$ & $\mathbf{1 2}$ & $\mathbf{6 3 6}$ & $\mathbf{3 6 , 0 0}$ & $\mathbf{6 2 2 8 , 0}$ & $\mathbf{3 3}$ \\
\hline Erco & $37619.0001 \times 32 W$ & 173 & 527 & 13 & 679 & 36,00 & 6228,0 & 34 \\
\hline Erco & $37617.0002 \times 32 W$ & 120 & 571 & 16 & 774 & 69,00 & 8280,0 & 35 \\
\hline Erco & $37605.0001 \times 26 W$ & 309 & 513 & 19 & 625 & 29,00 & 8961,0 & 36 \\
\hline Erco & $37609.0002 \times 26 W$ & 163 & 538 & 153 & 625 & 56,00 & 9128,0 & 37 \\
\hline Zumtobel & $\begin{array}{c}\text { Panos HM 60810264 } \\
1 \times 32 W\end{array}$ & 261 & 511 & 66 & 574 & 36,00 & 9396,0 & 38 \\
\hline Zumtobel & $\begin{array}{c}\text { Panos HM 60810239 } \\
1 \times 32 W\end{array}$ & 386 & 523 & 102 & 590 & 36,00 & 13896,0 & 39 \\
\hline Zumtobel & $\begin{array}{c}\text { Panos Q 60811108 } \\
\mathbf{1 x 3 2 W}\end{array}$ & $\mathbf{1 9 4}$ & 535 & $\mathbf{1 0 5}$ & $\mathbf{6 0 0}$ & $\mathbf{3 6 , 0 0}$ & $\mathbf{6 9 8 4 , 0}$ & $\mathbf{4 0}$ \\
\hline Zumtobel & $\begin{array}{c}\text { Panos Q 60811112 } \\
1 \times 32 W\end{array}$ & 194 & 533 & 105 & 598 & 36,00 & 6984,0 & 41 \\
\hline Zumtobel & $\begin{array}{c}\text { Panos Q 60811116 } \\
1 \times 32 W\end{array}$ & 201 & 533 & 107 & 599 & 36,00 & 7236,0 & 42 \\
\hline Zumtobel & $\begin{array}{c}\text { Panos Q 60811361 } \\
1 \times 32 W\end{array}$ & 310 & 511 & 21 & 605 & 36,00 & 11160,0 & 43 \\
\hline
\end{tabular}

As figuras 37 e 38 mostram a simulação das luminárias importadas mais eficientes. 


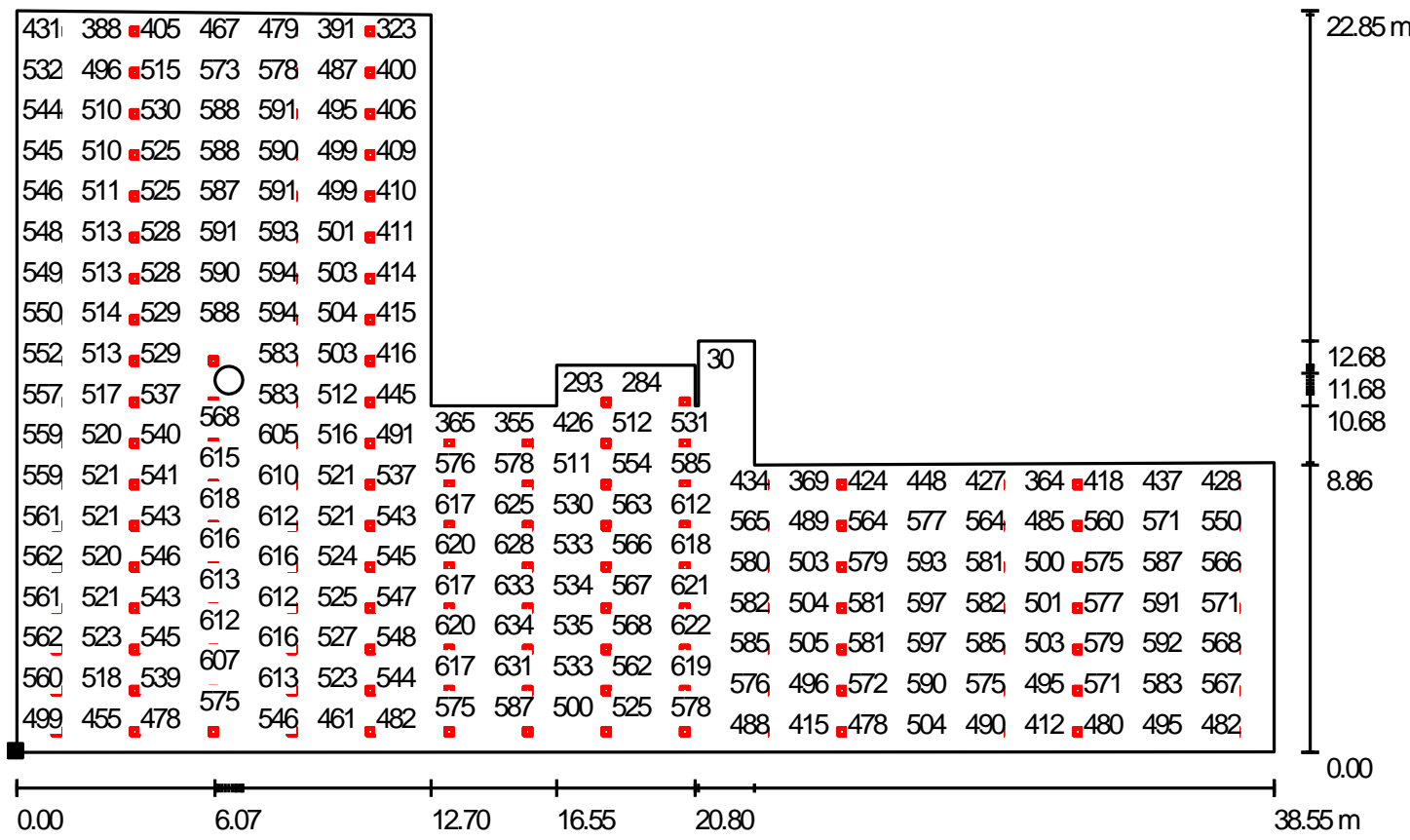

Figura 37: Simulação staff - luminária importada tipo 33 para fluorescente compacta (Arquivo: ET-ST-FCEX-3-MX.dlx)

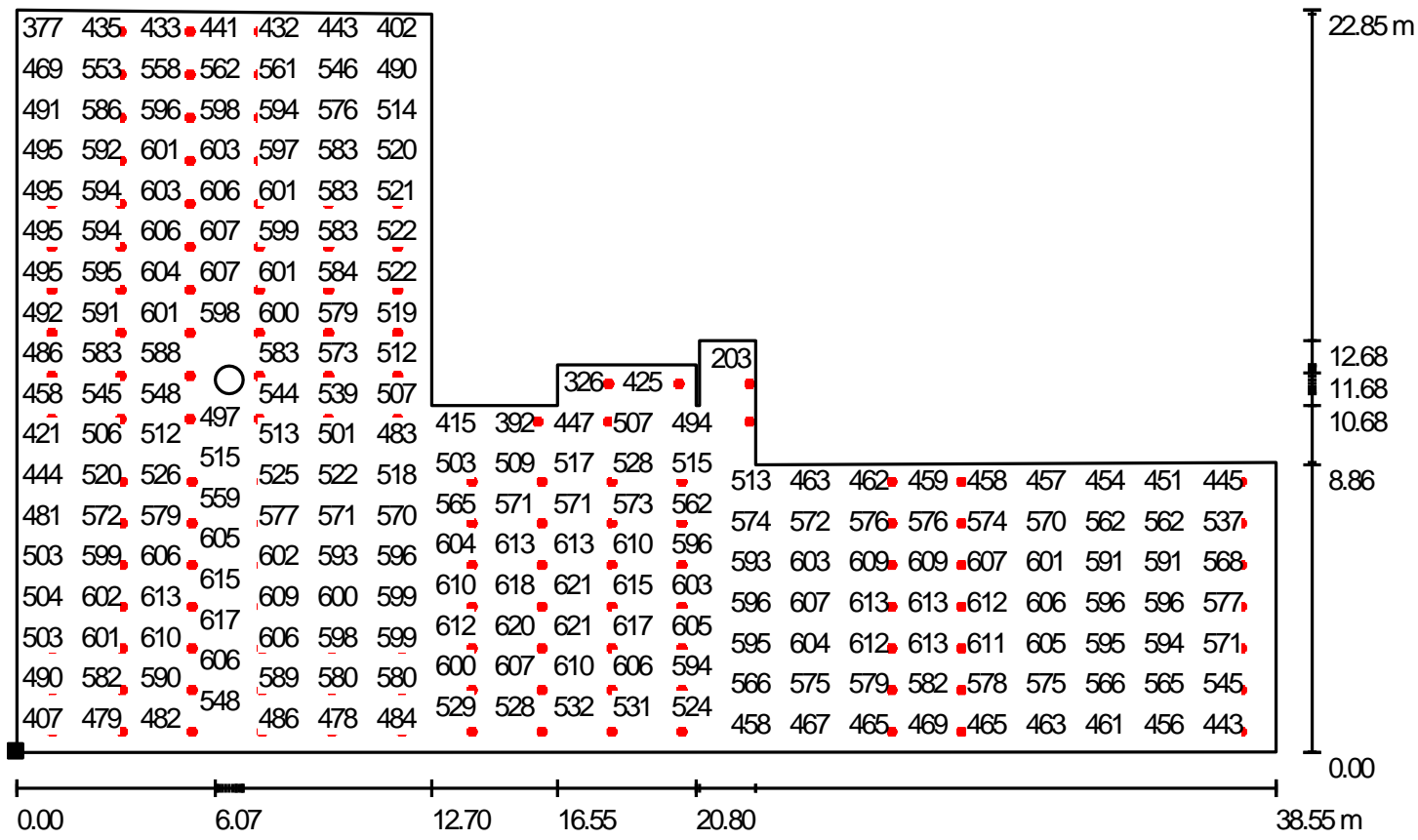

Figura 38: Simulação staff - luminária importada tipo 40 para fluorescente compacta (Arquivo: ET-ST-FCEX-4-MX.dlx)

Por fim, para simulação do staff, simularemos as luminárias em LED com o mesmo integrado na peça. Para a pesquisa consideramos 2 tipo de luminárias, uma onde podemos substituir em tamanho, uma luminária para fluorescente tubular de 3 
ou 4 lâmpadas 14W, e a outra, onde podemos substituir uma luminária para lâmpada fluorescente compacta não integrada.

Tabela 25: Tabela sistema de iluminação nacional com LED

\begin{tabular}{|c|c|c|c|c|c|c|c|c|}
\hline Fabricante & Código peça & $\begin{array}{c}\text { Qtde } \\
\text { pças }\end{array}$ & $\begin{array}{c}\text { Eméd } \\
\mathbf{( I x )}\end{array}$ & $\begin{array}{c}\text { Emín } \\
\mathbf{( I x )}\end{array}$ & $\begin{array}{c}\text { Emáx } \\
\mathbf{( I x )}\end{array}$ & $\begin{array}{c}\text { Potência } \\
\text { conj (W) }\end{array}$ & $\begin{array}{c}\text { Potência } \\
\text { total (W) }\end{array}$ & $\begin{array}{c}\text { Tipo/ } \\
\text { Anexo } \\
\text { luminária }\end{array}$ \\
\hline Itaim & Galaxia $\mathbf{M}-\mathbf{5 4 W}$ & $\mathbf{1 0 8}$ & $\mathbf{5 6 3}$ & $\mathbf{2 4}$ & $\mathbf{7 4 0}$ & $\mathbf{5 9 , 4 0}$ & $\mathbf{6 4 1 5 , 2 0}$ & $\mathbf{4 4}$ \\
\hline Philips & BBS496 - 40,5W & 115 & 560 & 25 & 686 & 44,50 & 5117,5 & 45 \\
\hline Philips & BBS497 - 40,5W & 122 & 587 & 168 & 781 & 44,50 & 5429,0 & 46 \\
\hline Philips & BBS498 - 28W & 147 & 530 & 18 & 602 & 30,80 & 4527,6 & 47 \\
\hline Philips & BBS488 - 13W & $\mathbf{3 0 0}$ & $\mathbf{5 2 3}$ & $\mathbf{1 8}$ & $\mathbf{6 0 3}$ & $\mathbf{1 4 , 3 0}$ & $\mathbf{4 2 9 0 , 0}$ & $\mathbf{4 8}$ \\
\hline
\end{tabular}

$\mathrm{Na}$ Tabela 25, a luminária do tipo 44, eficiente e única encontrada no mercado nacional, é uma luminária quadrada com difusor em acrílico prismático. Pode substituir em tamanho, uma luminária padrão modular 625×625mm.

A luminária do tipo 48 é circular, com refletor em alumínio e de tamanho reduzido, podendo substituir uma luminária para fluorescente compacta não integrada.

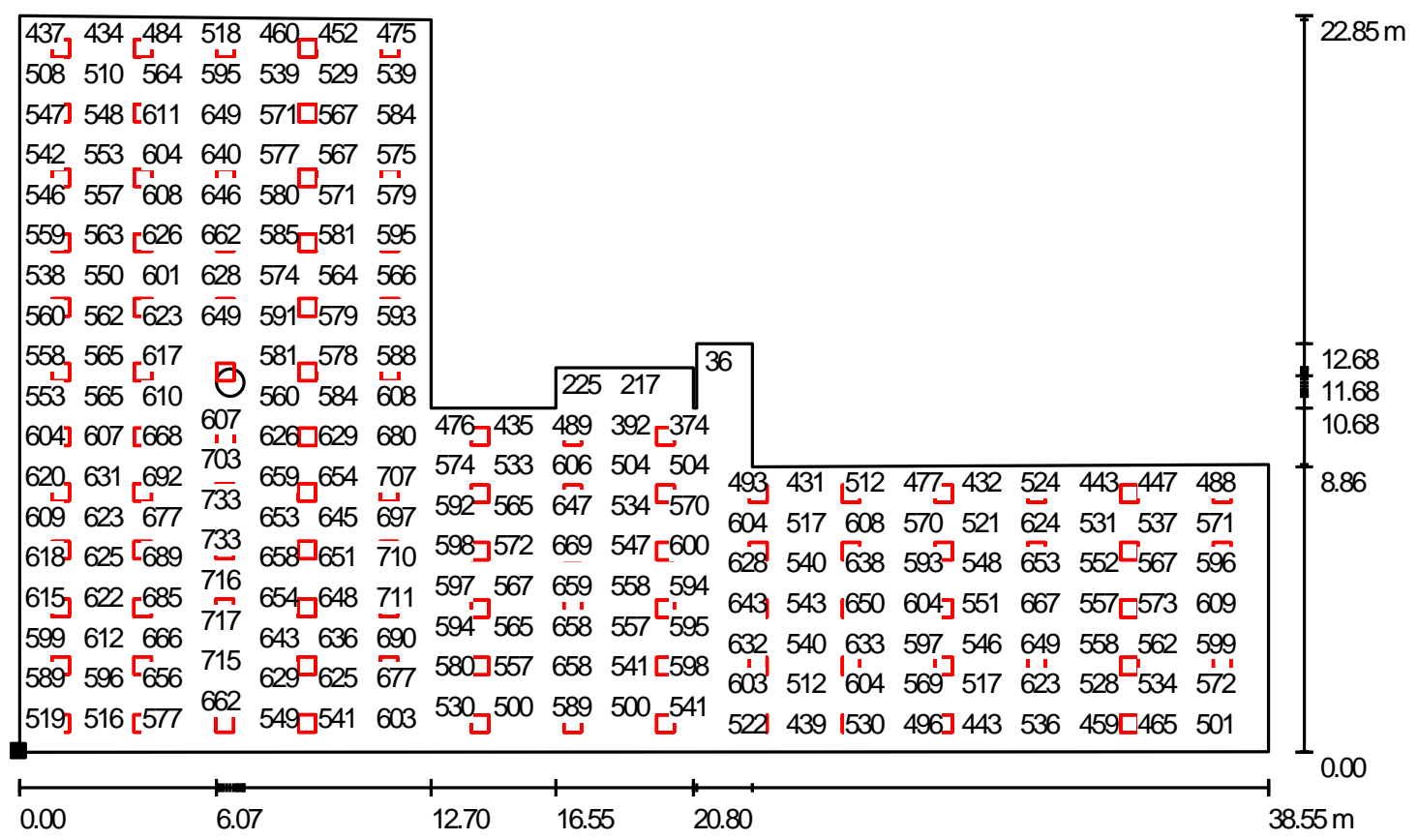

Figura 39: Simulação staff - luminária nacional tipo 44 para LED (Arquivo: ET-ST-LE-BR-1-MX.dlx) 


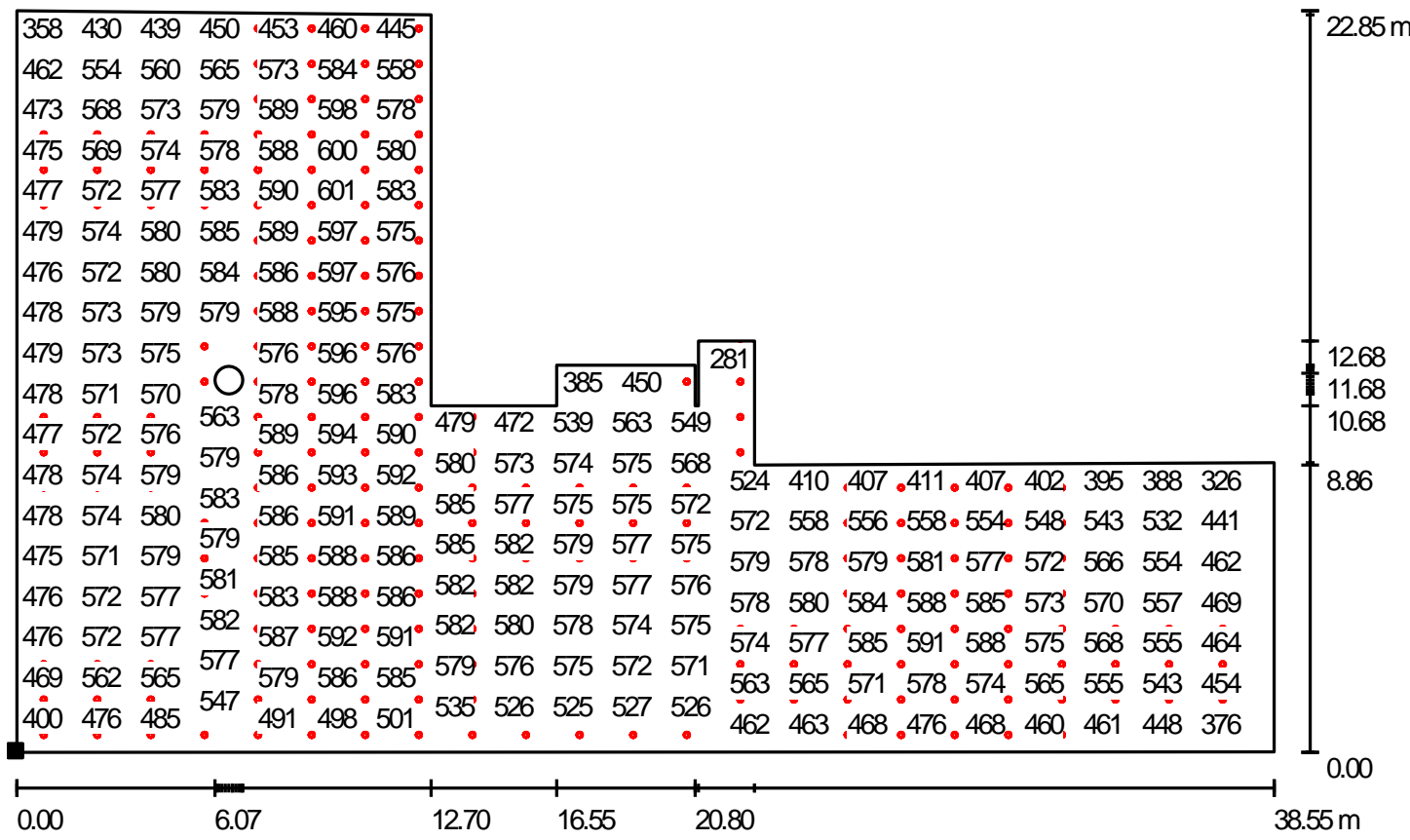

Figura 40: Simulação staff - luminária nacional tipo 48 para LED (Arquivo: ET-ST-LE-BR-2-MX.dlx)

As figuras 39 e 40 são as simulações ponto a ponto do staff utilizando luminárias LED. Comparando-as, observa-se que na simulação da figura 40, o nível é mais homogêneo apesar de apresentar mais luminárias do que a simulação da figura 39.

Tabela 26: Tabela sistema de iluminação importado com LED

\begin{tabular}{|c|c|c|c|c|c|c|c|c|}
\hline Fabricante & Código peça & $\begin{array}{c}\text { Qtde } \\
\text { pças }\end{array}$ & $\begin{array}{c}\text { Eméd } \\
\mathbf{( I x )}\end{array}$ & $\begin{array}{c}\text { Emín } \\
\mathbf{( I x )}\end{array}$ & $\begin{array}{c}\text { Emáx } \\
\mathbf{( I x )}\end{array}$ & $\begin{array}{c}\text { Potência } \\
\text { conj (W) }\end{array}$ & $\begin{array}{c}\text { Potência } \\
\text { total (W) }\end{array}$ & $\begin{array}{c}\text { Tipo/ } \\
\text { Anexo } \\
\text { luminária }\end{array}$ \\
\hline Zumtobel & $\begin{array}{c}\text { L-FIELDS 42179998 } \\
\mathbf{4 4 W ~ 4 0 0 0 K}\end{array}$ & $\mathbf{1 0 1}$ & $\mathbf{5 4 5}$ & $\mathbf{1 2 4}$ & $\mathbf{6 6 8}$ & $\mathbf{4 8 , 4 0}$ & $\mathbf{4 8 8 8 , 4}$ & $\mathbf{4 9}$ \\
\hline Zumtobel & $\begin{array}{c}\text { L-FIELDS 42180000 } \\
\text { 44W 3000K }\end{array}$ & 101 & 509 & 116 & 623 & 48,40 & 4888,4 & 50 \\
\hline Erco & $37731.00020 \mathrm{~W}$ & 339 & 514 & 16 & 632 & 22,00 & 7458,0 & 51 \\
\hline Erco & $47719.00020 \mathrm{~W}$ & 314 & 517 & 15 & 601 & 22,00 & 6908,0 & 52 \\
\hline Erco & $47725.00027 \mathrm{~W}$ & 233 & 565 & 61 & 709 & 29,70 & 6920,1 & 53 \\
\hline Erco & $\mathbf{4 7 7 6 5 . 0 0 0 ~ 3 4 W}$ & $\mathbf{1 7 0}$ & $\mathbf{5 9 9}$ & $\mathbf{5 6}$ & $\mathbf{7 8 0}$ & $\mathbf{3 7 , 4 0}$ & $\mathbf{6 3 5 8 , 0}$ & $\mathbf{5 4}$ \\
\hline Erco & $47761.00040 \mathrm{~W}$ & 147 & 584 & 100 & 771 & $\mathbf{4 4 , 0 0}$ & 6468,0 & 55 \\
\hline
\end{tabular}

Na Tabela 26 temos as simulações realizadas para luminárias do exterior com LED, notamos pela simulação das luminárias do fabricante Zumtobel, que as luminárias com a temperatura de cor $4000 \mathrm{~K}$ tem um fluxo luminoso maior que as com temperatura de cor 3000K. Essa diferença, também pode ser vista no próprio 
catálogo do fabricante Erco. Nesse caso foram pré-selecionadas as luminárias de $4000 K$.

Como é um ambiente de escritório, a temperatura de cor dos LEDs será por volta de $4000 \mathrm{~K}$, branco neutro em todas as simulações.

A luminária da simulação da figura 41 é uma luminária quadrada, com difusor especial "highlightTerm" que proporciona melhor difusão do LED e fácil manutenção de limpeza. Assim como a luminária nacional, pode substituir em tamanho uma luminária $625 \times 625 \mathrm{~mm}$.

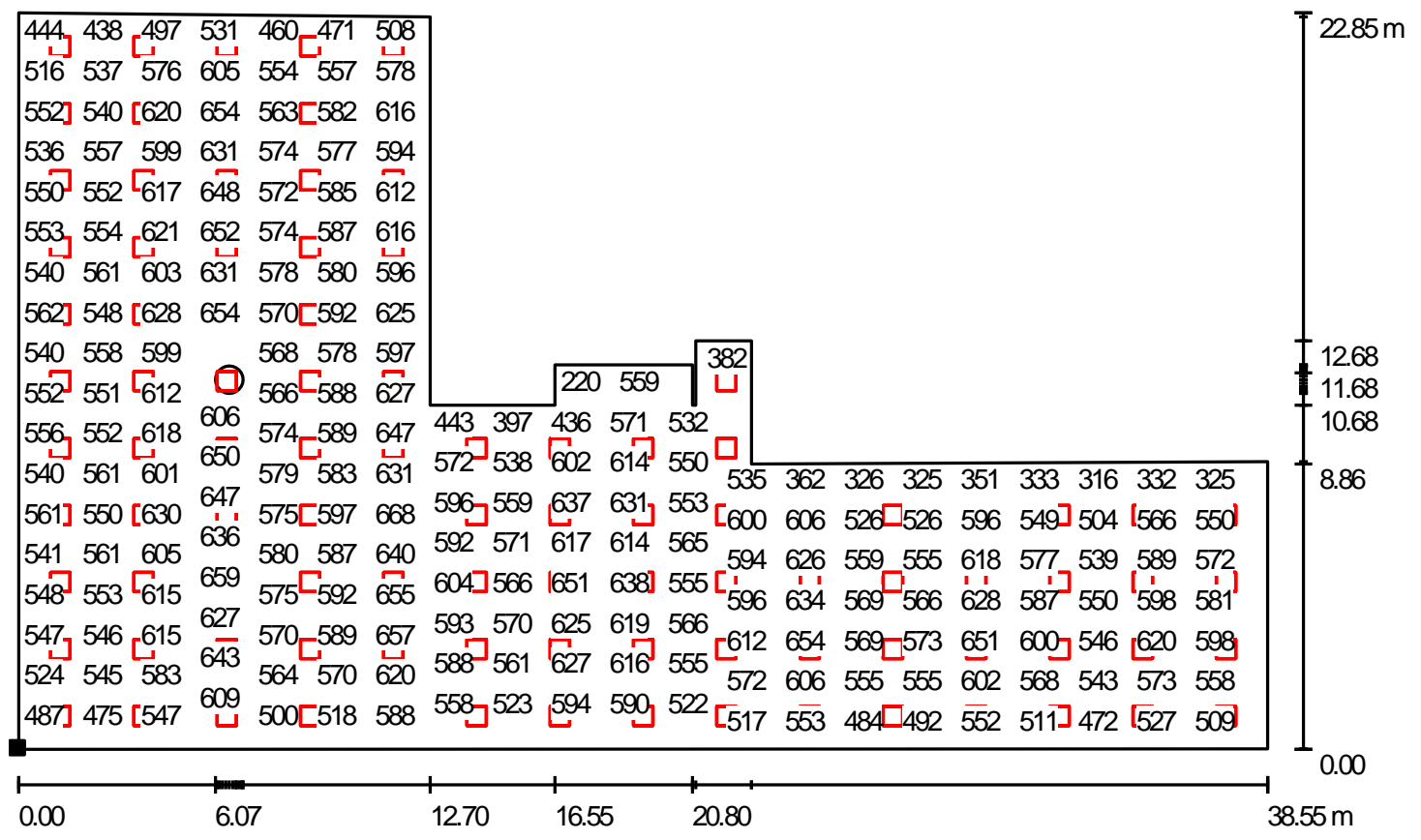

Figura 41: Simulação staff - luminária importada tipo 49 para LED (Arquivo: ET-ST-LE-EX-3-MX.dlx)

A luminária da próxima simulação é redonda, com refletor de alumínio anodizado e difusor em vidro fosco. Substitui em tamanho, uma luminária para fluorescente compacta. 


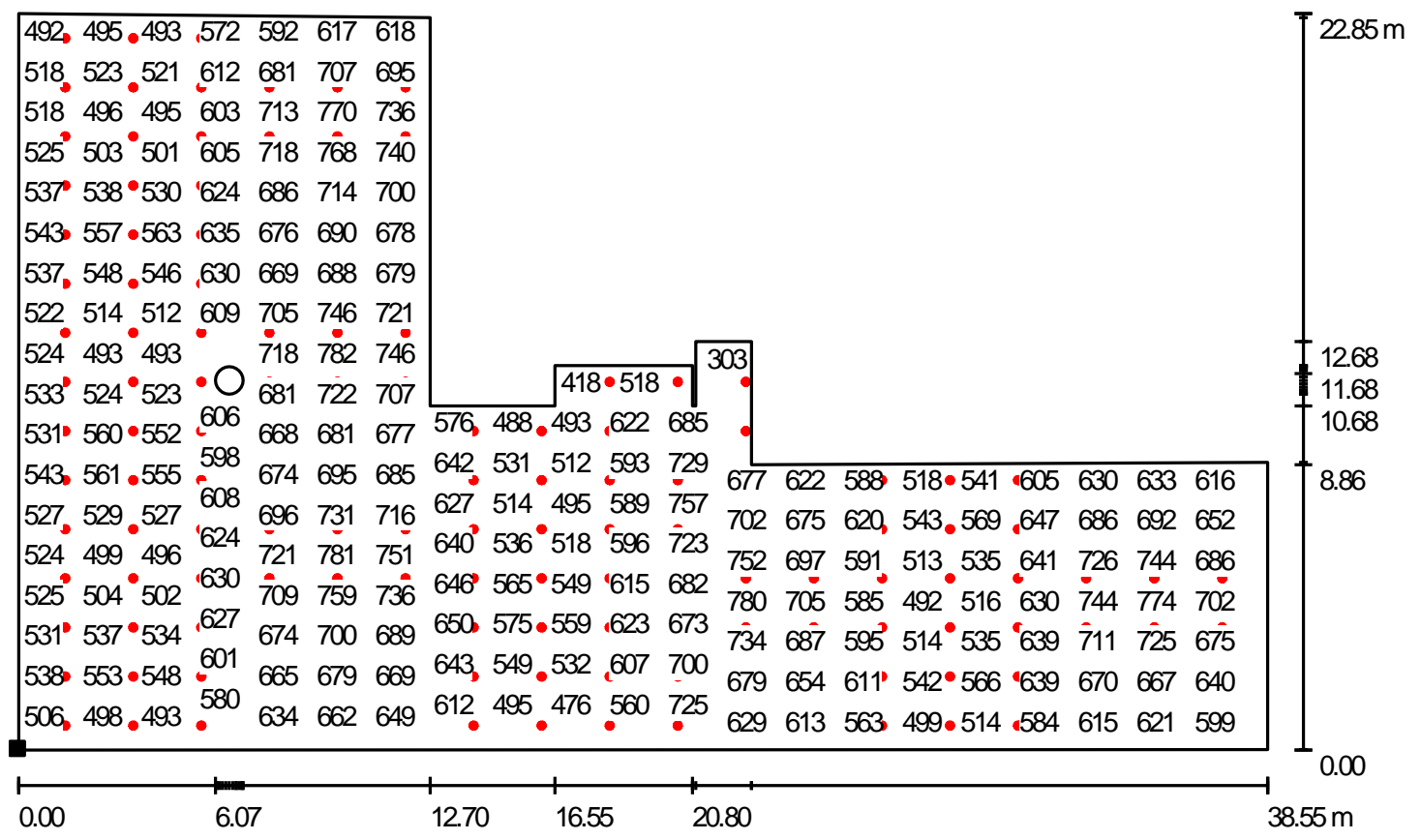

Figura 42: Simulação staff - luminária importada tipo 54 para LED (Arquivo: ET-ST-LE-EX-4-MX.dlx)

\subsubsection{Sala Individual}

As simulações da sala individual foram feitas com três tipos de lâmpadas utilizadas com mais frequência nesse tipo de sala. Em todos os casos, mesclamos dois sistemas de iluminação.

Temos uma luminária pendente para lâmpada fluorescente tubular no plano de trabalho e o complemento da iluminação da sala foi simulado com lâmpada fluorescente compacta não integrada ou lâmpada halógena ou LED. Segue figura 43 com o layout da sala individual. 


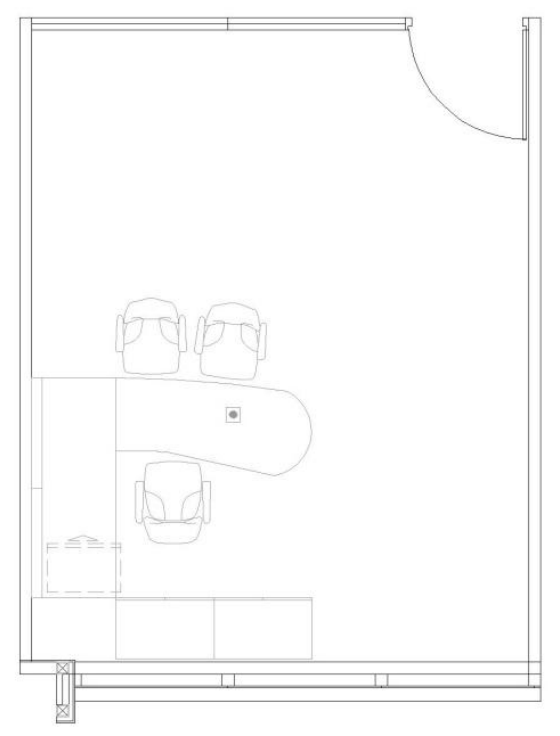

Figura 43: Sala individual a ser simulada

No caso da simulação para luminárias nacionais, utilizamos a luminária pendente do fabricante Itaim Iluminação, de código 3450 retangular, com aletas parabólicas, refletor em alumínio anodizado para duas lâmpadas fluorescente tubular de 28W.

Tabela 27: Tabela sistema de iluminação nacional - fluorescente compacta e pendente

\begin{tabular}{|c|c|c|c|c|c|c|c|c|}
\hline Fabricante & Código peça & $\begin{array}{l}\text { Qtde } \\
\text { pças }\end{array}$ & $\begin{array}{l}\text { Eméd } \\
\text { (Ix) }\end{array}$ & $\begin{array}{c}\text { Emín } \\
\text { (Ix) }\end{array}$ & $\begin{array}{c}\text { Emáx } \\
(\mathbf{I x})\end{array}$ & $\begin{array}{l}\text { Potência } \\
\text { conj (W) }\end{array}$ & $\begin{array}{l}\text { Potência } \\
\text { total (W) }\end{array}$ & $\begin{array}{c}\text { Tipo/ } \\
\text { Anexo } \\
\text { Iuminária }\end{array}$ \\
\hline \multirow{2}{*}{$\begin{array}{c}\text { Itaim } \\
\text { Iluminação }\end{array}$} & Delfos $1 \times 32 W$ & 6 & \multirow{2}{*}{525} & \multirow{2}{*}{170} & \multirow{2}{*}{1292} & 36,00 & \multirow{2}{*}{276,3} & 21 \\
\hline & $34502 \times 28 W$ & 1 & & & & 60,30 & & 56 \\
\hline \multirow{2}{*}{$\begin{array}{c}\text { Itaim } \\
\text { Iluminação }\end{array}$} & Iolita 2x26W & 6 & \multirow{2}{*}{527} & \multirow{2}{*}{240} & \multirow{2}{*}{1284} & 56,00 & \multirow{2}{*}{396,3} & 19 \\
\hline & $34502 \times 28 W$ & 1 & & & & 60,30 & & 56 \\
\hline \multirow{2}{*}{$\begin{array}{c}\text { Itaim } \\
\text { Iluminação }\end{array}$} & Delfos $1 \times 42 W$ & 4 & \multirow{2}{*}{520} & \multirow{2}{*}{155} & \multirow{2}{*}{1346} & 47 & \multirow{2}{*}{248,3} & 26 \\
\hline & $34502 \times 28 W$ & 1 & & & & 60,30 & & 56 \\
\hline \multirow{2}{*}{ Lumini } & $E-40391 \times 32 W$ & 5 & \multirow{2}{*}{531} & \multirow{2}{*}{216} & \multirow{2}{*}{1205} & 36,00 & \multirow{2}{*}{240,3} & 24 \\
\hline & $34502 \times 28 W$ & 1 & & & & 60,30 & & 56 \\
\hline \multirow{2}{*}{ Lumini } & E-4039 1x42W & 6 & \multirow{2}{*}{663} & \multirow{2}{*}{235} & \multirow{2}{*}{1233} & 47,00 & \multirow{2}{*}{342,30} & 28 \\
\hline & $34502 \times 28 W$ & 1 & & & & 60,30 & & 56 \\
\hline
\end{tabular}




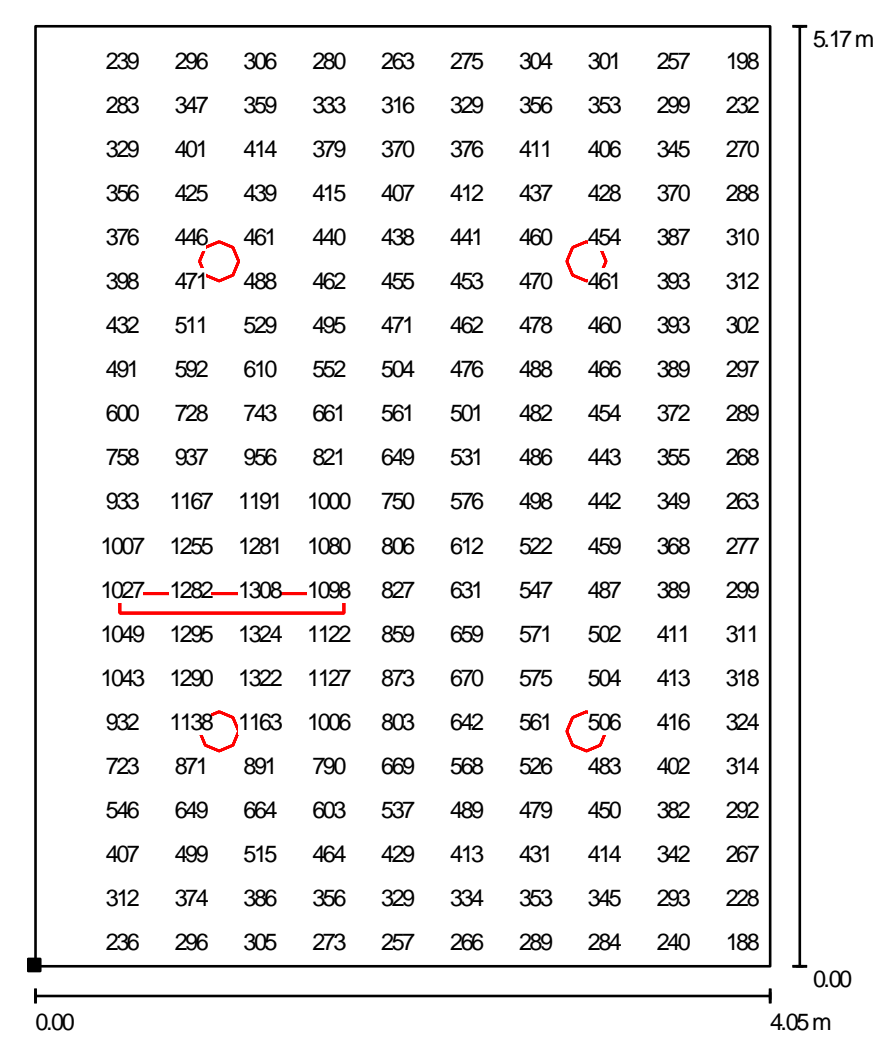

Figura 44: Simulação sala individual - luminária nacional tipo 26 para fluorescente compacta (Arquivo: ET-SI-FC-BR-1-MX.dlx)

A figura 44 mostra a simulação com uma luminária redonda, com aletas parabólicas e refletor em alumínio anodizado para 1 lâmpada fluorescente compacta tripla $4 \mathrm{P}$ de $42 \mathrm{~W}$.

A outra luminária possui as mesmas características da anterior, porém não possui aletas, e é para 1 lâmpada fluorescente compacta tripla 4P de $32 \mathrm{~W}$. A simulação realizada está na figura 45 . 


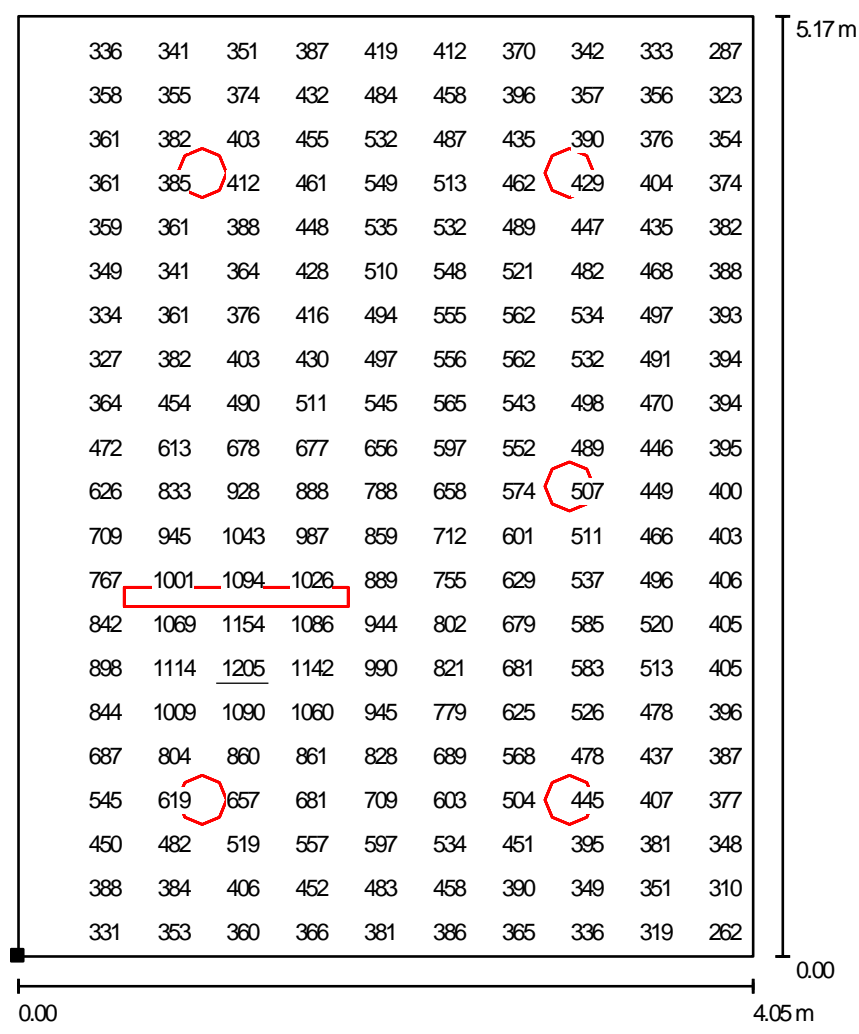

Figura 45: Simulação sala individual - luminária eficiente nacional tipo 24 para fluorescente compacta

Em ambas as simulações, notamos que no plano de trabalho, onde se localiza a luminária retangular pendente, temos um nível de iluminação muito alto. $\mathrm{Na}$ época em que foram realizadas as simulações, o único fabricante que disponibilizou as fotometrias, possuía apenas luminária pendente para 2 lâmpadas fluorescentes tubulares. $O$ ideal nesse caso, é que houvesse uma luminária pendente para apenas 1 lâmpada fluorescente tubular.

Para a luminária importada, foi escolhida uma luminária do fabricante Zumtobel, código 42156154 1x28W ou código 42156158 2x28W, ambas são retangulares, com aletas parabólicas, refletor em alumínio e ótimo controle de ofuscamento. Nesse caso, foram simuladas duas opções com 1 ou 2 lâmpadas fluorescentes tubulares. Segue a Tabela 28 com as simulações realizadas. 
Tabela 28: Tabela sistema de iluminação importado - fluorescente compacta e pendente

\begin{tabular}{|c|c|c|c|c|c|c|c|c|}
\hline Fabricante & Código peça & $\begin{array}{l}\text { Qtde } \\
\text { pças }\end{array}$ & $\begin{array}{c}\text { Eméd } \\
(\text { Ix) }\end{array}$ & $\begin{array}{l}\text { Emín } \\
\text { (Ix) }\end{array}$ & $\begin{array}{c}\text { Emáx } \\
(I x)\end{array}$ & $\begin{array}{l}\text { Potência } \\
\text { conj (W) }\end{array}$ & $\begin{array}{l}\text { Potência } \\
\text { total (W) }\end{array}$ & $\begin{array}{c}\text { Tipo/ } \\
\text { Anexo } \\
\text { Iuminária }\end{array}$ \\
\hline \multirow[b]{2}{*}{ Erco } & $37618.0001 \times 32 W$ & 6 & \multirow[b]{2}{*}{540} & \multirow[b]{2}{*}{211} & \multirow[b]{2}{*}{923} & 36,00 & \multirow[b]{2}{*}{246,5} & 33 \\
\hline & $\begin{array}{c}\text { CLARIS2 } 42156154 \\
1 \times 28 W\end{array}$ & 1 & & & & 30,50 & & 57 \\
\hline \multirow[b]{2}{*}{ Erco } & $37618.0001 \times 32 \mathrm{~W}$ & 6 & \multirow[b]{2}{*}{619} & \multirow[b]{2}{*}{226} & \multirow[b]{2}{*}{1331} & 36,00 & \multirow[b]{2}{*}{276,3} & 33 \\
\hline & $\begin{array}{c}\text { CLARIS2 } 42156158 \\
2 \times 28 W\end{array}$ & 1 & & & & 60,30 & & 58 \\
\hline \multirow[b]{2}{*}{ Erco } & $37609.0002 \times 26 \mathrm{~W}$ & 6 & \multirow[b]{2}{*}{593} & \multirow[b]{2}{*}{263} & \multirow[b]{2}{*}{933} & 56,00 & \multirow[b]{2}{*}{366,50} & 37 \\
\hline & $\begin{array}{c}\text { CLARIS2 } 42156154 \\
1 \times 28 W\end{array}$ & 1 & & & & 30,50 & & 57 \\
\hline \multirow[b]{2}{*}{ Erco } & $37609.0002 \times 26 W$ & 4 & \multirow[b]{2}{*}{506} & \multirow[b]{2}{*}{188} & \multirow[b]{2}{*}{1147} & 56,00 & \multirow[b]{2}{*}{284,3} & 37 \\
\hline & $\begin{array}{c}\text { CLARIS2 } 42156158 \\
2 \times 28 W\end{array}$ & 1 & & & & 60,30 & & 58 \\
\hline \multirow{2}{*}{ Zumtobel } & $\begin{array}{c}\text { PANOS Q } 60811108 \\
1 \times 32 W \\
\end{array}$ & 7 & \multirow{2}{*}{530} & \multirow{2}{*}{287} & \multirow{2}{*}{781} & 36,00 & \multirow{2}{*}{282,5} & 40 \\
\hline & $\begin{array}{c}\text { CLARIS2 42156154 } \\
1 \times 28 W\end{array}$ & 1 & & & & 30,50 & & 57 \\
\hline \multirow{2}{*}{ Zumtobel } & $\begin{array}{c}\text { PANOS Q } 60811108 \\
1 \times 32 W \\
\end{array}$ & 6 & \multirow{2}{*}{552} & \multirow{2}{*}{264} & \multirow{2}{*}{1202} & 36,00 & \multirow{2}{*}{276,3} & 40 \\
\hline & $\begin{array}{c}\text { CLARIS2 } 42156158 \\
2 \times 28 W\end{array}$ & 1 & & & & 60,30 & & 58 \\
\hline
\end{tabular}

A figura 46 a seguir é a simulação da luminária tipo 33 em destaque na Tabela 28, com uma luminária quadrada, com refletor em alumínio anodizado, onde o desenho do próprio refletor faz o controle de ofuscamento da peça. A lâmpada da peça é para uma fluorescente compacta tripla $4 \mathrm{P}$ de $32 \mathrm{~W}$. 


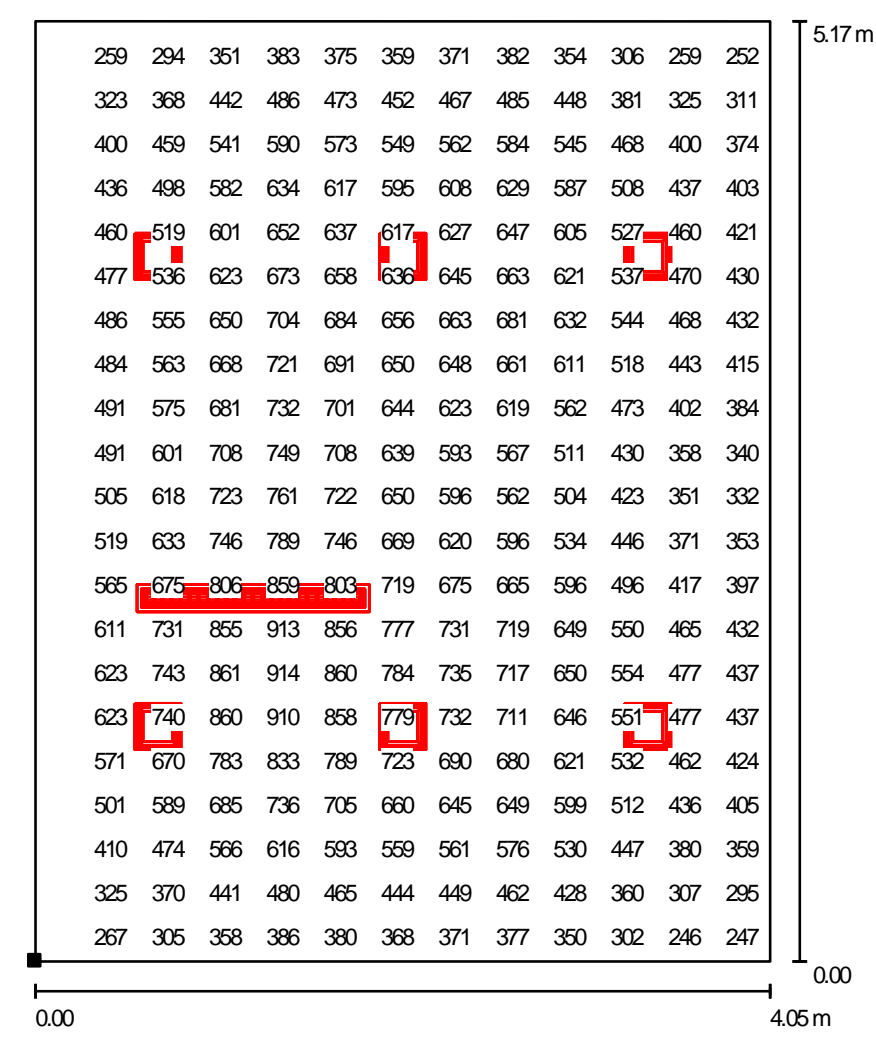

Figura 46: Simulação sala individual - luminária importada tipo 33 para fluorescente compacta (Arquivo: ET-SI-FC-EX-3-MX.dlx)

Comparando a simulação da figura 46 com as simulações das figuras 44 e 45, observamos que o nível de iluminação na mesa de trabalho é menor, pois nesse caso, a luminária pendente é para 1 lâmpada fluorescente tubular. 


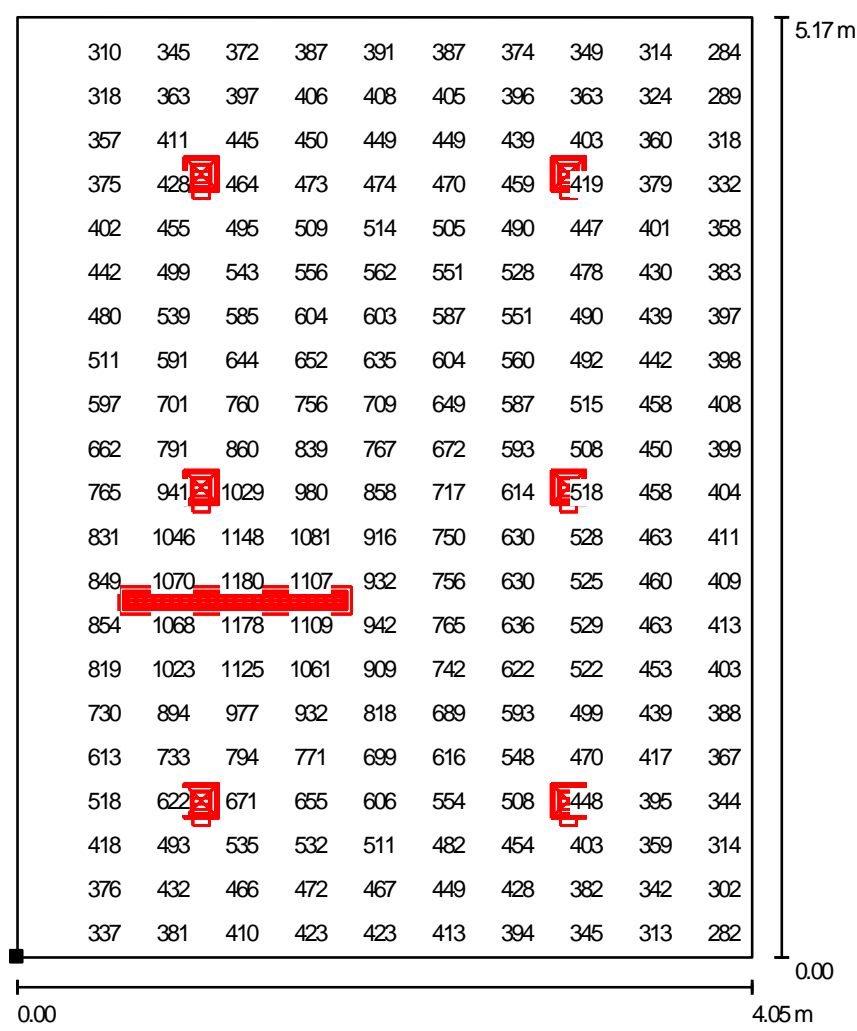

Figura 47: Simulação sala individual - luminária importada tipo 40 para fluorescente compacta (Arquivo: ET-SI-FC-EX-4-MX.dlx)

A simulação da figura 47 , com uma das luminárias mais eficientes para lâmpada fluorescente compacta, foi realizada com uma luminária quadrada, com refletor em alumínio facetado com alto controle de ofuscamento obtida pelo próprio desenho do refletor. A lâmpada da peça é uma fluorescente compacta tripla 4P de $32 \mathrm{~W}$.

O próximo sistema de iluminação que será simulado terá a mesma luminária pendente na mesa de trabalho, porém com lâmpadas halógenas complementando a luz geral. A lâmpada halógena é muito utilizada no mercado nacional por light designers por produzir uma luz mais aconchegante devido ao brilho e a temperatura de cor.

Geralmente, as salas individuais, são as salas de presidente e diretores, onde os projetistas visam conforto e elegância. No Brasil, é comum que o projeto luminotécnico dessas salas seja de melhor qualidade.

Infelizmente, no mercado nacional, não há tantas opções de produtos com luminárias de lâmpadas halógenas que produzam luz geral. As lâmpadas halógenas 
mais utilizadas no país, são as lâmpadas de destaque, com facho definido, como a lâmpada dicroica ou AR70 ou AR111.

A Tabela 29 mostram as simulações realizadas com as luminárias encontradas no mercado nacional. As duas primeiras são para lâmpada halopin tensão de rede, de vida útil baixa de 2000 horas e a última é para lâmpada bipino $12 \mathrm{~V}$. As duas luminárias de menor consumo em destaque, são circulares, com foco de luz recuado e difusor fosco. Ambas possuem refletor em alumínio.

Tabela 29: Tabela sistema de iluminação nacional - halógena e pendente

\begin{tabular}{|c|c|c|c|c|c|c|c|c|}
\hline Fabricante & Código peça & $\begin{array}{l}\text { Qtde } \\
\text { pças }\end{array}$ & $\begin{array}{c}\text { Eméd } \\
\text { (Ix) }\end{array}$ & $\begin{array}{c}\text { Emín } \\
\text { (Ix) }\end{array}$ & $\begin{array}{c}\text { Emáx } \\
(I x)\end{array}$ & $\begin{array}{l}\text { Potência } \\
\text { conj (W) }\end{array}$ & $\begin{array}{l}\text { Potência } \\
\text { total (W) }\end{array}$ & $\begin{array}{c}\text { Tipo/ } \\
\text { Anexo } \\
\text { luminária }\end{array}$ \\
\hline \multirow{2}{*}{ Itaim } & Iborã 1x60W & 25 & \multirow{2}{*}{414} & \multirow{2}{*}{138} & \multirow{2}{*}{1199} & 60,00 & \multirow{2}{*}{1560,3} & 59 \\
\hline & $34502 \times 28 W$ & 1 & & & & 60,30 & & 56 \\
\hline \multirow{2}{*}{ Lumini } & $E-0031 \times 60 W$ & 21 & \multirow{2}{*}{509} & \multirow{2}{*}{204} & \multirow{2}{*}{1171} & 60,00 & \multirow{2}{*}{1320,3} & 60 \\
\hline & $34502 \times 28 W$ & 1 & & & & 60,30 & & 56 \\
\hline \multirow{2}{*}{ Lumini } & $E-100200-1 \times 100 W$ & 9 & \multirow{2}{*}{574} & \multirow{2}{*}{92} & \multirow{2}{*}{2376} & 110,00 & \multirow{2}{*}{1050,3} & 61 \\
\hline & $34502 \times 28 W$ & 1 & & & & 60,30 & & 56 \\
\hline
\end{tabular}

Seguem as simulações com as duas peças de menor consumo.

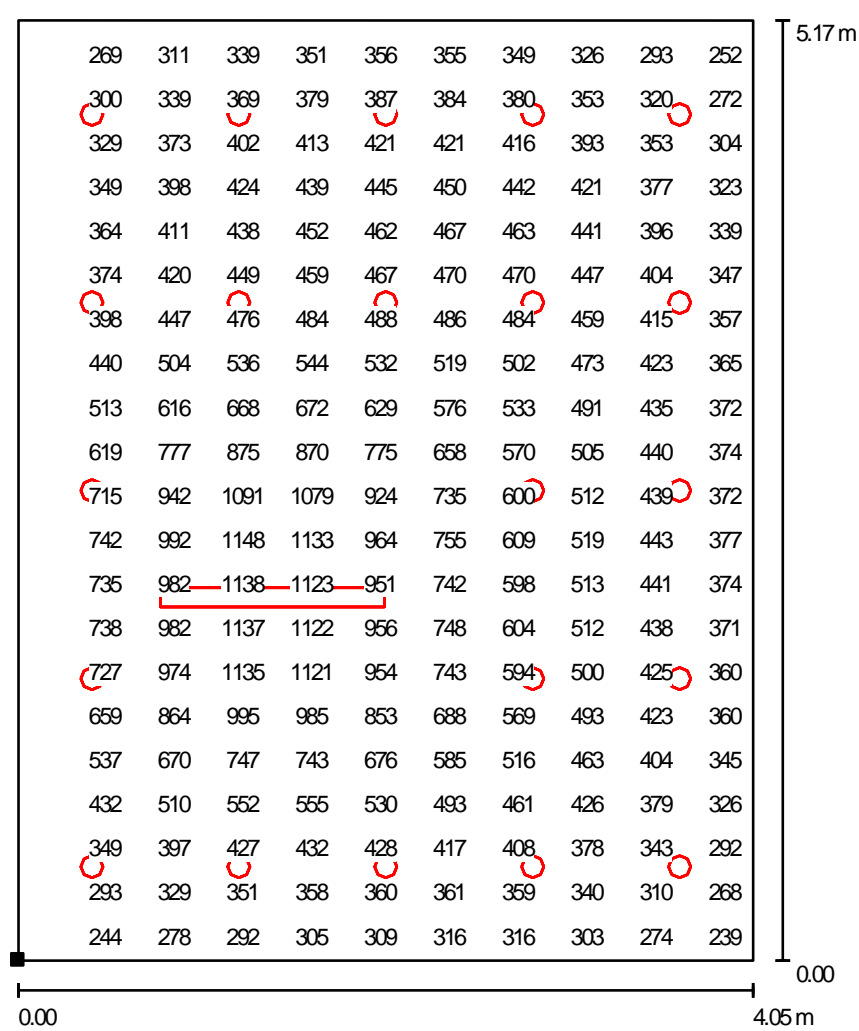

Figura 48: Simulação sala individual - luminária nacional tipo 60 para halógena (Arquivo: ET-SI-HA-BR-1MX.dlx) 


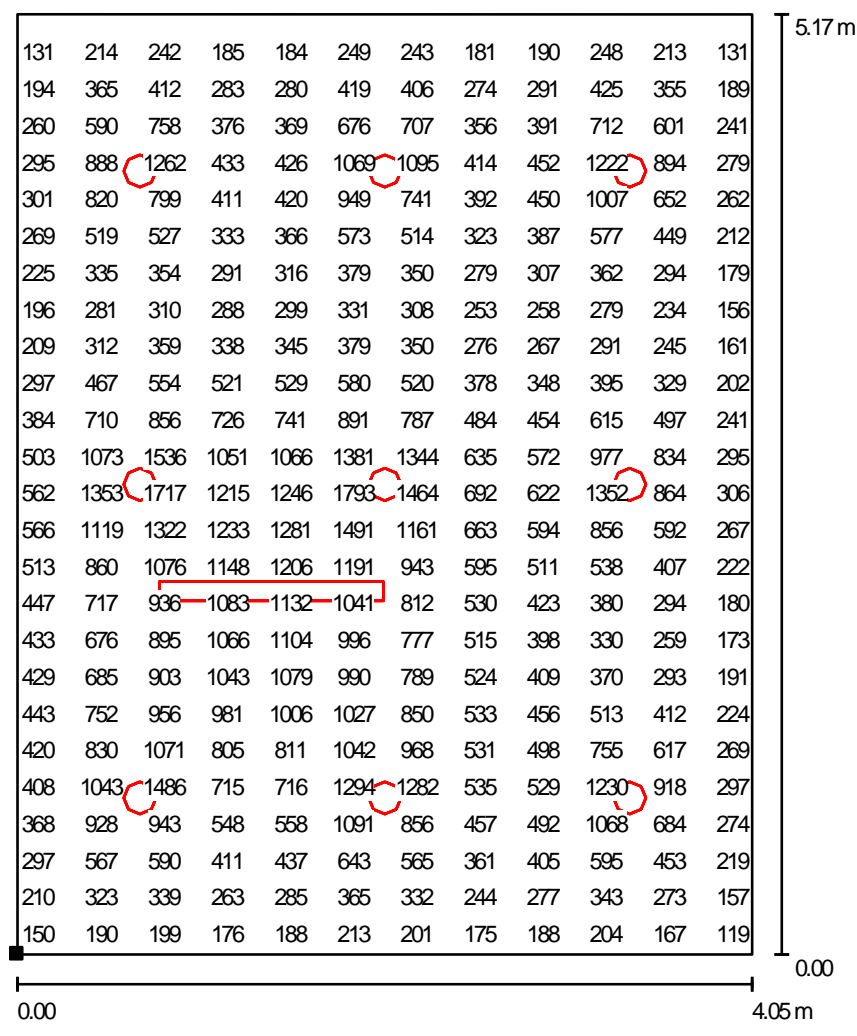

Figura 49: Simulação sala individual - luminária nacional tipo 61 para halógena (Arquivo: ET-SI-HA-BR-2MX.dlx)

Observando as figuras 48 e 49, percebemos que o conjunto não é eficiente, primeiro pela grande quantidade de pontos de luz no forro e segundo, observando o consumo na Tabela 29 , ambas tem um consumo quase $75 \%$ maior que utilizando lâmpadas fluorescentes compactas.

Para as próximas simulações, a lâmpada halógena será utilizada somente como luz de destaque.

Tabela 30: Tabela sistema de iluminação importado - halógena e pendente

\begin{tabular}{|c|c|c|c|c|c|c|c|c|}
\hline Fabricante & Código peça & $\begin{array}{l}\text { Qtde } \\
\text { pças }\end{array}$ & $\begin{array}{l}\text { Eméd } \\
(\mathrm{Ix})\end{array}$ & $\begin{array}{c}\text { Emín } \\
\text { (Ix) }\end{array}$ & $\begin{array}{c}\text { Emáx } \\
(I x)\end{array}$ & $\begin{array}{l}\text { Potência } \\
\text { conj (W) }\end{array}$ & $\begin{array}{l}\text { Potência } \\
\text { total (W) }\end{array}$ & $\begin{array}{c}\text { Tipo/ } \\
\text { Anexo } \\
\text { Iuminária }\end{array}$ \\
\hline \multirow[b]{2}{*}{ Erco } & $47011.0001 \times 100 \mathrm{~W}$ & 8 & \multirow[b]{2}{*}{550} & \multirow[b]{2}{*}{175} & \multirow[b]{2}{*}{970} & 110,00 & \multirow[b]{2}{*}{910,5} & 62 \\
\hline & $\begin{array}{c}\text { CLARIS2 } 42156154 \\
1 \times 28 W\end{array}$ & 1 & & & & 30,50 & & 57 \\
\hline \multirow[b]{2}{*}{ Erco } & $47011.0001 \times 100 \mathrm{~W}$ & 6 & \multirow[b]{2}{*}{515} & \multirow[b]{2}{*}{148} & \multirow[b]{2}{*}{1192} & 110,00 & \multirow[b]{2}{*}{720,3} & 62 \\
\hline & $\begin{array}{c}\text { CLARIS2 } 42156158 \\
2 \times 28 W\end{array}$ & 1 & & & & 60,30 & & 58 \\
\hline \multirow[b]{2}{*}{ Erco } & $47013.0001 \times 75 \mathrm{~W}$ & 12 & \multirow[b]{2}{*}{572} & \multirow[b]{2}{*}{230} & \multirow[b]{2}{*}{945} & 82,50 & \multirow[b]{2}{*}{1020,5} & 63 \\
\hline & $\begin{array}{c}\text { CLARIS2 } 42156154 \\
1 \times 28 W\end{array}$ & 1 & & & & 30,50 & & 57 \\
\hline \multirow{2}{*}{ Erco } & $47013.0001 \times 75 \mathrm{~W}$ & 9 & \multirow{2}{*}{532} & \multirow{2}{*}{183} & \multirow{2}{*}{1133} & 82,50 & \multirow{2}{*}{802,8} & 63 \\
\hline & CLARIS2 42156158 & 1 & & & & 60,30 & & 58 \\
\hline
\end{tabular}




\begin{tabular}{|c|c|c|c|c|c|c|c|c|}
\hline & $2 \times 28 W$ & & & & & & & \\
\hline \multirow[b]{2}{*}{ Erco } & $47046.0001 \times 100 \mathrm{~W}$ & 8 & \multirow[b]{2}{*}{619} & \multirow[b]{2}{*}{160} & \multirow[b]{2}{*}{1215} & 110,00 & \multirow[b]{2}{*}{910,5} & 64 \\
\hline & $\begin{array}{c}\text { CLARIS2 42156154 } \\
1 \times 28 \mathrm{~W}\end{array}$ & 1 & & & & 30,50 & & 57 \\
\hline \multirow[b]{2}{*}{ Erco } & $47046.0001 \times 100 \mathrm{~W}$ & 6 & \multirow[b]{2}{*}{567} & \multirow[b]{2}{*}{134} & \multirow[b]{2}{*}{1282} & 110,00 & \multirow[b]{2}{*}{720,3} & 64 \\
\hline & $\begin{array}{c}\text { CLARIS2 } 42156158 \\
\text { 2x28W }\end{array}$ & 1 & & & & 60,30 & & 58 \\
\hline \multirow{2}{*}{ Zumtobel } & $\begin{array}{c}\text { 2LIGHT MINI } \\
608109691 \times 75 \mathrm{~W} \\
\end{array}$ & 15 & \multirow{2}{*}{741} & \multirow{2}{*}{228} & \multirow{2}{*}{1069} & 82,50 & \multirow{2}{*}{1268,0} & 65 \\
\hline & $\begin{array}{c}\text { CLARIS2 } 42156154 \\
\text { 1x28W }\end{array}$ & 1 & & & & 30,50 & & 57 \\
\hline \multirow{2}{*}{ Zumtobel } & $\begin{array}{c}\text { 2LIGHT MINI } \\
608109691 \times 75 W\end{array}$ & 9 & \multirow{2}{*}{567} & \multirow{2}{*}{95} & \multirow{2}{*}{1310} & 82,50 & \multirow{2}{*}{802,80} & 65 \\
\hline & $\begin{array}{c}\text { CLARIS2 42156158 } \\
2 \times 28 W\end{array}$ & 1 & & & & 60,30 & & 58 \\
\hline
\end{tabular}

Comparando a Tabela 29 de luminárias nacionais e a Tabela 30 de luminárias importadas, percebemos que no sistema de iluminação internacional, a quantidade de luminárias de luz geral é bem menor que o do mercado nacional.

As peças tipo 61 e 62, são peças que utilizam o mesmo tipo de lâmpada e na simulação, para alcançar o nível médio de 500lux, foram necessárias cerca de 1/3 a menos de peças. Ou seja, a peça 62 é mais eficiente que a peça 61 .

Seguem as figuras 50 e $51 \mathrm{com}$ as simulações das luminárias de menor consumo no mercado internacional utilizando lâmpadas halógenas.

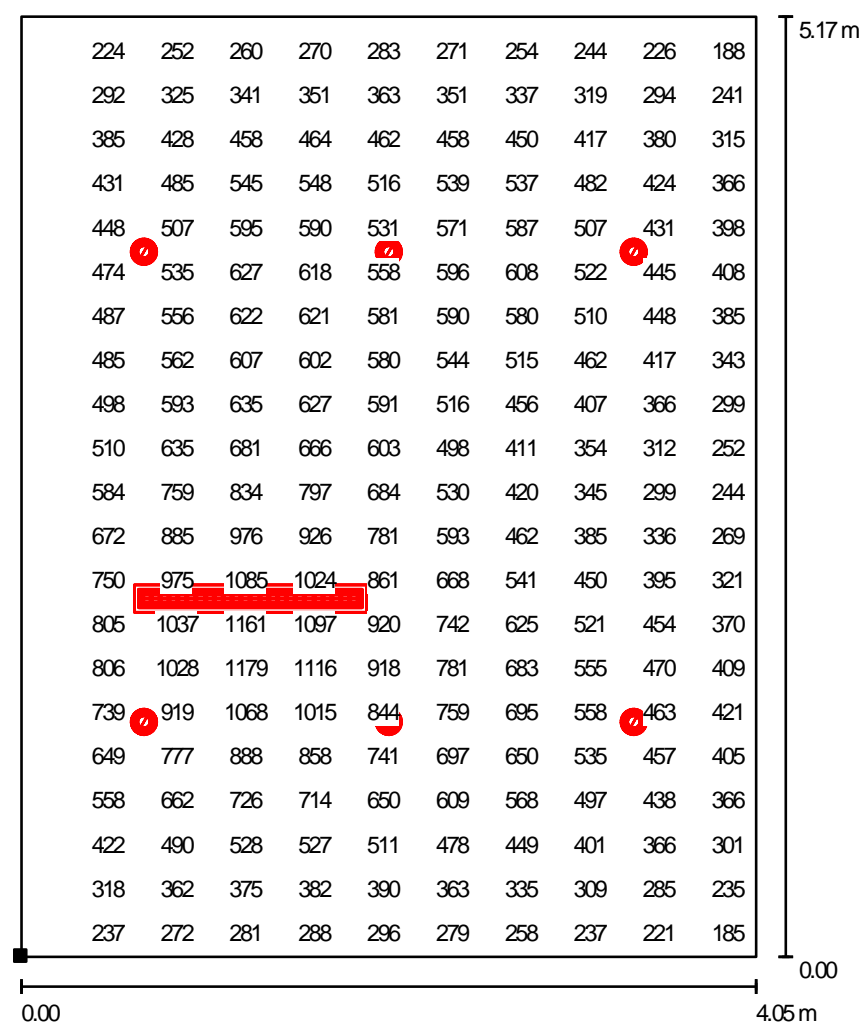


Figura 50: Simulação sala individual - luminária importada tipo 62 para halógena (Arquivo: ET-SI-HA-EX3-MX.dlx)

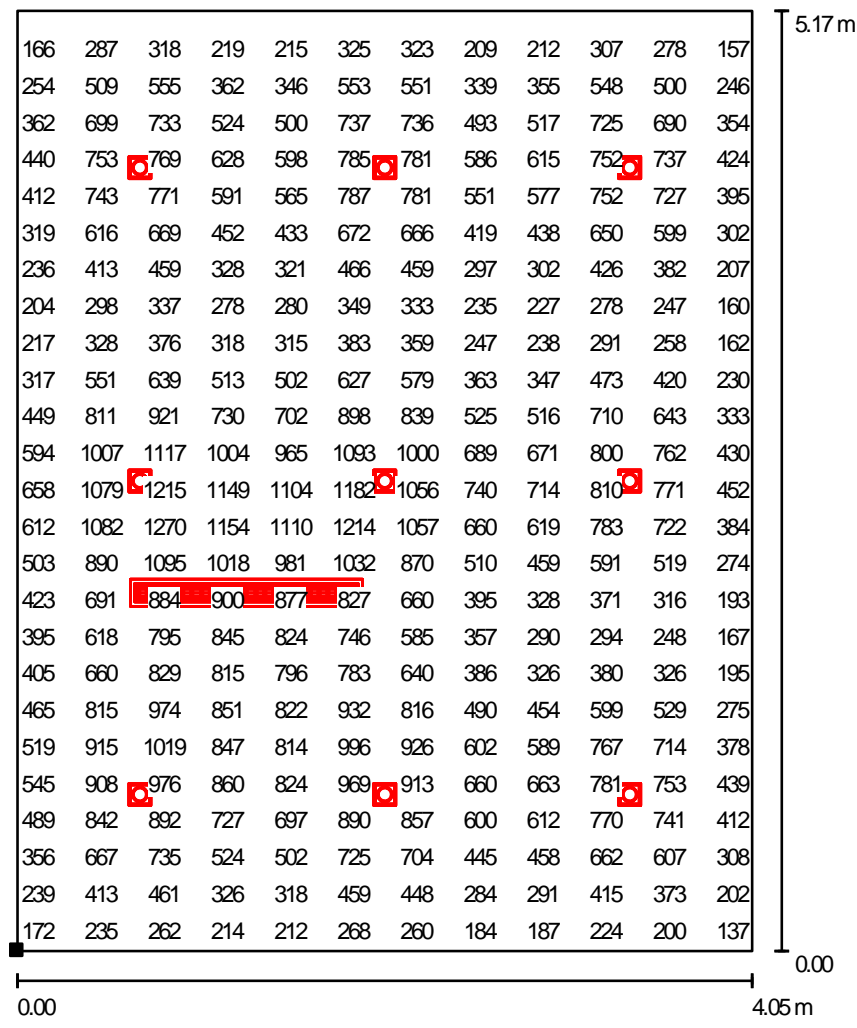

Figura 51: Simulação sala individual - luminária importada tipo 65 para halógena (Arquivo: ET-SI-HA-EX4-MX.dlx)

Por fim, simularemos para esta sala o conjunto com o mesmo pendente em cima da mesa de trabalho e luminária LED para luz geral.

Tabela 31: Tabela sistema de iluminação nacional - LED e pendente

\begin{tabular}{|c|c|c|c|c|c|c|c|c|}
\hline Fabricante & Código peça & $\begin{array}{l}\text { Qtde } \\
\text { pças }\end{array}$ & $\begin{array}{c}\text { Eméd } \\
\text { (Ix) }\end{array}$ & $\begin{array}{c}\text { Emín } \\
(\mathrm{Ix})\end{array}$ & $\begin{array}{c}\text { Emáx } \\
\text { (Ix) }\end{array}$ & $\begin{array}{l}\text { Potência } \\
\text { conj (W) }\end{array}$ & $\begin{array}{l}\text { Potência } \\
\text { total (W) }\end{array}$ & $\begin{array}{c}\text { Tipo/ } \\
\text { Anexo } \\
\text { Iuminária }\end{array}$ \\
\hline \multirow{2}{*}{$\begin{array}{c}\text { Itaim } \\
\text { Iluminação }\end{array}$} & Âmbar LED 23W & 6 & \multirow{2}{*}{534} & \multirow{2}{*}{248} & \multirow{2}{*}{1295} & 24,30 & \multirow{2}{*}{212,1} & 66 \\
\hline & 3450 2x28W & 1 & & & & 60,30 & & 56 \\
\hline \multirow{2}{*}{$\begin{array}{c}\text { Itaim } \\
\text { Iluminação }\end{array}$} & Asteca P 12W & 14 & \multirow{2}{*}{594} & \multirow{2}{*}{268} & \multirow{2}{*}{1310} & 13,20 & \multirow{2}{*}{245,1} & 67 \\
\hline & $34502 \times 28 W$ & 1 & & & & 60,30 & & 56 \\
\hline \multirow{2}{*}{$\begin{array}{c}\text { Itaim } \\
\text { Iluminação }\end{array}$} & Atlantis P 12W & 11 & \multirow{2}{*}{508} & \multirow{2}{*}{217} & \multirow{2}{*}{1258} & 13,20 & \multirow{2}{*}{205,5} & 68 \\
\hline & $34502 \times 28 W$ & 1 & & & & 60,30 & & 56 \\
\hline \multirow{2}{*}{$\begin{array}{c}\text { Itaim } \\
\text { Iluminação }\end{array}$} & Galaxia P 12W & 10 & \multirow{2}{*}{505} & \multirow{2}{*}{228} & \multirow{2}{*}{1219} & 13,20 & \multirow{2}{*}{192,3} & 69 \\
\hline & $34502 \times 28 W$ & 1 & & & & 60,30 & & 56 \\
\hline \multirow{2}{*}{$\begin{array}{c}\text { Itaim } \\
\text { Iluminação }\end{array}$} & Maia P 12W & 11 & \multirow{2}{*}{515} & \multirow{2}{*}{223} & \multirow{2}{*}{1259} & 13,20 & \multirow{2}{*}{205,5} & 70 \\
\hline & $34502 \times 28 W$ & 1 & & & & 60,30 & & 56 \\
\hline \multirow{2}{*}{ Philips } & $B B S 488-13 W$ & 8 & \multirow{2}{*}{521} & \multirow{2}{*}{185} & \multirow{2}{*}{1313} & 14,30 & \multirow{2}{*}{174,7} & 48 \\
\hline & $34502 \times 28 W$ & 1 & & & & 60,30 & & 56 \\
\hline \multirow{2}{*}{ Philips } & BBS498 - 28W & 4 & \multirow{2}{*}{537} & \multirow{2}{*}{191} & \multirow{2}{*}{1328} & 30,80 & \multirow{2}{*}{183,5} & 47 \\
\hline & $34502 \times 28 \mathrm{~W}$ & 1 & & & & 60,30 & & 56 \\
\hline
\end{tabular}


As luminárias de menor consumo, em destaque na Tabela 31, têm as seguintes características: a primeira é uma luminária quadrada com difusor em acrílico prismático e a segunda é circular, com fonte recuada, refletor em alumínio e fechamento em difusor translúcido.

Seguem as simulações dessas peças nas figuras 52 e 53.

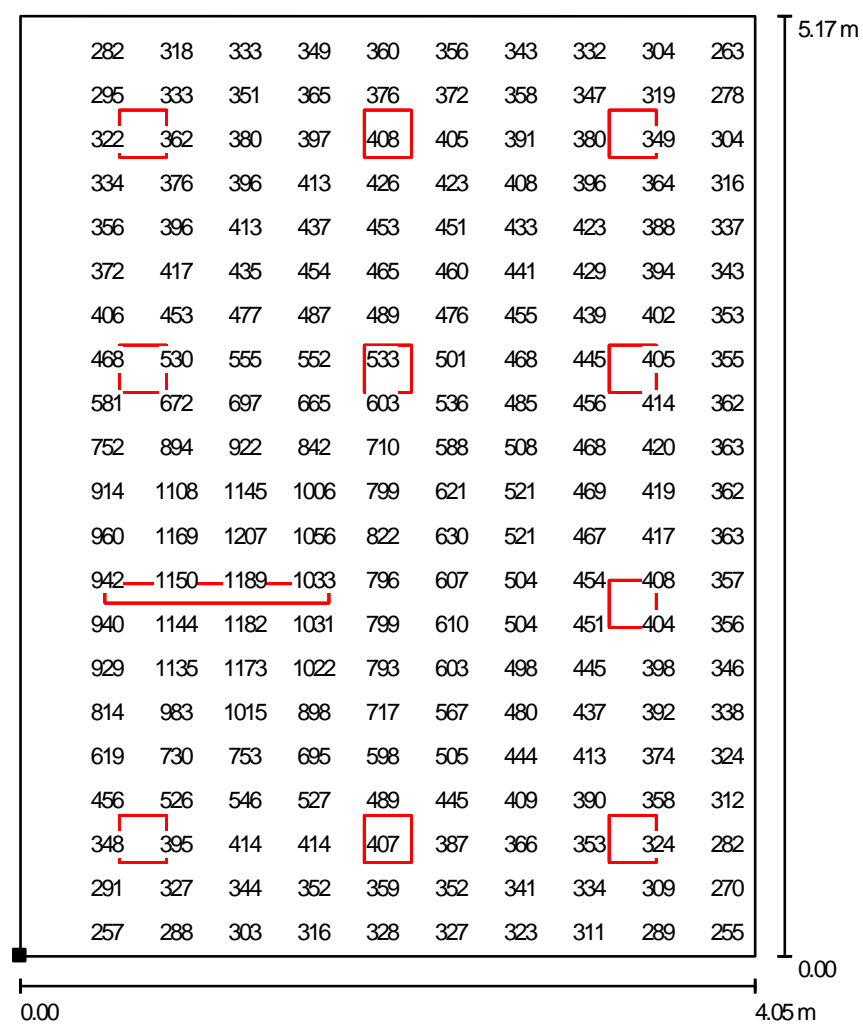

Figura 52: Simulação sala individual - luminária nacional tipo 69 para LED (Arquivo: ET-SI-LE-BR-1MX.dlx) 


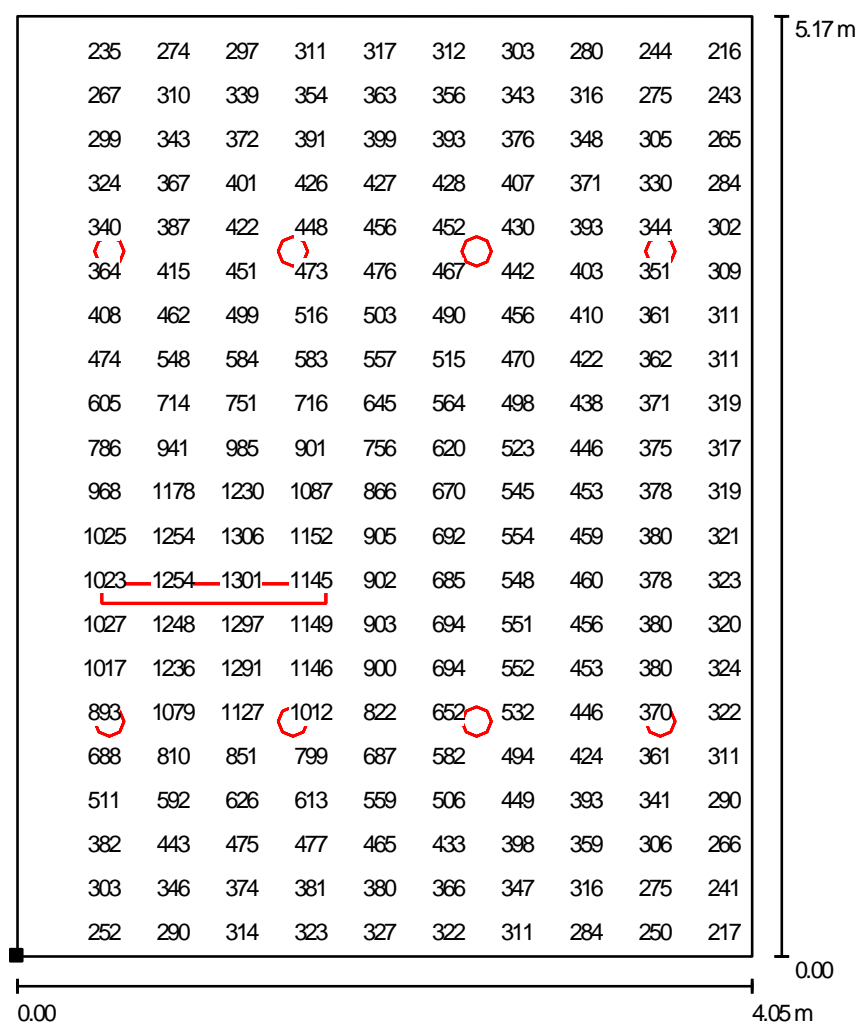

Figura 53: Simulação sala individual - luminária eficiente nacional tipo 48 para LED (Arquivo: ET-SI-LEBR-2-MX.dlx)

Do mesmo modo, foram feitas as simulações para escolha do sistema de iluminação de menor consumo para luminárias importadas. A Tabela 32 traz os resultados dessa simulação, onde as luminárias em destaque são as tipologias que tiveram menor consumo.

Tabela 32: Tabela sistema de iluminação importado - LED e pendente

\begin{tabular}{|c|c|c|c|c|c|c|c|c|}
\hline Fabricante & Código peça & $\begin{array}{l}\text { Qtde } \\
\text { pças }\end{array}$ & $\begin{array}{l}\text { Eméd } \\
(\mathrm{Ix})\end{array}$ & $\begin{array}{c}\text { Emín } \\
\text { (Ix) }\end{array}$ & $\begin{array}{c}\text { Emáx } \\
\text { (Ix) }\end{array}$ & $\begin{array}{l}\text { Potência } \\
\text { conj (W) }\end{array}$ & $\begin{array}{l}\text { Potência } \\
\text { total (W) }\end{array}$ & $\begin{array}{c}\text { Tipo/ } \\
\text { Anexo } \\
\text { Iuminária }\end{array}$ \\
\hline \multirow[b]{2}{*}{ Erco } & $47765.00034 \mathrm{~W}$ & 5 & \multirow[b]{2}{*}{581} & \multirow[b]{2}{*}{123} & \multirow[b]{2}{*}{1108} & 37,40 & \multirow[b]{2}{*}{217,5} & 54 \\
\hline & $\begin{array}{c}\text { CLARIS2 } 42156154 \\
1 \times 28 W\end{array}$ & 1 & & & & 30,50 & & 57 \\
\hline \multirow[b]{2}{*}{ Erco } & $47765.00034 W$ & 4 & \multirow[b]{2}{*}{558} & \multirow[b]{2}{*}{132} & \multirow[b]{2}{*}{1280} & 37,40 & \multirow[b]{2}{*}{209,9} & 54 \\
\hline & $\begin{array}{c}\text { CLARIS2 } 42156158 \\
2 \times 28 W\end{array}$ & 1 & & & & 60,30 & & 58 \\
\hline \multirow[b]{2}{*}{ Erco } & $47725.00027 \mathrm{~W}$ & 7 & \multirow[b]{2}{*}{542} & \multirow[b]{2}{*}{140} & \multirow[b]{2}{*}{950} & 29,70 & \multirow[b]{2}{*}{238,4} & 53 \\
\hline & $\begin{array}{c}\text { CLARIS2 } 42156154 \\
1 \times 28 W\end{array}$ & 1 & & & & 30,50 & & 57 \\
\hline \multirow[b]{2}{*}{ Erco } & Erco & 6 & \multirow[b]{2}{*}{551} & \multirow[b]{2}{*}{156} & \multirow[b]{2}{*}{1260} & 29,70 & \multirow[b]{2}{*}{238,5} & 53 \\
\hline & $\begin{array}{c}\text { CLARIS2 } 42156158 \\
2 \times 28 W \\
\end{array}$ & 1 & & & & 60,30 & & 58 \\
\hline Zumtobel & $\begin{array}{l}\text { L-FIELDS MINI } \\
4218016225 \mathrm{~W}\end{array}$ & 9 & 511 & 250 & 828 & 27,50 & 278,0 & 71 \\
\hline
\end{tabular}




\begin{tabular}{|c|c|c|c|c|c|c|c|c|}
\hline & $\begin{array}{c}\text { CLARIS2 } 42156154 \\
1 \times 28 W\end{array}$ & 1 & & & & 30,50 & & 57 \\
\hline \multirow{2}{*}{ Zumtobel } & $\begin{array}{l}\text { L-FIELDS MINI } \\
4218016225 \mathrm{~W}\end{array}$ & 8 & \multirow{2}{*}{550} & \multirow{2}{*}{231} & \multirow{2}{*}{1173} & 27,50 & \multirow{2}{*}{280,3} & 71 \\
\hline & $\begin{array}{c}\text { CLARIS2 } 42156158 \\
\text { 2x28W }\end{array}$ & 1 & & & & 60,30 & & 58 \\
\hline \multirow{2}{*}{ Zumtobel } & $\begin{array}{l}\text { L-FIELDS MINI } \\
4218016338 \mathrm{~W}\end{array}$ & 6 & \multirow{2}{*}{533} & \multirow{2}{*}{240} & \multirow{2}{*}{863} & 41,80 & \multirow{2}{*}{281,3} & 72 \\
\hline & $\begin{array}{c}\text { CLARIS2 } 42156154 \\
\text { 1x28W }\end{array}$ & 1 & & & & 30,50 & & 57 \\
\hline \multirow{2}{*}{ Zumtobel } & $\begin{array}{l}\text { L-FIELDS MINI } \\
4218016338 W\end{array}$ & 5 & \multirow{2}{*}{537} & \multirow{2}{*}{237} & \multirow{2}{*}{1086} & 41,80 & \multirow{2}{*}{269,3} & 72 \\
\hline & $\begin{array}{c}\text { CLARIS2 } 42156158 \\
2 \times 28 W\end{array}$ & 1 & & & & 60,30 & & 58 \\
\hline
\end{tabular}

A luminária da Erco é uma luminária circular, com refletor de alumínio, fonte de luz recuada, e difusor em vidro translúcido. A figura 54 mostra a simulação com esse sistema de iluminação.

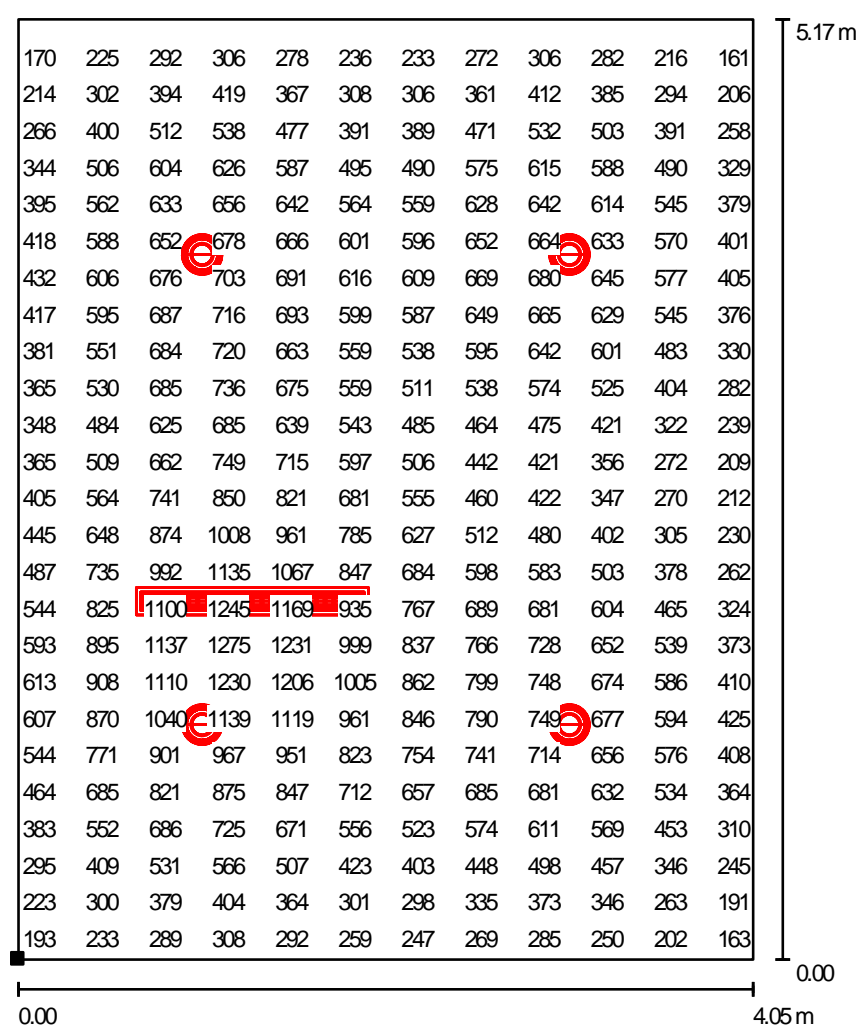

Figura 54: Simulação sala individual - luminária importada tipo 54 para LED (Arquivo: ET-SI-LE-EX-3MX.dlx)

E a figura 55 é a simulação da luminária da Zumtobel, quadrada com difusor translúcido. 


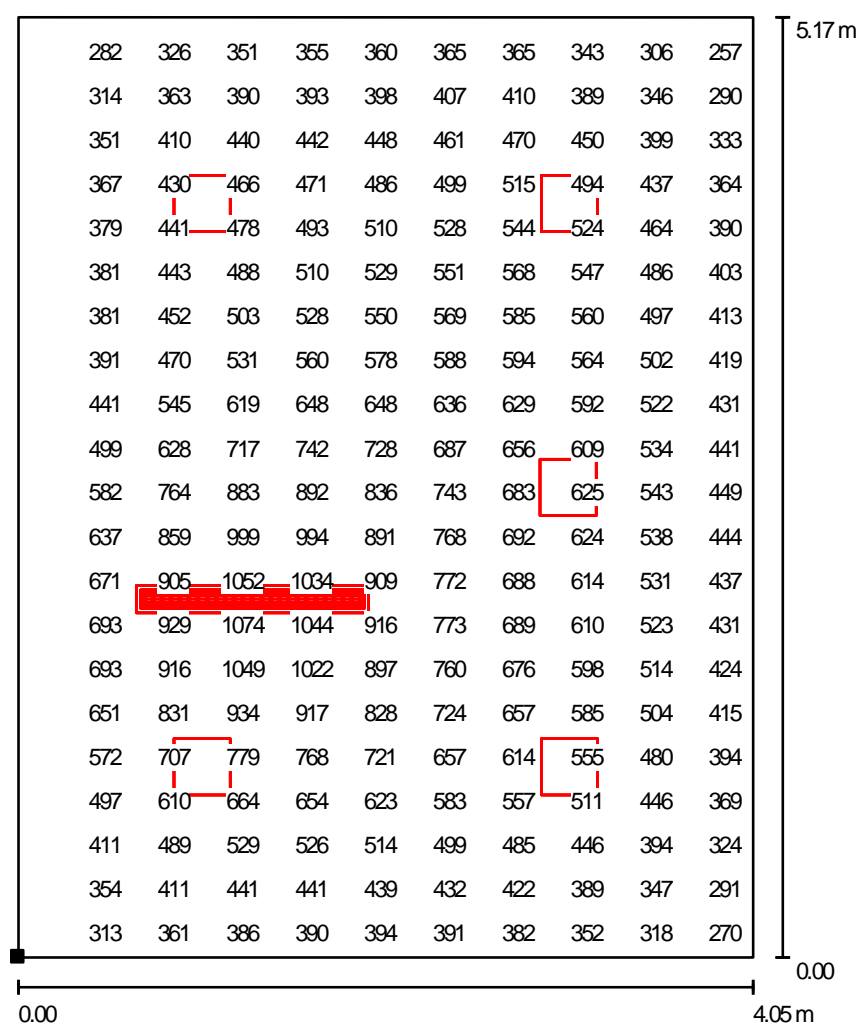

Figura 55: Simulação sala individual - luminária importada tipo 72 para LED (Arquivo: ET-SI-LE-EX-4MX.dlx)

\subsubsection{Sala de reuniões}

Para a sala de reuniões, também optou-se por mesclar dois sistemas de iluminação. Um que seria pontual e de destaque para a mesa de trabalho e outra que daria a luz geral do ambiente. Geralmente, nos projetos de iluminação, opta-se por diferenciar esse ambiente, uma vez que, é na sala de reuniões que ocorrem os grandes negócios.

Para simplificar a simulação, pois há inúmeras maneiras de projetar uma sala de reuniões, optou-se por um sistema de iluminação de destaque em cima da mesa de trabalho utilizando lâmpadas halógenas dicroicas, pois estas são próprias para essa finalidade ou apenas substituindo a lâmpada dicroica pela lâmpada LED de mesma base. 
E para simular a luz geral, optou-se por utilizar lâmpadas fluorescentes compactas não integradas ou LED, onde o sistema de iluminação produza luz difusa através de um difusor translúcido em vidro ou acrílico.

Na figura 56, temos a sala de reunião com o layout sugerido.

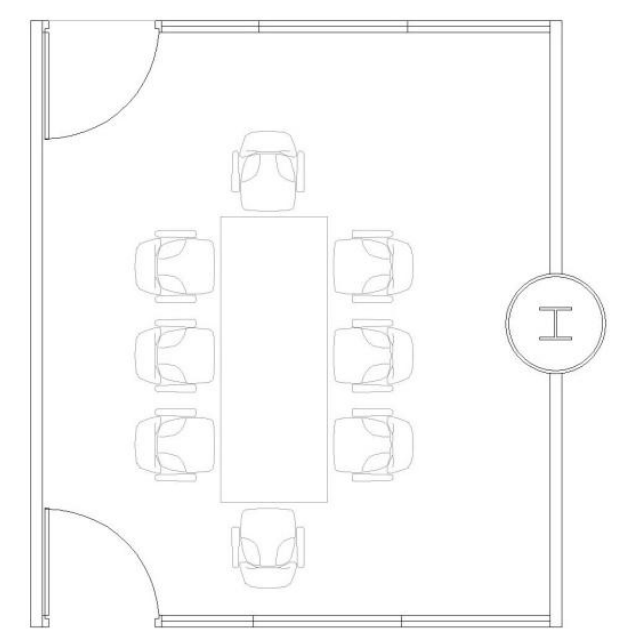

Figura 56: Sala de reunião a ser simulada

Para verificação do consumo energético, também foi feita uma simulação utilizando apenas um tipo de sistema de iluminação produzindo luz geral no ambiente.

Seguindo a NBR 5413/1992, o nível médio para a sala de reuniões é de 300 lux.

Iniciou-se a simulação utilizando apenas luz geral, com luminárias com difusor translúcido e luminárias com luz indireta, muito utilizada nesses ambientes.

Tabela 33: Tabela sistema de iluminação nacional - fluorescente tubular ou fluorescente compacta longa

\begin{tabular}{|c|c|c|c|c|c|c|c|c|}
\hline Fabricante & Código peça & $\begin{array}{c}\text { Qtde } \\
\text { pças }\end{array}$ & $\begin{array}{c}\text { Eméd } \\
\mathbf{( I x )}\end{array}$ & $\begin{array}{c}\text { Emín } \\
\mathbf{( I x )}\end{array}$ & $\begin{array}{c}\text { Emáx } \\
\mathbf{( I x )}\end{array}$ & $\begin{array}{c}\text { Potência } \\
\text { conj (W) }\end{array}$ & $\begin{array}{c}\text { Potência } \\
\text { total (W) }\end{array}$ & $\begin{array}{c}\text { Tipo/ } \\
\text { Anexo } \\
\text { luminária }\end{array}$ \\
\hline $\begin{array}{c}\text { Itaim } \\
\text { Iluminação }\end{array}$ & $21054 \times 14 W$ & 3 & 311 & 149 & 497 & 61,20 & 183,6 & 73 \\
\hline $\begin{array}{c}\text { Itaim } \\
\text { Iluminação }\end{array}$ & $25932 \times 24 W$ & 6 & 304 & 224 & 372 & 50,00 & 300,0 & 74 \\
\hline $\begin{array}{c}\text { Itaim } \\
\text { Iluminação }\end{array}$ & $\mathbf{2 5 9 4 2 \times 2 4 W}$ & $\mathbf{5}$ & $\mathbf{3 0 8}$ & $\mathbf{1 4 3}$ & $\mathbf{5 2 1}$ & $\mathbf{5 0 , 0 0}$ & $\mathbf{2 5 0 , 0}$ & $\mathbf{7 5}$ \\
\hline Lumini & FE-1433 4x14W & $\mathbf{3}$ & $\mathbf{3 5 7}$ & $\mathbf{1 6 0}$ & $\mathbf{5 8 3}$ & $\mathbf{6 1 , 2 0}$ & $\mathbf{1 8 3 , 6}$ & $\mathbf{7 6}$ \\
\hline Lumini & FE-4675 1x36W & $\mathbf{8}$ & 333 & 233 & 495 & 35,00 & 280,0 & 77 \\
\hline Lumini & FE-4680 2x36W & $\mathbf{4}$ & 313 & 202 & 381 & 69,00 & 276,0 & 78 \\
\hline
\end{tabular}


A luminária do fabricante Lumini em destaque na Tabela 33 é quadrada com difusor translúcido. Segue simulação na figura 57.

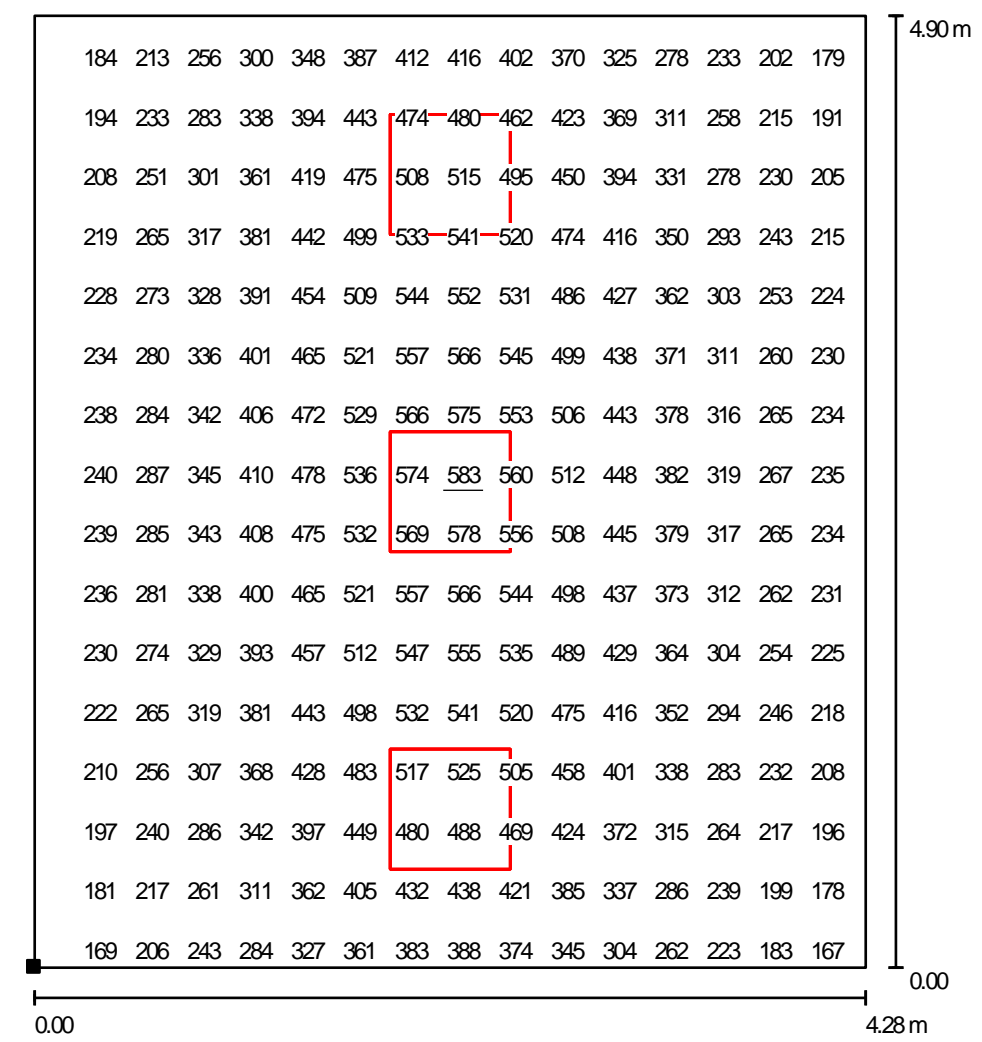

Figura 57: Simulação sala de reuniões - luminária nacional tipo 74 para fluorescente tubular (Arquivo: ET-SR-FT-BR-1-MX.dlx)

A outra luminária de menor consumo que foi utilizada na simulação é de luz indireta e difusa, quadrada, com refletor e defletor em aço pintados na cor branca. Essa luminária é muito especificada por light designers, por apresentar um design diferenciado da peça. Na figura 58 , temos a simulação feita com essa peça. 


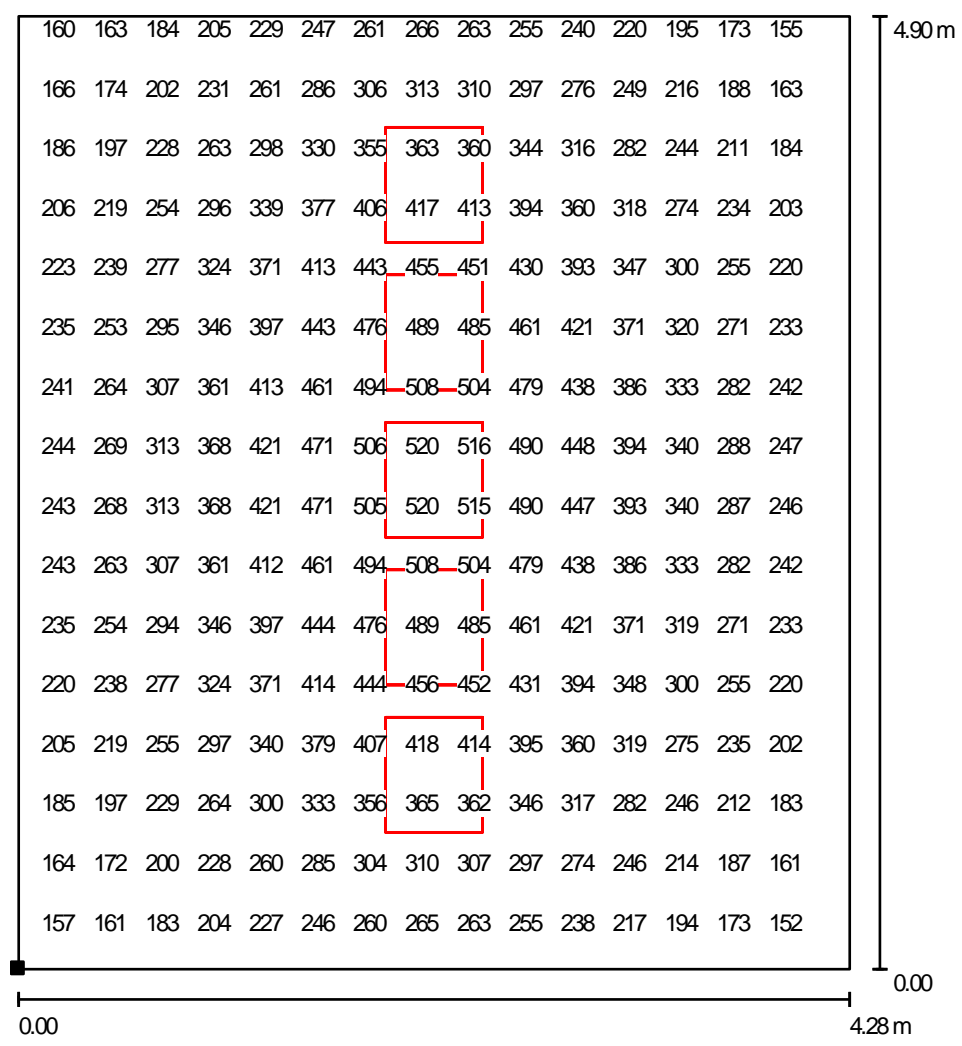

Figura 58: Simulação sala de reuniões - luminária nacional tipo 75 para fluorescente tubular (Arquivo: ET-SR-FT-BR-2-MX.dlx)

A Tabela 34 mostra a mesma situação das simulações realizadas anteriormente, aplicadas para luminárias importadas.

Tabela 34: Tabela sistema de iluminação importado - fluorescente tubular

\begin{tabular}{|c|c|c|c|c|c|c|c|c|}
\hline Fabricante & Código peça & $\begin{array}{l}\text { Qtde } \\
\text { pças }\end{array}$ & $\begin{array}{l}\text { Eméd } \\
\text { (Ix) }\end{array}$ & $\underset{\text { (Ix) }}{\text { Emín }}$ & $\begin{array}{c}\text { Emáx } \\
(I x)\end{array}$ & $\begin{array}{l}\text { Potência } \\
\text { conj (W) }\end{array}$ & $\begin{array}{l}\text { Potência } \\
\text { total (W) }\end{array}$ & $\begin{array}{c}\text { Tipo/ } \\
\text { Anexo } \\
\text { luminária }\end{array}$ \\
\hline Zumtobel & $\begin{array}{c}\text { L-FIELDS } 42177999 \\
4 \times 14 W\end{array}$ & 2 & 373 & 98 & 672 & 61,20 & 122,4 & 79 \\
\hline Zumtobel & $\begin{array}{l}\text { MELLOW LIGHT } \\
421748012 \times 24 W\end{array}$ & 3 & 314 & 133 & 499 & 50,00 & 150,0 & 80 \\
\hline Zumtobel & $\begin{array}{c}\text { MELLOW LIGHT } \\
421593612 \times 24 \mathrm{~W}+ \\
2 \times 24 \mathrm{~W}\end{array}$ & 4 & 321 & 204 & 400 & 100,00 & 400,0 & 81 \\
\hline Zumtobel & $\begin{array}{l}\text { MELLOW LIGHT } \\
421062352 \times 24 W \\
\end{array}$ & 3 & 303 & 130 & 471 & 50,00 & 150,0 & 82 \\
\hline
\end{tabular}

A luminária da Zumtobel corresponde às mesmas especificações da luminária da Lumini. É uma luminária quadrada, com difusor translúcido para 4 lâmpadas fluorescente tubular. 
Seguem as simulações das peças de menor consumo da Tabela 34 nas figuras 59 e 60 .

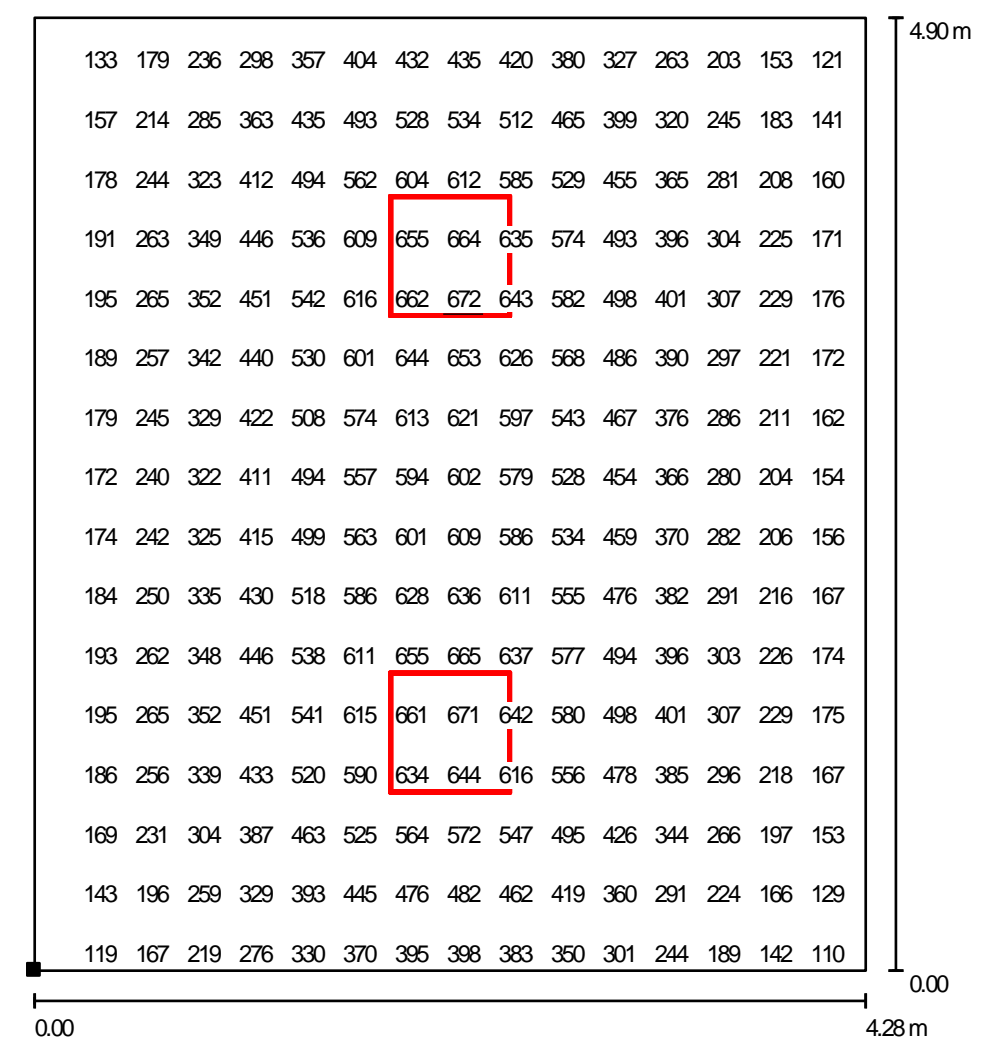

Figura 59: Simulação sala de reuniões - luminária importada tipo 79 para fluorescente tubular (Arquivo: ET-SR-FT-EX-3-MX.dlx)

Novamente, percebemos comparando as simulações da figura 57 e da figura 59 que a luminária importada é mais eficiente. Aparentemente as duas peças são iguais.

A outra luminária da Zumtobel é de luz indireta central com defletor e difusor para 2 lâmpadas fluorescente tubular T5 de 24W. 


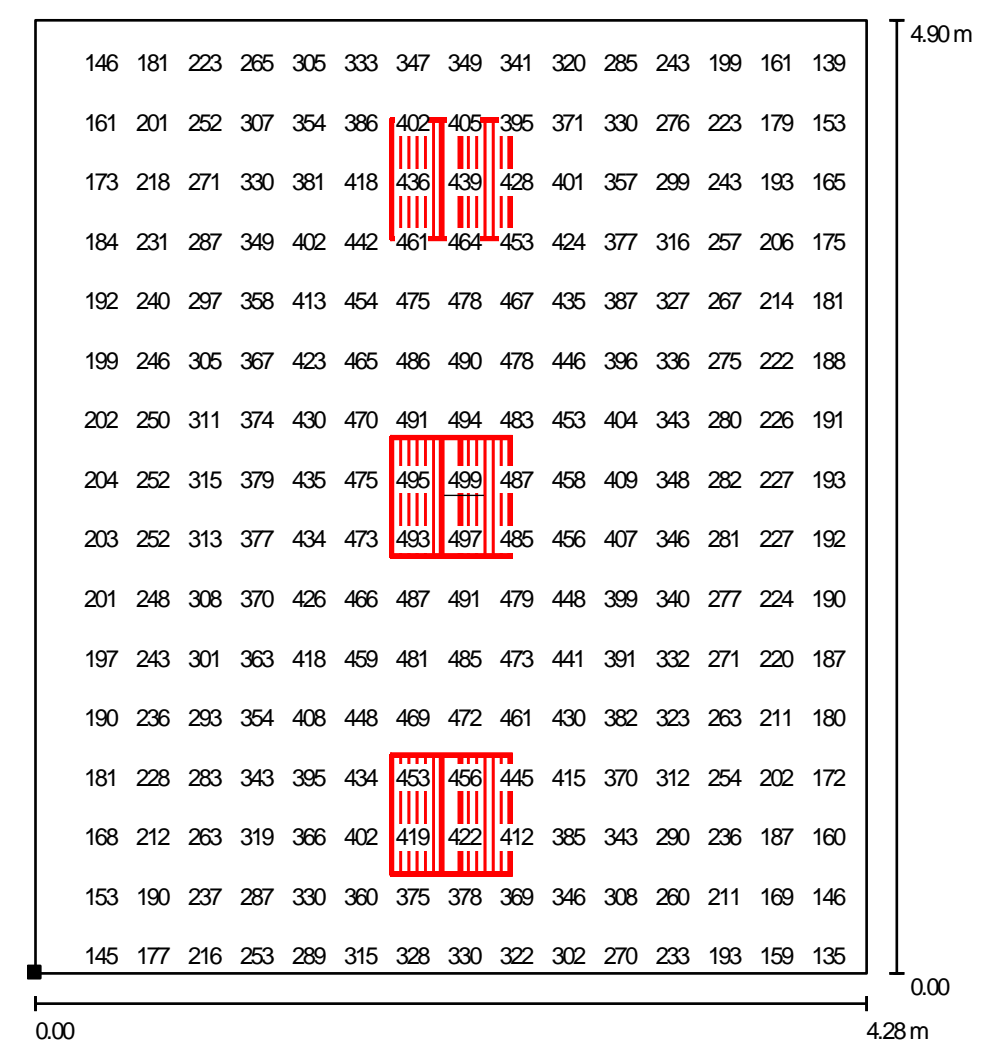

Figura 60: Simulação sala de reuniões - luminária importada tipo 80 para fluorescente tubular (Arquivo: ET-SR-FT-EX-4-MX.dlx)

As próximas simulações foram feitas a partir de 2 tipos de sistema de iluminação, luz de destaque sobre a mesa de reunião, com lâmpada halógena ou lâmpada LED e complemento de luz geral com lâmpada fluorescente compacta ou luminária de LED.

Para lâmpada dicroica utilizaremos apenas a fotometria da lâmpada, pois nas luminárias nacionais, ela serve apenas para segurar a lâmpada.

Tabela 35: Tabela sistema de iluminação nacional - halógena e fluorescente compacta

\begin{tabular}{|c|c|c|c|c|c|c|c|c|}
\hline Fabricante & Código peça & $\begin{array}{l}\text { Qtde } \\
\text { pças }\end{array}$ & $\begin{array}{l}\text { Eméd } \\
(\mathrm{Ix})\end{array}$ & $\begin{array}{l}\text { Emín } \\
\text { (Ix) }\end{array}$ & $\begin{array}{c}\text { Emáx } \\
\text { (Ix) }\end{array}$ & $\begin{array}{l}\text { Potência } \\
\text { conj (W) }\end{array}$ & $\begin{array}{l}\text { Potência } \\
\text { total (W) }\end{array}$ & $\begin{array}{c}\text { Tipo/ } \\
\text { Anexo } \\
\text { Iuminária }\end{array}$ \\
\hline \multirow{2}{*}{$\underset{\text { Iltaiminação }}{\text { Iluminact }}$} & $\begin{array}{c}\text { Lâmpada dicróica } \\
\text { 35W 36ㅇ }\end{array}$ & 3 & \multirow[t]{2}{*}{441} & \multirow[t]{2}{*}{199} & \multirow[t]{2}{*}{1374} & 38,50 & \multirow[t]{2}{*}{451,5} & 83 \\
\hline & Cianita 2x26W & 6 & & & & 56,00 & & 84 \\
\hline \multirow{2}{*}{$\begin{array}{c}\text { Itaim } \\
\text { iluminação }\end{array}$} & $\begin{array}{c}\text { Lâmpada dicróica } \\
\text { 35W 36o }\end{array}$ & 3 & \multirow[t]{2}{*}{382} & \multirow[t]{2}{*}{154} & \multirow[t]{2}{*}{1305} & 38,50 & \multirow[t]{2}{*}{451,50} & 83 \\
\hline & Prata-E 2x26W & 6 & & & & 56,00 & & 85 \\
\hline \multirow[t]{2}{*}{ Lumini } & $\begin{array}{c}\text { Lâmpada dicróica } \\
\text { 35W 36o }\end{array}$ & 3 & \multirow[t]{2}{*}{436} & \multirow{2}{*}{177} & \multirow[t]{2}{*}{1363} & 38,50 & \multirow[t]{2}{*}{339,5} & 83 \\
\hline & $E-44332 \times 26 W$ & 4 & & & & 56,00 & & 86 \\
\hline \multirow{2}{*}{ Lumini } & $\begin{array}{l}\text { Lâmpada dicróica } \\
\text { 35W 36으 }\end{array}$ & 3 & \multirow[t]{2}{*}{397} & \multirow{2}{*}{141} & \multirow{2}{*}{1326} & 38,50 & \multirow[t]{2}{*}{451,5} & 83 \\
\hline & E-4033 V 2x26W & 6 & & & & 56,00 & & 87 \\
\hline
\end{tabular}


Observando a Tabela 35, o conjunto em destaque da Lumini tem o menor consumo. E a escolha pela luminária da Itaim em destaque é justificada pela distribuição de luz mais homogênea com o nível médio mais alto. Ambas as luminárias escolhidas tem as mesmas características, são quadradas com difusor translúcido.

As figuras 61 e 62 mostram a simulação dessas peças. Os valores ponto a ponto são muito próximos, no entanto observando na simulação da figura 61 temos menos luminárias que na simulação da figura 62 com a luminária do fabricante Itaim Iluminação.

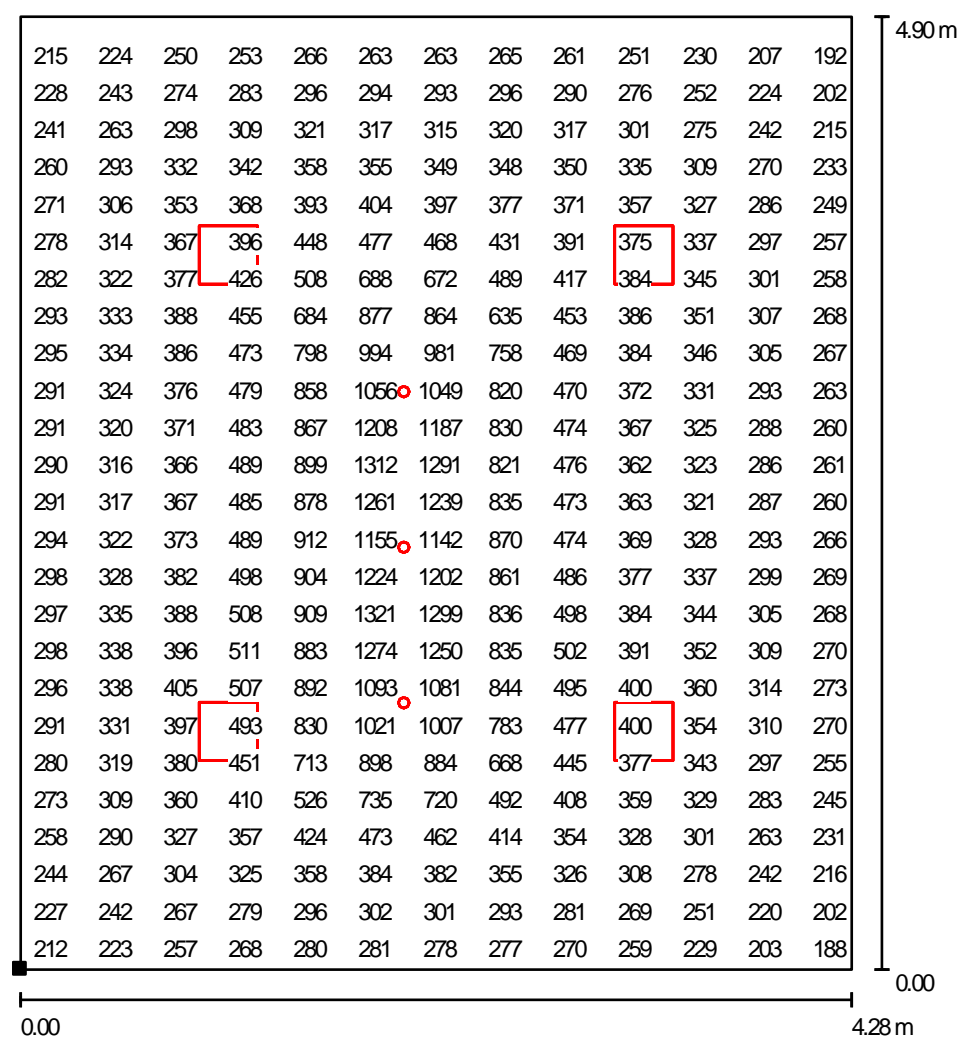

Figura 61: Simulação sala de reuniões - luminária nacional tipo 86 - halógena e fluorescente compacta (Arquivo: ET-SR-FH-BR-1-MX.dlx) 


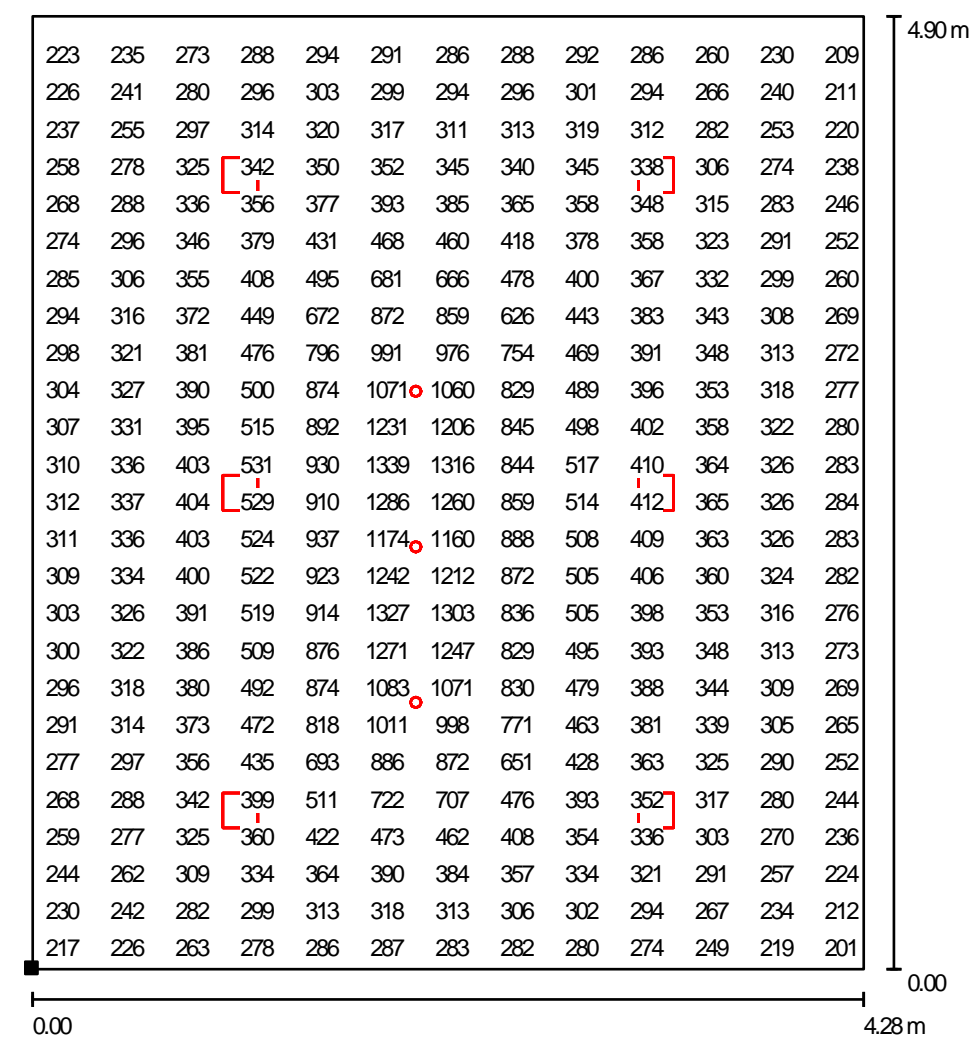

Figura 62: Simulação sala de reuniões - luminária nacional tipo 84 - halógena e fluorescente compacta (Arquivo: ET-SR-FH-BR-2-MX.dlx)

A Tabela 36 abaixo, temos os mesmos conjuntos: luz de destaque na mesa de reuniões e luz geral com lâmpadas fluorescente compacta. Nesse caso, foi utilizada uma luminária para a luz de destaque, pois na mesma, a fonte de luz é recuada para reduzir o ofuscamento.

Tabela 36: Tabela sistema de iluminação importado - halógena e fluorescente compacta

\begin{tabular}{|c|c|c|c|c|c|c|c|c|}
\hline Fabricante & Código peça & $\begin{array}{l}\text { Qtde } \\
\text { pças }\end{array}$ & $\begin{array}{l}\text { Eméd } \\
(I x)\end{array}$ & $\begin{array}{c}\text { Emín } \\
(\mathbf{I x})\end{array}$ & $\begin{array}{c}\text { Emáx } \\
(\mathbf{I x})\end{array}$ & $\begin{array}{l}\text { Potência } \\
\text { conj (W) }\end{array}$ & $\begin{array}{l}\text { Potência } \\
\text { total (W) }\end{array}$ & $\begin{array}{c}\text { Tipo/ } \\
\text { Anexo } \\
\text { luminária }\end{array}$ \\
\hline \multirow{2}{*}{ Erco } & $\begin{array}{c}37009.0001 \times 35 \mathrm{~W} \\
360\end{array}$ & 3 & \multirow{2}{*}{442} & \multirow[t]{2}{*}{162} & \multirow{2}{*}{1301} & 38,50 & \multirow{2}{*}{259,50} & 88 \\
\hline & $37618.0001 \times 32 W$ & 4 & & & & 36,00 & & 33 \\
\hline \multirow[t]{2}{*}{ Erco } & $\begin{array}{c}37009.0001 \times 35 W \\
36 \circ \\
\end{array}$ & 3 & \multirow[t]{2}{*}{308} & \multirow[t]{2}{*}{105} & \multirow[t]{2}{*}{1113} & 38,50 & \multirow[t]{2}{*}{217,5} & 88 \\
\hline & $37627.0001 \times 14 W$ & 6 & & & & 17,00 & & 89 \\
\hline \multirow{2}{*}{ Erco } & $\begin{array}{c}37009.0001 \times 35 \mathrm{~W} \\
36 \circ\end{array}$ & 3 & \multirow{2}{*}{304} & \multirow{2}{*}{102} & \multirow{2}{*}{1101} & 38,50 & \multirow{2}{*}{235,5} & 88 \\
\hline & $37600.0001 \times 18 \mathrm{~W}$ & 6 & & & & 20,00 & & 90 \\
\hline \multirow[t]{2}{*}{ Erco } & $\begin{array}{c}37009.0001 \times 35 \mathrm{~W} \\
360\end{array}$ & 3 & \multirow[t]{2}{*}{454} & \multirow[t]{2}{*}{159} & \multirow[t]{2}{*}{1269} & 38,50 & \multirow[t]{2}{*}{339,50} & 88 \\
\hline & $37614.0002 \times 26 \mathrm{~W}$ & 4 & & & & 56,00 & & 91 \\
\hline \multirow{2}{*}{ Zumtobel } & $\begin{array}{c}37009.0001 \times 35 W \\
360\end{array}$ & 3 & \multirow{2}{*}{343} & \multirow{2}{*}{107} & \multirow{2}{*}{1114} & 38,50 & \multirow{2}{*}{259,50} & 88 \\
\hline & $\begin{array}{c}\text { L-FIELDS } 42159214 \\
1 \times 32 W \\
\end{array}$ & 4 & & & & 36,00 & & 92 \\
\hline
\end{tabular}


Seguem as simulações das luminárias de menor consumo em destaque na tabela acima. A luminária da figura 63 é a luminária da Erco, quadrada, com refletor em alumínio, fonte de luz recuada, protegida com vidro translúcido.

\begin{tabular}{|c|c|c|c|c|c|c|c|c|c|c|c|c|c|}
\hline 113 & 125 & 137 & 146 & 152 & 158 & 166 & 158 & 152 & 147 & 138 & 129 & 118 & $90 \mathrm{~m}$ \\
\hline 122 & 138 & 153 & 164 & 170 & 175 & 182 & 174 & 171 & 165 & 155 & 143 & 127 & \\
\hline 129 & 149 & 168 & 178 & 188 & 192 & 199 & 190 & 187 & 179 & 170 & 154 & 133 & \\
\hline 132 & 157 & 174 & 183 & 196 & 202 & 207 & 198 & 194 & 184 & 175 & 163 & 137 & \\
\hline 139 & 166 & 186 & 198 & 217 & 231 & 237 & 220 & 211 & 196 & 185 & 172 & 145 & \\
\hline 147 & 173 & 194 & 213 & 246 & 278 & 286 & 250 & 224 & 205 & 191 & 178 & 153 & \\
\hline 158 & 182 & 207 & 239 & 304 & 377 & 389 & 313 & 248 & 219 & 203 & 185 & 163 & \\
\hline 162 & 187 & 214 & 266 & 385 & 505 & 517 & 397 & 275 & 226 & 206 & 188 & 167 & \\
\hline 167 & 192 & 223 & 304 & 481 & 644 & 656 & 495 & 313 & 235 & 209 & 192 & 170 & \\
\hline 169 & 195 & 232 & 342 & 568 & 788 & 800 & 580 & 350 & 244 & 214 & 194 & 172 & \\
\hline 168 & 199 & 243 & 372 & 642 & $919^{\circ}$ & 928 & 649 & 380 & 256 & 220 & 198 & 170 & \\
\hline 166 & 199 & 244 & 383 & 693 & 987 & 994 & 696 & 393 & 257 & 219 & 197 & 170 & \\
\hline 164 & 199 & 247 & 389 & 723 & 1011 & 1016 & 723 & 401 & 258 & 219 & 198 & 168 & \\
\hline 165 & 200 & 248 & 391 & 724 & 1032 & 1037 & 725 & 403 & 260 & 220 & 198 & 167 & \\
\hline 168 & 201 & 250 & 398 & 717 & . & 1055 & 721 & 406 & 264 & 222 & 198 & 170 & \\
\hline 170 & 201 & 249 & 396 & 720 & 1040 & 1051 & 727 & 403 & 262 & 221 & 198 & 171 & \\
\hline 170 & 198 & 243 & 387 & 720 & 1020 & 1031 & 730 & 394 & 255 & 216 & 194 & 171 & \\
\hline 168 & 195 & 240 & 379 & 700 & 996 & 1008 & 710 & 386 & 251 & 213 & 192 & 169 & \\
\hline 160 & 190 & 234 & 367 & 650 & 941 & 951 & 658 & 373 & 246 & 210 & 188 & 166 & \\
\hline 156 & 186 & 228 & 344 & 588 & $828^{\circ}$ & 836 & 592 & 351 & 239 & 207 & 185 & 160 & \\
\hline 147 & 176 & 211 & 300 & 501 & 674 & 680 & 503 & 311 & 222 & 196 & 178 & 151 & \\
\hline 139 & 168 & 200 & 260 & 404 & 530 & 535 & 405 & 270 & $209 \overline{1}$ & 188 & 170 & 144 & \\
\hline 132 & 155 & 182 & 220 & 306 & 390 & 395 & 307 & 230 & 194 & 177 & 158 & 136 & \\
\hline 127 & 147 & 170 & 193 & 234 & 277 & 284 & 237 & 201 & 182 & 168 & 150 & 130 & \\
\hline 118 & 133 & 150 & 166 & 186 & 204 & 209 & 191 & 172 & 160 & 149 & 135 & 121 & \\
\hline
\end{tabular}

Figura 63: Simulação sala de reuniões - luminária importada tipo 89 - halógena e fluorescente compacta (Arquivo: ET-SR-FH-EX-3-MX.dlx) 


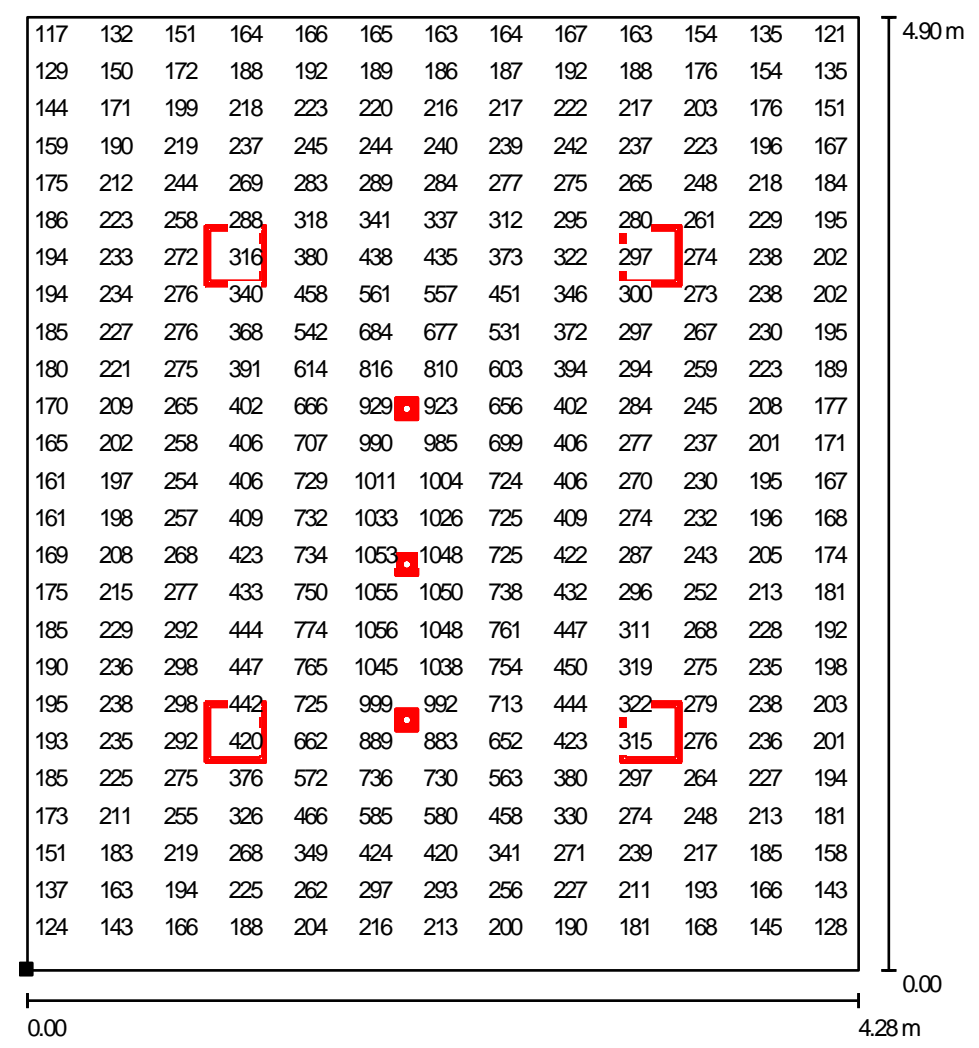

Figura 64: Simulação sala de reuniões - luminária importada tipo 92 - halógena e fluorescente compacta (Arquivo: ET-SR-FH-EX-4-MX.dlx)

Diferente das simulações do sistema de iluminação nacional anteriores, as luminárias utilizadas são diferentes. A da simulação da figura 64 Zumtobel, é uma luminária quadrada com difusor translúcido rente à borda.

No próximo conjunto de simulações, substituiremos a lâmpada dicroica, por uma lâmpada LED de 7W 25․ Nesse caso, também utilizaremos a fotometria da lâmpada diretamente.

Observando a Tabela 37, apenas com a substituição das lâmpadas de destaque, obtivemos o nível médio de acordo com a norma.

Tabela 37: Tabela sistema de iluminação nacional - LED e fluorescente compacta

\begin{tabular}{|c|c|c|c|c|c|c|c|c|}
\hline Fabricante & Código peça & $\begin{array}{l}\text { Qtde } \\
\text { pças }\end{array}$ & $\begin{array}{c}\text { Eméd } \\
\text { (Ix) }\end{array}$ & $\begin{array}{c}\text { Emín } \\
(\mathbf{I x})\end{array}$ & $\begin{array}{c}\text { Emáx } \\
\text { (Ix) }\end{array}$ & $\begin{array}{l}\text { Potência } \\
\text { conj (W) }\end{array}$ & $\begin{array}{l}\text { Potência } \\
\text { total (W) }\end{array}$ & $\begin{array}{c}\text { Tipo/ } \\
\text { Anexo } \\
\text { Iuminária }\end{array}$ \\
\hline \multirow{2}{*}{$\underset{\text { iluminação }}{\text { Itaim }}$} & $\begin{array}{c}\text { Lâmpada LED } 7 W \\
250\end{array}$ & 3 & \multirow[t]{2}{*}{336} & \multirow[t]{2}{*}{182} & \multirow[t]{2}{*}{724} & 7,70 & \multirow[t]{2}{*}{359,1} & 93 \\
\hline & Cianita $2 \times 26 \mathrm{~W}$ & 6 & & & & 56,00 & & 84 \\
\hline \multirow{2}{*}{ Lumini } & $\begin{array}{c}\text { Lâmpada dicróica } \\
25 W 360\end{array}$ & 3 & \multirow[t]{2}{*}{327} & \multirow[t]{2}{*}{162} & \multirow[t]{2}{*}{716} & 7,70 & \multirow[t]{2}{*}{247,1} & 93 \\
\hline & $E-44332 \times 26 W$ & 4 & & & & 56,00 & & 86 \\
\hline
\end{tabular}


Seguem nas figuras 65 e $66 \mathrm{com}$ as simulações dessa substituição. A figura

65 corresponde à simulação da luminária do fabricante Lumini e a figura 66 do fabricante Itaim lluminação.

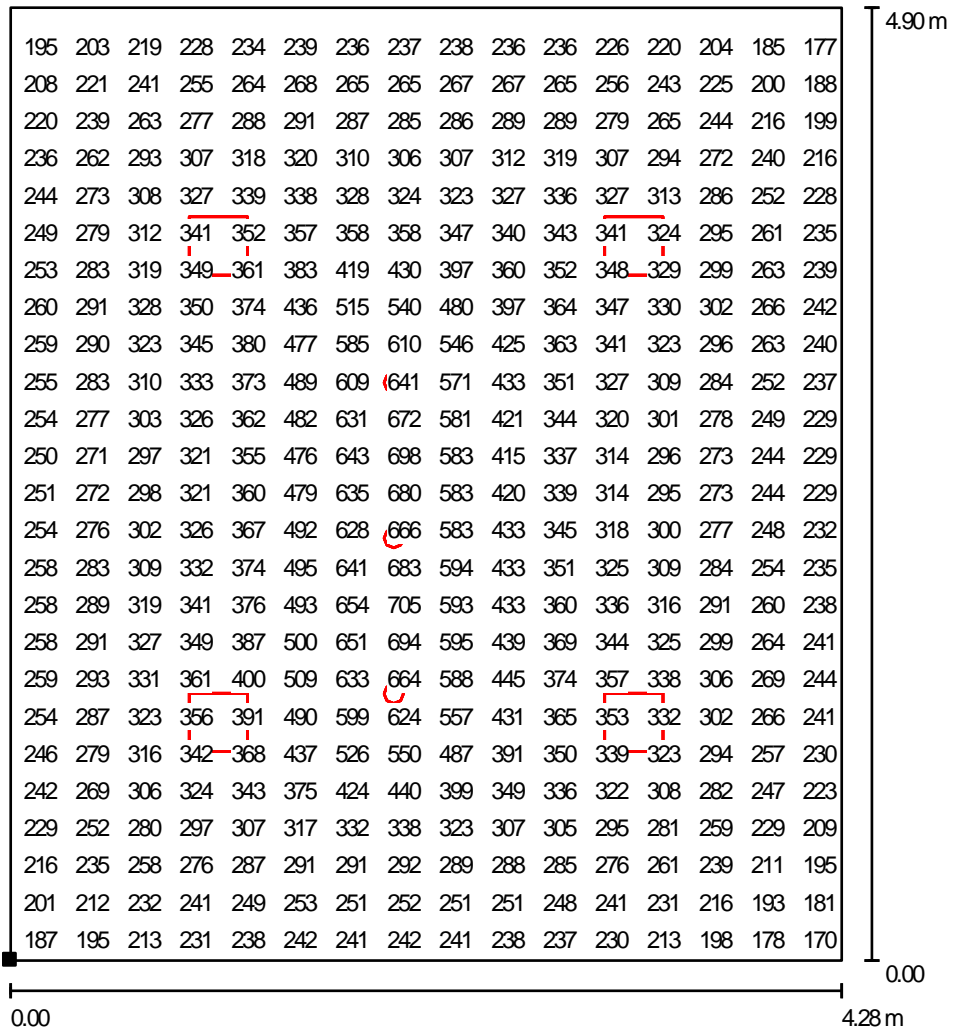

Figura 65: Simulação sala de reuniões - luminária nacional tipo 1 - LED e fluorescente compacta (Arquivo: ET-SR-FL-BR-1-MX.dlx) 


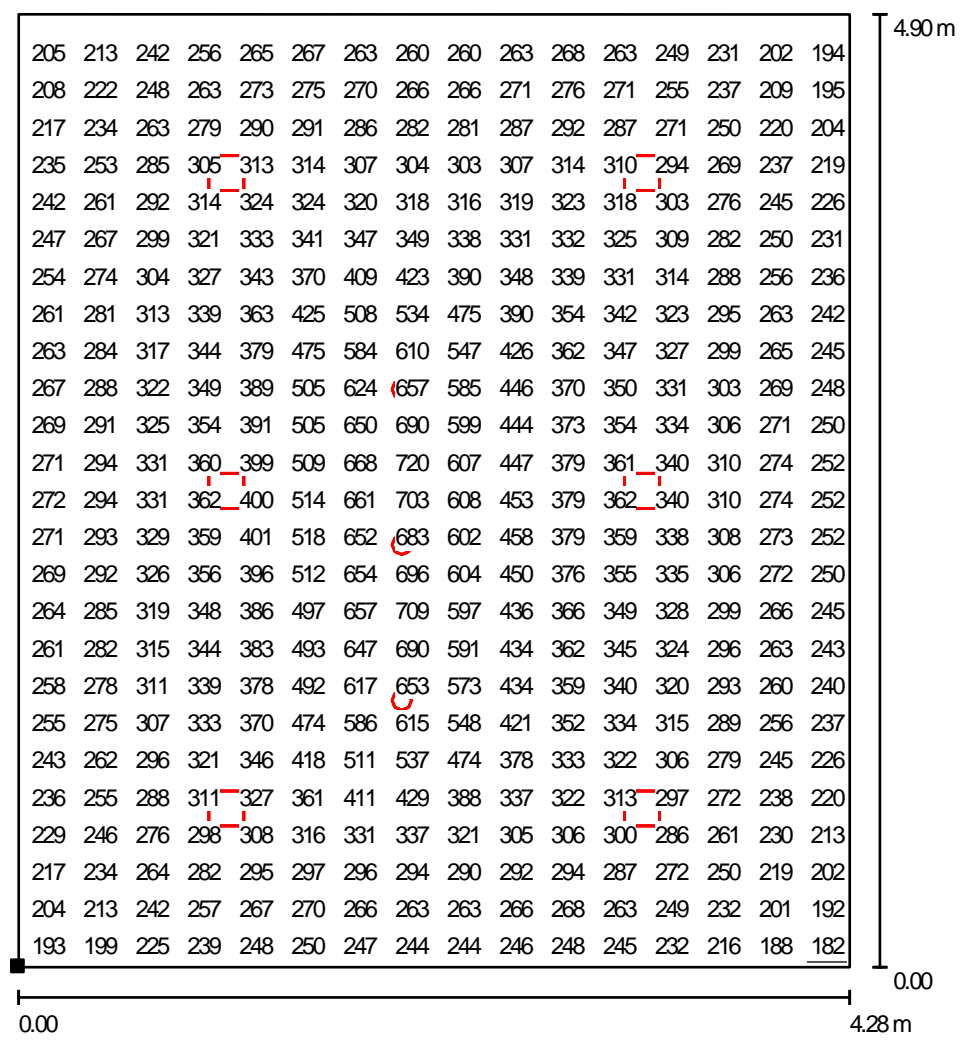

Figura 66: Simulação sala de reuniões - luminária nacional tipo 2 - LED e fluorescente compacta (Arquivo: ET-SR-FL-BR-2-MX.dlx)

Comparando as simulações dessa substituição, notamos que o valor ponto a ponto da mesa de reuniões teve uma redução, ou seja, apesar do fabricante afirmar que a lâmpada LED em questão pode substituir uma lâmpada dicroica sem perda de luz, a luminância das lâmpadas não é a mesma. Observa-se que é menor.

Na Tabela 38 onde foi feita apenas a substituição das lâmpadas de destaque dos sistemas de iluminação importados, não foi possível alcançar o nível solicitado pela norma. Então, foi realizada outra simulação, no caso, com outras luminárias, para assim alcançar o nível médio solicitado da norma.

As luminárias utilizadas para se alcançar o nível solicitado, tem mesmas características das luminárias importadas simuladas no conjunto halógena e fluorescente compacta, porém utilizam lâmpadas de potência maior. 
Tabela 38: Tabela sistema de iluminação importado - LED e fluorescente compacta

\begin{tabular}{|c|c|c|c|c|c|c|c|c|}
\hline Fabricante & Código peça & $\begin{array}{l}\text { Qtde } \\
\text { pças }\end{array}$ & $\begin{array}{c}\text { Eméd } \\
(\mathbf{I x})\end{array}$ & $\underset{(\mathbf{I x})}{\text { Emín }}$ & $\underset{\text { (Ix) }}{\text { Emáx }}$ & $\begin{array}{l}\text { Potência } \\
\text { conj (W) }\end{array}$ & $\begin{array}{l}\text { Potência } \\
\text { total (W) }\end{array}$ & $\begin{array}{c}\text { Tipo/ } \\
\text { Anexo } \\
\text { luminária }\end{array}$ \\
\hline \multirow{2}{*}{ Erco } & $\begin{array}{c}\text { Lâmpada LED 7W } \\
350\end{array}$ & 3 & \multirow{2}{*}{229} & \multirow{2}{*}{104} & \multirow{2}{*}{621} & 7,70 & \multirow{2}{*}{125,1} & 93 \\
\hline & $37627.0001 \times 14 \mathrm{~W}$ & 6 & & & & 17,00 & & 89 \\
\hline \multirow{2}{*}{ Erco } & $\begin{array}{c}\text { Lâmpada LED 7W } \\
\text { 35o }\end{array}$ & 3 & \multirow{2}{*}{308} & \multirow{2}{*}{165} & \multirow{2}{*}{779} & 7,70 & \multirow{2}{*}{197,1} & 93 \\
\hline & $37604.0001 \times 26 W$ & 6 & & & & 29,00 & & 94 \\
\hline \multirow{2}{*}{ Zumtobel } & $\begin{array}{c}\text { Lâmpada LED 7W } \\
350\end{array}$ & 3 & \multirow{2}{*}{263} & \multirow{2}{*}{104} & \multirow{2}{*}{646} & 7,70 & \multirow{2}{*}{167,1} & 93 \\
\hline & $\begin{array}{c}\text { L-FIELDS } 42159214 \\
1 \times 32 \mathrm{~W}\end{array}$ & 4 & & & & 36,00 & & 92 \\
\hline \multirow{2}{*}{ Zumtobel } & $\begin{array}{c}\text { Lâmpada LED } 7 W \\
350 \\
\end{array}$ & 3 & \multirow{2}{*}{340} & \multirow{2}{*}{140} & \multirow{2}{*}{742} & 7,70 & \multirow{2}{*}{211,1} & 88 \\
\hline & $\begin{array}{c}\text { L-FIELDS } 42159216 \\
1 \times 42 W\end{array}$ & 4 & & & & 47,00 & & 112 \\
\hline
\end{tabular}

Seguem nas figuras 67 e $68 \mathrm{com}$ as simulações ponto a ponto das substituições realizadas.

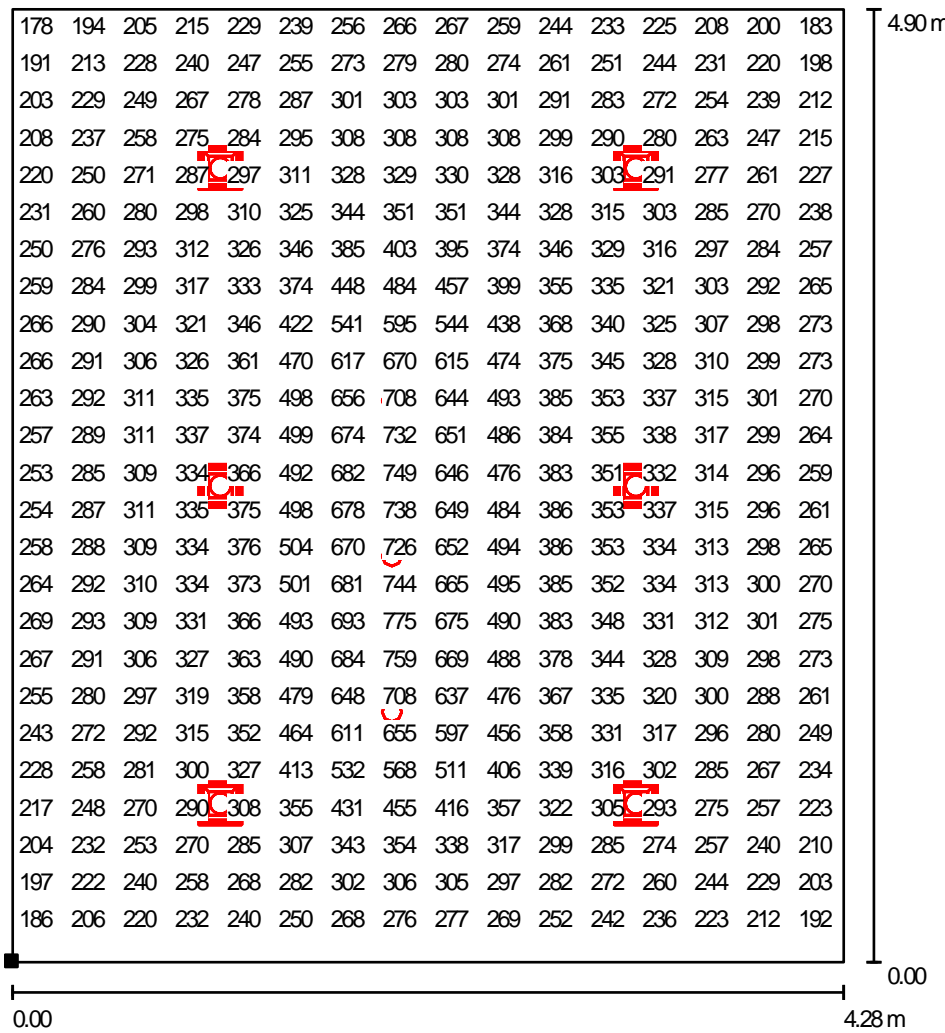

Figura 67: Simulação sala de reuniões - luminária importada tipo 94 - LED e fluorescente compacta (Arquivo: ET-SR-FL-EX-3-MX.dlx) 


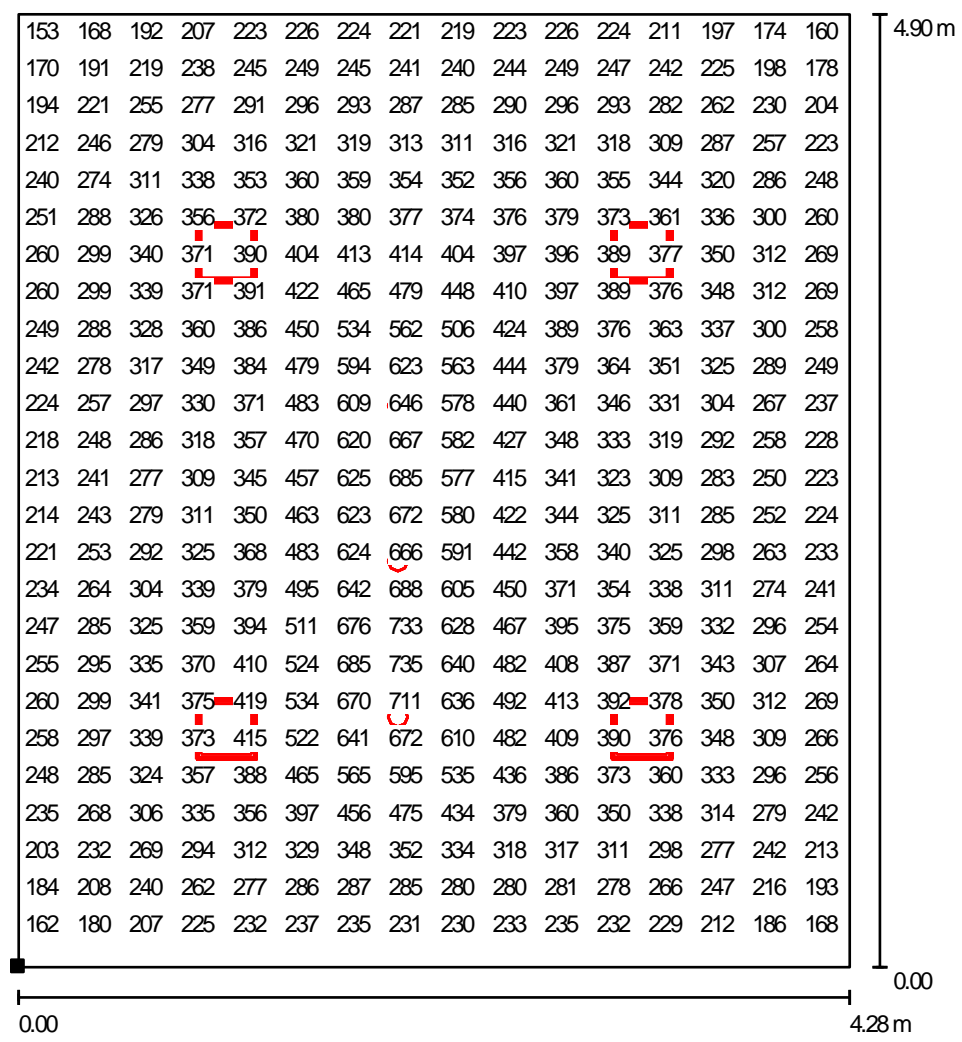

Figura 68: Simulação sala de reuniões - luminária importada tipo 112 - LED e fluorescente compacta (Arquivo: ET-SR-FL-EX-4-MX.dlx)

As próximas simulações serão as do conjunto luz de destaque com lâmpada halógena e luz geral com luminária em LED. Do mesmo modo que foi realizado nas outras simulações, faremos com o sistema de iluminação nacional e posteriormente com o sistema de iluminação importado.

Tabela 39: Tabela sistema de iluminação nacional - Halógena e LED

\begin{tabular}{|c|c|c|c|c|c|c|c|c|}
\hline Fabricante & Cóque as digo peça & $\begin{array}{l}\text { Qtde } \\
\text { pças }\end{array}$ & $\begin{array}{l}\text { Eméd } \\
(\mathbf{I x})\end{array}$ & $\begin{array}{c}\text { Emín } \\
\text { (Ix) }\end{array}$ & $\begin{array}{c}\text { Emáx } \\
\text { (Ix) }\end{array}$ & $\begin{array}{l}\text { Potência } \\
\text { conj (W) }\end{array}$ & $\begin{array}{l}\text { Potência } \\
\text { total (W) }\end{array}$ & $\begin{array}{c}\text { Tipo/ } \\
\text { Anexo } \\
\text { luminária }\end{array}$ \\
\hline \multirow{2}{*}{ Itaim } & $\begin{array}{c}37009.0001 \times 35 W \\
360\end{array}$ & 3 & \multirow[t]{2}{*}{365} & \multirow[t]{2}{*}{146} & \multirow[t]{2}{*}{1280} & 38,50 & \multirow[t]{2}{*}{194,7} & 88 \\
\hline & Galaxia P 12W & 6 & & & & 13,20 & & 69 \\
\hline \multirow[t]{2}{*}{ Itaim } & $\begin{array}{c}37009.0001 \times 35 \mathrm{~W} \\
36 \circ\end{array}$ & 3 & \multirow[t]{2}{*}{409} & \multirow[t]{2}{*}{157} & \multirow[t]{2}{*}{1331} & 38,50 & \multirow[t]{2}{*}{216,7} & 88 \\
\hline & Âmbar LED 23W & 4 & & & & 25,30 & & 66 \\
\hline \multirow[t]{2}{*}{ Philips } & $\begin{array}{c}37009.0001 \times 35 W \\
360\end{array}$ & 3 & \multirow[t]{2}{*}{332} & \multirow[t]{2}{*}{113} & \multirow[t]{2}{*}{1266} & 38,50 & \multirow[t]{2}{*}{172,7} & 88 \\
\hline & BBS488 - 13W & 4 & & & & 14,30 & & 48 \\
\hline
\end{tabular}




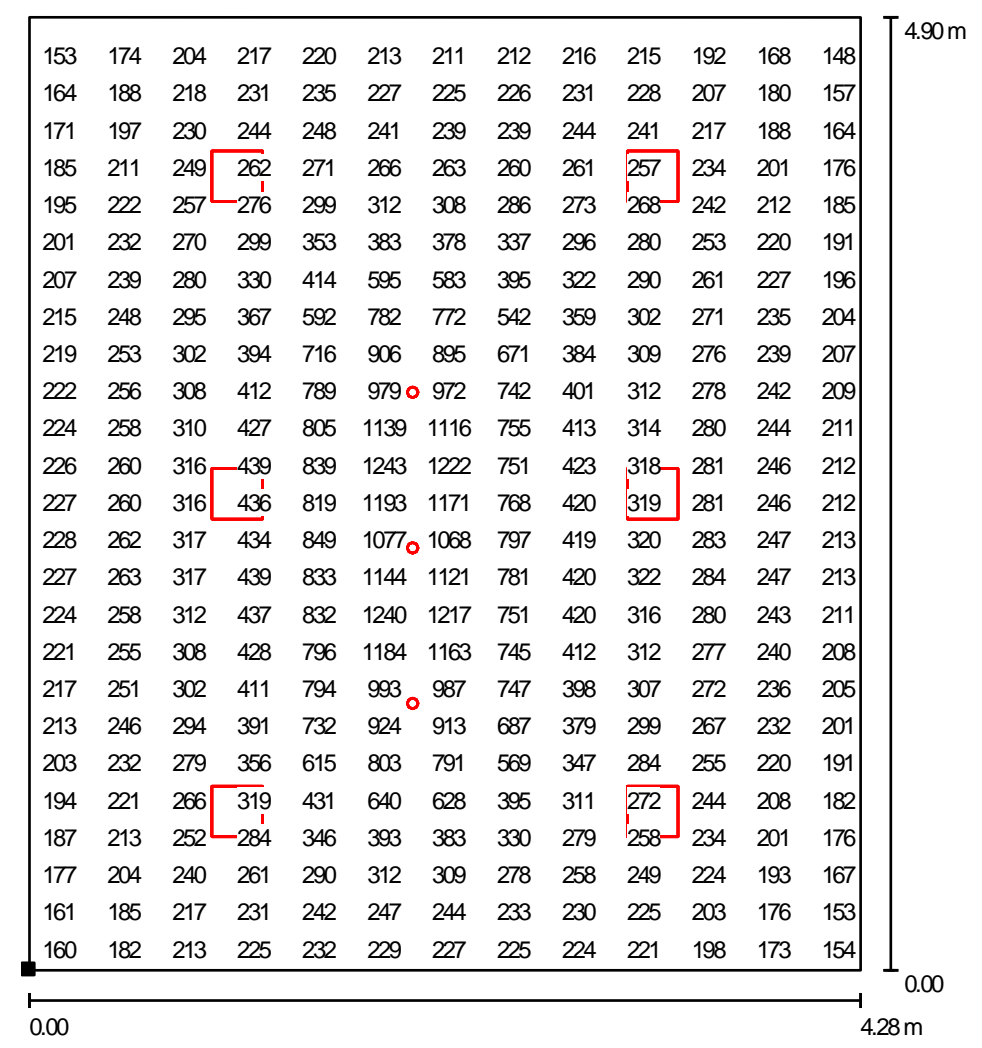

Figura 69: Simulação sala de reuniões - luminária nacional tipo 69 - halógena e LED (Arquivo: ET-SR-LHBR-1-MX.dlx)

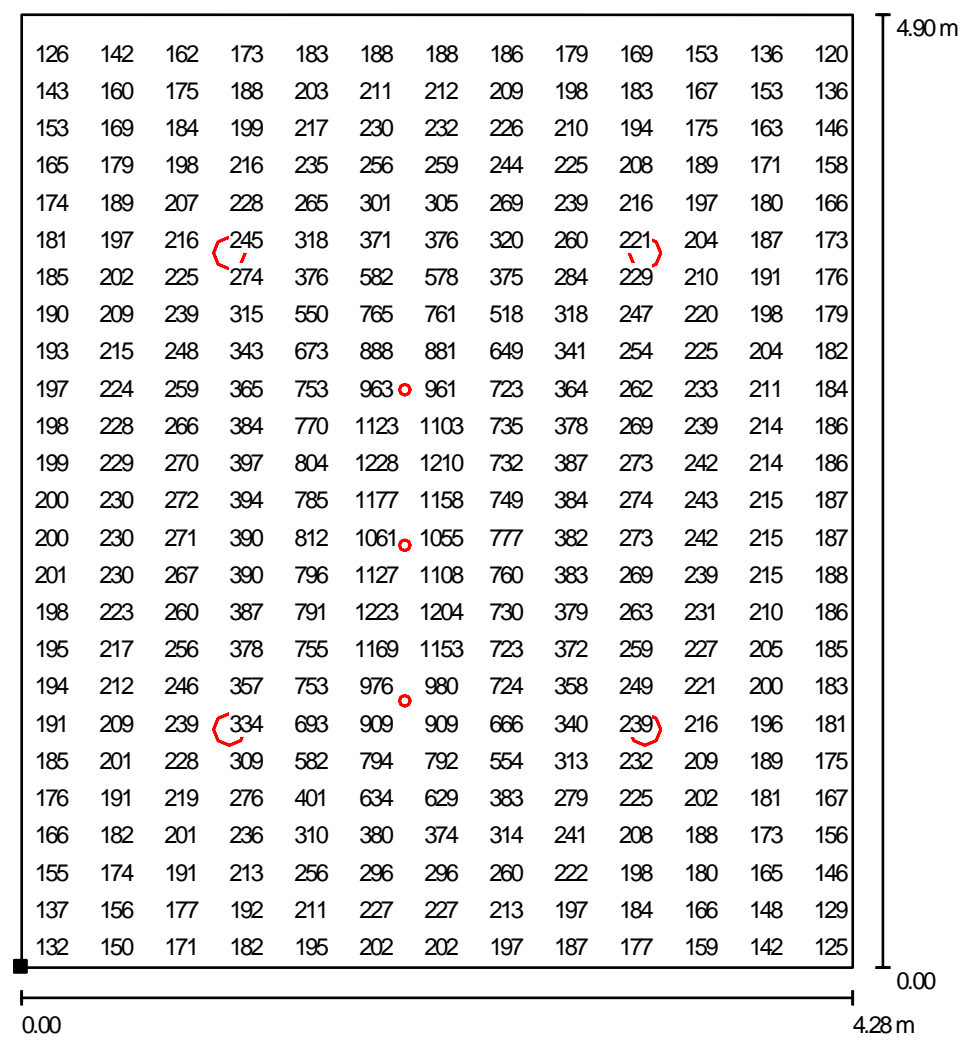

Figura 70: Simulação sala de reuniões - luminária nacional tipo 48 - halógena e LED (Arquivo: ET-SR-LHBR-2-MX.dlx) 
A escolha das peças para lâmpada fluorescente compacta para simulação, já foram pré-selecionadas no momento em que foram realizadas as simulações do staff. Nessa fase, utilizamos aquela que juntamente com a lâmpada de destaque, tenha o menor consumo além do nível de iluminação de acordo com a NBR 5413/1992.

Abaixo, temos a Tabela 40 referente às simulações para os sistemas de iluminação importados.

Tabela 40: Tabela sistema de iluminação importado - Halógena e LED

\begin{tabular}{|c|c|c|c|c|c|c|c|c|}
\hline Fabricante & Código peça & $\begin{array}{l}\text { Qtde } \\
\text { pças }\end{array}$ & $\begin{array}{c}\text { Eméd } \\
\text { (Ix) }\end{array}$ & $\begin{array}{c}\text { Emín } \\
\text { (Ix) }\end{array}$ & $\begin{array}{l}\text { Emáx } \\
(I x)\end{array}$ & $\begin{array}{l}\text { Potência } \\
\text { conj (W) }\end{array}$ & $\begin{array}{l}\text { Potência } \\
\text { total (W) }\end{array}$ & $\begin{array}{c}\text { Tipo/ } \\
\text { Anexo } \\
\text { Iuminária }\end{array}$ \\
\hline \multirow{2}{*}{ Erco } & $\begin{array}{c}\text { 37009.000 1x35W } \\
36 \text { o }\end{array}$ & 3 & \multirow{2}{*}{525} & \multirow{2}{*}{111} & \multirow{2}{*}{1294} & 38,50 & \multirow{2}{*}{265,1} & 88 \\
\hline & $47765.00034 \mathrm{~W}$ & 4 & & & & 37,40 & & 54 \\
\hline \multirow{2}{*}{ Erco } & $\begin{array}{c}37009.0001 \times 35 W \\
360\end{array}$ & 3 & \multirow[t]{2}{*}{313} & \multirow[t]{2}{*}{52} & \multirow[t]{2}{*}{1038} & 38,50 & \multirow{2}{*}{203,5} & 88 \\
\hline & $47719.00020 W$ & 4 & & & & 22,00 & & 52 \\
\hline \multirow{2}{*}{ Zumtobel } & $\begin{array}{c}37009.0001 \times 35 \mathrm{~W} \\
36 \%\end{array}$ & 3 & \multirow{2}{*}{433} & \multirow{2}{*}{164} & \multirow{2}{*}{1238} & 38,50 & \multirow{2}{*}{282,7} & 88 \\
\hline & $\begin{array}{l}\text { L-FIELDS MINI } \\
4218016338 \mathrm{~W}\end{array}$ & 4 & & & & 41,80 & & 72 \\
\hline \multirow{2}{*}{ Zumtobel } & $\begin{array}{c}37009.0001 \times 35 W \\
360\end{array}$ & 3 & \multirow{2}{*}{325} & \multirow{2}{*}{105} & \multirow{2}{*}{1112} & 38,50 & \multirow{2}{*}{225,5} & 88 \\
\hline & $\begin{array}{l}\text { L-FIELDS MINI } \\
4218016225 W\end{array}$ & 4 & & & & 27,50 & & 71 \\
\hline
\end{tabular}




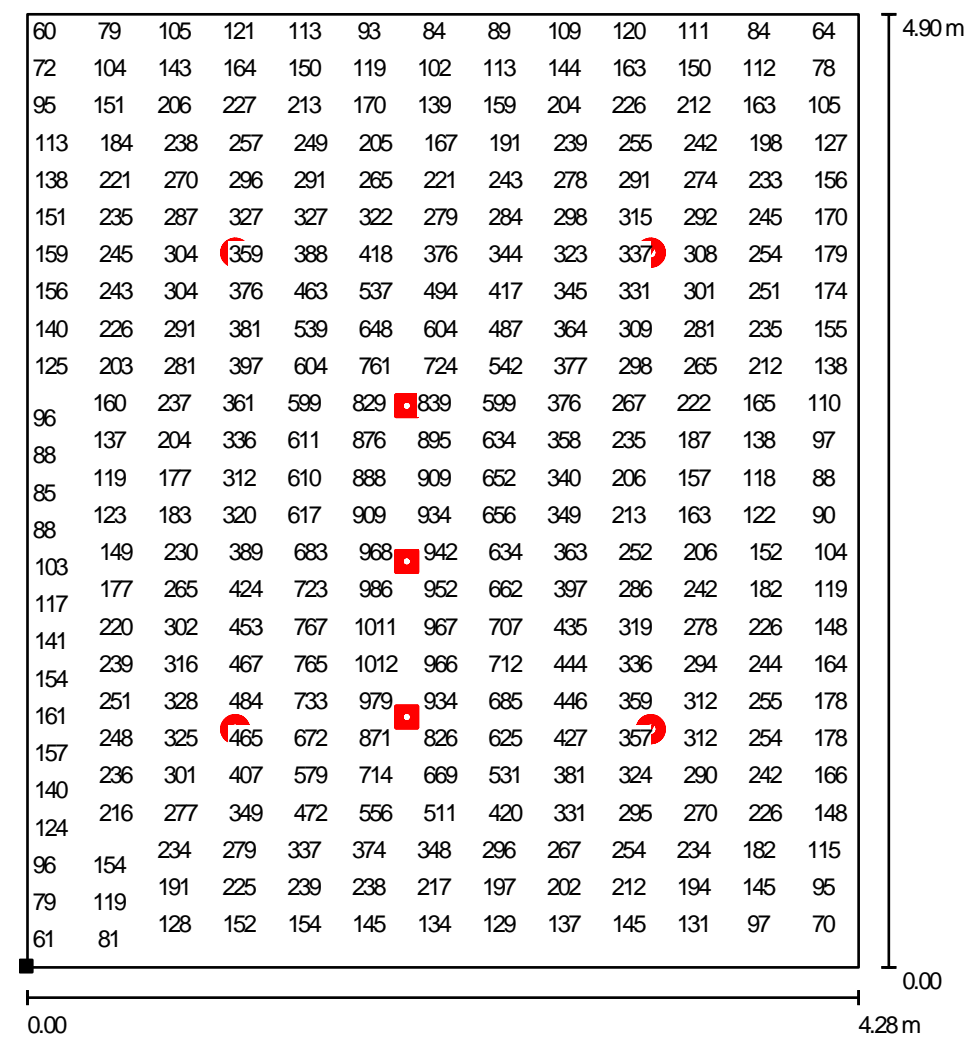

Figura 71: Simulação sala de reuniões - luminária importada tipo 52 - halógena e LED (Arquivo: ET-SRLH-EX-3-MX.dlx)

\begin{tabular}{|c|c|c|c|c|c|c|c|c|c|c|c|c|}
\hline 118 & 131 & 146 & 159 & 165 & 168 & 168 & 167 & 166 & 161 & 150 & 134 & 118 \\
\hline 122 & 139 & 157 & 172 & 177 & 178 & 177 & 177 & 178 & 173 & 161 & 143 & 127 \\
\hline 138 & 159 & 182 & 200 & 207 & 206 & 204 & 203 & 206 & 201 & 186 & 163 & 142 \\
\hline 146 & 171 & 197 & 214 & 222 & 221 & 219 & 217 & 219 & 214 & 200 & 175 & 150 \\
\hline 157 & 188 & 219 & 242 & 255 & 259 & 255 & 247 & 247 & 240 & २2 & 193 & 162 \\
\hline 166 & 199 & 231 & $261_{1}$ & 289 & 310 & 305 & 280 & 266 & 253 & $7^{233}$ & 204 & 171 \\
\hline 173 & 207 & 244 & 286 & 349 & 405 & 401 & 339 & 290 & 267 & 244 & 211 & 177 \\
\hline 173 & 209 & $250^{\circ}$ & -313 & 429 & 529 & 523 & 417 & 316 & 272 & 245 & 211 & 177 \\
\hline 169 & 205 & 253 & 344 & 517 & 659 & 653 & 506 & 346 & 274 & 243 & 208 & 174 \\
\hline 168 & 204 & 255 & 372 & 595 & 798 & 792 & 586 & 375 & 275 & 239 & 204 & 173 \\
\hline 169 & 199 & 253 & 389 & 656 & $922 \cdot$ & 921 & 651 & 392 & 273 & 232 & 198 & 171 \\
\hline 167 & 196 & 249 & 396 & 702 & 990 & 989 & 700 & 401 & 269 & 227 & 193 & 168 \\
\hline 165 & 194 & 248 & 397 & 727 & 1015 & 1013 & 728 & 405 & 265 & 223 & 191 & 167 \\
\hline 166 & 195 & 250 & 400 & 729 & 1036 & 1034 & 730 & 408 & 268 & 224 & 191 & 167 \\
\hline 169 & 200 & 258 & 412 & 728 & 1051 . & 1049 & 724 & 416 & 277 & 231 & 197 & 170 \\
\hline 170 & 203 & 262 & 417 & 738 & 1045 & 1043 & 730 & 420 & 282 & 237 & 201 & 172 \\
\hline 170 & 209 & 270 & 422 & 752 & 1032 & 1025 & 739 & 424 & 290 & 246 & 207 & 173 \\
\hline 172 & 211 & 273 & 421 & 738 & 1015 & 1006 & 725 & 422 & 293 & 250 & 210 & 175 \\
\hline 175 & 214 & 270 & -412 & 694 & 967 . & 960 & 681 & 415 & 292 & $7^{250}$ & 214 & 179 \\
\hline 173 & 211 & 266 & 392 & 633 & 858 & 851 & 620 & 394 & 287 & 249 & 212 & 177 \\
\hline 167 & 202 & 249 & 349 & 544 & 706 & 700 & 533 & 351 & 269 & 237 & 203 & 170 \\
\hline 157 & 188 & 231 & 301 & 440 & 557 & 552 & 431 & 303 & 249 & 223 & 190 & 160 \\
\hline 143 & 167 & 199 & 247 & 329 & 406 & 403 & 323 & 251 & 220 & 198 & 169 & 145 \\
\hline 130 & 153 & 179 & 209 & 249 & 287 & 285 & 246 & 214 & 197 & 179 & 154 & 135 \\
\hline 118 & 132 & 153 & 172 & 192 & 207 & 207 & 192 & 178 & 167 & 154 & 136 & 121 \\
\hline
\end{tabular}

Figura 72: Simulação sala de reuniões - luminária importada tipo 71 - halógena e LED (Arquivo: ET-SRLH-EX-4-MX.dlx) 
As figuras 71 e 72 são as simulações referentes às luminárias de menor consumo do conjunto lâmpadas halógenas e luminárias LED, do sistema de iluminação importado.

Por fim, a Tabela 41 mostra a substituição de todos os conjuntos em LED. Novamente, observa-se que apenas com a substituição de peças, não foi possível alcançar o nível de iluminação médio solicitado pela norma. Em ambos os casos, houve acréscimo de luminárias para atender a norma.

Tabela 41: Tabela sistema de iluminação nacional - LED e LED

\begin{tabular}{|c|c|c|c|c|c|c|c|c|}
\hline Fabricante & Código peça & $\begin{array}{l}\text { Qtde } \\
\text { pças }\end{array}$ & $\begin{array}{c}\text { Eméd } \\
\text { (Ix) }\end{array}$ & $\begin{array}{c}\text { Emín } \\
\text { (Ix) }\end{array}$ & $\begin{array}{c}\text { Emáx } \\
\text { (Ix) }\end{array}$ & $\begin{array}{l}\text { Potência } \\
\text { conj (W) }\end{array}$ & $\begin{array}{l}\text { Potência } \\
\text { total (W) }\end{array}$ & $\begin{array}{c}\text { Tipo/ } \\
\text { Anexo } \\
\text { Iuminária }\end{array}$ \\
\hline \multirow{2}{*}{ Itaim } & $\begin{array}{c}\text { Lâmpada LED 7W } \\
\text { 35o }\end{array}$ & 3 & \multirow{2}{*}{256} & \multirow{2}{*}{129} & \multirow{2}{*}{630} & 7,70 & \multirow{2}{*}{102,3} & 93 \\
\hline & $\begin{array}{l}\text { Galaxia P } 12 \mathrm{~W}- \\
\text { teste } 1\end{array}$ & 4 & & & & 13,20 & & 69 \\
\hline \multirow{2}{*}{ Itaim } & $\begin{array}{c}\text { Lâmpada LED 7W } \\
\text { 35o }\end{array}$ & 3 & \multirow{2}{*}{325} & \multirow{2}{*}{171} & \multirow{2}{*}{715} & 7,70 & \multirow{2}{*}{128,7} & 93 \\
\hline & $\begin{array}{c}\text { Galaxia P 12W- } \\
\text { teste } 2\end{array}$ & 6 & & & & 13,20 & & 69 \\
\hline \multirow{2}{*}{ Philips } & $\begin{array}{l}\text { Lâmpada LED 7W } \\
\text { 35o }\end{array}$ & 3 & \multirow{2}{*}{224} & \multirow{2}{*}{98} & \multirow{2}{*}{616} & 7,70 & \multirow{2}{*}{80,3} & 93 \\
\hline & $\begin{array}{l}\text { BBS488-13W- } \\
\text { teste } 1\end{array}$ & 4 & & & & 14,30 & & 48 \\
\hline \multirow{2}{*}{ Philips } & $\begin{array}{c}\text { Lâmpada LED } 7 W \\
\text { 35o }\end{array}$ & 3 & \multirow{2}{*}{307} & \multirow{2}{*}{145} & \multirow{2}{*}{732} & 7,70 & \multirow{2}{*}{108,9} & 93 \\
\hline & $\begin{array}{c}\text { BBS488-13W- } \\
\text { teste } 2\end{array}$ & 6 & & & & 14,30 & & 48 \\
\hline
\end{tabular}

As figuras 73 e 74 são os resultados dessas simulações. Nota-se que o nível está bem homogêneo, onde na mesa de trabalho (mesa de reuniões) alcançamos até o nível de 500 lux. A simulação dessa sala atenderia a nova norma para iluminância de interiores, onde é apresentada o nível no plano de trabalho do ambiente. 
\begin{tabular}{|llllllllllllllll|l}
178 & 194 & 220 & 239 & 249 & 252 & 246 & 243 & 242 & 245 & 253 & 252 & 243 & 227 & 201 & 180 \\
\hline 177 & 195 & 233 & 244 & 253 & 256 & 249 & 246 & 245 & 248 & 257 & 257 & 248 & 231 & 203 & 180
\end{tabular}

$\begin{array}{llllllllllllllll}177 & 195 & 223 & 244 & 253 & 256 & 249 & 246 & 245 & 248 & 257 & 257 & 248 & 231 & 203 & 180\end{array}$ $\begin{array}{lllllllllllllll}193 & 213 & 243 & 264-278 & 281 & 273 & 270 & 269 & 273 & 282 & 281-270 & 251 & 222 & 196\end{array}$ $\begin{array}{llllllllllllllll}201 & 220 & 253 & 275 & 288 & 290 & 281 & 278 & 277 & 280 & 291 & 290 & 281 & 262 & 230 & 204\end{array}$ $\begin{array}{llllllllllllllll}210 & 232 & 268 & 292 & 306 & 309 & 299 & 296 & 295 & 298 & 309 & 308 & 299 & 277 & 242 & 214\end{array}$ $\begin{array}{llllllllllllllll}218 & 240 & 277 & 304 & 319 & 321 & 315 & 316 & 311 & 311 & 321 & 321 & 311 & 286 & 251 & 222\end{array}$ $\begin{array}{llllllllllllllll}232 & 253 & 290 & 321 & 338 & 349 & 363 & 372 & 355 & 336 & 340 & 339 & 327 & 300 & 264 & 230\end{array}$ $\begin{array}{llllllllllllllll}236 & 257 & 296 & 327 & 348 & 383 & 437 & 463 & 425 & 366 & 351 & 345 & 333 & 305 & 269 & 235\end{array}$ $\begin{array}{llllllllllllllll}238 & 261 & 299 & 329 & 357 & 430 & 526 & 563 & 509 & 409 & 360 & 348 & 333 & 309 & 272 & 237\end{array}$ $\begin{array}{llllllllllllllll}241 & 264 & 302 & 333 & 370 & 468 & 584 & 623 & 568 & 443 & 371 & 352 & 337 & 311 & 274 & 239\end{array}$

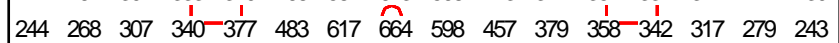
$\begin{array}{llllllllllllllll}246 & 269 & 309 & 344 & 377 & 481 & 637 & 700 & 614 & 454 & 378 & 362 & 346 & 319 & 280 & 245\end{array}$ $\begin{array}{llllllllllllllll}248 & 270 & 311 & 348 & 381 & 484 & 643 & 713 & 620 & 455 & 381 & 366 & 351 & 321 & 282 & 246\end{array}$ $\begin{array}{llllllllllllllll}247 & 270 & 310 & 347 & 384 & 491 & 634 & 686 & 614 & 463 & 384 & 365 & 349 & 320 & 281 & 246\end{array}$ $\begin{array}{llllllllllllllll}246 & 268 & 308 & 343 & 385 & 490 & 627 & 676 & 610 & 464 & 383 & 362 & 347 & 317 & 280 & 244\end{array}$

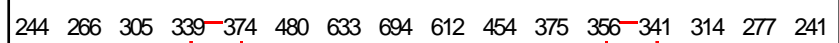
$\begin{array}{lllllllllllllll}242 & 264 & 303 & 336 \_371 & 474 & 633 & 706 & 610 & 447 & 372 & 355 \_339 & 312 & 275 & 240\end{array}$ $\begin{array}{llllllllllllllll}241 & 262 & 301 & 334 & 373 & 475 & 620 & 675 & 601 & 448 & 372 & 353 & 338 & 309 & 273 & 238\end{array}$ $\begin{array}{llllllllllllllll}233 & 253 & 291 & 324 & 361 & 463 & 588 & 630 & 570 & 436 & 360 & 342 & 327 & 301 & 264 & 230\end{array}$ $\begin{array}{llllllllllllllll}224 & 247 & 288 & 320 & 351 & 435 & 545 & 582 & 529 & 411 & 348 & 336 & 324 & 297 & 257 & 228\end{array}$ $\begin{array}{llllllllllllllll}218 & 240 & 279 & 307 & 328 & 382 & 458 & 493 & 444 & 363 & 331 & 322 & 310 & 287 & 250 & 221\end{array}$ $\begin{array}{lllllllllllllll}210 & 231 & 268 & 293 & 310 & 332 & 365 & 382 & 355 & 319 & 314 & 308 \_298 & 276 & 240 & 213\end{array}$ $\begin{array}{llllllllllllllll}194 & 216 & 247 & 270 & 286 & 292 & 296 & 299 & 291 & 284 & 289 & 285 & 275 & 255 & 224 & 197\end{array}$ $\begin{array}{llllllllllllllll}186 & 206 & 235 & 256 & 269 & 275 & 270 & 267 & 265 & 267 & 274 & 271 & 261 & 243 & 214 & 189\end{array}$ $\begin{array}{llllllllllllllll}175 & 192 & 221 & 242 & 254 & 255 & 251 & 248 & 247 & 249 & 256 & 255 & 247 & 228 & 200 & 177\end{array}$

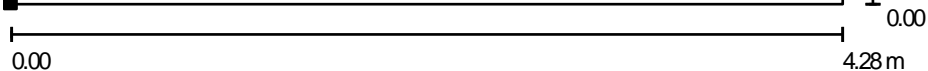

Figura 73: Simulação sala de reuniões - luminária nacional tipo 69 - LED e LED (Arquivo: ET-SR-LL-BR-1MX.dlx)

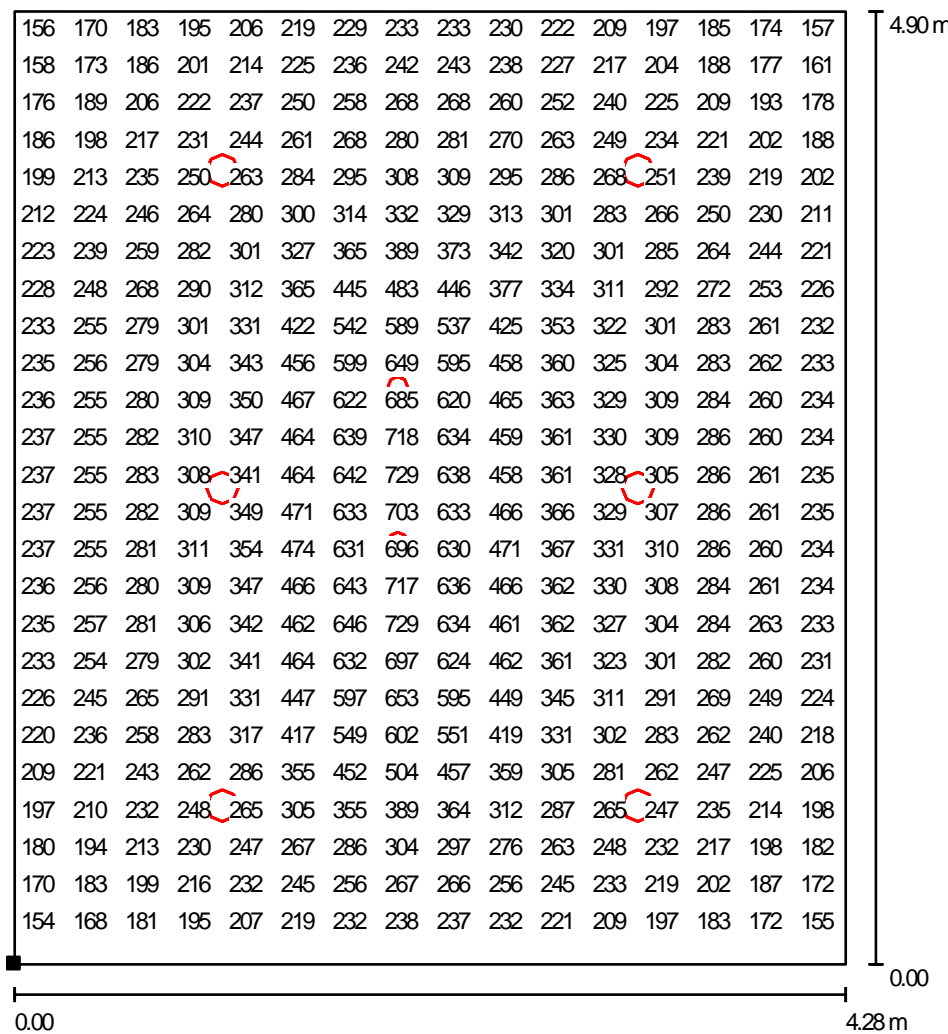

Figura 74: Simulação sala de reuniões - luminária nacional tipo 48 - LED e LED (Arquivo: ET-SR-LL-BR-2MX.dlx) 
Analisando a Tabela 42 com a simulação do sistema de iluminação importado, observamos que também não foi possível apenas a substituição das peças, assim como ocorreu nas simulações do sistema de iluminação nacional. Então foi acrescentado mais luminárias no ambiente para alcançar o nível solicitado pela norma.

Tabela 42: Tabela sistema de iluminação importado - LED e LED

\begin{tabular}{|c|c|c|c|c|c|c|c|c|}
\hline Fabricante & Código peça & $\begin{array}{l}\text { Qtde } \\
\text { pças }\end{array}$ & $\begin{array}{l}\text { Eméd } \\
\text { (Ix) }\end{array}$ & $\begin{array}{c}\text { Emín } \\
\text { (Ix) }\end{array}$ & $\begin{array}{c}\text { Emáx } \\
(\mathbf{I x})\end{array}$ & $\begin{array}{l}\text { Potência } \\
\text { conj (W) }\end{array}$ & $\begin{array}{l}\text { Potência } \\
\text { total (W) }\end{array}$ & $\begin{array}{c}\text { Tipo/ } \\
\text { Anexo } \\
\text { Iuminária }\end{array}$ \\
\hline \multirow{2}{*}{ Erco } & $\begin{array}{l}\text { Lâmpada LED 7W } \\
\text { 35o }\end{array}$ & 3 & \multirow{2}{*}{234} & \multirow{2}{*}{52} & \multirow{2}{*}{591} & 7,70 & \multirow{2}{*}{111,1} & 93 \\
\hline & $\begin{array}{c}47719.00020 \mathrm{~W}- \\
\text { teste } 1 \\
\end{array}$ & 4 & & & & 22,00 & & 52 \\
\hline \multirow{2}{*}{ Erco } & $\begin{array}{c}\text { Lâmpada LED } 7 W \\
\text { 35o }\end{array}$ & 3 & \multirow{2}{*}{321} & \multirow{2}{*}{94} & \multirow{2}{*}{677} & 7,70 & \multirow{2}{*}{155,1} & 93 \\
\hline & $\begin{array}{c}47719.00020 \mathrm{~W}- \\
\text { teste } 2\end{array}$ & 6 & & & & 22,00 & & 52 \\
\hline \multirow[b]{2}{*}{ Zumtobel } & $\begin{array}{l}\text { Lâmpada LED 7W } \\
\text { 35॰ }\end{array}$ & 3 & \multirow[b]{2}{*}{246} & \multirow[b]{2}{*}{106} & \multirow[b]{2}{*}{621} & 7,70 & \multirow[b]{2}{*}{133,1} & 93 \\
\hline & $\begin{array}{c}\text { L-FIELDS MINI } \\
4218016225 \mathrm{~W}- \\
\text { teste } 1\end{array}$ & 4 & & & & 27,50 & & 71 \\
\hline \multirow[b]{2}{*}{ Zumtobel } & $\begin{array}{c}\text { Lâmpada LED } 7 W \\
\text { 35^ }\end{array}$ & 3 & \multirow[b]{2}{*}{340} & \multirow[b]{2}{*}{160} & \multirow[b]{2}{*}{750} & 7,70 & \multirow[b]{2}{*}{188,1} & 93 \\
\hline & $\begin{array}{c}\text { L-FIELDS MINI } \\
4218016225 W- \\
\text { teste } 2\end{array}$ & 6 & & & & 27,50 & & 71 \\
\hline
\end{tabular}

Seguem as simulações do ambiente com o sistema de iluminação lâmpada LED e luminária LED. As figuras 75 e 76 correspondem às luminárias do fabricante da Erco e Zumtobel, respectivamente. 


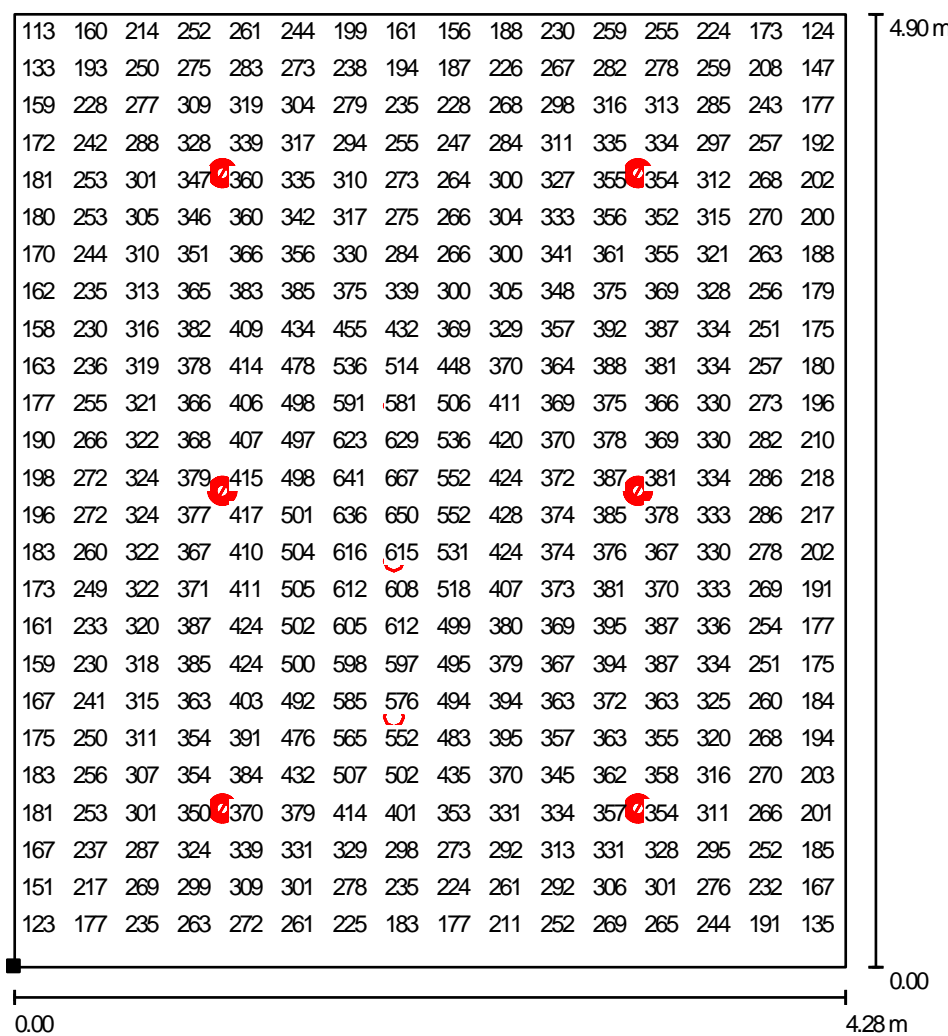

Figura 75: Simulação sala de reuniões - luminária importada tipo 52 - LED e LED (Arquivo: ET-SR-LL-EX3-MX.dlx)

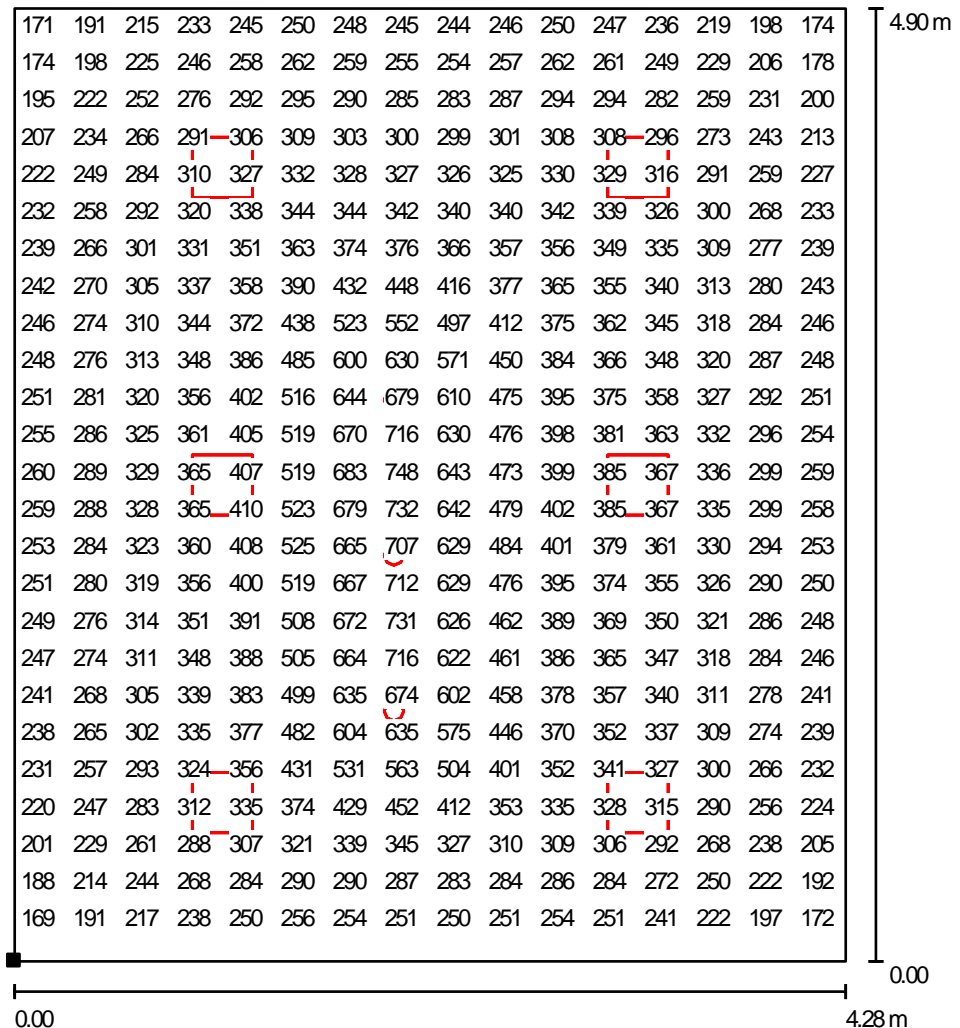

Figura 76: Simulação sala de reuniões - luminária importada tipo 71 - LED e LED (Arquivo: ET-SR-LL-EX4-MX.dlx) 


\subsubsection{Simulação 2o Etapa}

Simularemos nessa 20 parte do trabalho duas situações para posterior comparação. Será simulado um projeto com sistema de iluminação menos eficiente e um projeto que atenda a nova norma que substituirá a NBR 5413/1992. As simulações a seguir serão feitas apenas para o estudo de caso dos escritórios apenas para realizar os comparativos.

Chamaremos de menos eficiente, o sistema de iluminação formado por lâmpadas fluorescentes tubulares T8 de 32W com luminária de bom controle óptico com aletas parabólicas e sistemas de iluminação com lâmpadas fluorescentes compactas dupla 4P de $26 \mathrm{~W}$. Ambas as peças ainda são comercializadas e muito especificadas no país.

Escolheremos as luminárias do fabricante Itaim lluminação, pois o mesmo disponibiliza todas as fotometrias e fichas técnicas em seu website. Como analisaremos a situação de menor eficiência, não nos preocuparemos em conferir qual sistema de iluminação tem maior ou menor consumo.

Simularemos o staff com uma luminária do fabricante Itaim lluminação, quadrada, com aletas parabólicas e refletor em alumínio. O reator utilizado é o do fabricante Philips, código EL232A26 OS. Na Tabela 43 segue o resultado da simulação.

Tabela 43: Tabela sistema de iluminação Staff menos eficiente com fluorescente tubular

\begin{tabular}{|c|c|c|c|c|c|c|c|c|}
\hline Fabricante & Código peça & $\begin{array}{c}\text { Qtde } \\
\text { pças }\end{array}$ & $\begin{array}{c}\text { Eméd } \\
(\mathbf{I x})\end{array}$ & $\begin{array}{c}\text { Emín } \\
(\mathbf{I x})\end{array}$ & $\begin{array}{c}\text { Emáx } \\
(\mathbf{I x})\end{array}$ & $\begin{array}{c}\text { Potência } \\
\text { conj (W) }\end{array}$ & $\begin{array}{c}\text { Potência } \\
\text { total (W) }\end{array}$ & $\begin{array}{c}\text { Tipo/ } \\
\text { Anexo } \\
\text { luminária }\end{array}$ \\
\hline $\begin{array}{c}\text { Itaim } \\
\text { Iluminação }\end{array}$ & $20034 \times 16 W$ & 101 & 534 & 80 & 633 & 70,00 & 7070,0 & 95 \\
\hline
\end{tabular}

Para a sala individual e sala de reuniões, utilizaremos para luz geral a luminária Prata-E 2x26W do fabricante Itaim Iluminação. Manteremos na sala de reuniões uma luminária com lâmpada halógena dicroica no centro da mesa e para sala individual, simularemos o ambiente com o pendente 3457 2x32W. 
Tabela 44: Tabela sistema de iluminação sala individual menos eficiente

\begin{tabular}{|c|c|c|c|c|c|c|c|c|}
\hline Fabricante & Código peça & $\begin{array}{l}\text { Qtde } \\
\text { pças }\end{array}$ & $\begin{array}{c}\text { Eméd } \\
\text { (Ix) }\end{array}$ & $\begin{array}{l}\text { Emín } \\
\text { (Ix) }\end{array}$ & $\begin{array}{c}\text { Emáx } \\
\text { (Ix) }\end{array}$ & $\begin{array}{l}\text { Potência } \\
\text { conj (W) }\end{array}$ & $\begin{array}{l}\text { Potência } \\
\text { total (W) }\end{array}$ & $\begin{array}{c}\text { Tipo/ } \\
\text { Anexo } \\
\text { Iuminária }\end{array}$ \\
\hline \multirow{2}{*}{$\begin{array}{c}\text { Itaim } \\
\text { Iluminação }\end{array}$} & $\begin{array}{c}\text { Prata-E } 2 \times 26 W \\
\text { vidro iateado }\end{array}$ & 6 & \multirow{2}{*}{502} & \multirow{2}{*}{230} & \multirow{2}{*}{1123} & 56,00 & \multirow{2}{*}{409,0} & 85 \\
\hline & $34572 \times 32 W$ & 1 & & & & 73,00 & & 96 \\
\hline
\end{tabular}

$\mathrm{Na}$ Tabela 44, temos o resultado da simulação da sala individual e na Tabela 45 o da sala de reuniões.

Tabela 45: Tabela sistema de iluminação sala de reuniões menos eficiente

\begin{tabular}{|c|c|c|c|c|c|c|c|c|}
\hline Fabricante & Código peça & $\begin{array}{l}\text { Qtde } \\
\text { pças }\end{array}$ & $\begin{array}{l}\text { Eméd } \\
(\mathrm{Ix})\end{array}$ & $\begin{array}{c}\text { Emín } \\
\text { (Ix) }\end{array}$ & $\begin{array}{l}\text { Emáx } \\
(I x)\end{array}$ & $\begin{array}{l}\text { Potência } \\
\text { conj (W) }\end{array}$ & $\begin{array}{l}\text { Potência } \\
\text { total (W) }\end{array}$ & $\begin{array}{c}\text { Tipo/ } \\
\text { Anexo } \\
\text { Iuminária }\end{array}$ \\
\hline \multirow{2}{*}{$\begin{array}{c}\text { Itaim } \\
\text { iluminação }\end{array}$} & $\begin{array}{c}\text { Lâmpada dicróica } \\
\text { 35W 36ㅇ }\end{array}$ & 3 & \multirow[t]{2}{*}{382} & \multirow[t]{2}{*}{154} & \multirow[t]{2}{*}{1305} & 38,50 & \multirow{2}{*}{451,50} & 83 \\
\hline & Prata-E 2x26W & 6 & & & & 56,00 & & 85 \\
\hline
\end{tabular}

As figuras 77, 78 e 79 mostram o resultado das simulações ponto a ponto do sistema menos eficiente dos ambientes: staff, sala individual e sala de reuniões, respectivamente.

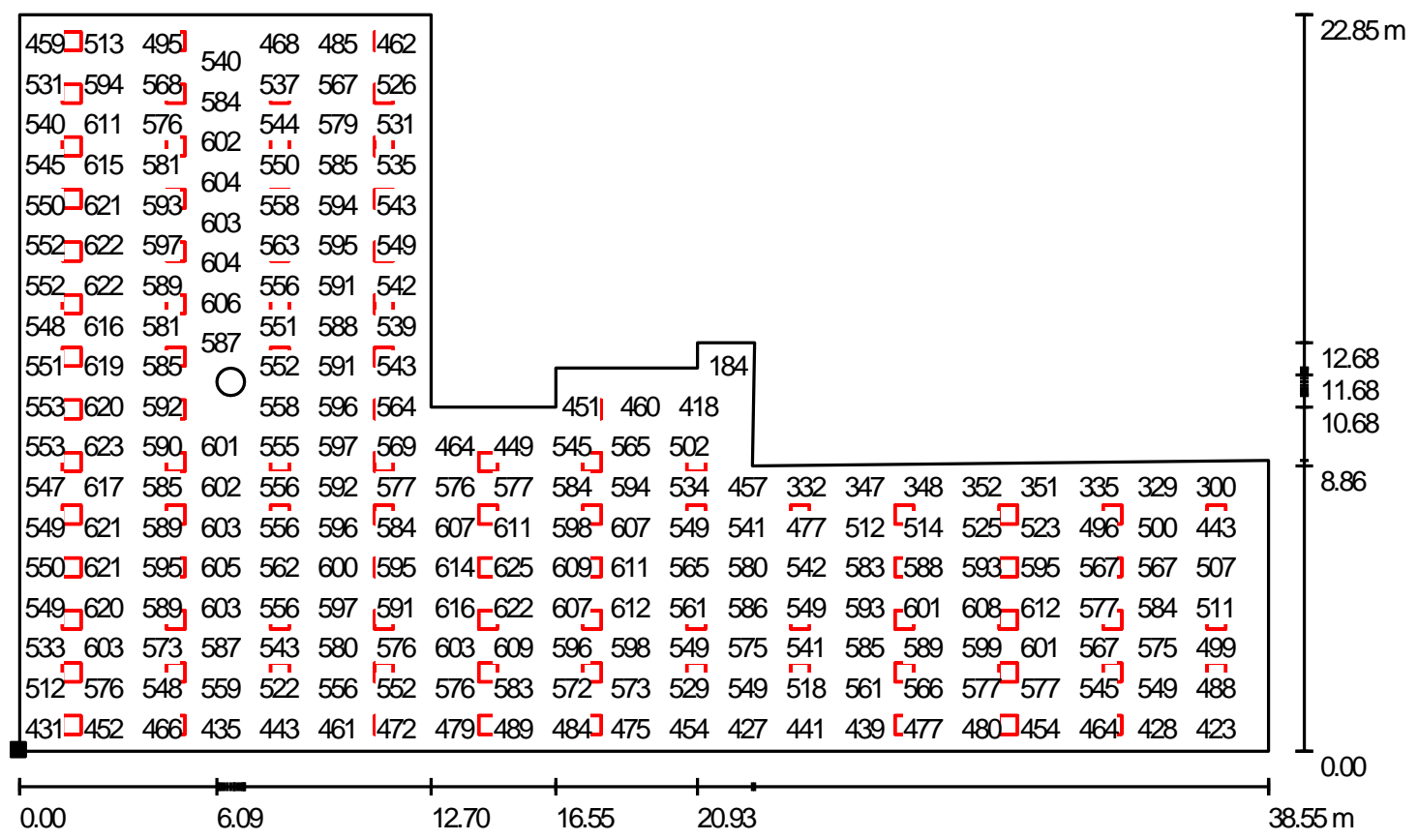

Figura 77: Simulação Staff - luminária nacional menos eficiente com fluorescente tubular (Arquivo: ETST-FT-BR-1-MI.dlx) 


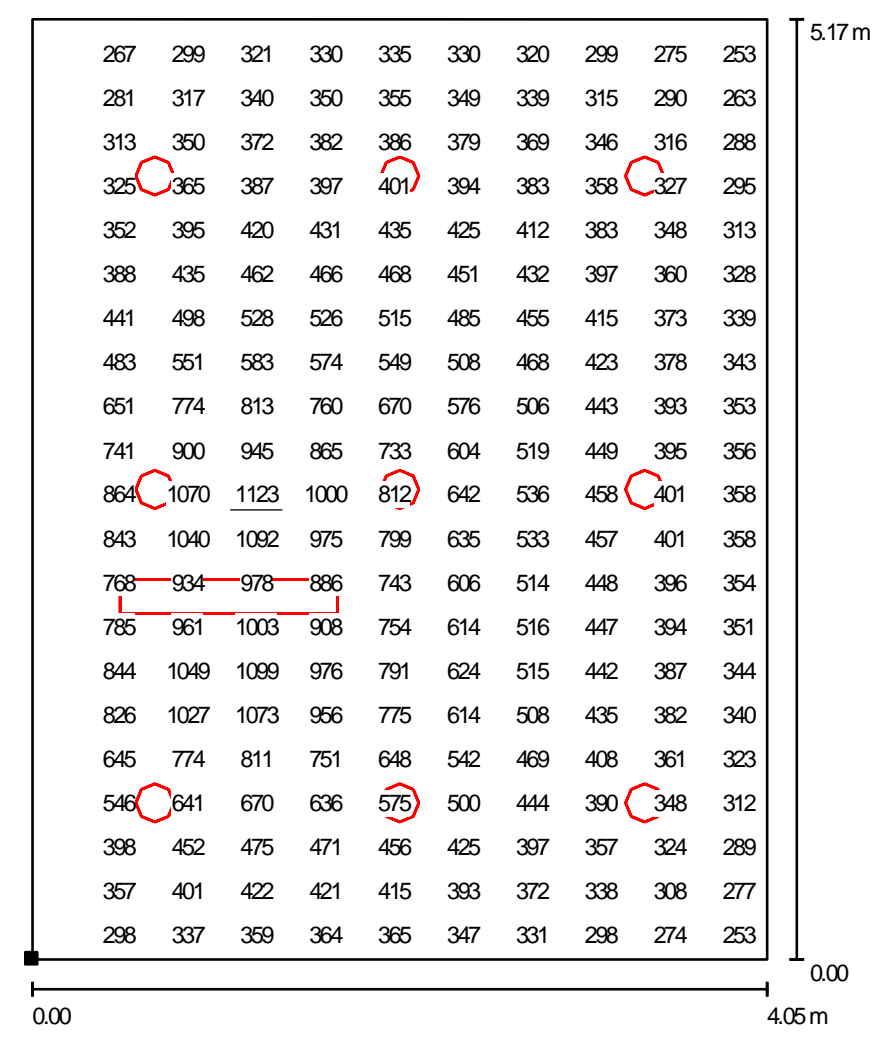

Figura 78: Simulação sala individual - luminária nacional menos eficiente com fluorescente compacta (Arquivo: ET-SI-FC-BR-1-MI.dlx)

\begin{tabular}{|c|c|c|c|c|c|c|c|c|c|c|c|c|}
\hline 174 & 185 & 216 & 229 & 233 & 232 & 226 & 228 & 230 & 225 & 204 & 181 & 161 \\
\hline 182 & 195 & 229 & 241 & 246 & 244 & 243 & 245 & 247 & 241 & 215 & 191 & 167 \\
\hline 191 & 206 & 242 & 255 & 259 & 258 & 256 & 258 & 261 & 255 & २27 & 202 & 174 \\
\hline 205 & 223 & 260 & 275 & 284 & 287 & 282 & 276 & 276 & 269) & 244 & 219 & 186 \\
\hline 214 & 233 & 270 & 289 & 311 & 328 & 320 & 300 & 290 & $281^{\circ}$ & 254 & २२८ & 193 \\
\hline 220 & 240 & 282 & 314 & 365 & 403 & 395 & 354 & 310 & 291 & 262 & 235 & 199 \\
\hline 229 & 249 & 293 & 342 & 427 & 615 & 600 & 412 & 333 & 302 & 271 & 242 & 206 \\
\hline 238 & 260 & 310 & 383 & 606 & 805 & 792 & 559 & 378 & 317 & 283 & 252 & 214 \\
\hline 241 & 264 & 318 & 410 & 729 & 923 & 909 & 686 & 402 & 324 & 287 & 256 & 217 \\
\hline 246 & 269 & 326 & 434 & 807 & $1004 \circ$ & 993 & 763 & 422 & 330 & 291 & 260 & २2२ \\
\hline 249 & 272 & 329 & 447 & 823 & 1163 & 1138 & $\pi 7$ & 429 & 334 & 293 & 262 & २२३ \\
\hline 251 & 275 & 332 & 457 & 858 & 1269 & 1245 & 774 & 444 & 336 & 296 & 265 & २२६ \\
\hline 252 & 276 & 334 & 454 & 838 & 1215 & 1189 & 788 & 441 & 337) & 297 & 266 & २26 \\
\hline 252 & 276 & 333 & 453 & 866 & 1104 。 & 1090 & 819 & 437 & 339 & 296 & 266 & 226 \\
\hline 252 & 275 & 334 & 454 & 854 & 1173 & 1143 & 804 & 436 & 338 & 296 & 265 & २२६ \\
\hline 246 & 269 & 327 & 452 & 847 & 1259 & 1236 & 769 & 439 & 332 & 292 & 259 & 222 \\
\hline 243 & 266 & 324 & 444 & 810 & 1204 & 1181 & 762 & 430 & 328 & 288 & 256 & 219 \\
\hline 239 & 262 & 318 & 427 & 809 & 1016 。 & 1004 & 764 & 414 & 323 & 284 & 253 & 215 \\
\hline 236 & 257 & 311 & 407 & 751 & 944 & 932 & 705 & 396 & 315 & 277 & 248 & 212 \\
\hline २२२ & 242 & 290 & 369 & 628 & 821 & 807 & 586 & 361 & 296 & 263 & 235 & 200 \\
\hline 214 & 233 & 278 & 332 & 444 & 657 & 643 & 412 & 325 & 284 & 254 & 226 & 192 \\
\hline 207 & २24 & 262 & 295 & 358 & 411 & 399 & 346 & 289 & 270 & 243 & 217 & 186 \\
\hline 198 & 214 & 252 & 273 & 303 & 330 & 324 & 297 & 274 & 262 & 236 & 208 & 178 \\
\hline 181 & 192 & 229 & 244 & 256 & 262 & 258 & 250 & 243 & 236 & 211 & 186 & 165 \\
\hline 171 & 180 & 213 & 227 & 234 & 235 & 232 & 230 & 226 & 219 & 198 & 175 & 156 \\
\hline
\end{tabular}

Figura 79: Simulação sala de reuniões - luminária nacional menos eficiente com fluorescente compacta (Arquivo: ET-SR-FC-BR-1-MI.dlx) 
Pela nova norma de iluminância de interiores, a principal modificação é referente ao nível de iluminância no plano de trabalho. Os valores contidos na tabelas (ver Anexo XX) serão valores considerados apenas nesse plano e não mais no ambiente como um todo. Assim, a tendência é reduzirmos a quantidade de luminárias em cada ambiente.

No staff, consideraremos 300 lux para luz geral e 500 lux no plano de trabalho. Simularemos utilizando a peça do fabricante Itaim lluminação 2691 4x14W, luminária quadrada, refletor em alumínio e aletas parabólicas em alumínio. A mesma peça eficiente encontrada para fluorescente tubular no staff.

Utilizaremos um pendente sob a mesa de trabalho, instalada à $1,80 \mathrm{~m}$ do piso, do fabricante Itaim Iluminação em LED. A luminária é a D'Art Gesso 1025 de 14W. Inclusive a peça ganhou o prêmio Design Abilux de 2012. Esta peça será utilizada somente nesta simulação, pois no momento em que foram realizadas as outras simulações, o fabricante ainda não havia fornecido a fotometria da peça.

Com a nova norma de iluminação de interiores, os resultados da simulação ponto a ponto e as curvas de distribuição luminosa passam a ter grande importância.

Tabela 46: Tabela simulação staff seguindo norma NBR ISO8995

\begin{tabular}{|c|c|c|c|c|c|c|c|c|}
\hline Fabricante & Código peça & $\begin{array}{l}\text { Qtde } \\
\text { pças }\end{array}$ & $\begin{array}{l}\text { Eméd } \\
\text { (Ix) }\end{array}$ & $\begin{array}{c}\text { Emín } \\
\text { (Ix) }\end{array}$ & $\begin{array}{c}\text { Emáx } \\
\text { (Ix) }\end{array}$ & $\begin{array}{l}\text { Potência } \\
\text { conj (W) }\end{array}$ & $\begin{array}{l}\text { Potência } \\
\text { total (W) }\end{array}$ & $\begin{array}{c}\text { Tipo/ } \\
\text { Anexo } \\
\text { Iuminária }\end{array}$ \\
\hline \multirow[b]{2}{*}{$\begin{array}{c}\text { Itaim } \\
\text { iluminação }\end{array}$} & $26914 \times 14 W$ & 61 & \multirow[b]{2}{*}{434} & \multirow[b]{2}{*}{15} & \multirow[b]{2}{*}{857} & 61,20 & \multirow[b]{2}{*}{3815,8} & 06 \\
\hline & $\begin{array}{c}\text { D'Art Gesso } 1025 \\
14 \mathrm{~W}\end{array}$ & 61 & & & & 15,40 & & 97 \\
\hline
\end{tabular}

Segue abaixo a figura 80 com o resultado da simulação ponto a ponto. No plano de trabalho, temos 500 lux e no entorno, cerca de 300 lux. 


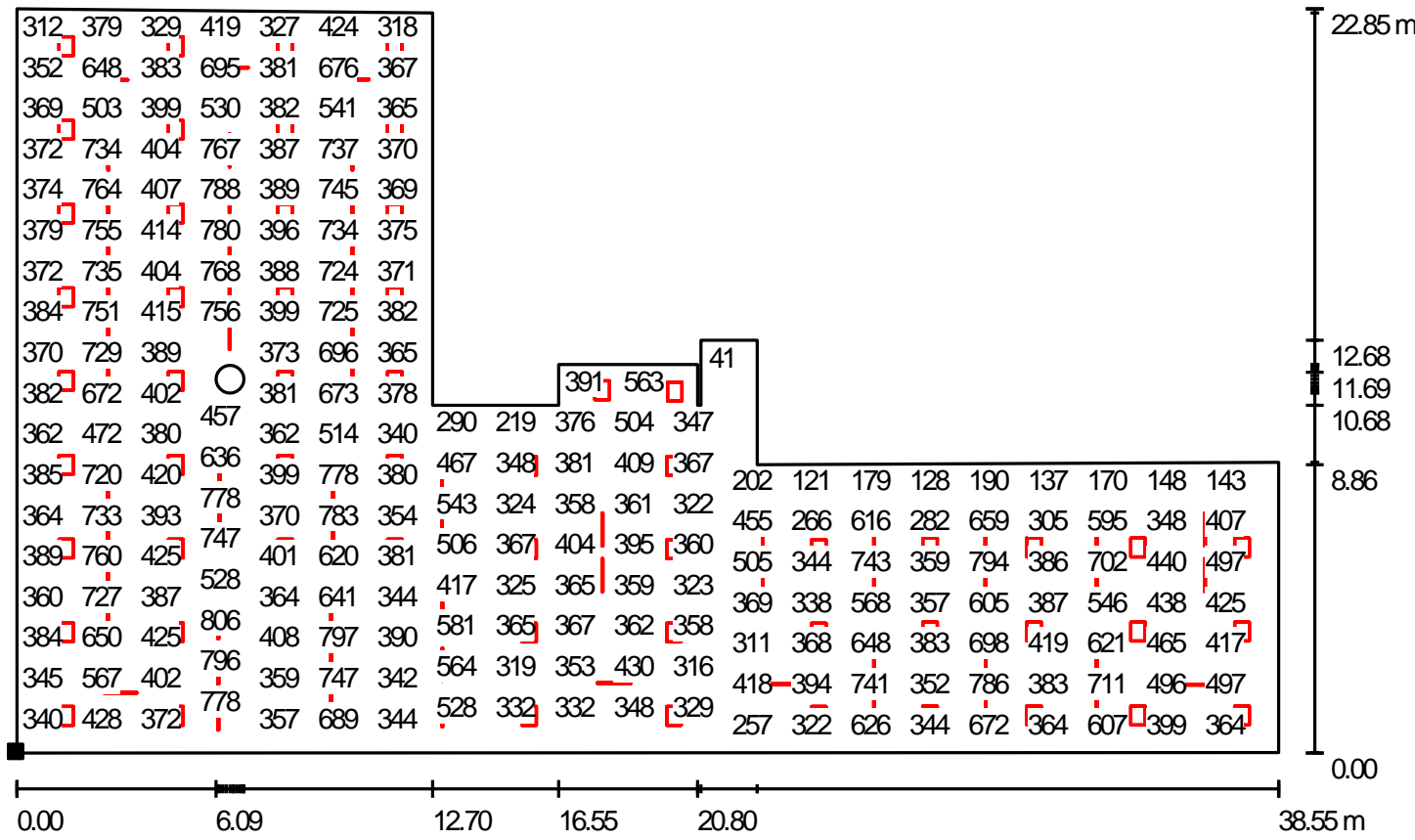

Figura 80: Simulação staff - luminária nacional eficiente seguindo NBR ISO8995 (Arquivo: ET-ST-FT-BR2-MX-ISO.dlx)

Para a sala individual, simularemos o ambiente utilizando o conjunto luminária pendente e fluorescente compacta. Como não é obrigatório que o Emédio seja de 500 lux, conseguimos reduzir a quantidade de peças por ambiente, pois alcançamos os 500 lux no plano de trabalho e temos 300 lux ao redor do plano de trabalho.

A figura 81 e a Tabela 47 nos mostra os novos valores e a nova distribuição de peças no ambiente.

Tabela 47: Tabela simulação sala individual seguindo norma NBR ISO8995

\begin{tabular}{|c|c|c|c|c|c|c|c|c|}
\hline Fabricante & Código peça & $\begin{array}{l}\text { Qtde } \\
\text { pças }\end{array}$ & $\begin{array}{c}\text { Eméd } \\
\text { (IX) }\end{array}$ & $\begin{array}{c}\text { Emín } \\
\text { (Ix) }\end{array}$ & $\begin{array}{c}\text { Emáx } \\
\text { (Ix) }\end{array}$ & $\begin{array}{l}\text { Potência } \\
\text { conj (W) }\end{array}$ & $\begin{array}{l}\text { Potência } \\
\text { total (W) }\end{array}$ & $\begin{array}{c}\text { Tipo/ } \\
\text { Anexo } \\
\text { luminária }\end{array}$ \\
\hline \multirow{2}{*}{ Lumini } & $E-40391 \times 32 W$ & 4 & \multirow{2}{*}{453} & \multirow{2}{*}{76} & \multirow{2}{*}{1195} & 36,00 & \multirow{2}{*}{204,3} & 24 \\
\hline & $34502 \times 28 W$ & 1 & & & & 60,30 & & 56 \\
\hline
\end{tabular}




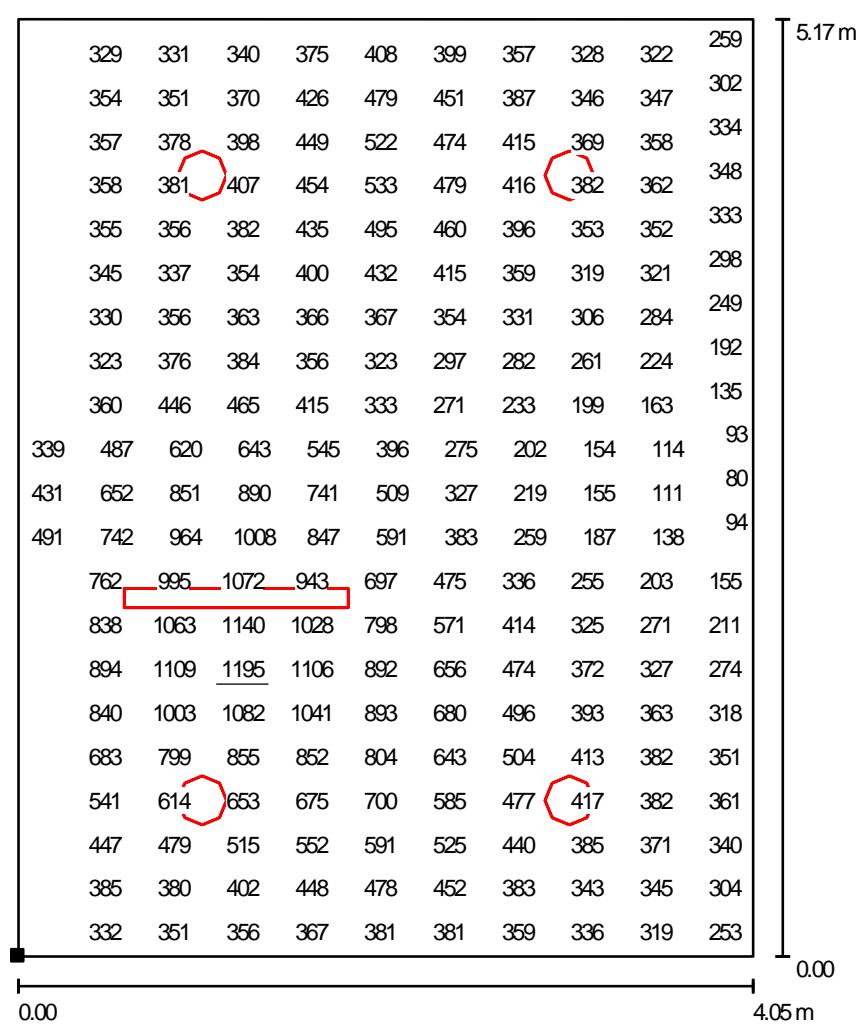

Figura 81: Simulação sala individual - luminária eficiente seguindo NBR ISO8995 (Arquivo: ET-SR-FT-BR2-MX-ISO.dlx)

No caso da sala de reunião, apesar no nível ter aumentado de 300 lux médio para 500 lux, a simulação já nos mostra que no plano de trabalho, já se alcançou os 500 lux. (ver figura 74).

\subsubsection{Projetos}

Nessa parte do trabalho, será simulado o andar do escritório escolhido com os sistemas de iluminação mais eficientes encontrados anteriormente.

A seguir, temos a tabela com o resumo das simulações realizadas. No Anexo - Parte 3, temos todos os resultados dessa tabela com os níveis médio, mínimo e máximo, e a simulação com curvas isolux dos ambientes. 
Tabela 48: Tabela resultados simulação do escritório

\begin{tabular}{|c|c|c|c|c|c|c|c|c|}
\hline Local & $\begin{array}{l}\text { Área } \\
\left(m^{2}\right)\end{array}$ & $\begin{array}{l}\text { Tipo } \\
\text { forro }\end{array}$ & $\begin{array}{c}\text { Tipo } \\
\text { lâmpada }\end{array}$ & Origem & $\begin{array}{l}\text { Potência } \\
\text { total (W) }\end{array}$ & $\begin{array}{c}\text { Máxima } \\
\text { eficiên- } \\
\text { cia } \\
(\mathrm{Im} / \mathrm{W})^{15}\end{array}$ & Lum. & Arquivo simulação \\
\hline \multirow{18}{*}{$\begin{array}{l}\text { 票 } \\
\text { ஸे }\end{array}$} & \multirow{18}{*}{$\begin{array}{c}537,3 \\
2\end{array}$} & \multirow{6}{*}{ 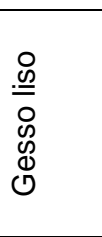 } & \multirow{6}{*}{$\begin{array}{c}\text { Fl. } \\
\text { Tubular }\end{array}$} & Brasil & 5508,0 & 96,43 & 1 & ET-ST-FT-BR-1-MX.dlx \\
\hline & & & & Brasil & 5474,0 & 96,43 & 2 & ET-ST-FT-BR-2-MX.dlx \\
\hline & & & & Exterior & 4968,0 & 96,43 & 3 & ET-ST-FT-EX-3-MX.dlX \\
\hline & & & & Exterior & 4896,0 & 96,43 & 4 & ET-ST-FT-EX-4-MX.dlx \\
\hline & & & & Brasil & 7070,0 & 84,04 & 1 & ET-ST-FT-BR-1-MI.dlx \\
\hline & & & & Brasil & 3815,8 & 96,43 & 2 & ET-ST-FT-BR-2-MX_ISO.dlx \\
\hline & & \multirow{4}{*}{$\begin{array}{l}\frac{\sigma}{\bar{T}} \\
\frac{0}{0} \\
\text { 음 }\end{array}$} & \multirow{4}{*}{$\begin{array}{c}\text { Fl. } \\
\text { Tubular }\end{array}$} & Brasil & 5752,8 & 96,43 & 5 & ET-ST-FT-BR-5-MX̄X.dlx \\
\hline & & & & Brasil & 6440,0 & 96,43 & 6 & ET-ST-FT-BR-6-MX.dlx \\
\hline & & & & Exterior & 5474,0 & 96,43 & 7 & ET-ST-FT-EX-7-MX.dlx \\
\hline & & & & Exterior & 5875,2 & 96,43 & 8 & ET-ST-FT-EX-8-MX.dlx \\
\hline & & \multirow{4}{*}{ 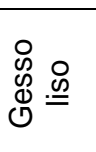 } & \multirow{4}{*}{$\begin{array}{c}\text { FI. } \\
\text { Compac }\end{array}$} & Brasil & 7488,0 & 75,00 & 1 & ET-ST-FC-BR-1-MX.dlx \\
\hline & & & & Brasil & 6876,0 & 75,00 & 2 & ET-ST-FC-BR-2-MX.dlX \\
\hline & & & & Exterior & 6228,0 & 75,00 & 3 & ET-ST-FC-EX-3-MX.dlx \\
\hline & & & & Exterior & 6984,0 & 75,00 & 4 & ET-ST-FC-EX-4-MX.dlx \\
\hline & & \multirow{4}{*}{ 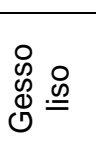 } & \multirow{4}{*}{ LED } & Brasil & 6415,2 & 71,11 & $\frac{T}{1}$ & ET-ST-LE-BR-1-MX.dlx \\
\hline & & & & Brasil & 4290,0 & 86,92 & 2 & ET-ST-LE-BR-2-MX.dlx \\
\hline & & & & Exterior & 4888,4 & 81,14 & 3 & ET-ST-LE-EX-3-MX.dlX \\
\hline & & & & Exterior & 6358,0 & 79,41 & 4 & ET-ST-LE-EX-4-MX.dlX \\
\hline \multirow{14}{*}{ 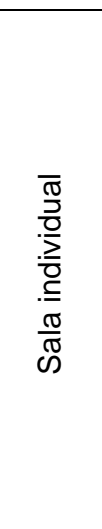 } & \multirow{14}{*}{20,96} & \multirow{6}{*}{ 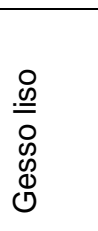 } & \multirow{6}{*}{$\begin{array}{c}\text { Fl. } \\
\text { Compac }\end{array}$} & Brasil & 248,3 & 76,19 & 1 & ET-SI-FC-BR-1-MX.dlx \\
\hline & & & & Brasil & 240,3 & 75,00 & 2 & ET-SI-FC-BR-2-MX.dlx \\
\hline & & & & Exterior & 246,3 & 75,00 & 3 & ET-SI-FC-EX-3-MX.dlx \\
\hline & & & & Exterior & 276,3 & 75,00 & 4 & ET-SI-FC-EX-4-MX.dlx \\
\hline & & & & Brasil & 409,0 & 69,23 & 1 & ET-SI-FC-BR-1-MI.dlx \\
\hline & & & & Brasil & 204,3 & 75,00 & 2 & ET-SI-FC-BR-2-MX-ISO.dlx \\
\hline & & \multirow{4}{*}{ 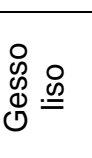 } & \multirow{4}{*}{ Halógena } & Brasil & 1320,2 & 13,17 & 1 & ET-SI-HA-BR-1-MX.dlx \\
\hline & & & & Brasil & 1050,3 & 22,00 & 2 & ET-SI-HA-BR-2-MX.dlx \\
\hline & & & & Exterior & 720,3 & 22,00 & $\frac{5}{3}$ & ET-SI-HA-EX-3-MX.dlx \\
\hline & & & & Exterior & 802,8 & 18,00 & 4 & ET-SI-HA-EX-4-MX.dlx \\
\hline & & \multirow{4}{*}{ 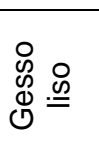 } & & Brasil & 192,3 & 87,83 & 1 & ET-SI-LE-BR-1-MX.dlx \\
\hline & & & & Brasil & 174,7 & 83,70 & 2 & ET-SI-LE-BR-2-MX.dlx \\
\hline & & & LED & Exterior & 209,9 & 79,41 & 3 & ET-SI-LE-EX-3-MX.dlx \\
\hline & & & & Exterior & 269,3 & 53,16 & 4 & ET-SI-LE-EX-4-MX.dlx \\
\hline & & & & Brasil & 183,6 & 96,46 & 1 & ET-SR-FT-BR-1-MX.dlx \\
\hline & & & & Brasil & 250,0 & 83,33 & 2 & ET-SR-FT-BR-2-MX.dlx \\
\hline & & $\Phi$ & Tubular & Exterior & 122,4 & 96,46 & 3 & ET-SR-FT-EX-3-MX.dlX \\
\hline & & & & Exterior & 150,0 & 83,33 & 4 & ET-SR-FT-EX-4-MX.dlX \\
\hline & & & & Brasil & 339,5 & 69,23 & 1 & ET-SR-FH-BR-1-MX.dlx \\
\hline & & $\stackrel{\mathscr{D}}{=}$ & Fl. & Brasil & 451,5 & 69,23 & 2 & ET-SR-FH-BR-2-MX.dlx \\
\hline & & 오 & Co & Exterior & 217,5 & 75,00 & 3 & ET-SR-FH-EX-3-MX.dlx \\
\hline & & d & & Exterior & 259,5 & 75,00 & 4 & ET-SR-FH-EX-4-MX.dlx \\
\hline & & & & Brasil & 451,5 & 69,23 & 1 & ET-SR-FH-BR-1-MI.dlx \\
\hline$\frac{10}{5}$ & & & & Brasil & 247,1 & 69,23 & 1 & ET-SR-FL-BR-1-MX.dlx \\
\hline$\stackrel{\vec{\Phi}}{\underline{\omega}}$ & ח & \& & Compac & Brasil & 359,1 & 69,23 & 2 & ET-SR-FL-BR-2-MX.dlx \\
\hline$\frac{1}{0}$ & 20,70 & $\stackrel{\infty}{\mathscr{D}}=$ & + & Exterior & 197,1 & 69,23 & 3 & ET-SR-FL-EX-3-MX.dlx \\
\hline$\underline{\widetilde{\sigma}}$ & & & LED & Exterior & 211,1 & 76,19 & 4 & ET-SR-FL-EX-4-MX.dlX \\
\hline$\overline{\mathscr{D}}$ & & & & Brasil & 194,7 & 87,83 & 1 & ET-SR-LH-BR-1-MX.dlx \\
\hline & & & & Brasil & 172,7 & 83,70 & 2 & ET-SR-LH-BR-2-MX.dlx \\
\hline & & $\stackrel{\mathscr{\omega}}{=}$ & & Exterior & 203,5 & 81,00 & 3 & ET-SR-LH-EX-3-MX.dlx \\
\hline & & & & Exterior & 225,5 & 52,80 & 4 & ET-SR-LH-EX-4-MX.dlx \\
\hline & & & & Brasil & 128,7 & 87,83 & 1 & ET-SR-LL-BR-1-MX.dlx \\
\hline & & $\underline{\underline{.0 p}}$ & LED & Brasil & 108,9 & 83,70 & 2 & ET-SR-LL-BR-2-MX.dlx \\
\hline & & 오 & + & Exterior & 155,1 & 81,00 & $\overline{3}$ & ET-SR-LL-EX-3-MX.dlX \\
\hline & & D & LED & Exterior & 188,1 & 52,80 & 4 & ET-SR-LL-EX-4-MX.dlx \\
\hline & & & & Brasil & 108,9 & 83,70 & 2 & ET-SR-LL-BR-2-MX-ISO.dlx \\
\hline
\end{tabular}

\footnotetext{
${ }^{15}$ Referente ao sistema de iluminação principal do ambiente
} 


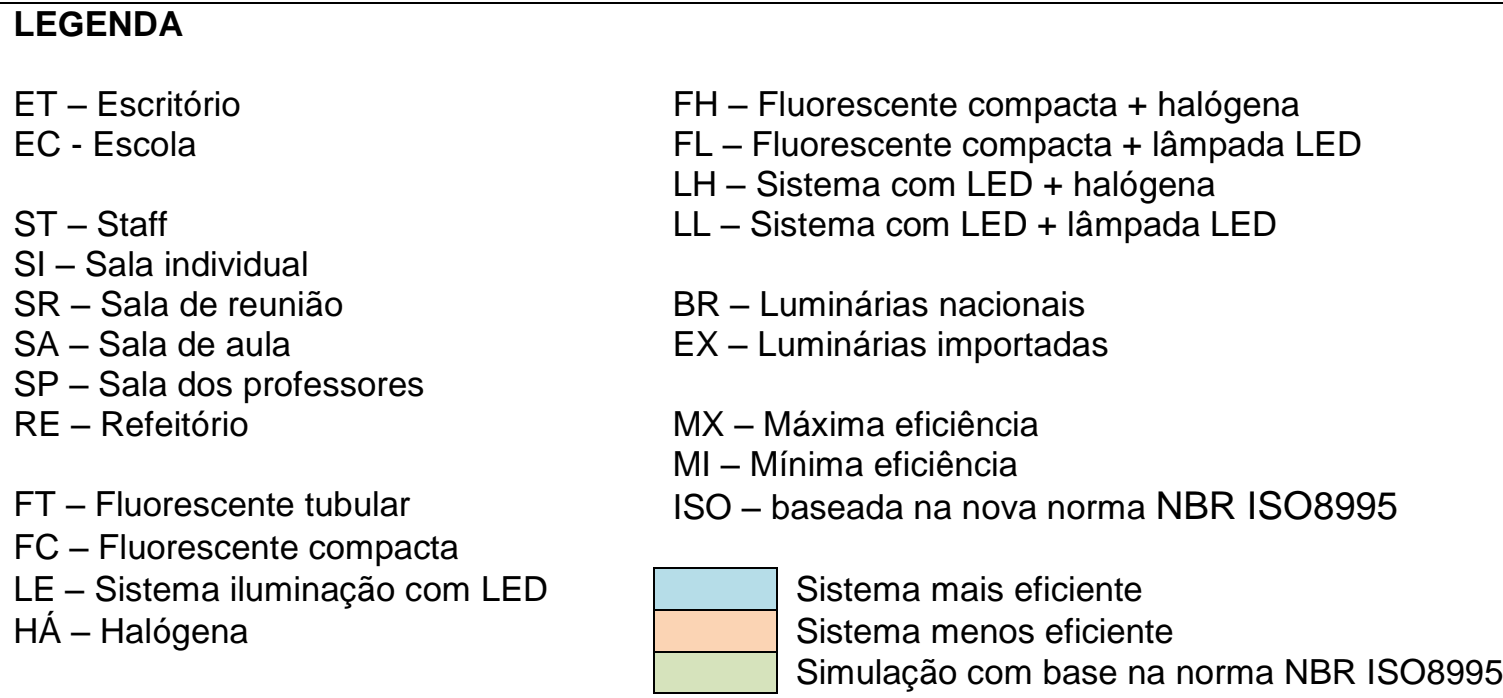

Pela Tabela 48 de resultados, observamos que o sistema de iluminação encontrado no exterior é mais eficiente que o sistema de iluminação encontrado no mercado nacional. No entanto, em relação às luminárias de LED, o sistema nacional é mais eficiente.

Como ainda não existem normas em relação à produção ou padronização na fabricação do LED no país, não há como justificar essa eficiência. No entanto, estão em estudo algumas normas internacionais que estão sendo traduzidas e discutidas pela Comissão de Estudos de Lâmpadas Elétricas.

Para comparação, faremos o projeto luminotécnico do escritório escolhido, utilizando os sistemas de iluminação mais eficientes tanto do mercado nacional quanto do mercado internacional. Os resultados podem ser vistos no Anexo Parte 3 nas plantas Projeto 1.

- Como os produtos importados utilizados nas simulações são comercializados no Brasil, será feito também o projeto utilizando essas peças, porém seguindo a norma brasileira. Os resultados podem ser vistos no Anexo Parte 3 na planta Projeto 2.

Observando os resultados da distribuição de peças no Projeto 1 e Projeto 2, há uma grande quantidade de luminárias em LED. Na primeira simulação temos 603 peças e na segunda simulação 170 . 
Como as peças em LED ainda tem um custo inicial muito alto, a grande maioria dos empreendedores não consegue investir na compra de cerca de 600 peças em LED. Então, para aproximarmos do emprendimento real, consideraremos as luminárias em LED somente nas menores áreas, como as salas individuais e salas de reunião. O resultado desse projeto, pode ser visto no Anexo Parte 3, Projeto 3 utilizando o sistema de iluminação nacional e Projeto 4 utilizando o importado.

O Projeto 5 será feito para uma situação onde o empreendedor invista parcialmente em luminárias LED, pois as luminárias nacionais em LED ainda não tem uma garantia de que o fluxo luminoso permanece ao longo dos anos ou que a vida útil e média seja o informado no catálogo. Esse é um dos projetos que mais se aproxima da situação real.

O Projeto 6 é um projeto onde somente os pontos de destaque na mesa de reuniões será em LED e todos os sistemas de iluminação será com fluorescente. Também pode ser considerado como um projeto próximo à situação real, muito encontrado nos escritórios do Brasil.

Para comparação, o Projeto 7 é um projeto onde foi simulado luminárias menos eficientes ainda comercializados no Brasil.

O Projeto 8 é um projeto onde foi considerado a nova norma que substitui a NBR 5413/1192. Consideramos a norma ABNT NBR ISSO 8995-1: lluminação de ambientes de trabalho - Parte 1: Interior. Tomaremos como base o Projeto 5 para analisar o quanto reduziremos a densidade de potência.

\subsection{Escola}

Serão simulados para a escola quatro ambientes: sala de aula, sala dos professores e refeitório, assinalados na figura 82 a seguir: 

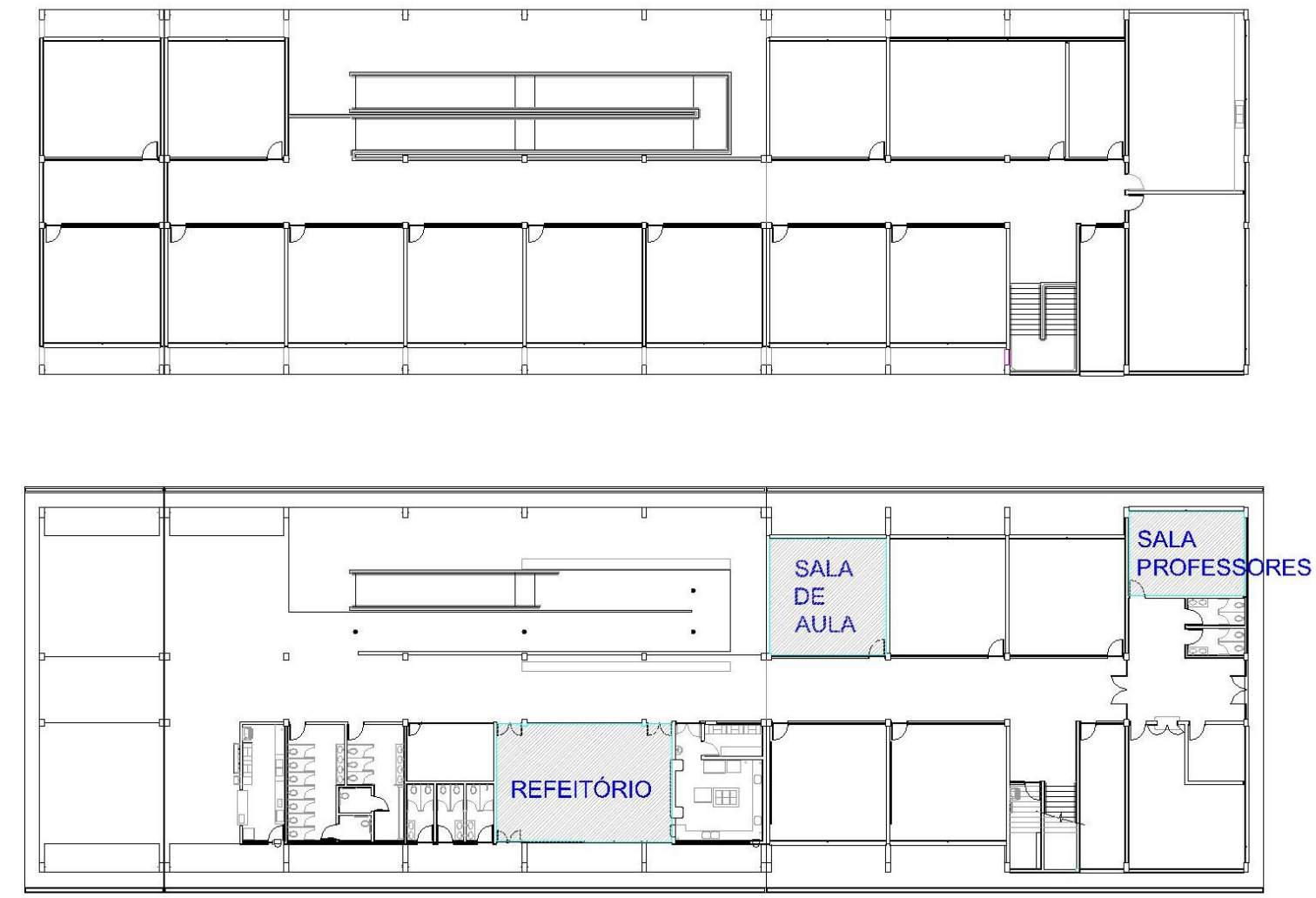

Figura 82: Ambientes simulados da escola

Para a simulação da escola, a escolha dos sistemas de iluminação para verificação dos indicadores de iluminação é mais restrita, pois em uma escola, é importante que os equipamentos para manutenção não tenham muita variedade.

Nesse caso, reduziremos a quantidade de tipo de lâmpada para no máximo dois tipos, facilitando assim, o estoque de produtos para reposição.

Assim como no escritório, considerou-se um pé direito padrão de 2,70m com forro de gesso liso.

Simularemos os ambientes utilizando lâmpada fluorescente tubular e sistemas de iluminação com LED, pois nas simulações de escritório, verificamos que o uso de lâmpada fluorescente compacta não integrada para ambientes maiores não é tão eficiente. 


\subsubsection{Simulação 1ํ Etapa}

\subsubsection{Sala de aula}

A planta padrão FDE não possui layout, ficando a critério de cada escola, distribuir seu mobiliário. Nesse caso, será feito uma simulação geral dos ambientes, sem ficar restrito ao layout como foi o caso dos ambientes de escritório.

Como nas salas de aula, temos o nível de trabalho vertical da lousa, imaginaremos que o mesmo esteja na parede lateral da porta.

Utilizaremos luminárias retangulares para lâmpada fluorescente tubular T5 de 28W, 4000K, com refletor e aletas parabólicas. Para o plano vertical, utilizaremos luminárias de facho assimétrico.

O nível médio da sala de aula é de 300 lux no plano de trabalho horizontal e no plano de trabalho vertical (lousa) consideraremos 500 lux.

Tabela 49: Tabela simulação sala de aula sistema de iluminação nacional - fluorescente tubular

\begin{tabular}{|c|c|c|c|c|c|c|c|c|}
\hline Fabricante & Código peça & $\begin{array}{l}\text { Qtde } \\
\text { pças }\end{array}$ & $\begin{array}{c}\text { Eméd } \\
(\mathbf{I x})\end{array}$ & $\begin{array}{c}\text { Emín } \\
\text { (Ix) }\end{array}$ & $\begin{array}{c}\text { Emáx } \\
\text { (Ix) }\end{array}$ & $\begin{array}{l}\text { Potência } \\
\text { conj (W) }\end{array}$ & $\begin{array}{l}\text { Potência } \\
\text { total (W) }\end{array}$ & $\begin{array}{c}\text { Tipo/ } \\
\text { Anexo } \\
\text { Iuminária }\end{array}$ \\
\hline \multirow{2}{*}{$\begin{array}{c}\text { Itaim } \\
\text { Iluminação }\end{array}$} & $20052 \times 28 W$ & 4 & \multirow{2}{*}{405} & \multirow{2}{*}{179} & \multirow{2}{*}{784} & 60,30 & \multirow{2}{*}{332,7} & 98 \\
\hline & $25271 \times 28 \mathrm{~W}$ & 3 & & & & 30,50 & & 99 \\
\hline \multirow{2}{*}{$\begin{array}{c}\text { Itaim } \\
\text { Iluminação }\end{array}$} & $23152 \times 28 W$ & 6 & \multirow{2}{*}{509} & \multirow{2}{*}{171} & \multirow{2}{*}{745} & 60,30 & \multirow{2}{*}{453,3} & 100 \\
\hline & $25271 \times 28 W$ & 3 & & & & 30,50 & & 99 \\
\hline \multirow{2}{*}{$\begin{array}{c}\text { Itaim } \\
\text { Iluminação }\end{array}$} & $26252 \times 28 W$ & 4 & \multirow{2}{*}{400} & \multirow{2}{*}{138} & \multirow{2}{*}{592} & 60,30 & \multirow{2}{*}{332,7} & 101 \\
\hline & $25271 \times 28 W$ & 3 & & & & 30,50 & & 99 \\
\hline \multirow{2}{*}{$\begin{array}{c}\text { Itaim } \\
\text { Iluminação }\end{array}$} & $27252 \times 28 W$ & 4 & \multirow{2}{*}{404} & \multirow{2}{*}{122} & \multirow{2}{*}{639} & 60,30 & \multirow{2}{*}{332,7} & 102 \\
\hline & $25271 \times 28 W$ & 3 & & & & 30,50 & & 99 \\
\hline \multirow{2}{*}{$\begin{array}{c}\text { Itaim } \\
\text { Iluminação }\end{array}$} & $26151 \times 28 W$ & 9 & \multirow[b]{2}{*}{385} & \multirow{2}{*}{178} & \multirow{2}{*}{642} & 30,50 & \multirow{2}{*}{366,0} & 103 \\
\hline & $25271 \times 28 W$ & 3 & & & & 30,50 & & 99 \\
\hline \multirow[t]{2}{*}{ Lumini } & FE1799 2x28W & 4 & \multirow{2}{*}{394} & \multirow{2}{*}{121} & \multirow{2}{*}{648} & 60,30 & \multirow{2}{*}{332,7} & 103 \\
\hline & $25271 \times 28 W$ & 3 & & & & 30,50 & & 99 \\
\hline
\end{tabular}

Optou-se por escolher o conjunto do sistema de iluminação em destaque na Tabela 49 por ser o conjunto que resultou em um nível médio mais homogêneo.

Na figura 83 e 84, podemos ver o nível ponto a ponto com o resultado dessa simulação, onde a figura 84 apresenta o resultado no plano vertical. 


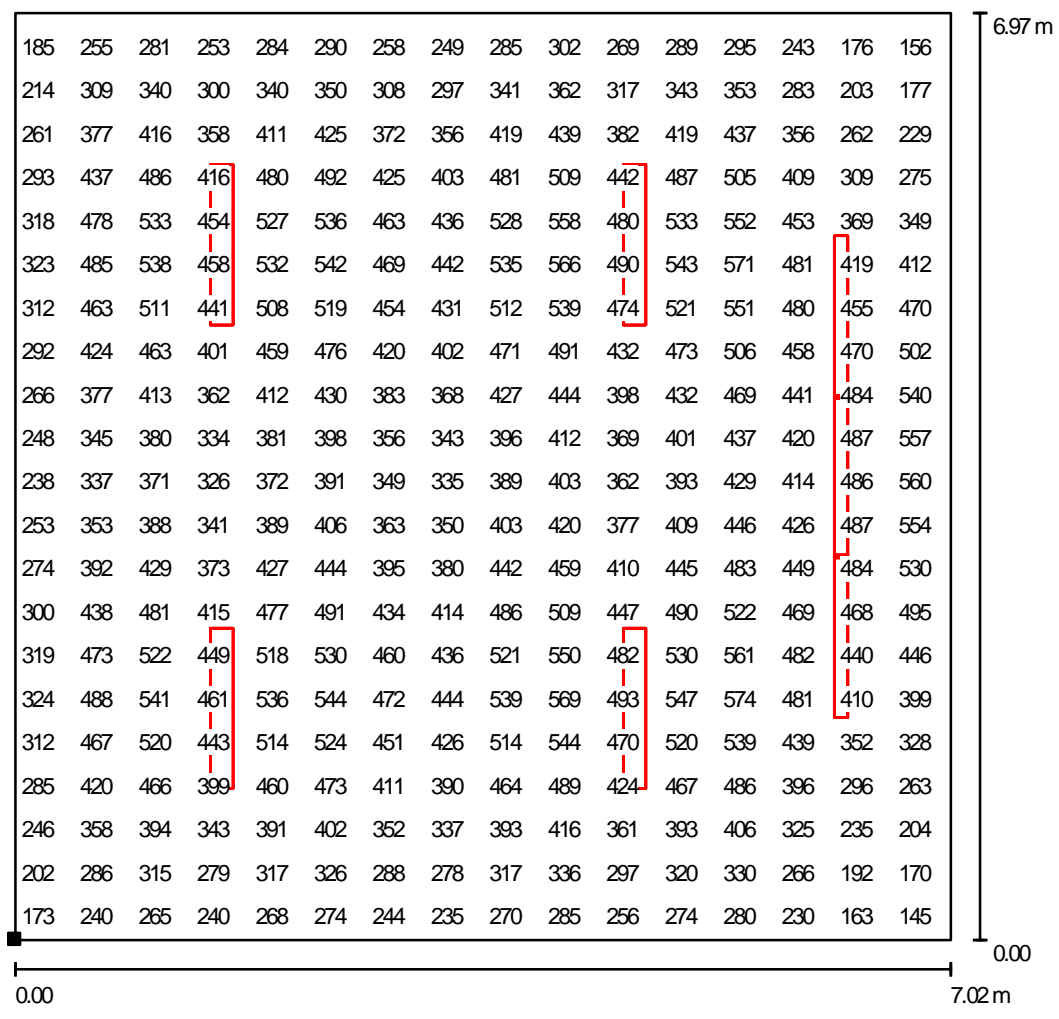

Figura 83: Simulação plano horizontal da sala de aula - luminária nacional tipo $101 \mathrm{com}$ fluorescente tubular (Arquivo: EC-SA-FT-BR-1-MX.dlx)

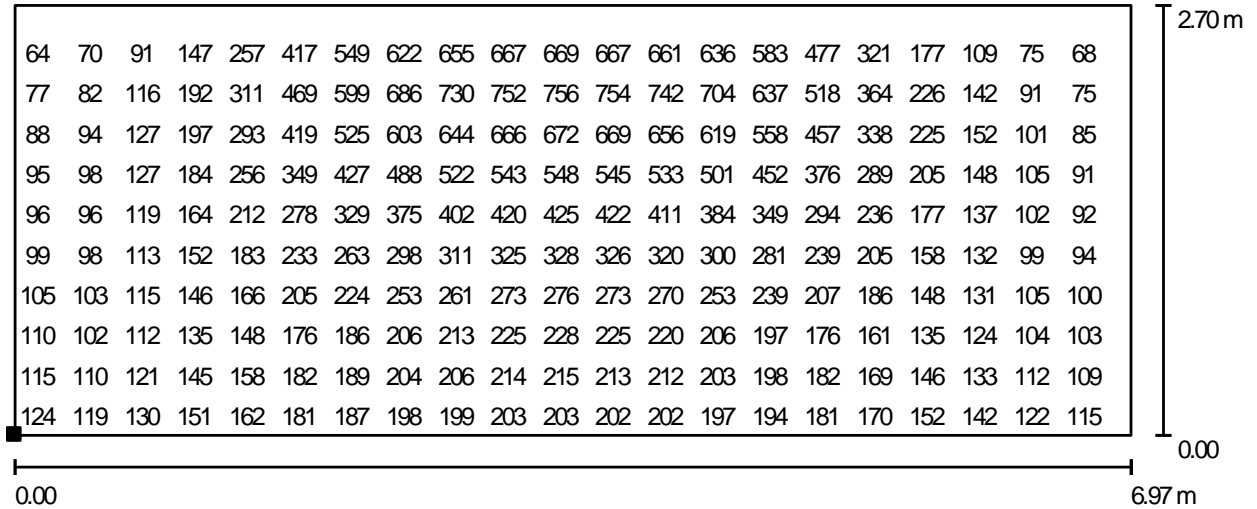

Figura 84: Simulação plano vertical da sala de aula - luminária nacional tipo $101 \mathrm{com}$ fluorescente tubular (Arquivo: EC-SA-FT-BR-1-MX.dlx)

Pelas simulações realizadas no escritório, sabemos que as luminárias para lâmpadas fluorescentes tubulares são mais eficientes no exterior, porém para comparação, seguem o resultado das simulações. 
Tabela 50: Tabela simulação sala de aula sistema de iluminação importado

\begin{tabular}{|c|c|c|c|c|c|c|c|c|}
\hline Fabricante & Código peça & $\begin{array}{l}\text { Qtde } \\
\text { pças }\end{array}$ & $\begin{array}{c}\text { Eméd } \\
(\mathrm{Ix})\end{array}$ & $\begin{array}{c}\text { Emín } \\
(\mathbf{I x})\end{array}$ & $\begin{array}{c}\text { Emáx } \\
(\mathbf{I x})\end{array}$ & $\begin{array}{l}\text { Potência } \\
\text { conj (W) }\end{array}$ & $\begin{array}{l}\text { Potência } \\
\text { total (W) }\end{array}$ & $\begin{array}{c}\text { Tipo/ } \\
\text { Anexo } \\
\text { luminária }\end{array}$ \\
\hline \multirow{2}{*}{ Zumtobel } & $\begin{array}{c}\text { Mirel2 } 42914862 \\
2 \times 28 W\end{array}$ & 4 & \multirow{2}{*}{418} & \multirow{2}{*}{141} & \multirow{2}{*}{845} & 60,30 & \multirow{2}{*}{332,7} & 105 \\
\hline & $\begin{array}{l}\text { Mirel Wallwasher } \\
429113521 \times 28 W\end{array}$ & 3 & & & & 30,50 & & 104 \\
\hline \multirow{2}{*}{ Zumtobel } & $\begin{array}{c}\text { Mirel2 42915021 } \\
1 \times 28 W \\
\end{array}$ & 6 & \multirow{2}{*}{332} & \multirow{2}{*}{132} & \multirow{2}{*}{769} & 30,5 & \multirow{2}{*}{274,5} & 106 \\
\hline & $\begin{array}{l}\text { Mirel Wallwasher } \\
429113521 \times 28 W\end{array}$ & 3 & & & & 30,50 & & 104 \\
\hline \multirow{2}{*}{ Zumtobel } & $\begin{array}{c}\text { Mirel2 } 42914845 \\
\text { 2x28W }\end{array}$ & 4 & \multirow{2}{*}{409} & \multirow{2}{*}{140} & \multirow{2}{*}{770} & 60,30 & \multirow{2}{*}{332,7} & 107 \\
\hline & $\begin{array}{l}\text { Mirel Wallwasher } \\
429113521 \times 28 W\end{array}$ & 3 & & & & 30,50 & & 104 \\
\hline \multirow{2}{*}{ Zumtobel } & $\begin{array}{c}\text { Mirel2 } 42914952 \\
1 \times 28 W \\
\end{array}$ & 6 & \multirow{2}{*}{332} & \multirow{2}{*}{128} & \multirow{2}{*}{763} & 60,30 & \multirow{2}{*}{274,5} & 108 \\
\hline & $\begin{array}{l}\text { Mirel Wallwasher } \\
429113521 \times 28 W\end{array}$ & 1 & & & & 30,50 & & 104 \\
\hline
\end{tabular}

Apesar dos resultados em relação à consumo se repetirem na Tabela 50, a luminária que iremos utilizar para cálculo é que está em negrito. A diferença das luminárias 106 e 108 estão no tipo refletor. A primeira é um refletor do tipo "darklight" e a segunda de alumínio "matt" anodizado.

Ambas as peças tem um bom controle de ofuscamento, porém ao analisar os resultados da simulação, nas figuras 85 e 86, observamos que a simulação da figura 85 atende melhor em relação à homogeneidade. 


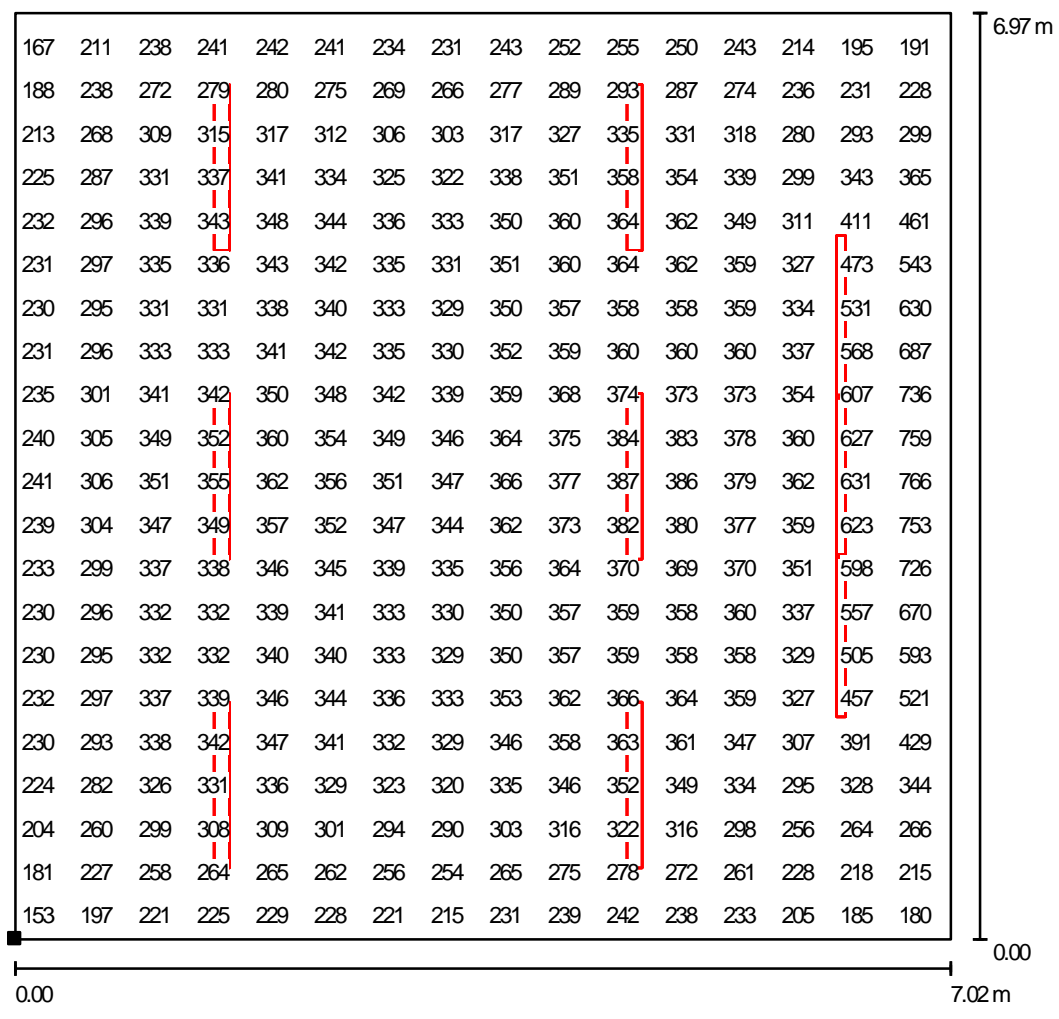

Figura 85: Simulação plano horizontal da sala de aula - luminária importada tipo 106 com fluorescente tubular (Arquivo: EC-AS-FT-EX-1-MX.dlx)

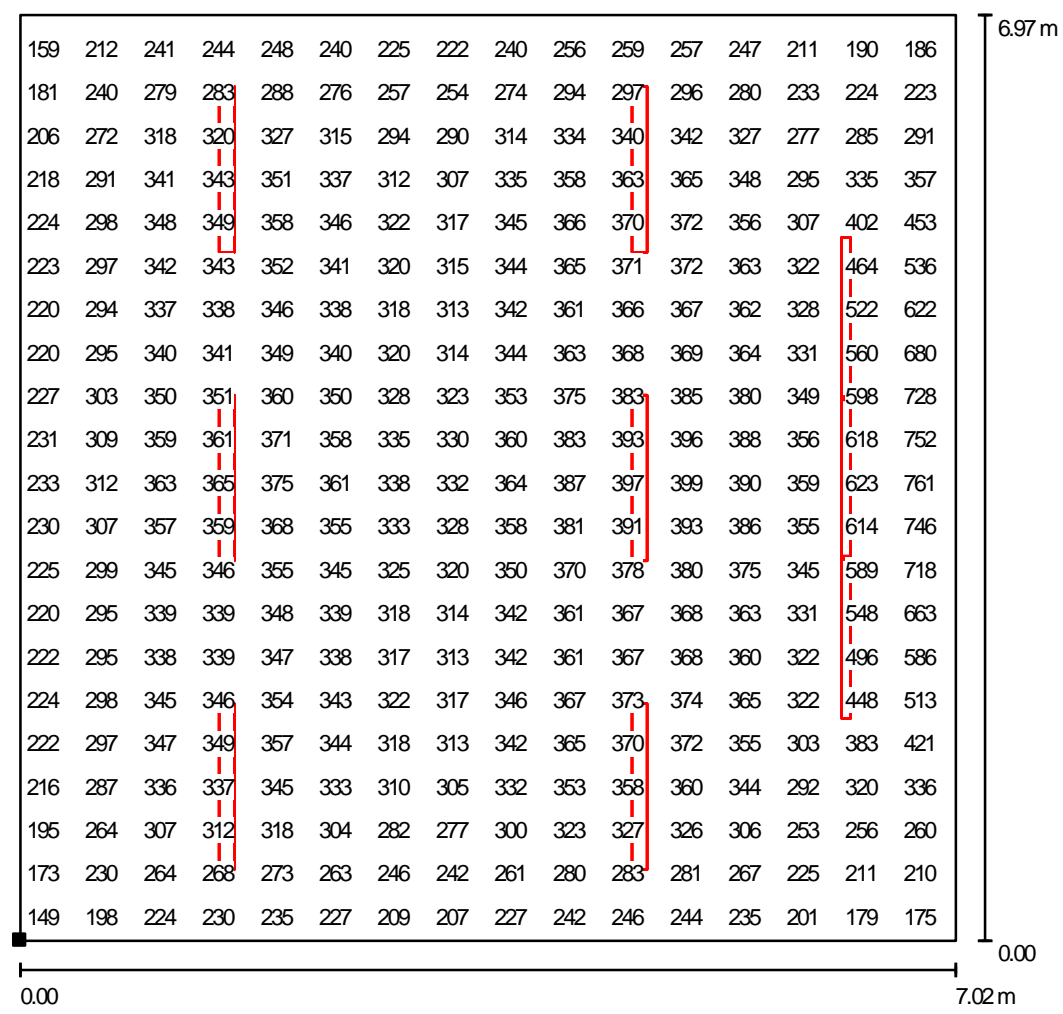

Figura 86: Simulação plano horizontal da sala de aula - sistema de iluminação importado tipo 108 com fluorescente tubular 
A figura 87 mostra a simulação no plano da lousa para a luminária do tipo 106.

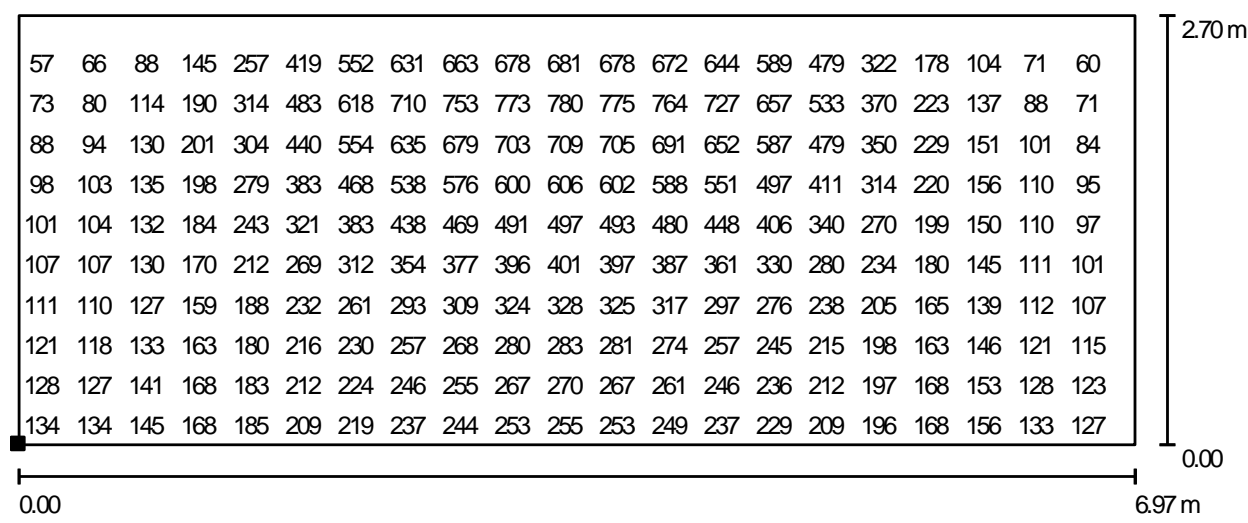

Figura 87: Simulação plano vertical da sala de aula - luminária importada tipo 106 com fluorescente tubular (Arquivo: EC-AS-FT-EX-1-MX.dlx)

Para a simulação do sistema de iluminação LED, simularemos com algumas luminárias do fabricante Itaim Iluminação. As luminárias são retangulares com fechamento em difusor. Não há ainda no mercado nacional muitos produtos no qual podemos substituir as de luminárias com lâmpada fluorescente tubular.

Tabela 51: Tabela simulação sala de aula sistema de iluminação nacional - LED

\begin{tabular}{|c|c|c|c|c|c|c|c|c|}
\hline Fabricante & Código peça & $\begin{array}{l}\text { Qtde } \\
\text { pças }\end{array}$ & $\begin{array}{l}\text { Eméd } \\
\text { (Ix) }\end{array}$ & $\underset{\text { (Ix) }}{\text { Emín }}$ & $\begin{array}{c}\text { Emáx } \\
\text { (Ix) }\end{array}$ & $\begin{array}{l}\text { Potência } \\
\text { conj (W) }\end{array}$ & $\begin{array}{l}\text { Potência } \\
\text { total (W) }\end{array}$ & $\begin{array}{c}\text { Tipo/ } \\
\text { Anexo } \\
\text { Iuminária }\end{array}$ \\
\hline \multirow{2}{*}{$\begin{array}{c}\text { Itaim } \\
\text { lluminação }\end{array}$} & Asteca R - 40W & 6 & \multirow{2}{*}{381} & \multirow{2}{*}{163} & \multirow{2}{*}{611} & 44,00 & \multirow{2}{*}{355,5} & 109 \\
\hline & $25271 \times 28 W$ & 3 & & & & 30,50 & & 99 \\
\hline \multirow{2}{*}{$\begin{array}{c}\text { Itaim } \\
\text { Iluminação }\end{array}$} & Maia $\mathrm{R}-40 \mathrm{~W}$ & 6 & \multirow{2}{*}{378} & \multirow{2}{*}{159} & \multirow{2}{*}{603} & 44,00 & \multirow{2}{*}{355,5} & 110 \\
\hline & $25271 \times 28 W$ & 3 & & & & 30,50 & & 99 \\
\hline \multirow{2}{*}{$\begin{array}{c}\text { Itaim } \\
\text { Iluminação }\end{array}$} & Minotauro $R-40 W$ & 6 & \multirow{2}{*}{366} & \multirow{2}{*}{175} & \multirow{2}{*}{634} & 44,00 & \multirow{2}{*}{355,5} & 111 \\
\hline & $25271 \times 28 W$ & 3 & & & & 30,50 & & 99 \\
\hline
\end{tabular}

Comparando as peças utilizadas nesta simulação, observamos que a diferença está no difusor. Como o consumo do sistema no ambiente é o mesmo, escolhemos a luminária analisando a simulação ponto a ponto. Segue a simulação da peça em destaque na figura 88 e 89. 


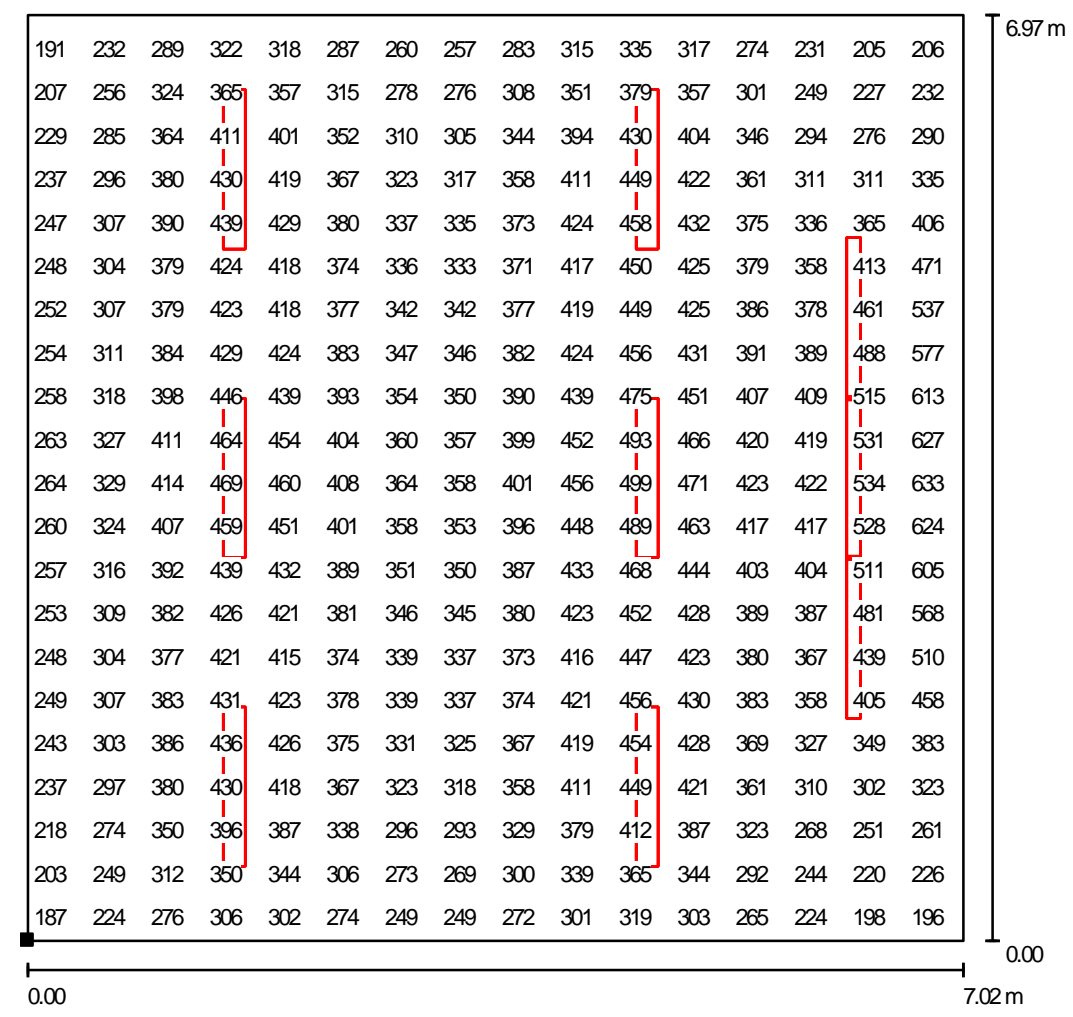

Figura 88: Simulação plano horizontal da sala de aula - luminária nacional com LED tipo 111 (Arquivo: EC-SA-LE-BR-1-MX.dlx)

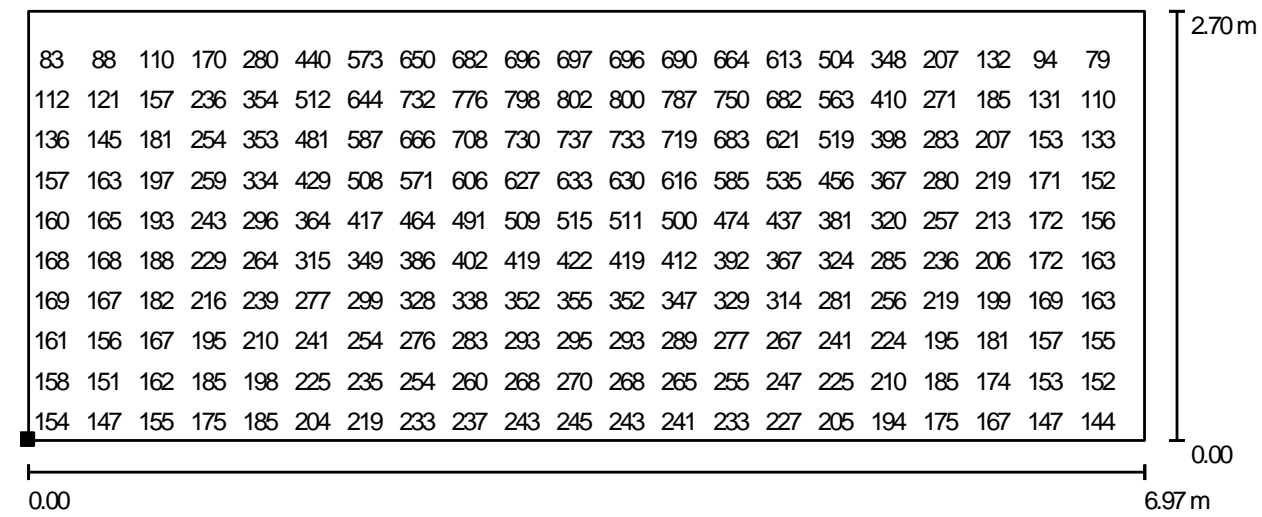

Figura 89: Simulação plano vertical da sala de aula - luminária nacional com LED tipo 111 (Arquivo: ECSA-LE-BR-1-MX.dlx)

Por fim, para a sala de aula, simularemos o sistema de iluminação de LED importado.

Segue a Tabela 52 com os resultados da simulação. 
Tabela 52: Tabela simulação sala de aula sistema de iluminação importado - LED

\begin{tabular}{|c|c|c|c|c|c|c|c|c|}
\hline Fabricante & Código peça & $\begin{array}{l}\text { Qtde } \\
\text { pças }\end{array}$ & $\begin{array}{c}\text { Eméd } \\
\text { (Ix) }\end{array}$ & $\begin{array}{c}\text { Emín } \\
\text { (Ix) }\end{array}$ & $\begin{array}{c}\text { Emáx } \\
\text { (Ix) }\end{array}$ & $\begin{array}{l}\text { Potência } \\
\text { conj (W) }\end{array}$ & $\begin{array}{l}\text { Potência } \\
\text { total (W) }\end{array}$ & $\begin{array}{c}\text { Tipo/ } \\
\text { Anexo } \\
\text { Iuminária }\end{array}$ \\
\hline \multirow{2}{*}{ Zumtobel } & $\begin{array}{c}\text { L-FIELDS } 42180002 \\
-44 \mathrm{~W}\end{array}$ & 6 & \multirow[b]{2}{*}{464} & \multirow[b]{2}{*}{189} & \multirow[b]{2}{*}{819} & 48,40 & \multirow{2}{*}{381,9} & 112 \\
\hline & $\begin{array}{l}\text { Mirel Wallwasher } \\
429113521 \times 28 W\end{array}$ & 3 & & & & 30,50 & & 104 \\
\hline \multirow{2}{*}{ Zumtobel } & $\begin{array}{c}\text { L-FIELDS } 42180006 \\
-55 W\end{array}$ & 4 & \multirow{2}{*}{399} & \multirow{2}{*}{139} & \multirow{2}{*}{762} & 60,50 & \multirow{2}{*}{333,5} & 113 \\
\hline & $\begin{array}{c}\text { Mirel Wallwasher } \\
429113521 \times 28 W\end{array}$ & 3 & & & & 30,50 & & 104 \\
\hline
\end{tabular}

As figuras 90 e 91 mostram os resultados da simulação do sistema mais eficiente.

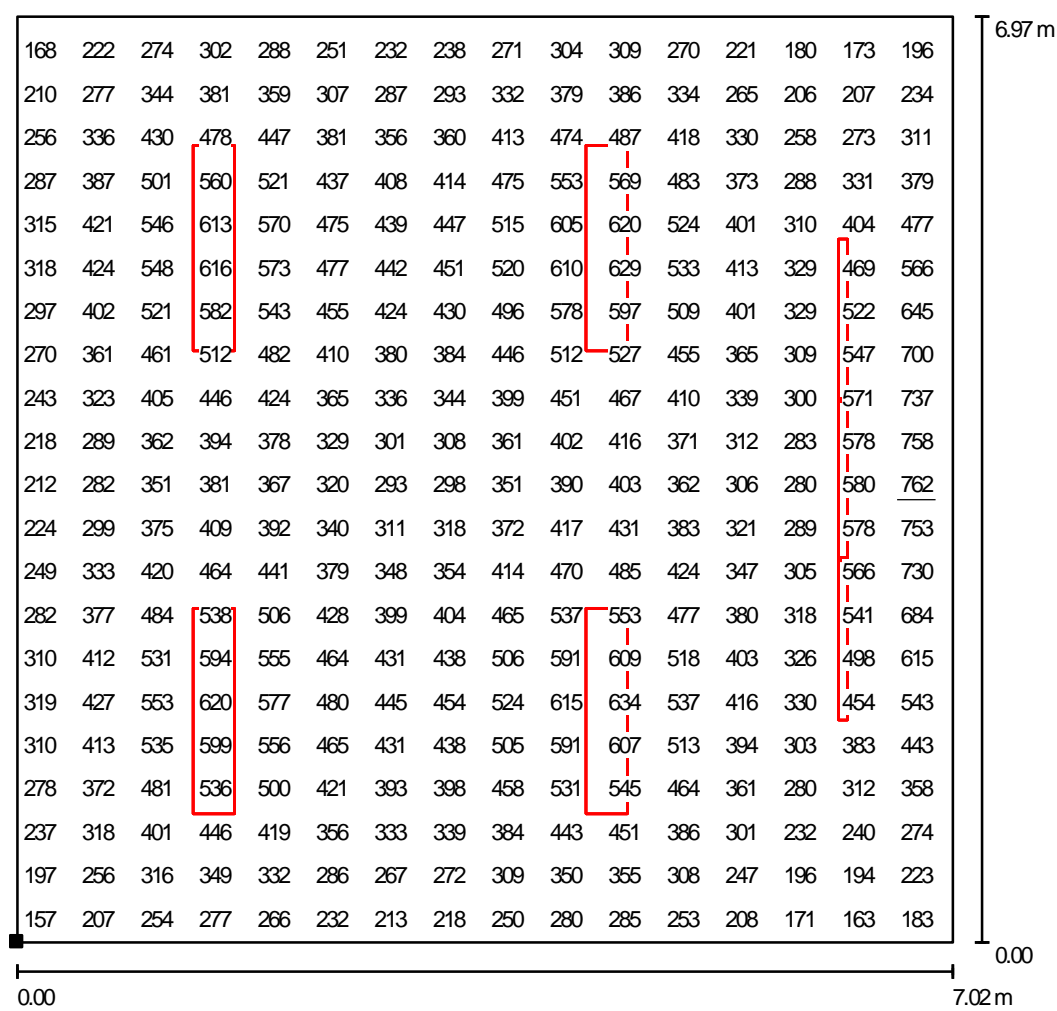

Figura 90: Simulação plano horizontal da sala de aula - luminária importada tipo 113 (Arquivo: EC-SA-LEEX-1-MX.dlx) 


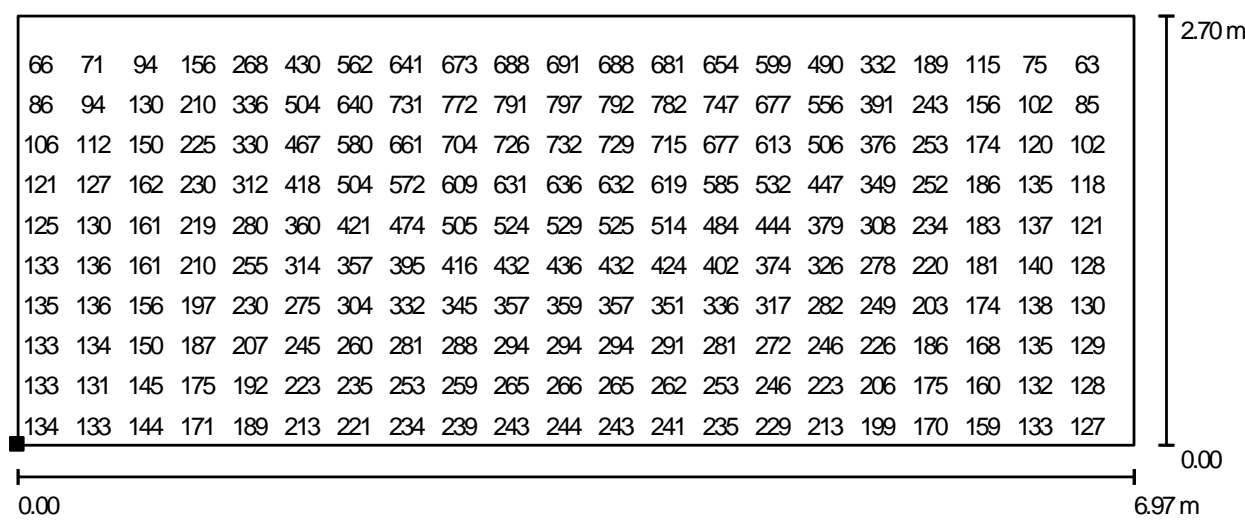

Figura 91: Simulação plano vertical da sala de aula - luminária importada tipo 113 (Arquivo: EC-SA-LEEX-1-MX.dlx)

\subsubsection{Sala dos professores}

Para padronizar o sistema de iluminação das escolas, optou-se por utilizar a mesma luminária nos outros ambientes. Na sala dos professores, a norma pede um nível médio de 300 lux.

Seguem na Tabela 53 e figura 92 e 93, os valores do nível de iluminação encontrados, utilizando as luminárias nacionais de menor consumo encontradas na simulação da sala de aula.

Tabela 53: Tabela de resultado da simulação de luminárias nacionais - sala dos professores

\begin{tabular}{|c|c|c|c|c|c|c|c|c|}
\hline Fabricante & Código peça & $\begin{array}{c}\text { Qtde } \\
\text { pças }\end{array}$ & $\begin{array}{c}\text { Eméd } \\
\text { (Ix) }\end{array}$ & $\begin{array}{c}\text { Emín } \\
\text { (Ix) }\end{array}$ & $\begin{array}{c}\text { Emáx } \\
\text { (Ix) }\end{array}$ & $\begin{array}{c}\text { Potência } \\
\text { conj (W) }\end{array}$ & $\begin{array}{c}\text { Potência } \\
\text { total (W) }\end{array}$ & $\begin{array}{c}\text { Tipo/ } \\
\text { Anexo } \\
\text { luminária }\end{array}$ \\
\hline $\begin{array}{c}\text { Itaim } \\
\text { Iluminação }\end{array}$ & $26252 \times 28 W$ & 4 & 442 & 192 & 672 & 60,30 & 241,2 & 101 \\
\hline $\begin{array}{c}\text { Itaim } \\
\text { Iluminação }\end{array}$ & Minotauro R-40W & 6 & 391 & 209 & 502 & 44,00 & 264,0 & 111 \\
\hline
\end{tabular}




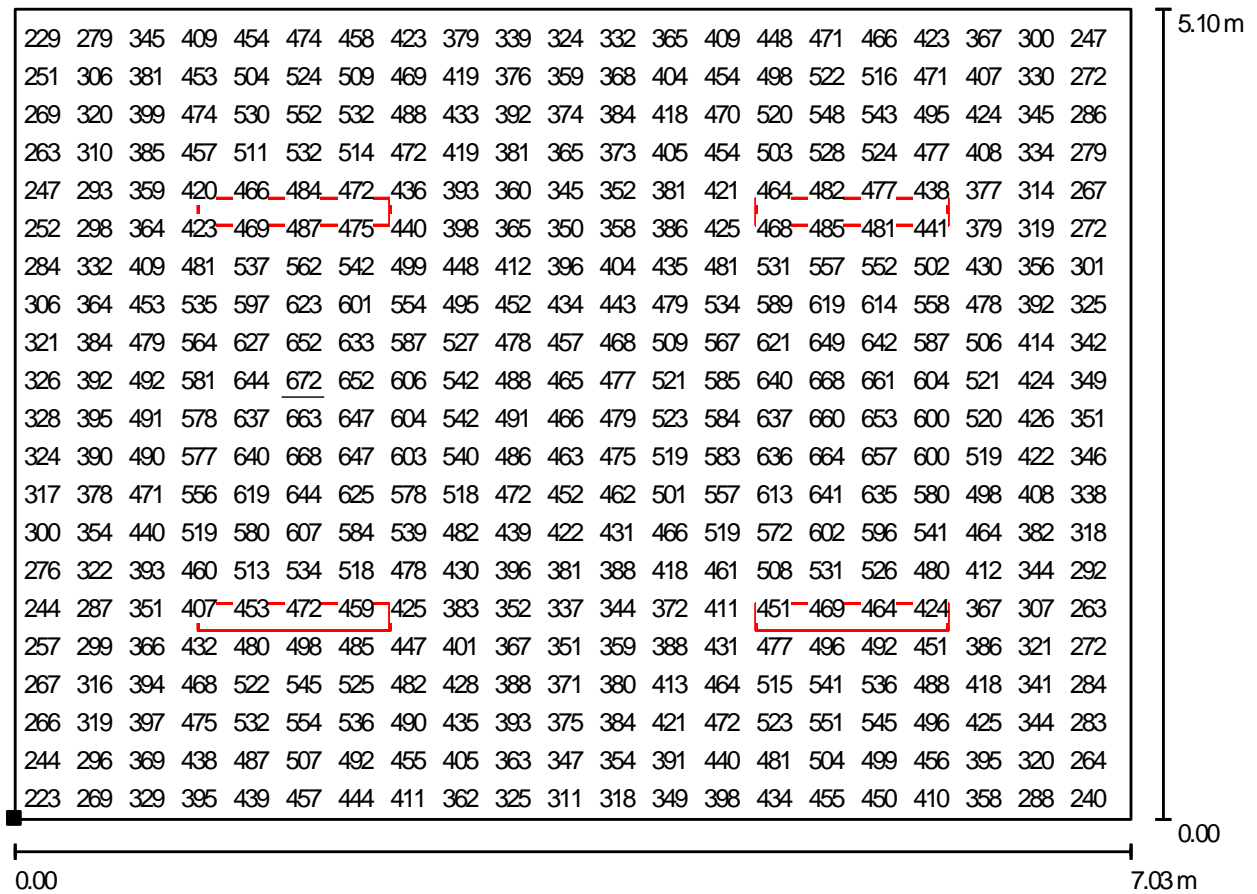

Figura 92: Simulação sala dos professores - luminária nacional tipo $101 \mathrm{com}$ fluorescente tubular (Arquivo: EC-SP-FT-BR-1-MX.dlx)

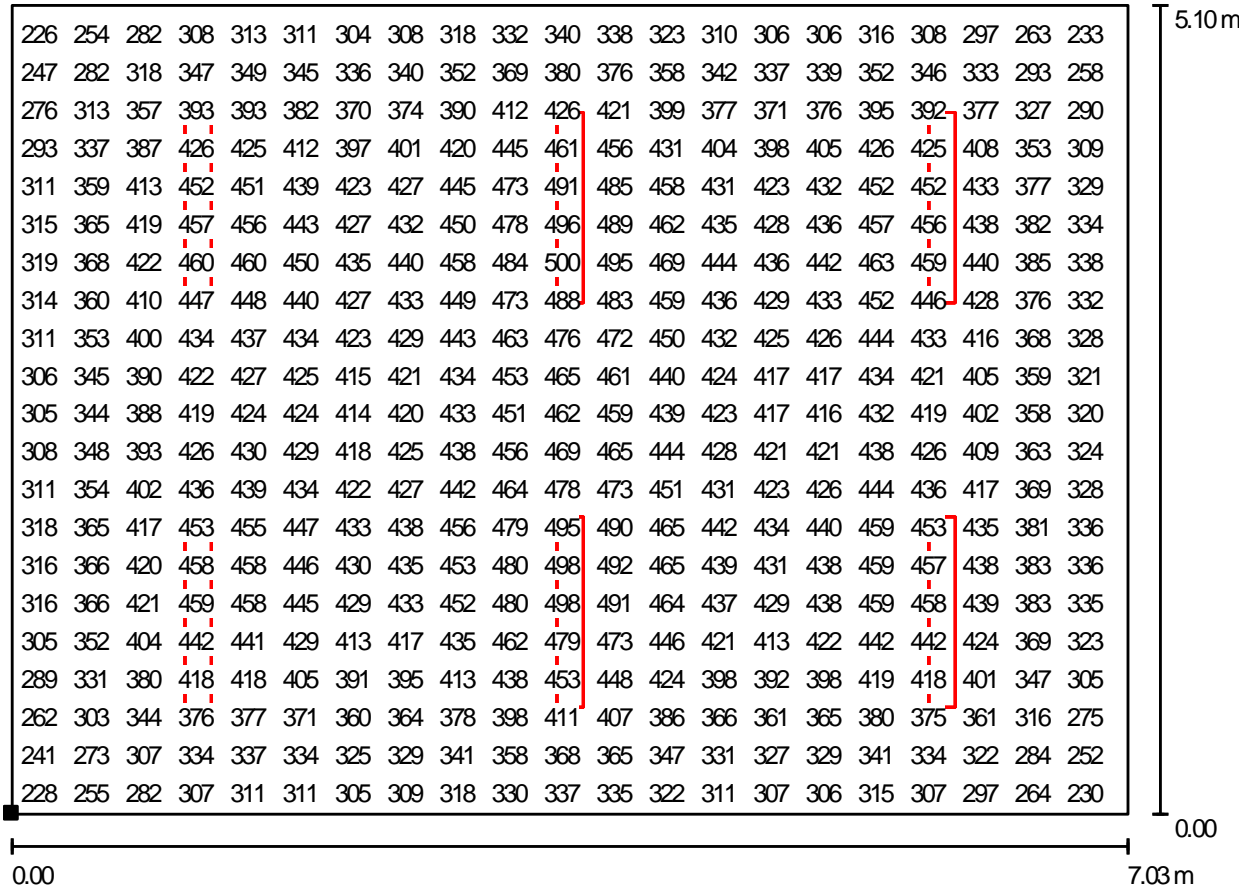

Figura 93: Simulação sala dos professores - luminária nacional tipo 111 com LED (Arquivo: EC-SP-LEBR-1-MX.dlx) 
A distribuição de peças no ambiente deve ser realizada para que o nível de iluminância esteja homogêneo. Muitas vezes, o projetista precisa acrescentar peças para que isso aconteça.

O arquiteto e/ou light designer devem ter "bom senso" para executar o projeto, para que o mesmo tenha qualidade e não somente quantidade para alcançar a densidade de potência solicitada.

Por exemplo, na distribuição de pontos da figura 92, percebemos que o nível de iluminação está homogêneo, pois não há uma grande diferença entre os níveis ponto a ponto. Para alcançarmos 300 lux no ambiente, três luminárias eram suficientes, porém o nível com a distribuição dessas peças não está homogêneo. Segue figura 94 abaixo que mostra essa situação.

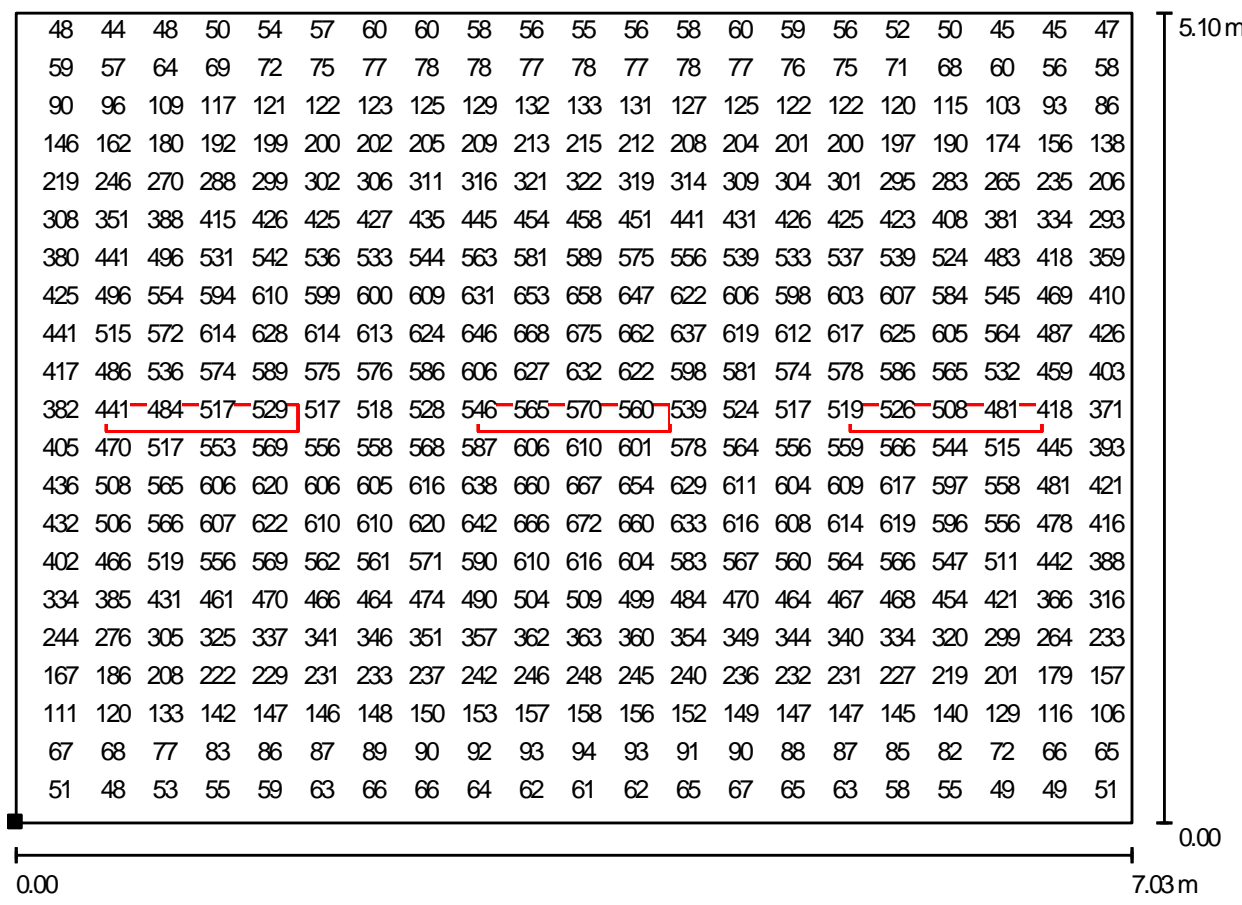

Figura 94: Simulação sala dos professores - luminária nacional tipo 101 com fluorescente tubular distribuição 3 luminárias

Da mesma maneira que fizemos a simulação com as luminárias nacionais, segue Tabela 54 com os resultados das simulações para as luminárias importadas. 
Tabela 54: Tabela de resultado da simulação de luminárias importadas - sala dos professores

\begin{tabular}{|c|c|c|c|c|c|c|c|c|}
\hline Fabricante & Código peça & $\begin{array}{c}\text { Qtde } \\
\text { pças }\end{array}$ & $\begin{array}{c}\text { Eméd } \\
\mathbf{( I x )}\end{array}$ & $\begin{array}{c}\text { Emín } \\
\mathbf{( I x )}\end{array}$ & $\begin{array}{c}\text { Emáx } \\
\mathbf{( I x )}\end{array}$ & $\begin{array}{c}\text { Potência } \\
\text { conj (W) }\end{array}$ & $\begin{array}{c}\text { Potência } \\
\text { total (W) }\end{array}$ & $\begin{array}{c}\text { Tipo/ } \\
\text { Anexo } \\
\text { Iuminária }\end{array}$ \\
\hline Zumtobel & $\begin{array}{c}\text { Mirel2 42915021 } \\
\text { 1x28W }\end{array}$ & 6 & 337 & 168 & 453 & 30,5 & 183,0 & 106 \\
\hline Zumtobel & $\begin{array}{c}\text { L-FIELDS 42180006 } \\
-55 W\end{array}$ & 4 & 425 & 159 & 644 & 60,50 & 242,0 & 113 \\
\hline
\end{tabular}

As figuras 95 e 96 mostram a simulação ponto a ponto das luminárias fluorescente tubular e do sistema de iluminação com LED respectivamente.

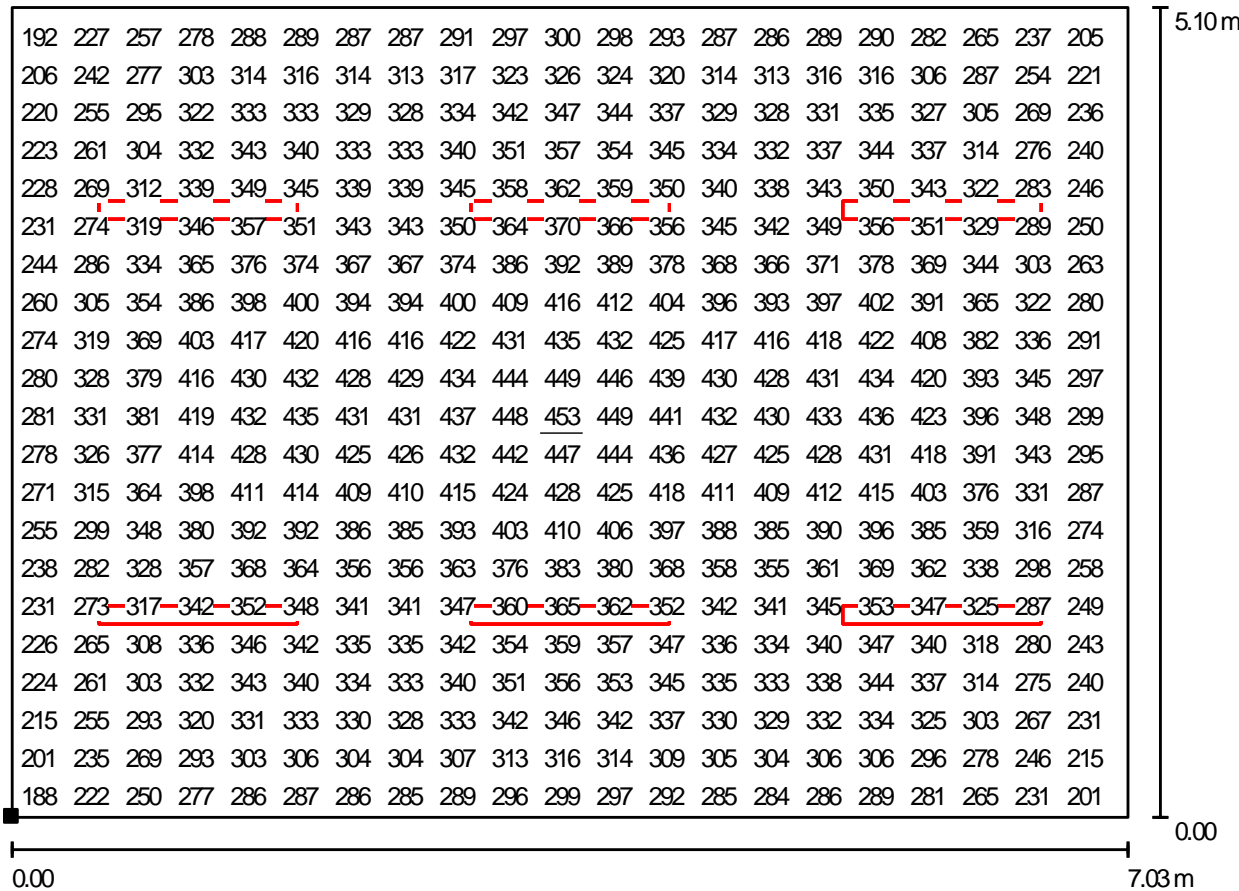

Figura 95: Simulação sala dos professores - luminária importada tipo 106 com fluorescente tubular (Arquivo: EC-SP-FT-EX-1-MX.dlx) 


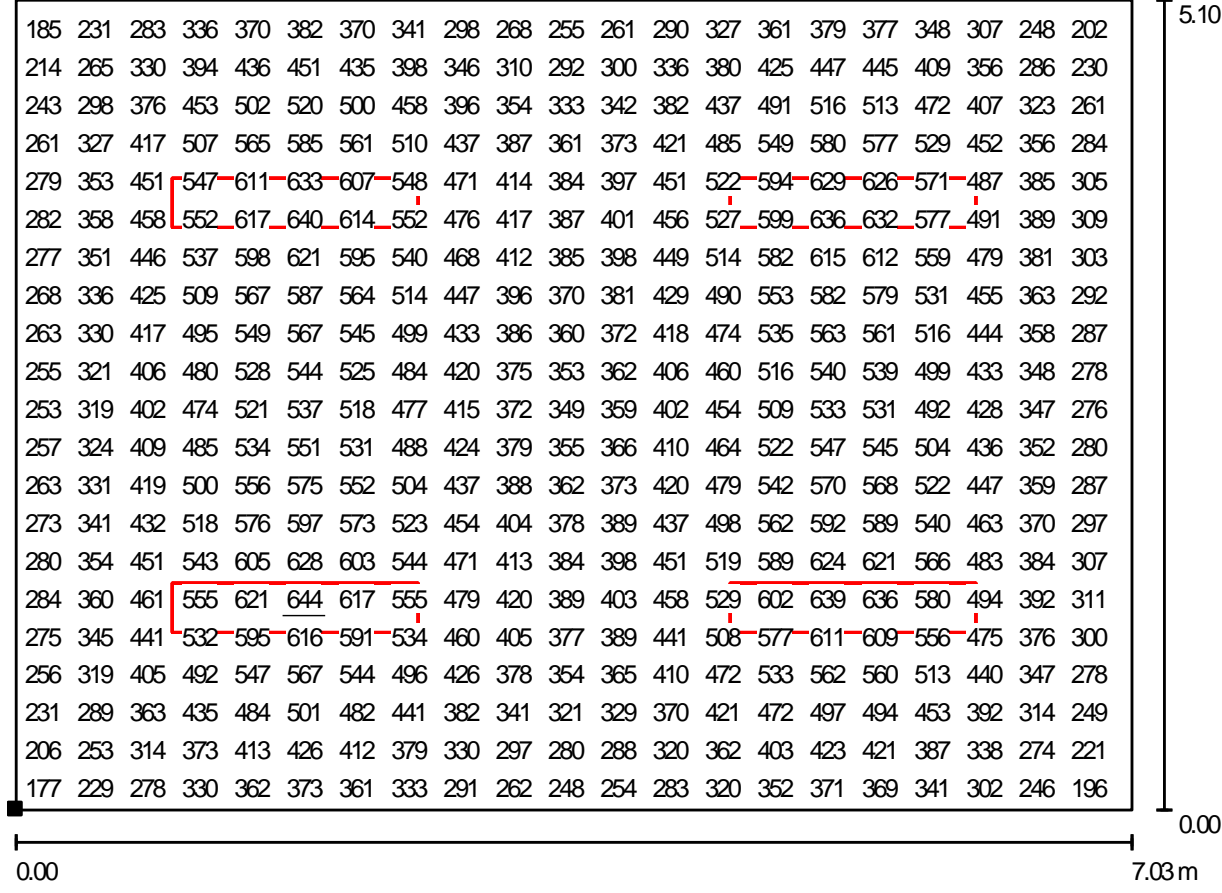

Figura 96: Simulação sala dos professores - luminária importada tipo 113 com LED (Arquivo: EC-SP-LEEX-1-MX.dlx)

\subsubsection{Refeitório}

Por fim, para a escola, faremos a simulação do ambiente refeitório. As luminárias para esse ambiente e para a cozinha, devem ser fechadas, para que a poeira e sujeira acumulada nas peças não contaminem os alimentos manipulados nesse ambiente.

Nesse caso, utilizaremos luminárias fechadas com difusor. As luminárias em LED serão as mesmas utilizadas nas simulações anteriores, pois todas possuem fechamento com difusor.

Segue a tabela com as simulações para fluorescente tubular das luminárias nacionais. O nível médio utilizado é de 200 lux para esse ambiente. 
Tabela 55: Tabela simulação refeitório sistema de iluminação nacional com fluorescente tubular

\begin{tabular}{|c|c|c|c|c|c|c|c|c|}
\hline Fabricante & Código peça & $\begin{array}{c}\text { Qtde } \\
\text { pças }\end{array}$ & $\begin{array}{c}\text { Eméd } \\
\mathbf{( I x )}\end{array}$ & $\begin{array}{c}\text { Emín } \\
\mathbf{( I x )}\end{array}$ & $\begin{array}{c}\text { Emáx } \\
\mathbf{( I x )}\end{array}$ & $\begin{array}{c}\text { Potência } \\
\text { conj (W) }\end{array}$ & $\begin{array}{c}\text { Potência } \\
\text { total (W) }\end{array}$ & $\begin{array}{c}\text { Tipo/ } \\
\text { Anexo } \\
\text { Iuminária }\end{array}$ \\
\hline $\begin{array}{c}\text { Itaim } \\
\text { Iluminação }\end{array}$ & $\mathbf{2 1 0 9} \mathbf{2 x 2 8 W}$ & $\mathbf{6}$ & $\mathbf{2 2 9}$ & $\mathbf{9 8}$ & $\mathbf{3 7 8}$ & $\mathbf{6 0 , 3 0}$ & $\mathbf{3 6 1 , 8}$ & $\mathbf{1 1 4}$ \\
\hline Lumini & FE1403 2x28W & 6 & 243 & 105 & 405 & 60,30 & 361,8 & 115 \\
\hline Lumini & FE1403 1x28W & 12 & 252 & 123 & 329 & 30,50 & 366,0 & 116 \\
\hline
\end{tabular}

Segue na figura 97 a simulação ponto a ponto da luminária em destaque da Tabela 55.

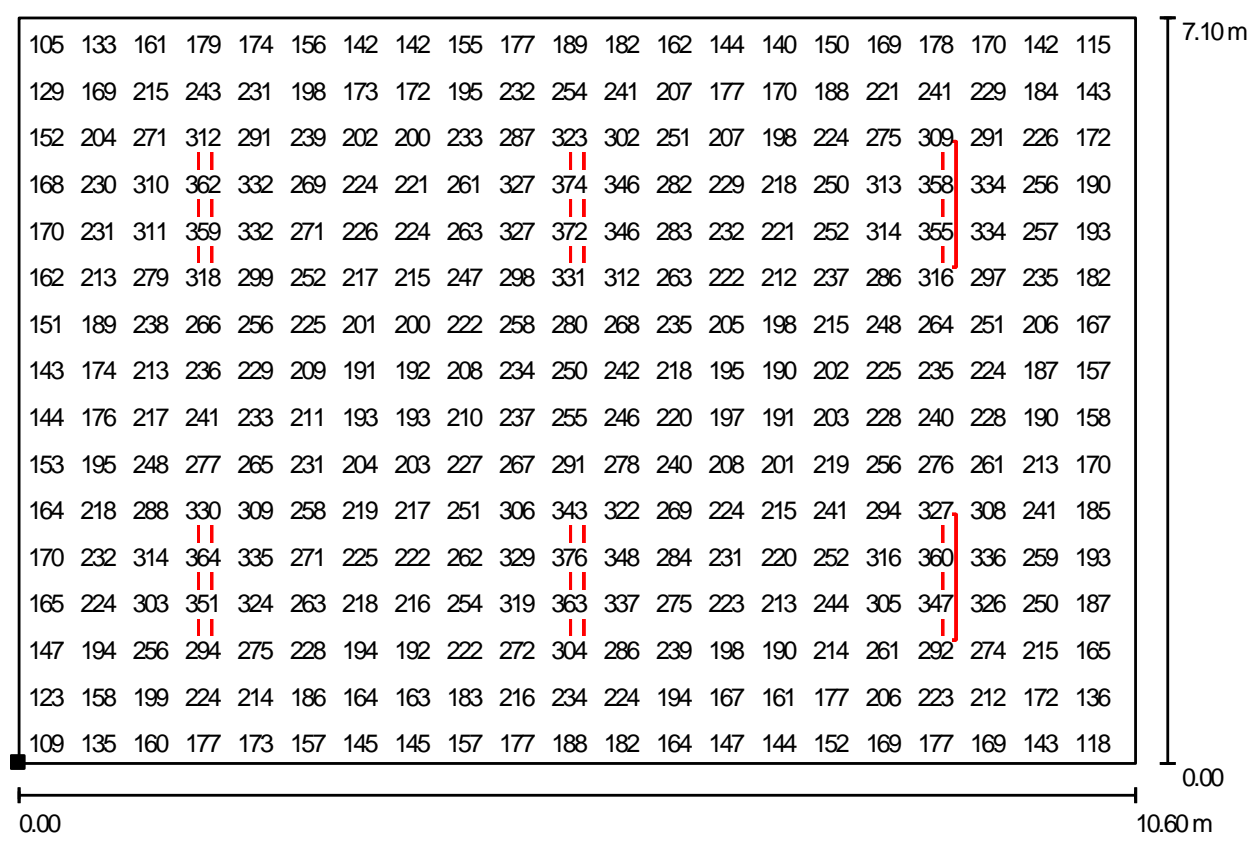

Figura 97: Simulação refeitório - luminária nacional tipo 114 com fluorescente tubular (Arquivo: EC-REFT-BR-1-MX.dlx)

Do mesmo modo que simulamos para os outros ambientes, seguem os resultados da simulação para luminária importada com lâmpada fluorescente tubular.

Tabela 56: Tabela de resultado da simulação de luminária fluorescente tubular importado - refeitório

\begin{tabular}{|c|c|c|c|c|c|c|c|c|}
\hline Fabricante & Código peça & $\begin{array}{c}\text { Qtde } \\
\text { pças }\end{array}$ & $\begin{array}{c}\text { Eméd } \\
\mathbf{( I x )}\end{array}$ & $\begin{array}{c}\text { Emín } \\
\mathbf{( I x )}\end{array}$ & $\begin{array}{c}\text { Emáx } \\
\mathbf{( I x )}\end{array}$ & $\begin{array}{c}\text { Potência } \\
\text { conj (W) }\end{array}$ & $\begin{array}{c}\text { Potência } \\
\text { total (W) }\end{array}$ & $\begin{array}{c}\text { Tipo/ } \\
\text { Anexo } \\
\text { luminária }\end{array}$ \\
\hline Zumtobel & $\begin{array}{c}\text { L-FIELDS 42176794 } \\
\mathbf{2 x 2 8 W}\end{array}$ & $\mathbf{5}$ & $\mathbf{2 7 0}$ & $\mathbf{3 7}$ & $\mathbf{5 7 8}$ & $\mathbf{6 0 , 3 0}$ & $\mathbf{3 0 1 , 5}$ & $\mathbf{1 1 7}$ \\
\hline Zumtobel & SLOT2 42177835 & 12 & 204 & 108 & 264 & 30,50 & 366,0 & 118 \\
\hline
\end{tabular}


Na figura 98 temos a simulação ponto a ponto da luminária em destaque na Tabela 56.

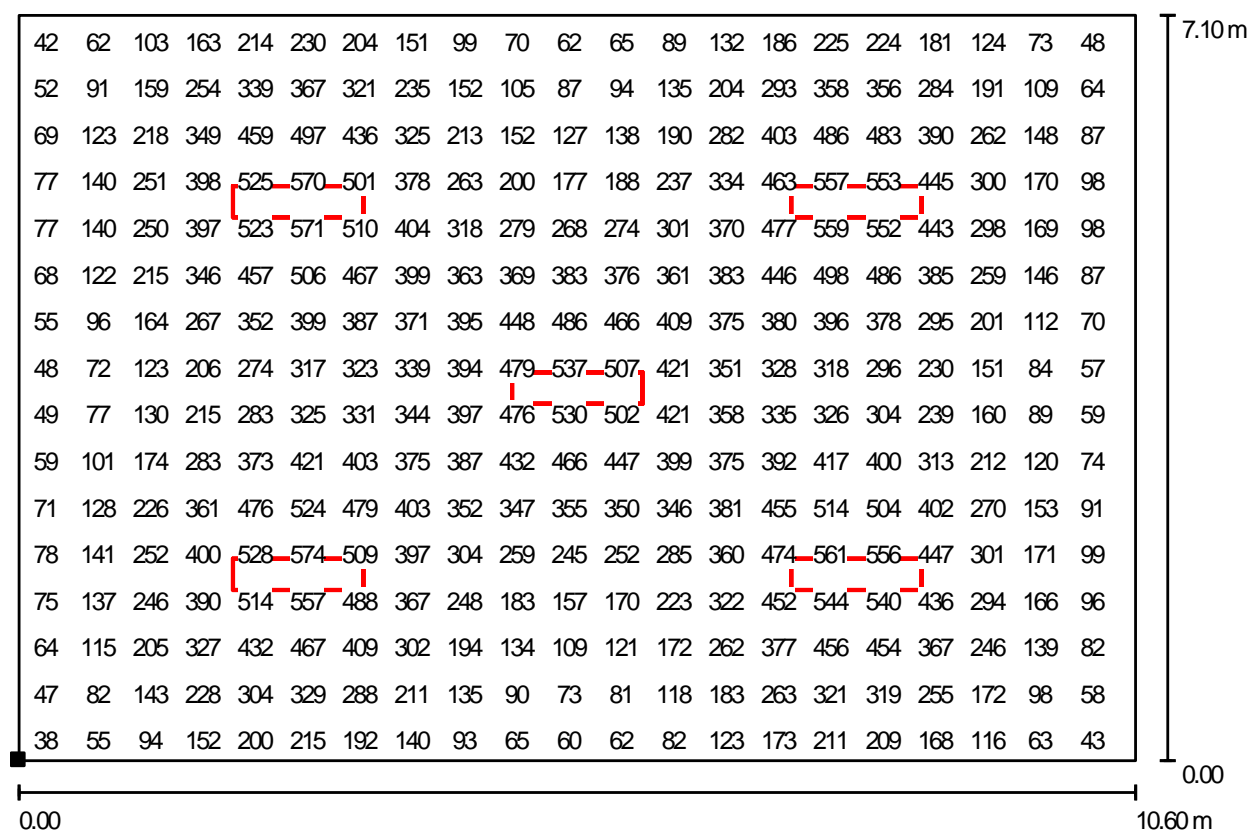

Figura 98: Simulação refeitório - luminária importada tipo 117 com fluorescente tubular (Arquivo: EC-REFT-EX-1-MX.dlx)

Seguem resultados da simulação utilizando as mesmas luminárias nacionais e importadas em LED utilizadas nos outros ambientes.

Tabela 57: Tabela de resultado da simulação de luminária LED - refeitório

\begin{tabular}{|c|c|c|c|c|c|c|c|c|}
\hline Fabricante & Código peça & $\begin{array}{c}\text { Qtde } \\
\text { pças }\end{array}$ & $\begin{array}{c}\text { Eméd } \\
(\mathbf{I x})\end{array}$ & $\begin{array}{c}\text { Emín } \\
\text { (Ix) }\end{array}$ & $\begin{array}{c}\text { Emáx } \\
\text { (Ix) }\end{array}$ & $\begin{array}{c}\text { Potência } \\
\text { conj (W) }\end{array}$ & $\begin{array}{c}\text { Potência } \\
\text { total (W) }\end{array}$ & $\begin{array}{c}\text { Tipo/ } \\
\text { Anexo } \\
\text { luminária }\end{array}$ \\
\hline $\begin{array}{c}\text { Itaim } \\
\text { lluminação }\end{array}$ & Minotauro R-40W & 8 & 279 & 127 & 410 & 44,00 & 352,0 & 111 \\
\hline Zumtobel & $\begin{array}{c}\text { L-FIELDS 42180006 } \\
-55 W\end{array}$ & 5 & 281 & 44 & 610 & 60,50 & 302,5 & 113 \\
\hline
\end{tabular}

As figuras 99 e 100 demonstram a simulação com luminária LED nacional e importado, respectivamente do ambiente refeitório. 


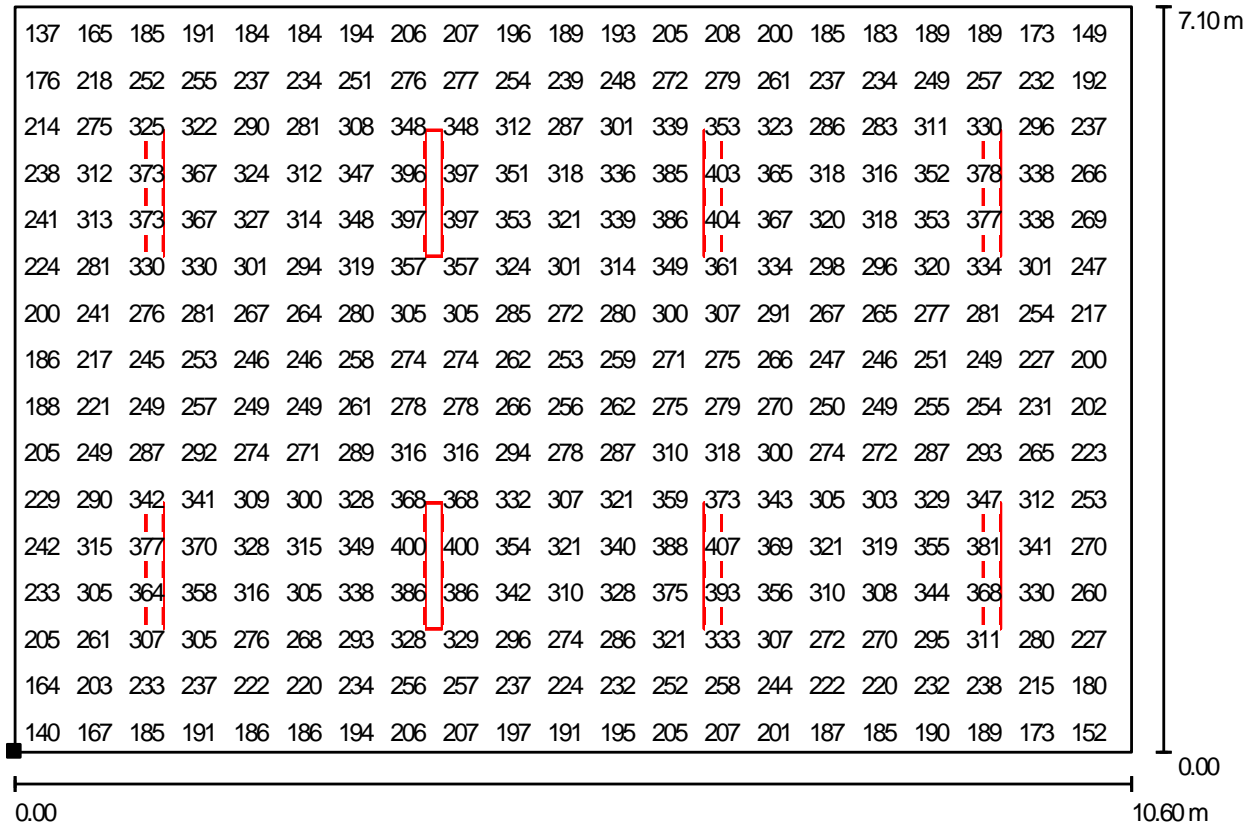

Figura 99: Simulação refeitório - luminária nacional tipo 111 com LED (Arquivo: EC-RE-LE-BR-1-MX.dlx)

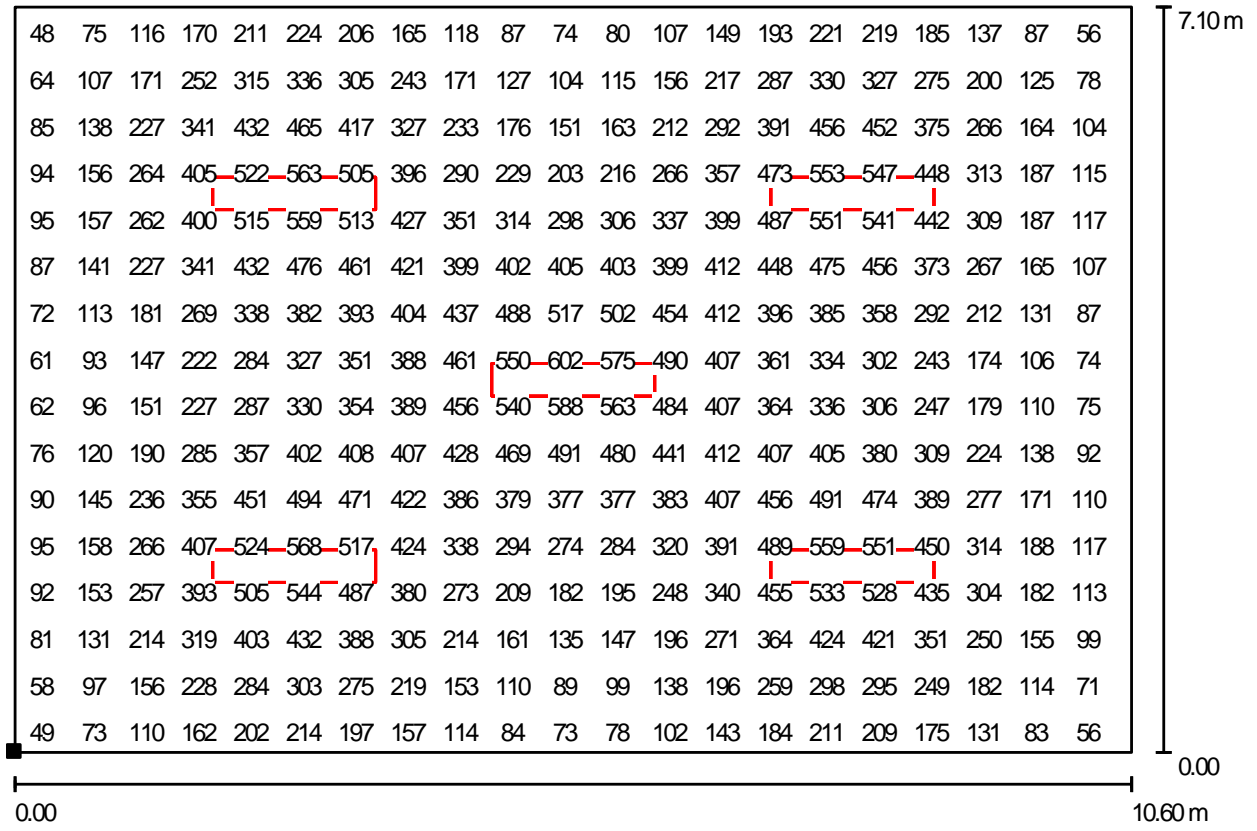

Figura 100: Simulação refeitório - luminária importada tipo 113 com LED (Arquivo: EC-RE-LE-EX-1MX.dlx) 


\subsubsection{Projeto}

Com os resultados das simulações, assim como foi realizado no escritório, será feito o projeto da escola utilizando os resultados e os sistemas de iluminação mais eficientes encontrados.

Segue tabela de resultados das simulações feitas na escola.

Tabela 58: Tabela resultados simulação - escola

\begin{tabular}{|c|c|c|c|c|c|c|c|}
\hline Local & $\begin{array}{l}\text { Área } \\
\left(m^{2}\right)\end{array}$ & $\begin{array}{c}\text { Tipo } \\
\text { lâmpada }\end{array}$ & Origem & $\begin{array}{l}\text { Potência } \\
\text { total (W) }\end{array}$ & $\begin{array}{l}\text { Máxima } \\
\text { eficiência } \\
(\operatorname{lm} / \mathrm{W})^{16}\end{array}$ & Lum. & Arquivo simulação \\
\hline \multirow{4}{*}{ 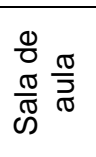 } & \multirow{4}{*}{48,97} & \multirow{2}{*}{$\begin{array}{c}\text { FI. } \\
\text { Tubular }\end{array}$} & Brasil & 332,7 & 103,57 & 1 & EC-SA-FT-BR-1-MX.dlx \\
\hline & & & Exterior & 274,5 & 103,57 & 1 & EC-SA-FT-EX-1-MX.dlx \\
\hline & & \multirow{2}{*}{ LED } & Brasil & 355,5 & 74,72 & 1 & EC-SA-LE-BR-1-MX.dlx \\
\hline & & & Exterior & 333,5 & 78,36 & 1 & EC-SA-LE-EX-1-MX.dlx \\
\hline \multirow{4}{*}{ 苞 } & \multirow{4}{*}{35,47} & \multirow{2}{*}{$\begin{array}{c}\text { Fl. } \\
\text { Tubular }\end{array}$} & Brasil & 241,2 & 103,57 & 1 & EC-SP-FT-BR-1-MX.dlx \\
\hline & & & Exterior & 183,0 & 103,57 & 1 & EC-SP-FT-EX-1-MX.dlx \\
\hline & & \multirow{2}{*}{ LED } & Brasil & 264,0 & 74,72 & 1 & EC-SP-LE-BR-1-MX.dlX \\
\hline & & & Exterior & 242,0 & 78,36 & 1 & EC-SP-LE-EX-1-MX.dlX \\
\hline \multirow{4}{*}{ 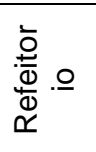 } & \multirow{4}{*}{75,59} & \multirow{2}{*}{$\begin{array}{c}\text { FI. } \\
\text { Tubular }\end{array}$} & Brasil & 361,8 & 103,57 & 1 & EC-RE-FT-BR-1-MX.dlX \\
\hline & & & Exterior & 301,5 & 103,57 & 1 & EC-RE-FT-EX-1-MX.dlx \\
\hline & & \multirow[t]{2}{*}{ LED } & Brasil & 352,0 & 74,72 & 1 & EC-RE-LE-BR-1-MX.dlX \\
\hline & & & Exterior & 302,5 & 78,36 & 1 & EC-RE-LE-EX-1-MX.dlX \\
\hline
\end{tabular}

Serão feitos dois projetos para posterior verificação dos indicadores de sustentabilidade das certificações e selos mais atuantes no país.

Pela Tabela 58 observa-se que os sistemas de iluminação importados são mais eficientes que os nacionais. No entanto, as peças em LED são menos eficientes que o sistema com fluorescente tubular.

Os projetos estão no Anexo 3: Resultados. O Projeto 9 será feito com o sistema de iluminação fluorescente tubular nacional e o Projeto 10 com o sistema de iluminação em LED nacional.

No caso da escola, faremos apenas o projeto referente às luminárias nacionais que é o objeto de pesquisa.

\footnotetext{
${ }^{16}$ Referente ao sistema de iluminação principal do ambiente
} 


\section{ANÁLISE DOS RESULTADOS}

Por fim, analisaremos cada projeto simulado no capítulo anterior conforme os indicadores de iluminação artificial nas certificações LEED, AQUA e do selo de sustentabilidade PROCEL Edifica.

Consideraremos que em todos os projetos, os sistemas de iluminação são dimerizáveis, separados por circuitos, são controlados por automação predial e no Projeto 8 , há possibilidade de controle de iluminação individual nas áreas de staff.

\subsection{Certificação LEED e o projeto}

No capítulo 3, descrevemos a certificação LEED e os indicadores de iluminação artificial necessários para obtenção do mesmo.

Em relação ao projeto de iluminação, vimos que o importante é a eficiência energética dos sistemas de iluminação utilizados, analisados através da densidade de potência em $\mathrm{W} / \mathrm{m}^{2}$. O valor limite para obtenção da certificação em escritórios é de $11 \mathrm{~W} / \mathrm{m}^{2}$, valor dado pela ANSI / ASHRAE / IESNA Standard 90.1-2007.

Analisando os 10 projetos do escritório em relação à densidade de potência, obtemos os seguintes resultados:

Tabela 59: Resultado simulação sistema de iluminação mais eficiente do Brasil utilizando luminária LED (Projeto 1)

\begin{tabular}{clrr}
\hline $\begin{array}{c}\text { Qtde de } \\
\text { peças }\end{array}$ & \multicolumn{1}{c}{ Luminária } & $\begin{array}{r}\text { Potência } \\
\text { conjunto }(\mathbf{W})\end{array}$ & $\begin{array}{r}\text { Potência total } \\
(\mathbf{W})\end{array}$ \\
\hline 603 & Philips BS488 13W & 14,30 & $8.622,90$ \\
14 & Lâmpada LED 7W 25o & 7,70 & 107,80 \\
8 & Itaim 3450 2x28W & 60,30 & 482,40 \\
\hline & Consumo Total & & $\mathbf{9 . 2 1 3 , 1 0}$ \\
\hline & Área Total projeto $\left(\mathbf{m}^{2}\right)$ & $\mathbf{1 . 1 8 0 , 0 7}$ \\
\hline & Densidade $\left(\mathbf{W} / \mathbf{m}^{2}\right)$ & $\mathbf{7 , 8 1}$ \\
\hline
\end{tabular}


Tabela 60: Resultado simulação sistema de iluminação mais eficiente do Brasil utilizando luminária LED (Projeto 2)

\begin{tabular}{clrr}
\hline $\begin{array}{c}\text { Qtde de } \\
\text { peças }\end{array}$ & \multicolumn{1}{c}{ Luminária } & $\begin{array}{r}\text { Potência } \\
\text { conjunto }(\mathbf{W})\end{array}$ & $\begin{array}{r}\text { Potência total } \\
(\mathbf{W})\end{array}$ \\
\hline 23 & Erco 47719.000 - 20W & 22,00 & 506,00 \\
26 & Erco 47765.000 - 38W & 37,40 & 972,40 \\
170 & Zumtobel 42 179 998 - 44W & 48,40 & $8.228,00$ \\
11 & Zumtobel 42 177 999 - 4x14W & 61,20 & 706,20 \\
8 & Zumtobel 42 156 158 - 2x28W & 60,30 & 482,40 \\
\hline & Consumo Total & & $\mathbf{1 0 . 8 9 5 , 0 0}$ \\
\hline & Área Total projeto $\left(\mathbf{m}^{2}\right)$ & $\mathbf{1 . 1 8 0 , 0 7}$ \\
\hline & Densidade $\left(\mathbf{W} / \mathbf{m}^{2}\right)$ & $\mathbf{9 , 2 3}$ \\
\hline
\end{tabular}

Comparando as Tabelas 59 e 60, observamos que ambos os projetos atendem a densidade de potência do LEED. Podemos ver que os sistemas de iluminação nacional são mais eficientes que os importados, no entanto, no Brasil ainda não há regulamentação que padroniza as luminárias de LED.

Além disso, ainda não é possível avaliar e nem comparar os materiais utilizados na produção da peça em LED no país.

Tabela 61: Resultado simulação sistema de iluminação mais eficiente do Brasil utilizando luminária fluorescente tubular (Projeto 3)

\begin{tabular}{clrr}
\hline $\begin{array}{c}\text { Qtde de } \\
\text { peças }\end{array}$ & \multicolumn{1}{c}{ Luminária } & $\begin{array}{r}\text { Potência } \\
\text { conjunto }(\mathbf{W})\end{array}$ & $\begin{array}{r}\text { Potência total } \\
(\mathbf{W})\end{array}$ \\
\hline 106 & Philips BS488 13W & 14,30 & $1.515,80$ \\
14 & Lâmpada LED 7W 25o & 7,70 & 107,80 \\
8 & Itaim 3450 2x28W & 60,30 & 482,40 \\
157 & Itaim 2691 4x14W & 61,20 & $9.608,40$ \\
\hline & Consumo Total & & $\mathbf{1 1 . 7 1 4 , 4 0}$ \\
\hline & Área Total projeto $\left(\mathbf{m}^{2}\right)$ & $\mathbf{1 . 1 8 0 , 0 7}$ \\
\hline & Densidade $\left(\mathbf{W} / \mathbf{m}^{2}\right)$ & $\mathbf{9 , 9 2}$ \\
\hline
\end{tabular}


Tabela 62: Resultado simulação sistema de iluminação mais eficiente importado utilizando luminária fluorescente tubular (Projeto 4)

\begin{tabular}{clrr}
\hline $\begin{array}{c}\text { Qtde de } \\
\text { peças }\end{array}$ & \multicolumn{1}{c}{ Luminária } & $\begin{array}{r}\text { Potência } \\
\text { conjunto }(\mathbf{W})\end{array}$ & $\begin{array}{r}\text { Potência total } \\
(\mathbf{W})\end{array}$ \\
\hline 23 & Erco 47719.000 - 20W & 22,00 & 506,00 \\
26 & Erco 47765.000 - 38W & 37,40 & 972,40 \\
136 & Zumtobel 42 176 184-4x14W & 61,20 & $8.323,20$ \\
11 & Zumtobel 42 177 999-4x14W & 61,20 & 706,20 \\
8 & Zumtobel 42 156 158 - 2x28W & 60,30 & 482,40 \\
\hline Consumo Total & & $\mathbf{1 0 . 9 9 0 , 2 0}$ \\
\hline & Área Total projeto $\left(\mathbf{m}^{2}\right)$ & $\mathbf{1 . 1 8 0 , 0 7}$ \\
\hline & Densidade $\left(\mathbf{W} / \mathbf{m}^{2}\right)$ & $\mathbf{9 , 3 1}$ \\
\hline
\end{tabular}

As tabelas 61 e 62 correspondem aos projetos 3 e 4 respectivamente, onde foi realizada a simulação utilizando no staff, as luminárias com lâmpadas fluorescente tubular mais eficientes, tanto do mercado nacional, quanto do mercado internacional.

Nesse caso, conseguimos comparar as peças utilizadas, pois ambas tem características bem semelhantes, onde o desenho do refletor e o tipo de alumínio influenciam no rendimento da peça.

Ambos os projetos também atendem a densidade de potência da certificação LEED.

Tabela 63: Resultado simulação sistema de iluminação eficiente nacional utilizando luminária fluorescente tubular no staff e fluorescente compacta nas salas individuais (Projeto 5)

\begin{tabular}{|c|c|c|c|}
\hline $\begin{array}{l}\text { Qtde de } \\
\text { peças }\end{array}$ & Luminária & $\begin{array}{r}\text { Potência } \\
\text { conjunto (W) }\end{array}$ & $\begin{array}{r}\text { Potência total } \\
\text { (W) }\end{array}$ \\
\hline 42 & Philips BS488 13W & 14,30 & 600,60 \\
\hline 14 & Lâmpada LED 7W 25을 & 7,70 & 107,80 \\
\hline 8 & Itaim 3450 2x28W & 60,30 & 482,40 \\
\hline 157 & Itaim $26914 \times 14 \mathrm{~W}$ & 61,20 & $9.608,40$ \\
\hline \multirow[t]{4}{*}{40} & Lumini E-4039 1x32W & 36,00 & $1.440,00$ \\
\hline & Consumo Total & & $12.239,20$ \\
\hline & Área Total projeto $\left(\mathrm{m}^{2}\right)$ & & $1.180,07$ \\
\hline & Densidade $\left(\mathrm{W} / \mathrm{m}^{2}\right)$ & & 10,37 \\
\hline
\end{tabular}


Tabela 64: Resultado simulação sistema de iluminação eficiente nacional sem a utilização de luminárias com LED (Projeto 6)

\begin{tabular}{clrr}
\hline $\begin{array}{c}\text { Qtde de } \\
\text { peças }\end{array}$ & \multicolumn{1}{c}{ Luminária } & $\begin{array}{r}\text { Potência } \\
\text { conjunto }(\mathbf{W})\end{array}$ & $\begin{array}{r}\text { Potência total } \\
(\mathbf{W})\end{array}$ \\
\hline 31 & Lumini E-4433 2x26W & 56,00 & $1.736,00$ \\
14 & Lâmpada LED 7W 25o & 7,70 & 107,80 \\
8 & Itaim 3450 2x28W & 60,30 & 482,40 \\
157 & Itaim 2691 4x14W & 61,20 & $9.608,40$ \\
40 & Lumini E-4039 1x32W & 36,00 & $1.440,00$ \\
\hline & Consumo Total & & $\mathbf{1 3 . 3 7 4 , 6 0}$ \\
\hline & Area Total projeto $\left(\mathbf{m}^{2}\right)$ & $\mathbf{1 . 1 8 0 , 0 7}$ \\
\hline & Densidade $\left(\mathbf{W} / \mathbf{m}^{2}\right)$ & $\mathbf{1 1 , 3 3}$ \\
\hline
\end{tabular}

As Tabelas 63 e 64 mostram os resultados dos projetos 5 e 6 em Anexo. Foi realizada uma variação de peças, procurando substituir as luminárias eficientes em LED, pois ainda o custo desses sistemas ainda é muito alto.

Podemos dizer que essas últimas simulações, se aproximam muito da situação real dos escritórios hoje. Infelizmente, não é possível alcançar a densidade de potência do LEED utilizando apenas os sistemas de iluminação mais eficientes com lâmpadas fluorescentes como podemos ver na Tabela 64 .

Como no Brasil ainda são comercializadas as lâmpadas fluorescentes tubulares T8, para comparação, foi feita uma simulação/projeto utilizando essa lâmpada. A seguir temos o resultado de um projeto padrão de cerca de 5 anos atrás, onde o sistema de iluminação utilizando lâmpadas T5 ainda tinha um custo alto. 
Tabela 65: Resultado simulação sistema de iluminação menos eficiente nacional (Projeto 7)

\begin{tabular}{clrr}
\hline $\begin{array}{c}\text { Qtde de } \\
\text { peças }\end{array}$ & \multicolumn{1}{c}{ Luminária } & $\begin{array}{r}\text { Potência } \\
\text { conjunto }(\mathbf{W})\end{array}$ & $\begin{array}{r}\text { Potência total } \\
(\mathbf{W})\end{array}$ \\
\hline 104 & Itaim Prata-E 2x26W & 56,00 & $5.824,00$ \\
14 & Lâmpada dicróica 35W 36o & 38,50 & 539,00 \\
8 & Itaim 3457 2x32W & 73,00 & 584,00 \\
166 & Itaim 2002 4x16W & 70,00 & $11.620,00$ \\
\hline & Consumo Total & & $\mathbf{1 8 . 5 6 7 , 0 0}$ \\
\hline & Área Total projeto $\left(\mathbf{m}^{2}\right)$ & $\mathbf{1 . 1 8 0 , 0 7}$ \\
\hline & Densidade $\left(\mathbf{W} / \mathbf{m}^{2}\right)$ & $\mathbf{1 5 , 7 3}$ \\
\hline
\end{tabular}

Como podemos ver na Tabela 65 , a densidade de potência é quase $30 \%$ maior que o limite permitido para a obtenção do certificado. Atualmente já não é possível utilizar esses sistemas de iluminação.

Por fim, devido à modificação da norma NBR5413/1992 para a ABNT ISO8995/2013, foram feitas simulações e projeto para verificar se modificando os valores dos níveis de iluminação, a densidade de potência final atenderia a certificação.

Segue a Tabela 66 e o projeto 8 em anexo com os resultados dessa mudança. Tabela 66: Resultado simulação sistema de iluminação nacional com valores da norma ISO8995. (Projeto 8)

\begin{tabular}{clrr}
\hline $\begin{array}{c}\text { Qtde de } \\
\text { peças }\end{array}$ & \multicolumn{1}{c}{ Luminária } & $\begin{array}{r}\text { Potência } \\
\text { conjunto }(\mathbf{W})\end{array}$ & $\begin{array}{r}\text { Potência total } \\
\text { (W) }\end{array}$ \\
\hline 42 & Philips BS488 13W & 14,30 & 600,60 \\
14 & Lâmpada LED 7W 25o & 7,70 & 107,80 \\
8 & Itaim 3450 2x28W & 60,30 & 482,40 \\
111 & Itaim 2691 4x14W & 61,20 & $6.793,20$ \\
37 & Lumini E-4039 1×32W & 36,00 & $1.332,00$ \\
95 & Itaim D'Art Gesso 14W & 15,40 & $1.463,00$ \\
\hline & Consumo Total & & $\mathbf{1 0 . 7 7 9 , 0 0}$ \\
\hline & Área Total projeto $\left(\mathbf{m}^{2}\right)$ & $\mathbf{1 . 1 8 0 , 0 7}$ \\
\hline & Densidade $\left(\mathbf{W} / \mathbf{m}^{2}\right)$ & $\mathbf{9 , 1 3}$ \\
\hline
\end{tabular}


Com relação ao Projeto 5 que foi utilizado como referência, reduzimos cerca de $10 \%$ utilizando o nível de iluminação da nova norma.

Para a escola, o valor limite dado pela ANSI / ASHRAE / IESNA Standard 90.1-2007 para obtenção da certificação é de $13 \mathrm{~W} / \mathrm{m}^{2}$.

Segue Tabela 67 com resultados do Projeto 9 da escola, utilizando sistema de iluminação com lâmpadas fluorescentes tubulares.

Tabela 67: Resultado simulação sistema de iluminação eficiente nacional com fluorescentes tubulares (Projeto 9)

\begin{tabular}{clrr}
\hline $\begin{array}{c}\text { Qtde de } \\
\text { peças }\end{array}$ & \multicolumn{1}{c}{ Luminária } & $\begin{array}{r}\text { Potência } \\
\text { conjunto }(\mathbf{W})\end{array}$ & $\begin{array}{r}\text { Potência total } \\
\text { (W) }\end{array}$ \\
\hline 129 & Itaim 2625 2x28W & 60,30 & $7.778,70$ \\
48 & Itaim 2527 1x28W & 30,50 & $1.464,00$ \\
21 & Itaim 2109 2x28W & 60,30 & $1.266,30$ \\
13 & Itaim 2109 2x14W & 30,60 & $3.396,60$ \\
\hline & Consumo Total & & $\mathbf{1 3 . 9 0 5 , 6 0}$ \\
\hline & Área Total projeto $\left(\mathbf{m}^{2}\right)$ & $\mathbf{2 . 2 2 9 , 3 1}$ \\
\hline & Densidade $\left(\mathbf{W} / \mathbf{m}^{2}\right)$ & $\mathbf{6 , 2 3}$ \\
\hline
\end{tabular}

Observa-se que a densidade está dentro do valor limite para obtenção do certificado.

Tabela 68: Resultado simulação sistema de iluminação eficiente nacional com LED (Projeto 10)

\begin{tabular}{clrr}
\hline $\begin{array}{c}\text { Qtde de } \\
\text { peças }\end{array}$ & \multicolumn{1}{c}{ Luminária } & $\begin{array}{r}\text { Potência } \\
\text { conjunto }(\mathbf{W})\end{array}$ & $\begin{array}{r}\text { Potência total } \\
(\mathbf{W})\end{array}$ \\
\hline 283 & Itaim Minotauro R - 40W & 44,00 & $12.452,00$ \\
48 & Itaim 2527 1x28W & 30,50 & $1.464,00$ \\
\hline & Consumo Total & & $\mathbf{1 3 . 9 1 6 , 0 0}$ \\
\hline & Área Total projeto $\left(\mathbf{m}^{2}\right)$ & $\mathbf{2 . 2 2 9 , 3 1}$ \\
\hline & Densidade $\left(\mathrm{W} / \mathbf{m}^{2}\right)$ & $\mathbf{6 , 2 4}$ \\
\hline
\end{tabular}

A Tabela 68 é o resultado do Projeto 10 utilizando luminárias LED. Como era esperada, a densidade de potência total também atende o valor limite da certificação LEED. 
Como resultado final, podemos dizer que os Projetos 1, 2, 3, 4, 5, 8, 9 e 10, alcançam a pontuação em relação à densidade de potência solicitado do LEED Existing Buildings, LEED New Construction e LEED Schools New Construction.

Em relação ao LEED Commercial Interiors, deve haver uma redução de no mínimo $15 \%$ em relação ao valor base de $11 \mathrm{~W} / \mathrm{m}^{2}$, sendo este de $9,35 \mathrm{~W} / \mathrm{m} 2$. Assim sendo, os Projetos 1, 2, 4 e 8 alcançam essa pontuação.

\subsection{Certificação AQUA e o projeto}

Na certificação AQUA, em relação à iluminação artificial, o guia faz referência à qualidade da luz. É importante que o projeto luminotécnico atenda a norma brasileira, a escolha das lâmpadas tenha uma temperatura de cor adequada e de acordo com o IRC ideal para cada atividade.

Nas simulações realizadas, todos esses itens foram atendidos. Em relação à iluminação artificial os projetos estão dentro do solicitado.

Para este trabalho, não foi possível realizar o cálculo da economia de energia em relação à iluminação artificial, pois os cálculos englobam a economia de energia de outros equipamentos. No entanto, com os resultados obtidos para verificação da certificação LEED, podemos dizer que dependendo dos sistemas de iluminação utilizados no projeto há grande economia de energia.

\subsection{Selo PROCEL Edifica e o projeto}

Seguindo o referencial técnico, o projeto contempla a divisão de circuitos, contribuição da luz natural e será previsto um sistema para desligamento automático do sistema de iluminação artificial.

Atendendo os requisitos acima, o projeto poderá alcançar o nível $A$ em relação ao sistema de iluminação. 
Para verificação do nível de eficiência, realizaremos o método da área do edifício. Para a atividade de escritório temos as seguintes densidades de potência de iluminação limite mostrada na Tabela 69.

Tabela 69: Limite máximo aceitável de densidade de potência de iluminação (DPI $\mathrm{L}_{\text {) }}$ para 0 nível de eficiência pretendido

\begin{tabular}{|c|c|c|c|c|}
\hline $\begin{array}{c}\text { Função do } \\
\text { Edifício }\end{array}$ & $\begin{array}{c}\text { Densidade de } \\
\text { Potência de } \\
\text { Iluminação limite } \\
\text { W/m² (Nível A) }\end{array}$ & $\begin{array}{l}\text { Densidade de } \\
\text { Potência de } \\
\text { lluminação limite } \\
\text { W/m² (Nível B) }\end{array}$ & $\begin{array}{l}\text { Densidade de } \\
\text { Potência de } \\
\text { lluminação limite } \\
\text { W/m² (Nível C) }\end{array}$ & $\begin{array}{l}\text { Densidade de } \\
\text { Potência de } \\
\text { lluminação limite } \\
\text { W/m² (Nível D) }\end{array}$ \\
\hline Escritório & 9,70 & 11,20 & 12,60 & 14,10 \\
\hline $\begin{array}{c}\text { Escola / } \\
\text { Universidade }\end{array}$ & 10,70 & 12,30 & 13,90 & 15,50 \\
\hline
\end{tabular}

Observando a Tabela acima e comparando com a densidade de potência encontrada nas Tabelas 59 a 68, temos o seguinte resumo e os níveis que cada projeto irá obter:

Tabela 70: Resumo do nível de eficiência alcançado nos projetos

\begin{tabular}{lrr}
\hline Projeto & $\begin{array}{r}\text { Densidade de } \\
\text { Potência }\left(\mathbf{W} / \mathbf{m}^{\mathbf{2}}\right)\end{array}$ & $\begin{array}{r}\text { Nível de eficiência } \\
\text { alcançado }\end{array}$ \\
\hline Projeto 1 & 7,81 & Nível A \\
Projeto 2 & 9,23 & Nível A \\
Projeto 3 & 9,92 & Nível B \\
Projeto 4 & 9,31 & Nível A \\
Projeto 5 & 10,37 & Nível B \\
Projeto 6 & 11,33 & Nível C \\
Projeto 7 & 15,73 & Nível A \\
Projeto 8 & 9,13 & Nível A \\
Projeto 9 & 6,23 & Nível A \\
\hline Projeto 10 & 6,24 & \\
\hline
\end{tabular}

Descartando o Projeto 1, observa-se que somente os projetos com sistema de iluminação importados alcançam o Nível A. Com a revisão da norma NBR 5413/1992 no Brasil, será possível alcançar o nível A como mostrado no Projeto 8, Tabela 66. 
Os projetos que se aproximam do real existente (Projetos 3, 5 e 6 ) ficam no nível $B$ e $C$ de eficiência. Ou seja, não está correto dizer que todo projeto LEED obtem certificação Nível A no Procel Edifica. Mas todo projeto LEED poderá alcançar pelo menos o Nível B de eficiência.

O projeto 9 e 10 referente à escola são um dos únicos que alcançam o nível $\mathrm{A}$ com grande margem. 


\section{CONCLUSÕES}

No Brasil, em relação à iluminação artificial, as certificações LEED e Procel Edifica possuem uma preocupação com a economia de energia, pois medem a densidade de potência no projeto luminotécnico, enquanto no AQUA e parte no PROCEL Edifica, a qualidade da luz do projeto tem maior importância.

A qualidade da luz faz referência à características como temperatura de cor da lâmpada, índice de reprodução de cor da lâmpada e uniformidade no nível de iluminação. Com a revisão da norma NBR 5413/1992, nota-se que o Brasil começa a se preocupar um pouco mais com a qualidade do projeto.

No entanto, segundo estudo pela arquiteta Claudia N. D. Amorim na comparação dos níveis, 34\% dos valores da CIE são maiores que os da NBR 5413, $34 \%$ são menores e $32 \%$ são equivalentes. Essa diferença de níveis é um ponto interessante a ser estudado, pois quanto menor o valor, mais fácil seria obter a certificação em casos onde a densidade de potência é o mais importante. No caso do Brasil para a certificação LEED e da regulamentação de etiquetagem do selo PROCEL Edifica.

Em conferência e reuniões, questionam-se muito os valores em relação à regulamentação do PROCEL Edifica no Brasil, pois afirmam que no país, ainda é difícil obter a classificação máxima. Observando a Tabela 57, realmente é muito difícil chegar ao Nível $A$, pois a maioria dos empreendedores não investe nos sistemas de iluminação LED como um todo, apenas parcialmente.

Analisando os sistemas de iluminação do país, observa-se que luminárias importadas apresentam melhor desempenho que as nacionais, com exceção das luminárias LED. Estas, no entanto, não possuem regulamentação para sua fabricação, ou seja, não sabemos se o rendimento informado ou as informações fornecidas em catálogos e data sheets são corretos.

Por outro lado, podemos dizer que as luminárias brasileiras também estão buscando a qualidade dos produtos importados. Percebemos isso principalmente 
nas luminárias da Itaim Iluminação onde a fábrica tem um grande interesse em divulgar as certificações que possui.

Nos projetos para obtenção de certificado ou selo, poderíamos também utilizar luminárias importadas pois os sistemas simulados neste trabalho possuem representantes no Brasil e são comercializadas no país. Porém, além do valor de investimento ser maior, pode ocorrer que muitas dessas luminárias importadas não utilizem lâmpadas e equipamentos fabricados no país. No caso de queima de equipamento ou lâmpada, o cliente terá que recorrer também à importação, ficando muitas vezes dependente do tempo que o produto leva para chegar ao país.

Para um projeto sustentável em relação à iluminação artificial, devemos nos atentar sempre para o conjunto luminária, lâmpadas e equipamentos, pois esse sistema define a economia de energia, além de fornecer a qualidade de projeto em questões de nível de iluminação, IRC e temperatura de cor.

Das comparações de produtos importados e nacionais conclui-se que o Brasil, a principio, não tem as mesmas condições para um projeto de eficiência energética com relação aos sistemas de iluminação, porém com um bom projeto de iluminação, consegue-se alcançar os indicadores de iluminação das certificações LEED, AQUA e do selo PROCEL Edifica.

Outro ponto interessante, e de certa forma inesperado, foram os resultados da densidade de potência obtidos nas simulações do projeto de escola, pois os valores ficaram bem abaixo do valor limite tanto na ANSI / ASHRAE / IESNA Standard 90.1 2007 como do selo PROCEL Edifica. A partir desses resultados, podemos questionar se que o lighting designer, projetista ou arquitetos brasileiros utilizam as ferramentas corretas e se estão preparados para se fazer um bom projeto luminotécnico.

A simulação através de programas de cálculo, como foi demonstrada, pode ser um dos meios para a escolha correta do sistema de iluminação a ser utilizado. No entanto, muitos lighting designers e projetistas questionam a fidelidade dos arquivos fotométricos fornecidos pelos fabricantes, que são as únicas ferramentas que temos para fazer um projeto de iluminação. 
Pelas simulações e projetos de iluminação desenvolvidos neste trabalho, concluiu-se que é possível, com os sistemas de iluminação comercializados atualmente no Brasil e os dados fornecidos pelos fabricantes, obter as certificações e selos de sustentabilidade presentes no país. 


\section{REFERÊNCIA BIBLIOGRÁFICA}

9o COBEE, 2012, Centro de convenções Frei Caneca. Avaliação da Tecnologia LED - Estudos. São Paulo. Disponível em:

http://www.osetoreletrico.com.br/web/documentos/fasciculos/Ed77_fasc_sistemas_il uminacao_cap6.pdf. Acessado em 15 de janeiro de 2013.

AMORIN, Claudia Naves David. Relatório técnico - comparação dos níveis de iluminância recomendados em diversas normas. Faculdade de Arquitetura e Urbanismo da Universidade de Brasília. Brasília, DF, 2010. 15p.

ELETROBRÁS/Procel Educação. Conservação de Energia. Eficiência Energética de Equipamentos e Instalações. Itajubá. Universidade Federal de Itajubá, 2006

FARIA, Nara. NBR 5413: $O$ que e por que deve mudar? Revista Lumière, São Paulo, № 21, p.56-59, 2008.

FREITAS, Paula Campos Fadul. Luminotécnica e lâmpadas elétricas. Faculdade de Engenharia elétrica da Universidade Federal de Uberlândia. 60p.

GANSLANDT, R.; HOFMANN, H.. Handbook of Lighting Design, Erco Edition, Germany, $1^{\text {st }}$. Edition, 1992. 289p.

IWASHITA, Juliana. Eficiência energética em sistemas de iluminação de interiores: análise de luminárias comerciais, São Paulo: Universidade de São Paulo, 2004. 205p.

LANCELLE, Luis. Softwares para projetos de iluminação, São Paulo. Disponível em: http://www.lumearquitetura.com.br/softwares.html

OSRAM. Manual Osram, Iluminação: Conceitos e projetos. Impresso em 22.12.2006.

PROCEL Edifica. RTQ-C (Regulamento Técnico da Qualidade do Nível de Eficiência Energética de Edifícios Comerciais, de Serviços Públicos). 2010. 87p. RODRIGUES, Pierre. Manual de Iluminação Eficiente. Procel, 1a. edição, julho 2002. 36p. 
ROMERO, M. A.; REIS, L. B. Eficiência energética em edifícios. São Paulo: Manole, 2011 (no prelo). 195p.

\section{BIBLIOGRAFIA CONSULTADA}

ALVARES, André Luiz Monteiro. Uso racional e eficiente de energia elétrica: Metodologia para a determinação dos potenciais de conservação dos usos finais em instalações de ensino e similares. Dissertação. POLI-USP, São Paulo, 1998. 183p.

ARAUJO, Guilherme Augusto Marques. Avaliação dos ganhos de eficiência energética em iluminação adotando a regulamentação de etiquetagem em edificações. Dissertação para Escola Politécnica da Universidade de São Paulo. São Paulo, 2009. 136p.

BERTOLETTI, Luana Eid Piva. Comparação do desempenho energético de edifícios comerciais de referência usando as certificações LEED e PROCELEdifica. Trabalho de graduação apresentado à Escola Politécnica da Universidade de São Paulo. São Paulo, 2011. 47p.

Catálogo Geral de produtos Itaim 2008. São Paulo, 2008.

CAVALCANTE, Rodrigo de Castro Dantas. Simulação energética para análise da arquitetura de edifícios de escritório além da comprovação de conformidade com códigos de desempenho. Dissertação para Faculdade de Arquitetura e Urbanismo da Universidade de São Paulo. São Paulo, 2010.135p.

DEGANI, Clarice Menezes. Modelo de gerenciamento da sustentabilidade de facilidades construídas. Tese para Escola Politécnica da Universidade de São Paulo. São Paulo, 2009. 205p.

FEIJÓ, Maria Alice de Souza. Leis, normas e certificações de qualidade referentes à iluminação natural em edifícios comerciais. São Paulo, 2008. 
Trabalho programado para obtenção do título de mestre para Faculdade de Arquitetura e Urbanismo da Universidade de São Paulo. São Paulo, 2008. 131p.

HERNANDES, Thiago Zaldini. LEED-NC como sistema de avaliação da sustentabilidade: uma perspectiva nacional? Dissertação para Faculdade de Arquitetura e Urbanismo da Universidade de São Paulo. São Paulo, 2006. 134p.

JACOB, Edson. Manual de Utilização de Leds e Fontes de Alimentação.

MASCARÓ, Lúcia R. de. Energia na edificação - estratégia para minimizar seu consumo. São Paulo, Editora Projeto, 1991.

OSRAM. Manual Osram, Iluminação: Conceitos e projetos. Impresso em 22/12/2006. PHILIPS. Manual de Iluminação, $3^{\circledR}$ edição, 1981

VALENTE, Josie Pingret. Certificações na construção civil: comparativo entre LEED e HQE. Projeto de graduação do Curso de Engenharia Civil da Escola Politécnica da Universidade Federal do Rio de Janeiro. Rio de Janeiro, 2009. 71p.

VIANNA, Nelson \& Gonçalves, Joana Carla Soares. Iluminação e Arquitetura. Virtus S/C Ltda, São Paulo, SP, 2001. 378p.

Leis, Normas técnicas, guias e certificações

ABNT. NBR 5413 lluminância de Interiores, abr/1992

BRE. BREEAM New Construction. Technical Manual SD5073-2.0:2011

Certivéa. Guide Pratique du Référentiel pour la Qualité Environnementale des Bâtiments - Bureau/ Enseignement. décembre 2008

CIBSE. Code for Lighting, London: Butterworth-Heineman, 2007

Eletrobrás/PROCEL Educação. Conservação de Energia. Eficiência Energética de Equipamentos e Instalações. Itajubá. Universidade Federal de Itajubá, 2006. $597 \mathrm{p}$.

Fundação Vanzolini. Referencial Técnico de certificação. Edifícios do setor de serviços - Processo AQUA. Escritórios - Edifícios escolares, outubro 2007. 
HKGBC. BEAM Plus Existing Buildings. Version 1.1 (2010.04)

HKGBC. BEAM Plus New Buildings. Version 1.1 (2010.04)

IBEC. CASBEE for New Construction. Technical Manual 2008 Edition

IESNA. IES Lighting Handbook, Reference and Application - 8a. ed. New York, 1995

ISO 8995:2002 / CIE S 008/E-2001. Lighting of indoor work places

LEED. LEED for Commercial Interiors 2009. USGBC, 2009

LEED. LEED for New Construction and Major Renovation, 2009. USGBC, 2009

LEED. LEED for Existing Building Operations and Maintenance 2009. USGBC, 2009

PROCEL Edifica. RTQ-C (Regulamento Técnico da Qualidade do Nível de Eficiência Energética de Edifícios Comerciais, de Serviços e Públicos).

Sites consultados

http://en.wikipedia.org/wiki/Green building - acessado em agosto/2010

http://www.usgbc.org - acesso freqüente desde março/2010

http://www.gbcbrasil.org.br - acesso freqüente desde março/2010

http://www.labeee.ufsc.br - acesso freqüente desde agosto/2010

http://www.eletrobras.com/PCl/main.asp?View=\{89E211C6-61C2-499A-A791-

DACD33A348F3 - acesso freqüente desde agosto/2010

http://www.nabers.com.au/ - acesso freqüente desde março/2011

http://www.greenglobes.com/ - acesso freqüente desde março/2011

http://www.beamsociety.org.hk/general/home.php - acesso freqüente desde março/2011 
http://www.breeam.org/page.jsp?id=66 - acesso freqüente desde abril/2011 http://www.ibec.or.jp/CASBEE/english/index.htm - acesso freqüente desde abril/2011 http://www.itaca.org/valutazione sostenibilita.asp - acesso em abril/2011 http://www.gbcsa.org.za/home.php - acesso freqüente desde maio/2011 http://assohqe.org/hqe/ - acesso freqüente desde junho/2011 http://www.planningportal.gov.uk/buildingregulations/approveddocuments/partl/appro ved - acesso em 10.09.2011

http://www.legifrance.com/affichCode.do;jsessionid=9F6D8FE450FA4FBC6E0D7FF3 A558375F.tpdjo05v 2?idSectionTA=LEGISCTA000006189198\&cidTexte=LEGITEX $\underline{\text { T000006074096\&dateTexte }=20110911}$ - acesso em 11.09.2011

http://pt.wikipedia.org/wiki/Sustentabilidade acesso em 01.08.11

http://patmullins.com/Outdoor Lighting.html acesso em 01.10.11

http://www.peachtreelighting.com/education topic.cfm?cld=6 acesso em 13.10.11

http://www.osram.com/osram com/index.html - acesso constante desde março/2010 http://www.gelampadas.com.br/ - acesso constante desde maio/2011

http://www.gelighting.com/na/ - acesso constante desde maio/2011

http://pt.wikipedia.org/wiki/Osram - acesso em 15/nov/2011

http://www.gaiacentrodeestudos.com.br/muitos-paises-no-mundo-baniram-aslampadas-incandescentes - acesso em 24/nov/2011

http://users.telenet.be/worldstandards/electricity.htm - acesso em 25/nov/2011 


\section{ANEXO - PARTE 1}

INDICADORES DE ILUMINAÇÃO ARTIFICIAL 


\section{ANEXO - PARTE 2}

FICHA TÉCNICA LUMINÁRIAS 
ANEXO - PARTE 3

RESULTADOS 